

\section{YOUNG CHILDREN AND THEIR PARENTS}





\section{YOUNG CHILDREN AND THEIR PARENTS \\ Perspectives from Psychoanalytic Infant Observation}

\section{Gertraud Diem-Wille}

Translated by Benjamin Mcquade 
Originally published in Germany as Das Kleinkind und Seine Eltern: Perspektiven Psychoanalytischer Babybeobachtung (C) 2009 W. Kohlhammer GmbH Stuttgart.

First published in English in 2014 by

Karnac Books Ltd

118 Finchley Road

London NW3 5HT

Copyright (c) 2014 by Gertraud Diem-Wille

Translated from the German by Benjamin Mcquade.

The translation was prepared with financial support from the Austrian Science Fund (FUF).

The right of Gertraud Diem-Wille to be identified as the author of this work has been asserted in accordance with $\S \S 77$ and 78 of the Copyright Design and Patents Act 1988.

All rights reserved. No part of this publication may be reproduced, stored in a retrieval system, or transmitted, in any form or by any means, electronic, mechanical, photocopying, recording, or otherwise, without the prior written permission of the publisher.

British Library Cataloguing in Publication Data

A C.I.P. for this book is available from the British Library

ISBN-13: 978-1-78049-143-1

Typeset by V Publishing Solutions Pvt Ltd., Chennai, India

Printed in Great Britain

www.karnacbooks.com 
To my grandchildren Samira, Karim, and Olivia 



\section{CONTENTS}

ACKNOWLEDGEMENTS ix

ABOUT THE AUTHOR X xi

PREFACE xiii

Margaret Rustin

FOREWORD xvii

FOREWORD TO THE SECOND EDITION Xix

INTRODUCTION Xxi

CHAPTER ONE

Understanding psychological development 1

CHAPTER TWO

The first year of life $\quad 63$ 
viii CONTENTS

CHAPTER THREE

The second year of life

CHAPTER FOUR

The third year of life

CHAPTER FIVE

Outlook and perspectives: mastering early childhood

REFERENCES

INDEX 


\section{ACKNOWLEDGEMENTS}

The poem by Peter Rühmkorf, "Es lohnt sich nicht" ("It's not worth it") is taken from Peter Rühmkorf, Gedichte-Werke 1, edited by Bernd Rauschenbach, copyright (C) 2000 Random House GmbH, Reinbek, and the poem by Ernst Jandl is taken from Ernst Jandl, poetische Werke, edited by Klaus Silewski, published 1997 by Luchterhand Literaturverlag, Munich, Germany, part of theRandom House GmbH publishing group, and both are reprinted by kind permission of the publisher.

The two images by Emi Pikler are taken from Laßt mir Zeit by Emmi Pikler (2001), Munich: Richard Pflaum Verlag, and are reproduced by kind permission of the publisher. 



\section{ABOUT THE AUTHOR}

Gertraud Diem-Wille is professor of psychoanalysis in education at the University of Klagenfurt. She is a training analyst for children, adolescents, and adults of the Viennese Psychoanalytic Society and the International Psychoanalytical Association (IPA). She has pioneered and supported the training in psychoanalytic observational approaches to training in the psychoanalytic and educational fields. She is the Organizing and Scientific Tutor of the PG MA in Psychoanalytic Observational Studies at the University of Klagenfurt. She is the author of The Early Years of Life: Psychoanalytical Development Theory According to Freud, Klein, and Bion (Karnac). 



\section{PREFACE}

Margaret Rustin

This book is an original meditation on the momentous tasks (for child and parents) and long-term significance of the first three years of a child's life. Gertraud Diem-Wille is a psychoanalyst with a long-held passion for investigating the processes of psychological development in babies and young children and their family relationships. She has adopted an approach to her subject which aims to interest parents, teachers, and a wider readership in thinking at depth about children's growth in body and mind, their physical, emotional, cognitive, and social development. She writes in a clear and accessible way, and she has a distinctive personal voice.

While there is a great deal of wise experience behind a volume of this sort, it is by no means a handbook of advice on how to bring up a child. Indeed, it contrasts greatly with the numerous publications now available which convey the sense that there is a right way to parent children that the expert author can prescribe. Instead, Diem-Wille wishes to open the minds of her readers to the richness of everyday experience, to encourage their curiosity about the complexity and individuality of each family context and of each young child.

She uses three types of material-observational, clinical, and theoretical—to expound her ideas. To help her readers to understand 
and appreciate development across time, she uses three children as case studies in the path from babyhood to the third birthday. Two of these are children studied with the methods of longitudinal infant observation and a follow-up research study she conducted. Her research built on already completed detailed observations from the first two years of life and includes data from her interviews with the original observers as well as the records of their observations, interviews with the children's parents, and some later observations of her own. These multiple perspectives proved very fertile. Alongside this, her third case study based on clinical data is of a child in analysis. The three children come alive in the text as we follow their stories in detailed vignettes.

This clinical and observational material is then related to the theories of early development current in psychoanalysis and in more traditional academic research. There is both controversy and convergence among these theoretical discoveries. Starting from the vivid descriptions of particular children across time we are led into a vigorous critical account of these theories and the debates they gave rise to in the twentieth century. Diem-Wille is very well versed in the psychoanalytic literature-Freud, Anna Freud, Mahler, Klein, Winnicott, Bion-and also in those strands of child development research which have some affinity with psychoanalysis. Her account of Bowlby's attachment theory is outstandingly clear, and she outlines both its great strength and important limitations. What she stresses in her review of the field is her conviction that psychoanalytic infant observation is a neglected resource in linking the insights of paradigms often presented as in opposition to each other. She draws in the expanding infant observation literature to show, for example, how fruitful it can be in exploring links between the internal and external and in investigating intergenerational patterns of personality and relationship. Actual babies and their families turn out to be rather different and even more interesting than the babies encountered in laboratory experiments.

Dien-Wille's wide experience as clinician, researcher, and ordinary human being are all in evidence. She makes frequent use of everyday observations of young children's behaviour and of the representations of childhood in books and nursery rhymes: Winnie the Pooh, for example, turns out to provide memorable instances of the young child's way of seeing the world.

The sympathy with which she writes of how hard it can be to grow up, and how hard the task of being a parent can sometimes be, conveys 
the warmth and depth of her conviction that psychoanalytic discoveries presented in this way are an enormous resource for everyone interested in the early years. She writes from a base of very disciplined work as psychoanalyst and observer, but in this book she steps out of these specialised roles to communicate what she has learnt to a very much wider public, and she succeeds very well in doing so. 



\section{FOREWORD}

In this book I focus on the intertwining between the development of a child's psyche and its parents' behaviour. These complex patterns of interdependency are approached on a number of levels. Starting from a psychoanalytic tradition, concrete cases are used to demonstrate emotional development, with examples of real children observed in the framework of a two-year infant observation programme in London or from psychotherapy. By the same token, several significant theories on early development are discussed critically.

My thanks are due to all those who assisted me in gathering theoretical and clinical experiences from psychoanalysis. My psychoanalytic trainer, Dr Lambert Bolterauer helped me to understand and discover order in my life from a new perspective-whereby integrating these painful experiences, new perspectives, and insights was not always easy. My teachers and professors in the Viennese Society for Psychoanalysis succeeded, through their active efforts in rebuilding the society-which was reduced to three members after the forced emigration of almost all psychoanalysts in 1938 - in bringing it back to life, and to newly establish psychoanalytic training and psychoanalytical discourse.

Through my one-and-a-half year research stay at the Tavistock Clinic in London in the 1990s and my participation in the activities of the 
Institute of Psychoanalysis there, I became acquainted with valuable developments in Kleinian thinking as well as attendant technical practices of which I had previously not been adequately aware.

I want to express my thanks to Betty Joseph, who supported me with her supervision of my work as a child psychoanalyst over the course of many years. Elisabeth Bott Spillius enabled me and a group of psychoanalysts to participate in a postgraduate clinical seminar in Vienna for several years. For a number of years, Michael Feldman has led a European clinical group of psychoanalysts that provided valuable insights and inspiration for me, as participant, in my work with patients.

In particular, it was Margaret Rustin at the Tavistock Clinic who provided support for my research activities in "Infant Observation FollowUp Studies", by meeting with me every week and reflecting on the data collected from the observed families. Isca Wittenberg and Anne Alvarez made it possible for me and a group of psychoanalysts in London and Vienna to train as psychoanalytical infant observation teachers. In the "Under Five Counselling Service", I received valuable inspiration and ideas from Dilys Daws and Lisa Miller. Anton Obholzer encouraged me and provided essential support in organising my transfer between London and Vienna.

My thanks are due to the families who enabled me to carry out my psychoanalytical observation of them, and who during interviews provided me with insights into their experiences during pregnancy, birth, and the early years of their children.

I thank Gucki Siegl for the numerous suggestions she gave me after carefully reading my manuscript. Peter Marginter made substantial contributions to making my text comprehensible through his critical examination of terminology and viewpoints. 


\section{FOREWORD TO THE SECOND EDITION}

My publisher's invitation to revise Young Children and Their Parents for a second edition is a sign of the great interest in psychoanalytic infant research. On the one hand, infant research provides psychoanalytic research and clinical practice with new insights; on the other hand, it has developed from a specialised area of research into an effective introduction to psychoanalytic thought. This book is used as an introduction to psychoanalytic training and as a basic text for university lectures. I am glad that the integration of developmental theories with examples from infant observation and clinical work with children in analysis evokes such great interest. From personal conversations, I have discovered that the book has often been presented to pregnant women by their own parents. One reader wrote me that this was the first psychoanalytic book "that didn't give me a bad conscience, but made comprehensible to me the complex intertwining of the parent-child relationship". Revising the book also provided me with the opportunity to newly organise the explication of the four relevant developmental theories, describing them more completely and giving emphasis to their respective advantages and problematic areas. I hope that the connection between theory and practice will thus be easier to trace. 
I am keenly aware that I could only write this book with the consideration and support of my own family. A very special enrichment is my relationship with my two daughters, Katja and Johanna, as well as my grandchildren, Samira, Karim, and Olivia.

Gertraud Diem-Wille

Vienna 


\section{INTRODUCTION}

This book seeks to show the importance of the earliest period of childhood for the development of basic emotional patterns of the personality. In the first four years of his life, the child is usually cared for by his parents. Only later do trained nursery school and kindergarten teachers or other educators come into contact with a child already shaped in these first early years. For this reason, this stage is either ignored or only given cursory discussion in some books on developmental psychology. Since psychoanalysis, however, proceeds from the assumption that these years impart fundamental experiences, this book will attempt to show how the main underlying personality patterns emerge in the context of the first family relationships. These early experiences are stored within the deepest layers of our mind, and are revived in situations of joy and security, in grief over separation and helplessness, leading Melanie Klein to speak of "memory in feeling". This is not conscious memory, but-since such memories emerge from the pre-linguistic realm-lies rather in physical perceptions and intangible moods that arise in the imagination and in dreams. Only by understanding how a baby or young child experiences hundreds of specific interactive patterns every day with its parents and others important to it can we also comprehend the deep traces this leaves on the infant's 
mind. Understanding early emerging patterns of experience that have a strong influence on us can help us to openly accept and investigate the meaning of infants' and young children's behaviour patterns and their seemingly inappropriate reactions, and can help the educator or teacher understand the apparently irrational reactions of their own "inner child" as the expression of painful experiences, providing impetus for further reflection.

The first years of life are a period of radical change, of dramatic physical and psychological development. From the moment of birth, the human being learns; he has to deal with a multitude of impressions, functions and perceptions from outside, and emotions, wishes, and feelings from within. Learning takes place in relationship to one or more other people. It is the nature of these relationships, with their love or emotional qualities, that determines whether the child will develop confidence, joy in life, interest in the world, openness to novelty, and a sense of curiosity. The quality of the emotional relationship determines whether the child's talents are encouraged or neglected, whether the infant is given help in overcoming his fears and the new challenges he faces, whether he will seek and be open to social contact, or whether he will tend to withdraw timidly, playing by himself. (Throughout, the child will be referred to as "he", rather than "he or she" or "it".)

Since early emotional experiences in interaction with parents shape how the growing child perceives himself and the world, this evolution will be described in detail using examples from psychoanalytic infant observation. Already pregnancy and birth are strongly influenced by parental wishes and fantasies, since the preparation for a new baby evokes early unconscious experiences in the deepest layers of the personality. The book follows the development of the child's relationship with his parents from birth through to the end of his third year.

In this book, the focus will be on the interaction between the development of the child's psyche and the actions of the parents. This complex interaction is approached on a number of levels. Starting from the psychoanalytical tradition of using case material to demonstrate emotional development, I will describe the development of specific children as seen within the framework of a two-year psychoanalytical infant observation study in London or within the framework of therapeutic treatment. In addition, we shall examine a number of important theories about early development, also discussing their differences and similarities. 
In comparison, examples from psychoanalytic parent-child therapy and from child psychoanalysis will be provided, in order to demonstrate how parents can be helped to render unconscious conflicts conscious.

For readers who seek an introduction to the broad range of various psychoanalytic theories on the early years of life, the book offers at the end of the second chapter an orientation on the four most important theoretical directions-Freud and Mahler, Klein and Bion, Stern's empirical infant research, and Bowlby's attachment theory. 

CHAPTER ONE

Understanding psychological development

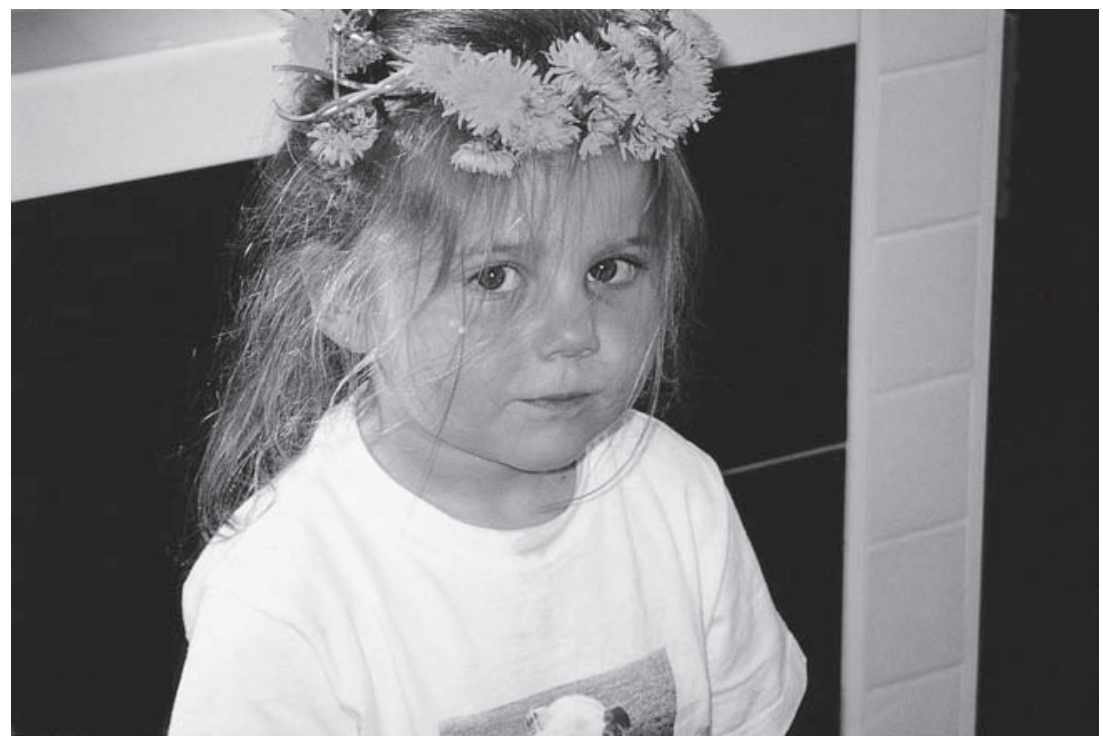





\section{Theoretical basis of a psychoanalytical interpretation of human development}

Our main theme is the development of the psyche and the young child's emotional, symbolic, and linguistic skills in his relationship with the relevant persons surrounding him within our Western culture.

The child's development will be illustrated using narrations, descriptions, and case studies, the key to this approach being a direct focus on actual children. Narratives supplied by adults, above all the parents of some of the children described, can supplement regularly repeated observation. This approach of attempting to understand human development through observation, description, and the analysis of what is observed contrasts with the behaviourist method. Although the latter focuses on behaviour, it is not the child's behaviour but rather the behaviour of animals in an experimental situation that is chosen as the reference system. Thus in textbooks on developmental psychology, the chapter on birth and early development will sometimes contain a description of the behaviour of primates in caring for their young.

If we consider the psychological importance of the relationship between parents and baby, the varied and complex relationships 
between the parents' psyches, ideas, and internal images on the one hand and the developmental conditions for the new living being on the other become evident. If we wish to understand the psychological development of the child's personality, it is necessary to focus our attention on the relationship between parents and child. This attaches crucial importance both to the real world and to inner reality.

Where I speak of inner reality, I mean the psychological reality that is expressed in the images and concepts of the parents about themselves and about the baby. There are two parallel worlds, that of the real babyparent interaction and that of the parents' ideas about the baby and themselves as parents. These two worlds can be in harmony or at oddseither slightly or radically-with each other. There is the real baby in the mother's or father's arms, and at the same time there is the image of the baby, "the imaginary baby", in the mother's experience. There is also the real mother who holds the baby, and at the same time the inner image she has of herself as a mother. These inner images influence the baby's development dramatically, both positively and negatively. The relationship between mother and baby is, however, also always influenced by the relationship between the mother and the baby's father, with the result that the relationships between three persons are always of essential importance (cf. Green, 1993). Hence I view the existence of "inner images", also known as "representations", as a necessary and important part of a relationship. However, the quality of the relationship can vary, encouraging or restricting a child's development. These inner images the parents make of their baby necessarily differ from the image formed by a neutral observer, ${ }^{1}$ since the parents include within them their hopes and fears, their memories of other family members, and aspects of their self-image. It is equally important to describe how the "inner world" of a baby develops. At the outset, I would only like to say here that it is not sufficient to describe the external reality; it is also necessary to observe how the baby's psyche develops. Here, I assume that the baby internalises, as a kind of model, the manner in which he experiences the world through his mother or other relevant reference persons, making this the starting point of his image of himself and of the world, an image then modified and adjusted through the baby's feelings and fantasies.

Seeing one's own child as the cutest and sweetest of childrentransformed through the eyes of love-is part of "normal" parenting. The perception of the real baby is influenced by this inner image, as well 
as by the feelings, hopes, or emotions at any particular time. A restless screaming baby that co-opts his parents' attention up to the limits of their physical and psychological capacities may temporarily seem ugly and repulsive to those frustrated, bleary-eyed parents at the end of their tether. Only a short time later, the same baby—satisfied, happy, and sleeping peacefully-will seem to them a little angel for whom they have only the tenderest feelings.

From the way parents describe their feelings about their child, it becomes clear that there is simultaneously love and hate, sacrificial devotion and distance, helplessness and aggression, joy and desperation. Freud's great contribution was to show that human relationships are always marked by ambivalence, that is, by different qualities of feelings that affect us at the same time and that can rapidly shift. The closer a relationship is, the more violent the contrast can be. Someone who very much loves another hopes for the same intense feelings in return, and for this reason is hurt and offended by rejection, indifference, or even simply different wishes. The aim of the psychoanalytical approach is to understand these complicated interactions, to identify the hidden meanings behind apparently logical contradictions and incompatibilities, and to reveal this to the persons involved. When I here go into detail concerning the variety of relationships between parents and child, I should point out that it is a question of understanding and not of prescriptive standards, rules of conduct, or the allocation of blame. Often, analyses of a relationship have been misunderstood as accusations or as placing blame on the mothers and fathers-as if it would ever be possible to bring up a child without conflict or misunderstandings. It is not my aim here to establish rules for a good or "correct" upbringing, but instead to show the broad range within which an upbringing is "good enough" to encourage the child's development. ${ }^{2}$ The aim is to encourage an attitude of openness and observation that allows the relationship between the baby and his parents to be understood. The knowledge that there is no mother or father who "can throw off their past", that they are themselves the product of their own life history, should help readers to adopt a tolerant and understanding attitude towards themselves. The reader may ask whether his or her experiences and upbringing practices fall outside the framework of "normality". In order to show how broad and varied relationship patterns are between parents and children, I shall describe two families in more detail, and use these empirical case studies to hypothesise about the families' relationship 
patterns and emotional structures. The fact that "normality" is put in inverted commas should indicate that there is no clear border between the normal and the abnormal, between healthy and pathological. The phenomena obviously manifested in problem families also are partially at work in "normally neurotic" persons.

I should like to point out another aspect that might be misunderstood: the hope of being presented with a generally applicable description of a family. Particularly in the close relationship between children and parents, the observer's perspective plays a major role. Description and assessment of feelings, offences, joys, and experiences depend on who is providing the description: six children could see the same mother differently, as either strict or encouraging, loving, indulgent, cold, or out of control. The description is always the result of the relationship between the person providing it and the object of the description. The same applies in reverse-when, for example, the same mother is asked to describe her relationship with the six children and the atmosphere within her family. These points of view necessarily differ, since they are always influenced by imagination, wishes, hopes, and underlying emotional states. The same person would also assess the relationship with his or her father or mother differently depending on the situation or their age; a father who was critically rejected by his adolescent daughter might be regarded by the adult daughter later as considerably more loving and tolerant.

In order to establish a balance between understanding the development of an individual's personality and the various theoretical concepts, we shall begin by presenting children between the ages of three and four, then describing — as far as empirical data permits - their path through life from birth up to the period of observation.

\section{Perspectives of psychoanalytical infant observation}

How is it in principle possible to make statements about the psychological development of young children? With adults, Freud discovered that he could analyse dreams and make use of free association in order to draw conclusions about subconscious wishes, inhibitions, and defence mechanisms of the psyche, the "psychological apparatus". Children express their imagination, inner conflicts, and forms of defence through play, so that understanding children's play permits access to their inner world. The interaction and physical contact with their parents also 
expresses the emotional proximity between them, while eye contact and the negotiation of rules and regulations reveals to the observer the quality of the relationship between parents and child.

In order to show the complexity of development in these first few years, I wish to view the earliest stages in hindsight, from the vantage point reached after four years. For psychoanalysis, the main source of data and observations concerning the psychological development of the individual is therapeutic work with patients and children with problems or developmental difficulties. Difficulties and problems make these phenomena far more apparent than in normal relationships. The path towards psychoanalytical discovery moves from the psyche to the body. In the course of research, it has penetrated to the early stages of a child's development and the initial stages of the psychological differentiation of the physical functions. The "ego is above all something physical" claimed Gaddini (1998), with reference to Freud, and he speaks of a mirror-like image of the body-soul and soul-body continuum, depending on intellectual approach and research methodology. Freud writes of the psychological as ultimately always related to the physical. The psychological situation reveals itself holistically, that is, not only verbal expressions are of importance but also body language. A baby experiencing eating problems is expressing that something is wrong. This may be a physical illness or defect-or, if nothing physical is found, the baby may be showing something about a problem in its relationship with its mother. The use the word "may" indicates that these assumptions are provisional, and it is important to be open to a variety of possibilities. In the case of Max, to be discussed, we will see that his frequent screaming also had a somatic cause: only when he was eighteen months old did doctors accidentally discover a chronically inflamed kidney during a medical examination. However, for Max's psychological development, what was important was the manner in which his parents were able to deal with his seemingly inexplicable crying.

The distinction between the behaviour of a person significant to the subject or an external event and its emotional importance is of central importance in psychoanalytic interpretation. The emphasis on "psychological reality" has led to the common misunderstanding that it means real events do not play a role-a criticism especially made against Melanie Klein and her group. Instead, it is more of a special point of view from which real events are observed. If, for instance, a man says his young wife is sexually so experienced since she had every form 
of sexual experience from as early as age thirteen, this would give a psychoanalyst pause. The assumption-perhaps common in everyday awareness - that this woman was particularly interested in sex or had an unproblematic relationship with her body, had no fear of the other sex, was self-assured and reckless, would not be shared by an analyst. Instead, an analyst would ask what the meaning of such promiscuous conduct might be. Did this "orgiastic experience" represent a defence against her fear of closeness? How did she experience group sex herself? Did she enjoy it? Did she feel devalued? Did she look for a type of physical proximity in this kind of bodily contact because she felt lost and alone and had nobody to talk to? Or was this hectic sexual activity a way of distracting herself from threatening inner dangers? Did she act in this way to subconsciously conceal her fear of a mental breakdown? Was there anyone important to her amongst all her sexual partners? Was there a longer relationship that was emotionally important? We would tend to assume that this young woman has difficulties in seeing herself and her body as something valuable, in accepting herself as a person worth loving. The promiscuous activity is probably a cover for fear and uncertainty, often in the very fundamental sense that she does not know who she is. Pausing to reflect would then be very threatening - therefore, she must always be active and be in permanent tension as a result of her hazardous way of life. Where I speak of a lack of prejudice, which might for instance lie behind "free" sexual activity, what I mean is that it is not possible to conclude the underlying reasons from a particular conduct. One might also ask why the older man makes this statement. Is he boasting about his young wife and her potency, or is he showing his uncertainty and fear of not being able to satisfy her demands? This multitude of questions reflects the different possibilities of subconscious conflicts that might lie behind such conduct - conflicts that must be insulated if the subject is not to become aware of them. Interestingly, this interpretation is confirmed by many people who have concluded from experience that a wild sexual indulgence is unsatisfying.

Similarly, in assessing the emotional situation of children and their psychological development, external factors do not offer an unambiguous explanation: a child whose parents divorce early can be in a better emotional condition than a child from an intact marriage, if the father is depressive or if the mother, even if at home, is emotionally inaccessible. 
For this reason, psychoanalytic infant observation based on Esther Bick's method (Bick, 1964; Miller, Rustin, Rustin \& Shuttleworth, 1989) entails precise observation and perception of details in interaction and the emotional quality of the relationship. Less important than how long the mother breastfeeds or how long the baby is picked up and carried by the father is their emotional registration of their baby's feelings. We can attempt to understand the quality of the parents' attention and the baby's reaction through precise description. Only the infant's reaction to contact with his parents, the emotional "dialogue", can provide us with an indication of the quality of the relationship between parents and infant.

Since these assumptions may be difficult to follow, I should like to cite a number of examples in clarification. These are partial results of a larger study examining the development of children in the first four years of life. ${ }^{3}$ Four pairs of parents and their children were observed once a week over a period of two years. This psychoanalytic training method is known as "infant observation". It was developed by Esther Bick, an English psychoanalyst, around 1950 in London and has since become an important element in the training of psychoanalysts and psychotherapists. The observer first establishes contact with a couple expecting a baby, in order to obtain permission for observing the baby and his development once a week over a period of two years. The aim is to learn to perceive as accurately as possible everything that concerns the baby within his surroundings, with the observer remaining true to the role of observer but also open to what the parents have to say about their situation with the baby. The observer should exercise no other function within the family, should not give any advice or comments, make any interpretations, or take on any domestic or personal functions. In small seminar groups with a psychoanalyst, the observations, impressions, feelings, and moods of the observer are discussed and hypotheses drawn up about the development of the baby's personality. Detailed reports on Esther Bick's mode of infant observation have been published (Bick, 1964; Briggs, 1997; Diem-Wille, Finger \& Heintel, 1998; Ermann, 1996; Lazar, Lehmann \& Häußinger, 1986; Miller, Rustin, Rustin \& Shuttleworth, 1989; Reid, 1997). The International Journal of Infant Observation (1998-2013) discusses a wide variety of questions and results of infant observation. This is not an artificial investigation situation, but takes place within the natural surroundings of the young family. 
In the follow-up study, I examined whether the hypotheses about the observed infants corresponded with their further development. To this end, having first read the written work on the observation, I spoke with the observer and we then discussed the observation together with the seminar leader of the infant observation group. It was only at this stage that I contacted the parents of the child observed, by now four years old, and asked for permission to carry out additional observations at home and in the kindergarten. After finishing the observation, I held detailed narrative interviews with each parent separately. In a narrative interview, the interviewee is requested to expound freely and in detail on topics or events from his or her life on the basis of a few open questions. During the interviews, parents told me how they had experienced pregnancy, birth, and the first few years of their child's development, and what influence the birth of their child had had on their lives and their marital relationship. I then asked them to tell me how their relationships had been with their own parents when they were children. The experience of the parents and the multi-generation perspective constitutes an important supplement to the data about the child acquired during the observation. Descriptions of the parents' feelings provide an indication of whether the observers' hypotheses correspond to the parents' own self-perceptions. I shall also use examples from autobiographical reports and cases from clinical therapeutic work as illustration.

\section{From the young child to the infant and back again}

When depicting the full drama of the development from infant to fouryear-old child, observing a child of this age can show the huge development that has taken place during these four years. The four-year-old child can control his bodily functions, understands the language of adults, and can give linguistic expression to hiswishes and feelings. For this, he must be able to access his experiences in retrospect and to symbolise them.

The four-year-old child already constitutes a personality in the way he deals with people and things, whether he is shy or assertive, and expresses his wishes and proposals cautiously or forthrightly. The quality of his emotional relationship with parents and siblings and his basic attitude towards the world are just as important as his attitude towards himself, whether generally optimistic (trusting himself to do something) or timid, uncertain, and pessimistic. 
Describing the behaviour of such various children has a two-fold purpose: first of all, to bring real living children to life in the readers' eyes, showing how great the differences are between individual children whose behaviour we can unequivocally term "normal". It reminds us that each child is a unique person with his own character, his own approach, and a unique biography that already structures the way he experiences the world. Tracing a child's age-related developments can easily lead to the misconception that there is one correct path of development. I intend to show that there is a variety of possible developments, at the same time nevertheless pointing out the specific opportunities and encouragement that a child receives and the specific strains that a particular family constellation or quality of relationship with the parents can place.

Secondly, I aim to demonstrate the application of the psychoanalytic approach to the understanding of the psyche by attempting to use visible behaviour to draw conclusions about the emotional proclivities and sensitivities lying behind it, and to take seriously children's conduct and play as a means of access to their "inner world". The reference system for the interpretations of children's play or conduct relates to everyday knowledge and should be plausible. Freud relied on the knowledge of writers and poets such as Shakespeare, who deeply understood psychological truths. Wittgenstein applied a similar approach when he said: "A common-sense person, when he reads earlier philosophers, thinks-quite rightly_-'Sheer nonsense'. When he listens to me, he thinks-quite rightly again-'Nothing but stale truisms'. That is how the image of philosophy has changed" (Rhees, 1984, MS 219.6).

Taking this cue from Wittgenstein, my aim in this book is to make explicit the deep insights embedded in everyday knowledge and to direct attention to otherwise hidden processes in the background. Descriptions of the start of Kelly's and Max's lives, as well as reports by child therapists on Patrick, Malcolm, and Joseph, are intended to reveal this deeper perspective behind observed behaviour.

\section{Children's developmental histories}

What now follows is a series of short scenes I wrote down during my observation of Kelly and Max, together with an interpretation of this data. A detailed description of the children in different surroundingssuch as family and kindergarten-is manifestly necessary in order to show that this involves more than a simple categorisation of 
securely/insecurely attached or successfully reared/problem child: rather, the aim is to do justice to the many aspects, levels, and mixtures of the child's psychological reality. I hope that this will encourage the reader to be intellectually open, to become attentive to particularities of personality development instead of applying a simple classification. I shall begin the description of the children's behaviour at the age of four, then go back to their birth, to the parents' wishes and hopes before the birth, and then depict the developmental process of these children in the first three years of their lives. Our greatest interest is in the psychological aspect, the inner reality, the subconscious fantasies that colour the perception of reality. I shall endeavour to examine the interaction between real experience and the children's inner world by attempting to understand how the psychological development of the child and his personality development is influenced by the real experiences, a nurturing or a deprived environment, the parents' interaction patterns with the child, and their conscious and unconscious notions before and after the birth that are projected onto the child. The crux is whether and how the parents are able to accept their baby's personality, and to perceive, identify, and respond to his emotional and communicative needs. I can only make assumptions about the development of the child's personality and attempt to render them plausible by means of the many sequences from observation.

Of the seven dimensions of personality development, the first four concern the inner world, the remaining three to the interaction with the parents and other relevant persons. This brief explanation of the dimensions constitutes a rough-and-ready introduction to the psychoanalytical perspectives of human development set out in detail in this book. The description of the opposing poles demonstrates the scope of each dimension, with every individual displaying mixed forms and a mix of experiences lying between these extremes (Salzberger-Wittenberg, 1970; Waddell, 2002).

First dimension: is there a basis for good internal objects, or predominately a split into either idealised or persecuting, bad internal objects?

Psychoanalysis assumes that the baby's inborn ability to enter into a relationship with a loving mother can only develop if these preconceptions materialise through genuine experience. The ongoing positive experience of being lovingly cared for and fed allows the 
child to internalise these good experiences. The internalisation of these satisfying experiences gradually allows the baby to feel within himself this source of goodness, to experience it, through repetition of the experience, more as part of his own personality-while also enabling him to accept frustration, disappointment, and rejection, and to be aware of the good and bad feelings within himself. If good experiences predominate, the image of the world is peaceful and optimistic, corroborated by an underlying feeling of being wanted and of joy in life.

Put simply, it can be said that the shine in his parents' eyes is experienced by a baby as confirmation of being wanted by them and of containing goodness within himself.

If the baby's expectations of communication, of being taken up and accepted are not satisfied, these abilities shrivel or cannot develop, or only develop to a reduced extent. If the baby feels emotionally rejected by his parents, if the feelings he projects onto his parents cannot be received, digested, and returned to the baby in a manner the baby can handle, he feels unprotected, the victim of both his own feelings and hostile elements in the world. He then perceives the world as a dangerous and threatening place from which he prefers to withdraw. His self-image is of a wicked being, unworthy of love, and he accordingly experiences his parents' reactions, expressed in their looks and actions and internalised in the baby's imagination, even more as rejection. He cannot integrate his own good and bad aspects, instead tending to experience good and evil as incompatible opposites both in persons around him and in himself.

Second dimension: is the child's personality accepted and encouraged or does the wish predominate to form the child according to the parents' concepts without taking account of the child's talents?

If the parents are able to see the child as a separate and unique person, someone they will get to know, someone whose particular abilities, wishes, and talents they want to encourage, they create the basis for self-confidence and for good body coordination. If they give the child tenderness and stimuli, if they can delight in the child's development, he will develop pleasure in his own actions and confidence in his own abilities. On the basis of a secure emotional relationship with his parents, the child will be curious about the world and wish to explore his surroundings. Separation and reunification are possible, since he feels 
secure and basically cared for. Interest in the world is shown through the child's creative play, his wish to investigate his surroundings and to explore the secrets of the world. He will develop confidence and resilience, enabling him to cope with disappointment without immediately giving up. Unimpeded play constitutes the important form of a child's expression. In play, he can present his feelings, conflicts, and wishes in symbolic form. Given encouragement, self-assured children can play freely, displaying their feelings.

The opposite pole is the situation of a child who is not accepted as what he is by his parents, whose existence simply constitutes a burden for them. He will tend to cling to his mother or father fearfully, be shy, timid, and uncertain and lacking in self-confidence. He will harbour the deep-seated feeling that he cannot do anything right, of needing to disguise himself in order to please his parents. He can then develop modes of conduct that please the parents but that do not correspond with his own nature, which Winnicott describes as a "false self" or Jacobs an "as-if personality". Instead of being self-assured and confident, he feels empty and cannot establish a relationship to himself, being physically awkward with a tendency towards self-injury. The most important indication of emotional inhibition is a child's inability to be play and cheerful.

Third dimension: mature forms of defence versus primitive defence mechanisms

Another important dimension of personality relates to the manner in which the person handles unbearable internal impulses and emotions. In psychoanalysis, we speak of these inner mechanisms as "defence mechanisms" which the ego uses subconsciously in order not to become aware of forbidden sexual and egoistic desires and impulses, or intolerable feelings such as shame, aggression, envy, and jealousy. A distinction is made between early and mature defence mechanisms. If he has developed these mature forms, the child is able to show sadness and to console himself. He can feel concern for other persons and develop generosity. He can demonstrate his feelings, and wish to make amends for something bad he has done.

The other pole represents a personality that falls back on early forms of subconscious defence by projecting undesired feelings onto other persons and fighting them there. It divides the world into good, 
idealised persons and entities, which contrast with evil and dangerous persons. It cannot truly see itself as a separate entity and requires reassurance and satisfaction from other persons; it is dependent and attempts to control its reference persons. In its egocentric view of the world, it relates everything that happens in the world to itself. As a result, it cannot care for and look after other persons.

Fourth dimension: has the child been supported in his feelings and emotionally "contained", or has the attention given him been either intrusive or unreliable?

If the parents are able to accept and understand the overwhelming feelings projected on them by the baby and then return them in a linguistic, "emotionally digested" form, they enable the child to accept and integrate these feelings. The child will then be increasingly able to recognise, express, and subsequently name his positive and negative feelings, which leads to an enrichment of his personality. He can to some extent accept his dependence in the role of a child, and knows that his parents are caring for him. These experiences then enable the child to identify with this role and also to care for others.

At the opposite pole is a child who experiences that his psychic limits are not accepted, that his mother and father either want to feel "on behalf" of the child, to impose feelings and conduct on the child, or turn away from the child emotionally. Instead of registering and accepting the child's feelings, they reject them, make fun of the child, or mock him. Alternatively, the parents may demand from the child a kind of attention he cannot provide, for example as a substitute for an inadequate spouse.

Fifth dimension: are rules explained and open to negotiation, or are there either fixed rules without explanation or no clear limits at all?

A salutary factor for a child's development is parents explaining limits. Patient explanation allows the child to recognise the sense of demands and prohibitions. Joint negotiation allows the child to see his wishes and ideas reflected in the solution. This form of negotiation also constitutes an important model for the child in dealing with other children and conflicts. 
At the other pole, parents establish rigid rules and demands the child cannot understand. He must subject himself to them and be drilled, since only external visible conduct can actually be punished. It is doubtful whether the child can see the point of these demands or can internalise these standards. It is equally difficult for the child when parents are too weak to see to it that rules are followed and enforced. The child may then become a tyrant, ordering everyone around according to his wishes. The absence of external limits can also be threatening, since the child is then at the mercy of his own impulses.

Sixth dimension: does the child receive acknowledgement and encouragement or does the child's development tend to be inhibited?

A small child is particularly dependent on loving sympathy and encouragement. The child's realisation that his parents devote attention to his play and can delight in his physical and intellectual development has a stimulating effect. If treated by his parents with respect and humour, he can show his abilities and talents. In particular, the activities of parents and child together such as singing, playing, swimming, running, reading aloud, or storytelling, performed in a cheerful and relaxed atmosphere, will then be associated with pleasant experiences, and the child will then wish to pursue these activities himself.

At the opposite pole are children who tend to be experienced as a burden to their parents, intended to serve the parents' narcissistic wishes, and not loved for their own sake. Sensitive children often guess their parents' wishes and then base their actions less on their own ideas and wishes and more on the ideas of their parents. Their actions are then not creative or independent but have a false, artificial, or precocious quality. Children whose parents are emotionally inaccessible are also restricted in their development.

Seventh dimension: has the child good social skills or does he tend to withdraw from his peers and adults?

A self-assured child will be curious about other children and want to play with them. Openness to other children, and the ability to contribute suggestions as to what to play, constitute the positive pole. Children who are fearful tend to withdraw from their peers, who often 
take their inhibitions and fears as an occasion for making fun of them and excluding them. Equally unfortunate are attempts by children to dominate their peers, to intimidate, threaten, and hurt other children. For them, the only type of social contact is to force smaller children to go through what they have had to endure themselves as children. With their peers, they do not associate feelings of friendship, but instead affects of power and triumph.

These dimensions are intended merely as orientational guidelines for comparing actual children, and are closely related to each other (cf. Briggs, 1997; Waddell, 2002). I would now like to present the children Kelly and Max on the basis of empirical observation, and will then endeavour to compare their behaviour in light of the seven dimensions. The third child I describe is Patrick, who was in child analysis.

At first glance, we might expect Kelly's situation to be difficult. Her parents were divorced when she was eighteen months old. Kelly was an unplanned baby, her mother becoming pregnant after she had known Kelly's father for three months. The divorce was contrary to the wish of the father, who later fought in court for custody of Kelly for over a year. Since there was physical violence during the divorce and the mother left their home without prior warning, Kelly might be included in a risk group of "divorce children" who have suffered emotionally.

The external conditions for Max, the second child observed, initially appear quite favourable. His parents had been married for a number of years before they were certain that they could now turn their attention to a child. Both are employed, their financial situation is comfortable, and they live in a house in a good location in London.

Patrick's parents also wanted a child at the time. They had already been married two years and their relationship was harmonious. Patrick's birth was spontaneous. He was a baby who nursed well, and quickly learned to sleep through the night. We shall see that external conditions, although representing an important framework, are not sufficient for a reliable forecast of the child's emotional development.

Let me now describe the three children.

\section{Kelly}

The girl that I call Kelly is an attractive blonde child. She has an infectious laugh, is imaginative, and uses her creativity. Her father is an insurance agent in London and her mother works as a business 
consultant. Her parents were divorced when she was eighteen months old. Kelly lives with her mother, but has regular contact with her father. She has a great deal of physical contact with her mother. While her mother was telling me that she was going on a business trip the next day, Kelly leaned against her and her mother stroked her hair. Kelly was very attentive and willingly took up every suggestion from her mother. Here is a sequence from the second observation:

In her room, Kelly went straight to the plastic play house which was full of different dolls and other toys. She took out a doll, told me her name, and put it in the cot. As she passed by, she looked at me and said: "Let's play mother, father, and child. I'm the mother and you are father." Without waiting for an answer, she talked to the little doll the way a mother does to her child. "Well darling, how was your day? My day was very busy, I had a lot to do, but now I'm so happy to be back with you." As she spoke she held the doll close to her head, laughing and speaking as an adult woman would speak to her baby. She then lay the doll down carefully, covering it with a blanket, and went back to take out her teddy bear.

When making statements about a child's inner world, it is only possible to draw conclusions about their inner experiences on the basis of observed conduct. What do we observe here with Kelly? When she automatically takes on the role of mother for her little doll in play, she shows us that she identifies with her caring mother, that she wants to be a mother. She gave me the role of father, thereby expressing her inner image of a parental couple that cares for the baby. In play, she behaves tenderly and lovingly with her "baby" (doll). Since her mother is going away the next day, she seems to be expressing both the mother's and the baby's feelings. She also seems to be expressing her infantile wish to be mothered. As Anna Alvarez says, "Imagination is the great healing ground and the great area of potential development". (1992, p. 81)

By including the father, she showed that she has a strong and reliable relationship with him. Here is an extract from the second observation, with her father:

When he opened the door the father explained that they were in the middle of a story. He sat down on the sofa. Kelly cuddled close to him and made a kind of purring noise like a cat. He put his arms around her, she had her head on his chest and he started to read. It 
seemed to be a familiar situation for both of them. The father has a deep and pleasant voice. He read the story like a radio play, imitating different characters, occasionally whispering into Kelly's ear. From time to time he looked at me ... Kelly snuggled her face close to her father's chest while he was reading, reacting to his story with laughter and joy, turning her head towards me and giving me a big smile, and I smiled back.

Observing this reading aloud, I can clearly see it is a three-person situation-both father and daughter involve me and invite me to share their pleasure in reading. It is almost as if Kelly takes the observer as a substitute for a mother who allows her and her father to be together, accepting their proximity to one another from a certain distance. There is a relaxed and happy atmosphere and I do not feel excluded.

Since we do not have direct access to Kelly's inner world, we can only interpret her behaviour. When she is playing at being the doll's mother, we can assume that she has an internal image of a mother who looks after her child. She was able to cope with her parents' divorce and can inwardly adjust to two familiar environments, her mother's and her father's. I would therefore assume that she has had primarily good experiences with her mother and her father, with the result that she has internalised stable good parental objects.

In all the observations of Kelly, there are many examples of how she can use her imagination at play by inventing new rules and being creative. She can express her wishes and has plenty of ideas, as well as an attractive ability to busy herself with new things. At play, she giggles and is happy. I would like to show an example of how she uses her imagination in order to handle fear. During the observation at her father's home, he showed me her room, on the door of which there was a sign with the words "KELLY'S ROOM, monsters keep out!" When I asked what that meant, she explained by going into the kitchen and drawing me a picture:

As she was drawing her father asked her what it was. She had drawn a large figure, a many-limbed monster. She explained which part was the head, then she named each part that she was drawing (Figure 1). "These are the eyes, the nose and the mouth." He asked if it was a nice monster. Kelly replied: "No, a bad one", but laughed mischievously. She then drew a spider that looked more like a flower and said the monster would eat it. Her father 
explained to her that a spider had eight legs and was black. He took a black crayon and drew a spider in one corner. Kelly watched him closely, laughed, waited till he was finished, and helped him count the eight legs that he had drawn. She then took a red crayon and crossed out the spider and said that the monster was eating it. Her father seemed to be enjoying the game and asked her whether he should draw another spider. She nodded and he drew another spider in a different corner. Once again, it was then eaten by the monster. Now Kelly's father, encouraged by her response, suggested drawing a huge spider. He took a purple crayon and made a giant spider. She watched him with interest, waited until he was finished and then said: "Look what I'm doing now!" She then took the pen he had put to one side and drew over the huge spider. Her father protested and said that this spider was too big to be eaten, that the monster's mouth was not big enough. Kelly just laughed and made the mouth bigger. When her father again said that the mouth was not big enough, she made a huge mouth.

This sequence shows Kelly's ability to share her imaginary world with her father, namely in the form of play that can be enjoyed by both. One could say they are drawing together. The spider-monster can be understood as an expression of her angry feelings. However, the monster can devour the spider and thus deal with the threatening feelings. Kelly told me that the monster was so hungry that it could eat all spiders. The monster's huge mouth might also indicate her fear of being eaten by the monster. At the end of the observation, Kelly gave me the picture, thus including me. My presence might also have made it easier for her to be with her father.

In general Kelly appears to accept rules. She listens to what her mother tells her. Her mother's tone of voice is mostly friendly and gentle. She also explains to Kelly why she can or cannot do something. For instance, shortly before dinner, Kelly wanted to paint something. Her mother explained to her that she would be going to bed in ten minutes and that there would not be enough time to even get her painting things out. Instead, she suggested that Kelly play with plasticine or another toy. Kelly listened attentively and then decided to play with plasticine.

Her father also ensures that she keeps to the rules and tries to explain them to her though play. When Kelly asks him to bring three sheets of paper to draw on and forgets to say "Please", he puts his hands to his 


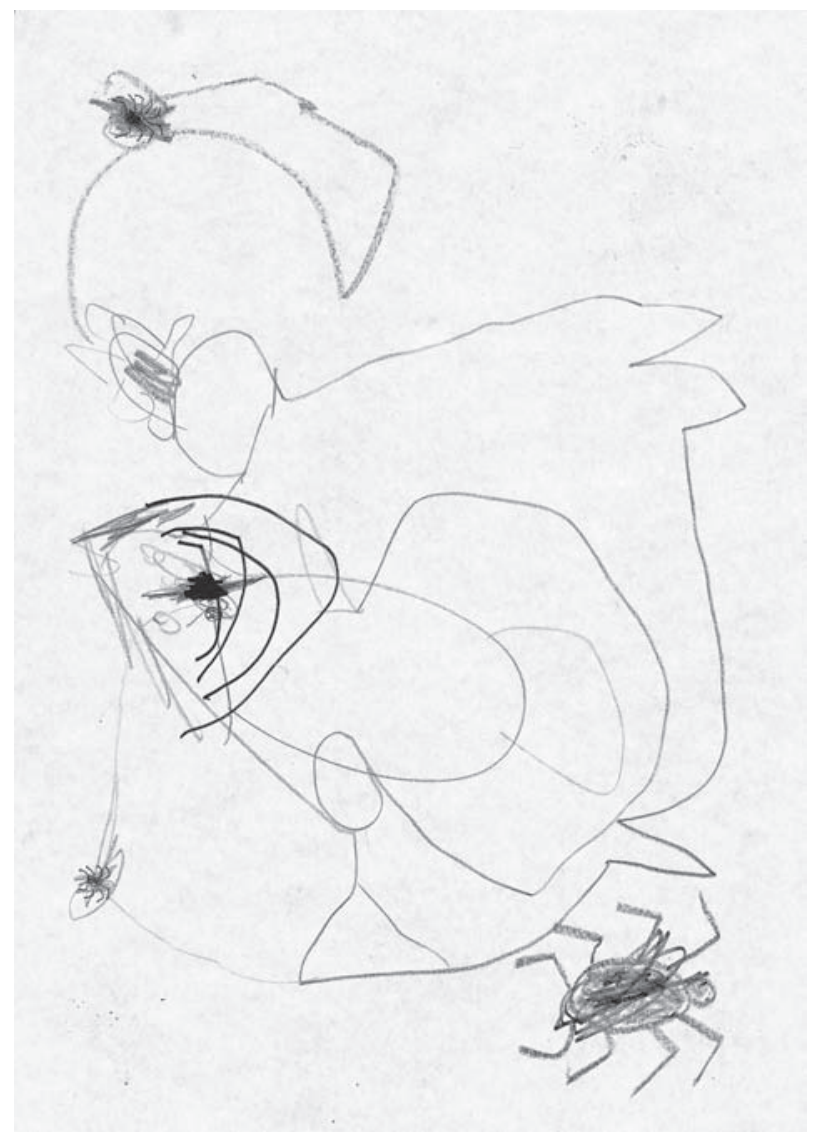

Figure 1. Kelly's drawing.

ear, looks at her and waits. Kelly understands immediately, laughing and adding loudly "Please daddy". Both parents attempt if possible to satisfy her wishes and explain to her when this is impossible.

When the adults cannot grasp her urgent wishes, Kelly becomes upset. She directs her negative feelings to the observer. Conflict arose regarding Kelly's wish to include her father in the game. The scene occurred after Kelly, her mother, and I had played two games together:

"What next?" asked the mother, and Kelly wanted us to get up, form a circle, and sing "A farmer wants a wife ..." Kelly said I should stand in the centre. They sang and I chose her; she was very 
excited, but then her mother said they could not continue since they would need many more children, and she should think of something else. Kelly wanted to play mother, father, nanny, and one person should be the mother. Nobody said anything, and after Kelly had asked several times, her mother said she was too tired to stand up. Her mother then explained that she had gone to her gymnastics class and that her legs were aching. When Kelly, after insisting they play the game, then saw she was not going to succeed, she became angry, accusing her mother of spoiling the game and then disappearing behind the sofa. Her mother tried to placate her by suggesting some other games, but Kelly was cross and did not want to play any more.

This sequence shows clearly Kelly's mother's limitations in responding to her feelings and desires. If we keep in mind that Kelly had spent all day with her father, we can interpret Kelly's desire to play a game with the whole family as an indication of her desire to express her internal situation in symbolic form. It was presumably too painful for her mother to be reminded of Kelly's absent father. Her mother appeared to have taken Kelly's game literally and felt under attack, not only because of the game but also because of the implicit accusation that she had destroyed the entire family. Kelly did not give up easily. She was able to modify her wish, but again her mother could not join in.

What happened in the observation when Kelly's feeling was not contained?

She was offended and angry and went upstairs. Her mother followed her a few minutes later, and I followed them. Her mother said to me that Kelly was often like this after she had spent the day with her father. Kelly lay on her bed on her stomach, looking angry but not crying. Her mother sat down next to her on the bed and explained once again that three women could not play mother, father, child ... and she also referred to me, explaining to Kelly that I was there to watch her play. I remained close to the door and looked at them. Whatever the mother suggested, playing with the dolls' house or kitchen, Kelly said "No, I don't want to!" Finally her mother changed the subject and asked her what she wanted to eat, saying that she was hungry and tired. Kelly accepted her mother's idea of mushroom soup. Her mother went into the kitchen and left the two of us alone. Kelly got cross with me, first telling me that she 
did not want to play anything and then that I should leave: "Go away!" she shouted in an angry voice.

We again see that her mother is unable to respond to Kelly's sadness and vulnerability. Even in a situation in which Kelly is hurt and cross, her mother wants her to play for me so I can observe her-in other words, Kelly should play for somebody else's benefit. Only when her mother changes the subject, addressing her at the more infantile level of feeding her mushroom soup, is there reconciliation. Her mother can see that she has a tired and hungry little girl who needs to be looked after and fed. In contrast, Kelly is not allowed to show her disappointment and sadness. She seems to realise that her mother is unable to cope with her provocative behaviour and thus turns her provocative behaviour against me. I then become the one who is abandoned, excluded like her father. I am meant to feel what it is like for her not to be able to be with him.

These brief descriptions of how Kelly deals with her mother and her father show a child who has positive, trusting relationships with both parents, who plays actively, and who is socially sensitive. For both parents, Kelly appears to play a large part in their lives. They manage to show her how important she is for them, the joy and the enrichment that her existence represents.

Although Kelly's situation can be assessed as potentially problematic, under observation she shows nothing out of the ordinary. On the contrary she is socially well integrated, bright, full of confidence about life, willing to learn, and full of creative ideas. She likes playing and drawing and can take up her parents' suggestions. She shows how lovingly she is attached to both parents by physically touching them and through her conduct. However, there are also indications that she is expected to be cheerful and entertaining, as if she had to console her two parents who both live alone. They have little understanding for her sad, annoyed, or disappointed feelings. The extensive observation material from the first two years of her life and subsequently at the age of four will help us to see the conditions that have led to her good development despite adverse circumstances.

Max

Max is the only son of a German mother and an English father, both of whom went through many years of analytic therapy helping them 
to overcome their doubts regarding whether they should ever have children. Max is a serious and very intelligent child who prefers being alone with his books to playing with his friends. Linguistically, he is very well developed.

The family lives in a stylish part of London. I will describe the impression that Max gave at the first meeting with his mother.

When I arrived, his mother opened the door, welcomed me in German and shook my hand. Max was standing behind her but ran away immediately, and I was hardly able to see him. His mother said he should say hello but he did not come.

Max, over five years old at the time of the first observation, was very shy. He ran away like a shy animal and only reappeared at the end of my visit. He then only managed to speak to his mother by whispering in her ear.

Max's behaviour is often confusing and contradictory. He is of above average intelligence, by far the best at nursery school, solves mathematical problems from the class above him, but emotionally he is as vulnerable as a very small child. The slightest frustration makes him cry or get upset. The great discrepancy between his childish and fearful behaviour and his independence and intelligence is remarkable. This clinging to behaviour from very early childhood seems to be related to an oral need. In all observations he is constantly occupied with putting something in his mouth: he seemed to become completely self-absorbed when licking at an ice cream cone.

Max said that he did not recall the observer who had observed him once a week two years previously and had also visited him occasionally when he was two and three. This is all the more remarkable in that all other children not only clearly remembered the observer and showed me the presents they had brought them, but also linked me with this person: Kelly and another child assumed that I was married to the previous male observer.

When I arrived, Max was licking at his ice cream cone. I first spoke in English but his mother switched to German. I welcomed Max and passed on to him and his mother greetings from Sylvia, the previous observer. His mother asked if he still remembered Sylvia but he answered in the negative. She then reminded him 
that she had brought him such an attractive present, but he still could not remember her. This time Max looked at me and seemed to be less afraid ...

When Max and his mother had finished looking at the book, his mother reminded him that he wanted to finish "his book", and he agreed. While he went upstairs to fetch his painting things, his mother took a pile of papers and showed me what he had already done. He had written a story and done drawings. His mother then went upstairs. They looked for some coloured paper, scissors, and glue. "What else?" asked his mother and Max replied "A stapler". She nodded and took it out of the cupboard. Everything happened calmly without any stress, Max's mother doing most of the preparation and Max watching calmly, checking that she had not forgotten anything. Max only spoke to his mother; he never included me in the conversation.

Going down to the kitchen, Max wanted to look at the different colours of the papers. He told his mother that he only wanted red paper and she replied that there was a red one there. He insisted that it had to be "dark red". His mother showed him the colour and he said, in a placated tone, "Yes, that's my favourite colour." In the kitchen, his mother put newspaper on the table to protect it. In the meantime, Max had unscrewed the glue and taken some on the newspaper, which led his mother to say, "What a good thing the table is protected." Her voice was calm and gentle, and it was not clear if she was talking to him or to herself. There was a contrast between the way in which Max's mother prepared everything for him as if he were a small child and the book that was his product, in which he had written a long story and done some drawings. He knew everything and checked everything she did, but let her prepare it all. As he watched her preparing things, he ate without interruption. Once he had finished his ice cream he took small chocolate candies that he stuffed into his mouth one after the other. If he lost one he carefully picked it up from the floor. He always knew exactly how many had fallen down and looked until he had found them all. His mother folded the paper into four parts and cut it. As Max watched her, she explained to him what she was doing. He was not impatient, nor did he want to do it himself: in fact, before she did anything, she asked him whether he wanted to do it, to cut the paper, etc. Since he did not react, she did it herself. 
Only once-when she had glued and stapled the third sheet of paper-did he take over. His mother observed him and since he was able do this himself, she went back to washing up. Max was completely absorbed in his work, only interrupted by eating grapes or Smarties. When he wanted to glue the paper on, his mother came over. He gave her the glue and said it was very difficult. She explained to him that the glue had not been used for some time and had therefore dried out. She encouraged him to try it himself, but since he made no attempt she continued to glue the pages ....

After his mother had asked him three times whether he wanted to read the story to me, he finally let her do it, having warned her that the story was written in English.

The story went: "It was Ferdinand's birthday but he had to go to school. This was very difficult for him since had to wait such a long time for his birthday party. When his friends came he received many presents and he stayed up late until his mother and his father also went to bed." He had written the story entirely by himself and there were many mistakes in it; having written it according to how he heard things, he occasionally had to help his mother understand a word.

It is remarkable how serious Max was. There was no laughter or cheerful movement to and fro, no physical contact. His mother behaved more like a teacher helping him to do his homework. Max behaved all the time as if I were not present. His social skills were rather underdeveloped. He seemed to be so close to his mother that he did not seem internally free enough to make contact with other children or adults. He apparently saw me as someone stupid who did not understand English. He was an extremely gifted and ambitious child, who seemed to find it intolerable not to know something. Max was not a happy child who enjoyed playing. He got his mother to make suggestions about what he should play, and to ask about what had happened at school. The situation generally recalled a conversation between a mother and an adolescent child, with the child remaining passive so that the mother would keep after him. Everything was reasonable, with no room for fun.

His "baby component", the part within him that kept alive his wishes from the time he was a baby, appeared to be localised in his mouth. But neither the flavour nor the kind of food was important-it seemed more to be a question of possessing and incorporating. His mother 
appeared not to notice the split between an adult, intelligent person and a dependent, passive baby. His passivity was astonishing, as if he and his mother were one person in his imagination. He was not impatient; he seemed to be doing everything through his mother in his imagination. Whenever his mother wanted to involve me as a third person, he pushed me away, excluded me. We can interpret this behaviour as an indication that he might think that a third person could threaten the imagined unity with his mother. We must ask whether in Max's case, the mother refused to see her child's pseudo-independence.

His great fear of his latent aggression was clear in one observation when his friend Alexander was there.

\begin{abstract}
Alexander was holding a rubber arrow, turned to the front door, and fired it. The rubber arrow stuck to the door, which delighted Alexander, who laughed and went to get it. Then it was Max's turn; he was a little nervous and did not aim exactly. When he fired, the arrow hit the door but then fell off. After Max had picked up the arrow again, Alexander was standing so close to him that the gun went off and hit Alexander in the eye. Alexander was surprised, but did not cry and instead rubbed his eye, while Max ran crying to his mother and shouted that he had not wanted to hurt him, it had gone off by itself. After his mother had examined Alexander, who was not crying, she soothed Max by telling him that the soft part of the arrow had hit Alexander. It was very difficult to soothe Max.
\end{abstract}

Max panicked when he accidentally hit Alexander in the eye. What should we make of the crying and shouting that were in such contrast to Alexander's behaviour, who neither cried nor accused Max? Max appeared to be terrified of having done something wrong-of having injured Alex. Perhaps he was also envious of his friend's better shot. Alexander appeared to be a more robust child. In a later observation Alexander was playing with Max's toys, his motorway and his animals, while Max kept running to his mother to tell her something or ask her what he should play. However, they did not play together; they did not develop a story. Max was always the one who explained everything to Alexander. When they were playing with the dinosaurs, Max gave a small lecture about the types of dinosaurs, mentioning the different and very complicated names and explained what they ate and why they died out. He always wanted to be the one who knew everything and 
decided everything. When Alexander wanted to put the crocodile on the mountain, Max kept moving it and putting it where he wanted it, explaining why this had to be so. He used his intelligence as a means of being superior, expecting the others to marvel at him, probably acting as servants in his imagination. It was as if Max identified with a superior father who had no sympathy for anyone who did not know something. He also knew a huge amount of legends and fairy tales. Later when watching television, Max guessed that the film was about Prince Ironheart. When it became clear that it was about King Arthur and the Knights of the Round Table, he played down his wrong guess by telling Alexander everything that he knew about King Arthur. Alexander was a normally curious child who asked me questions, wanted to hear my views, kept eye contact with me, and showed me his toys.

During an observation of Max and his father, it became apparent how quickly he would revert to childish behaviour. He and Alexander were sitting quietly in front of the television, at some distance from each other. When a ghost appeared in the film, Max suddenly ran to the kitchen to get a box of biscuits. When his father did not let him take the entire box but only a few biscuits, he began to cry.

Max began to shout as if he was in a panic: "I cant, I can't! I'll miss something on television." At first his father tried to help him open the tin, but Max went to the door crying. His father tried to calm him by telling him he would bring the biscuits to him in the living room. Max refused to calm down and shouted "But do it soon!" and ran away as if he were being chased.

At the moment when he was perhaps afraid of the ghost on television, thus desiring to fill his inner space with food as a means of calming down, he was unable to tolerate the slightest delay. He did not want to miss any of the flow on television, as if he himself would be then cut off. The ghosts that came and disappeared were presumably uncontrollable in Max's mind, and for this reason frightening. His father appeared worried about Max's reaction, perhaps understanding something of his underlying fear. When Max was afraid he asked Alexander to put his arm round him, but it was a short and purely physical contact. Max appeared to understand that Alexander possessed something he did not-warmth and sympathy. Playing a ghost, Max said: "I'm cold, put your arm around me," which his friend was happy to do. The relationship between the boys was cool. Max's identity appeared to be 
based on the fact that he knew more than all the others-an impression confirmed by observing him in pre-school.

The day before, the class had been to a pirate museum. Today the children's task was to draw a picture and write a short story. The class seemed to be a mixture of kindergarten and school, containing different areas with toys, a sandpit, books, and equipment. There was a "thinking book" in which the children were able to write their ideas and stories (in their own free spelling), a working book in which they practised each letter and a special book in which they did drawings and wrote down the words spelt correctly.

Max was sitting at a table with four other children. Each child had a sheet of paper in front of him on which the teacher had written a few important words that they were to use in their essays. The other children had written three sentences as a story. Max had written a story that was more than twice as long:

\section{MY PIRATE STORY}

A long time ago there was a pirate called the black pirate. $\mathrm{He}$ lived in a ship. One day a captain with his crew came along. $\mathrm{He}$ was planning to kill Black. Black the pirate saw them. Black the pirate's crew came on board. He got all the flags. But Black's crew was killed but the captain didn't get killed. But the captain fought on. He fought on with a cutlass. They both killed themselves by themselves.

His spelling was not easy to follow, and this is how the original looked:

My Pirate Story (title already spelled out by the teacher)

A long time ago. There was a Pirate collt black birate. Hh livt in a shif. One day a captain with his crooe came a logn. He was planing to cile black. Black biyte saw them. Black biytes crooe came on boord. He got all the treg. But the captain's crooe ocilde but the captain didnte get killt. But the captain foort on. He foort on with a cutlas. they both cild them silws. by thesilvs.

The words "ship", "island", "aye aye captain", "cutlass", "cannon", and "land ahoy" were written on the sheet of paper next to a picture of what the words stand for. 


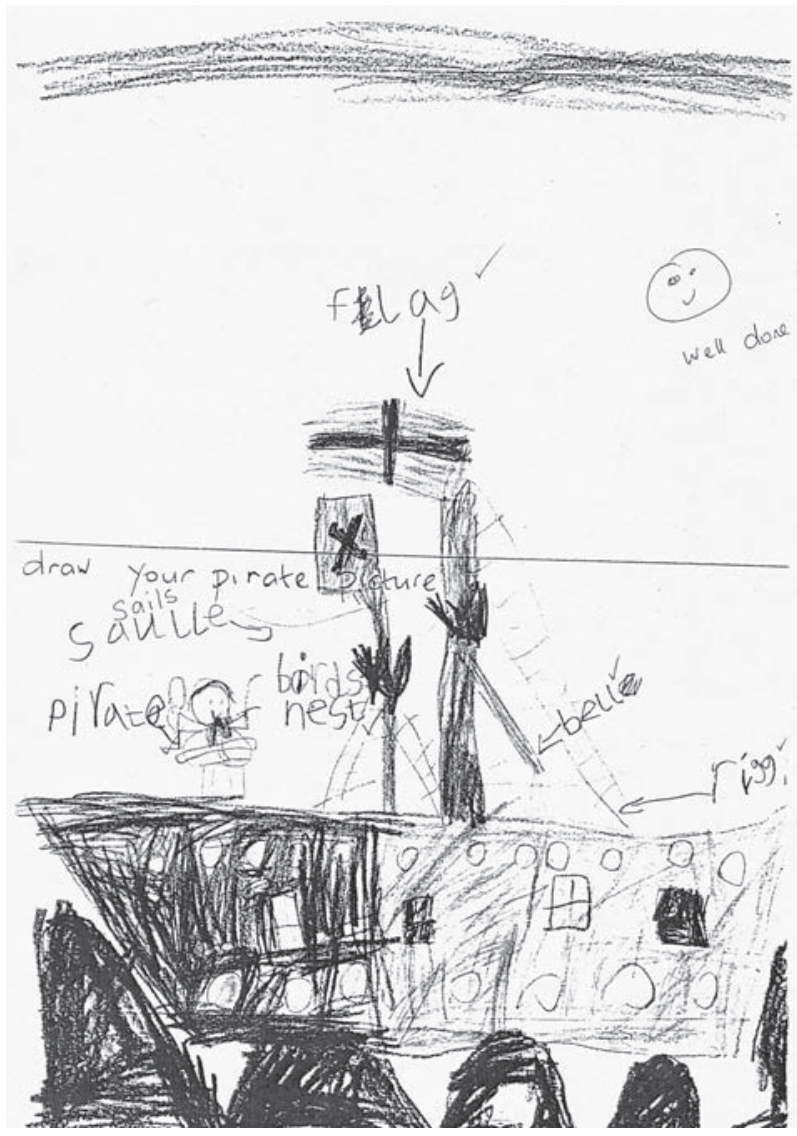

Figure 2. Max's drawing of the pirate.

Both Max's drawing and story are unusual for a child aged four and three quarters, distinguishing themselves above the other children's work.

Both the drawing (Figure 2) and the story presented Black the Pirate as being alone-alone on his ship. If we understand the ship as a symbol of Max's mother, the pirate no doubt stood for Max himself. In the drawing, Max expressed his wish to be all alone with his mother. The others did not interest him. No other life existed in his drawing, save for a bird's nest suggesting the possibility of other living beings. When drawing, he was completely absorbed by his activity. He drew for the teacher, ignoring the other children, showing only the teacher 
his drawing twice. In the story he, as the pirate, was also alone, but busy. The other children meant nothing to him and were only there to marvel at his drawing, since he was far better than they were. When the teacher asked who might have done the drawing, it was clear that it could only be Max, since the other children had only scribbled or done very simple drawings. The labelling of different parts on the drawing using words was the teacher's idea: since Max had finished his drawing very quickly, she wanted to give him something else to do. Apart from the battle between the crews in the story, who no doubt stand for the other children, the other children were irrelevant. Max as a pirate was isolated, autistically withdrawn, and the intense relationship was with his mother, who was represented as a ship. His dealings with the teacher, onto whom he transferred his relationship with his mother, also showed his extraordinary position. He was the captain of the ship, the classroom-everything was under his control. Was there an idea of an excluded father? Did he feel himself to be the pirate who had driven away the father? Did the captain who wanted to defeat him suggest a suppressed oedipal father? What was the bird's nest concealing? Max was closely tied to the teacher, who gave him particular encouragement, and it was for her that he drew, it was to her that he wanted to show his essay and his drawing. He did not look at the other children's drawings; he was not interested in them. His patience when having to wait for the teacher and queue suggested that he had no need to be jealous of anyone since he had such an outstanding position in relation to the teacher. No one could compare with him. He was above all the others, the star looking down on the others. When the other children praised his picture, he did not seem to notice them and only reacted to the teacher's words of praise.

His isolation and loneliness was only interrupted briefly when they sang a song together: he was involved in the singing like the others. While eating, he did not speak with his neighbour. When he was drawing, he was concentrating so hard that everything else seemed to disappear; he did not look at the other children, only keeping an eye on the teacher and glancing at her from time to time. The other pupils seemed no more important to him than I was, as the observer. Many of the children had made contact with me, talked to me, asking me whether I also wanted to be a teacher, showing me their drawings and smiling at me, coming up to me and welcoming me. Max hardly paid any attention to me, and only when I left at the end of the observation did 
he smile, flattered by the fact that the other children had noticed his special position. If another child did something, like one boy using a calculator, Max watched in silence until he understood and then did the same. No words or eye contact were exchanged. When he went to wash his hands, he walked seriously and dealt with the job without being distracted and without laughing with other children or pushing as the other children did. He was remarkably different, serious, quick, and efficient. Max did not play, he dealt with things very seriously. It was remarkable that there was a complete lack of physical contact, both at home with his mother and his father and with his fellow pupils.

The behaviour of both children, Kelly and Max, reflects an interior world we will attempt to understand. Both fall within the spectrum of normal behaviour, and yet they evince enormous differences.

The use of the term "normal development" makes it sound as if a child could develop without any involvement on the part of the parents. I would like to show here how complicated and demanding it is to bring up a child, the huge demands made of parents, the great amounts of patience, love, and conflict management required, the extent to which the parents must subordinate their own needs to the benefit of the child in order to enable a positive approach to the world. At the same time, we can see how robust children are. If positive experiences of acceptance and love prevail, they may overcome many deprivations and parental problems. Even with parents who make a great deal of effort for their child, problems can arise making psychotherapeutic help necessary. Let us now look at the behaviour of a child with great emotional problems.

\section{Patrick}

A boy I will call Patrick was three and a half when his parents turned to me, following the advice of his kindergarten teacher. The test given him by the psychotherapist confirmed his average intelligence despite a resistance to being involved. He displayed an extremely aggressive form of play, and was described as being completely without orientation or structure. He was still in the scribbling stage and could not draw any recognisable figures or objects.

Patrick's mother began to work more than a year ago after his little sister was born. At the first meeting, his parents said that he was refusing to go to nursery school, where he had been completely isolated, had no friends, and was very aggressive. He awoke at night out of 
his nightmares shouting and was difficult to pacify. He could express himself well in words, but only scribbled when drawing. In particular, his father was often involved in power struggles with Patrick, the boy provoking his father to rage by not obeying him at all or doing the opposite of what he ordered. Often his parents did not know what to do with him.

I agreed to see Patrick twice and then-together with the parentsto consider whether therapy would be of use to him. During the first session he was unable to separate himself from his mother; he clung to her or sat on her lap. Patrick would scribble something on his drawing block and then cut a piece of string into small pieces. He threatened his mother with the scissors, and attempted to cut her clothes, which she prevented. After half an hour he allowed his mother to go into the waiting room, then playing with his small cars for a short time. When two of his cars collided, he began to sob uncontrollably like a small baby, ran out to his mother, put his arm around her neck, and was difficult to console.

At the second therapy session, his mother explained to Patrick that she would collect him fifty minutes later, which he accepted. He was very different during this session than in his mother's presence, more like a child of his own age. Patrick sat down at the table and tried to draw, that is, he scribbled. He then discovered the glue, picked it up, and, looking at me, squeezed some onto the drawing paper. When I described how he wanted to put a lot of glue onto the paper, and perhaps even glue himself to me, he pressed even more glue onto the page, smearing it with his fingers in obvious enjoyment. He then deliberately and violently broke of the tips of the coloured pencils with a ferocious expression on his face, first breaking off the tips of the new pencils and throwing them around the room, then stamping on them. I suggested to him that he wanted to show me how easy it was to make useless broken pencils out of beautiful new pencils, and that he perhaps felt broken himself. He seemed not to hear my voice, became more and more excited and ferocious, not stopping until all the pencils had been broken. I said that he wanted to show me what it was like in his head when everything was chaotic and broken. When I told him that he wanted to see whether I would turn away from him and not allow him to come back if he made such a mess, he suddenly changed his behaviour. As if accidentally, he came up close to me, leaning trustingly on my legs. I told him that this was his way of showing me that he now felt understood by coming so close to me. I would speak to his parents and 
suggest he should come regularly. (The parents informed me at the next discussion that he told them I had pulled his T-shirt and slapped him when he was naughty.)

Patrick's behaviour at play shows an interior world ruled by chaos, a chaos I interpret as expressing his despair. He made a mess in the therapy room because he felt he was a mess: someone everyone wants to throw away. The story he told his parents could indicate that he has often been beaten by his father. Instead of using the coloured pencils for communication, he broke them - as if nothing beautiful or new should exist alongside him. Breaking the pencils made him happy, as if his intellect were not willing to think but only willing to destroy. When I addressed his hopelessness and despair and showed I understood his wish to come back, he pressed his whole body against me-showing how he felt he had made contact with me.

From the very beginning, the sessions assumed a huge importance for him. He asked me to draw him a calendar where the days on which he was to come to me were written down. He showed that he did not want to establish connections but rather to cut everything into small pieces. He made chaos in the room; he lived in an unintelligent, broken world where his only activity was to destroy. The fact that I remained with him, not turning away from him, was very important. He saw me as someone who wished to help him understand what was transpiring inside his head. He had hardly any patience for learning anything, and wanted to be able to do everything by himself from the very start. If this did not work, everything collapsed, and he had no confidence he would be able to do it later. He could not wait, instead camouflaging his uncertainty by ordering me and his mother around as if he had the power of decision.

Patrick arrived at the third session with three pages of white labels. He told me he had been given them by his grandmother and that he wanted to give them to the other children. (Next to his drawer in the cabinet there were three other drawers that he associated with other children who came to therapy.) I told him he wanted to show me how friendly he was today, perhaps also because I endured his devastation of the room during the last session and remained with him. When he opened the drawer he saw the calendar that I had drawn for him and he asked me to draw a circle around that day, which I did; then he wanted to know exactly where he was today and how many sessions he would have up to his holidays. Patrick drew a line and stuck three labels on it. I said: 
"Could it be that you have mixed feelings about the other children that you want to cover up?" He tore the labels off again and asked me: "What did you do with the mess yesterday? Did you throw it away?"

His question indicates that he assumed I might be like him, that I could clear away the destruction, forget everything, and begin again the next day without thinking about the consequences. The gifts to the other children should cover up the many more threatening thoughts about new babies, about other children, a means of suppressing his traumatic experiences with his sister, of not having to feel them.

These short descriptions exhibit three children markedly different from one another, and it is interesting to examine their development from the beginning and what they are now. What was the pregnancy and birth like? How did their parents behave with them? In what kinds of environment did they grow up? What problems, strokes of fate, or beneficial conditions affected them?

Before I move on to the three families and describe the beginnings of the relationships between parents and children during the pregnancy, birth, and the first three years of life, I wish to explicate the differences between the children described on the basis of the seven dimensions of personality development.

First dimension: a basis of good internal objects or a split into idealised and dangerous internal objects

Kelly seems to have a good and warm relationship with both parents. At play, she takes on the role of the loving mother to her doll, which I understand as a reference to a good internalised mother image. She cuddles up to her father when being read to, she includes me through eye contact, and both enjoy it. Kelly is optimistic and open to the world.

Max has a very close relationship with his mother but his seriousness and fearfulness suggest a partially insecure inner world. For emotional stabilisation, Max frequently needs oral satisfaction which he gets by eating, sucking, or putting something into his mouth. He seems to be afraid that things could rapidly become threatening. He uses his intelligence to try to control the risks in the world.

With Patrick, despite his positive development in the first two years of his life, the situation later so worsened that his parents turned to therapeutic help. The rapid success in therapy suggests that there was within him the basis of a good internal mother that was then overlaid 
by other conflicts. At the beginning of the therapy, he sank into chaos, hopelessness, and despair. For him, the world was threatening and frightening, and he suffered from nightmares.

Second dimension: acceptance of the child's personality or shaping to fit the parents' notions

Kelly's self-assurance suggests that her parents respected her as an independent person from a very early age. Kelly had confidence in her abilities, and a wide variety of interests and ideas that she enjoyed putting into practice at play. She appeared to be aware of her parents' love and attention. She was persevering and confident of being able to overcome obstacles, and also appeared to have overcome her parents' early separation, able to maintain a loving relationship with both of them.

Max also had great perseverance and many creative ideas, but their implementation seemed to be something difficult, serious, and of little pleasure. He seemed to be under pressure to prove what he could do. Separations were difficult for him. Max switched between stages of independence and superiority and phases of fearfulness, during which he would hide behind his mother.

Patrick's independence, which presumably had existed during the first two years of his life, was seriously shaken at the time therapy began. He doubted whether he was wanted at all, clung to his mother, and would not let her leave him. He derived attention by being difficult, having tantrums, and throwing himself on the ground and shouting. He was hardly able to express his feelings symbolically, could not draw but instead scribbled wildly.

Third dimension: mature type of defence or primitive defence

With Kelly, we see mature ways of dealing with emotions by the manner in which she was able to express her fears of monsters in her drawings. When her wish to be allowed to represent a complete family in play was not satisfied, she returned to early defences, becoming a small baby, saying no to everything, and projecting evil onto the observer, who should feel excluded in place of her. There was also an apparent tendency to hide deep and painful feelings behind hyperactive and exciting games. 
Max attempted to overcome his fears by intellectualisation and a know-it-all attitude. He used his considerable intelligence to learn as much as possible so that he would know everything in preschool and be better than the others. Whenever this failed, his adult-like behaviour broke down; he began to cry and ran to his mother or father. In particular he seemed to have difficulty integrating dark feelings such as envy and aggression. He would become upset if he thought he had hurt his friend.

Patrick showed he was at the mercy of his destructive impulses. The ability to destroy things and make chaos of everything seemed to have become a preferred source of pleasure. Once he began to break the coloured pencils, he was unable to stop himself. He was not certain whether other people were dangerous and bad or were idealised good people such as his mother, to whom he clung - this mood then shifted and he attacked her with the scissors. He liked to smear, which suggested an early developmental stage.

Fourth dimension: acceptance of the child's feelings by the parents (containment) or rejection

Kelly had probably often experienced her mother and father accepting her and her feelings and this helped her accept her bad feelings. What seemed to be a difficult area were the separation and her mother's associated feelings of guilt. Kelly's mother was often unable to accept and understand her daughter's painful feelings of loss and sadness. However, both parents succeeded in creating plenty of space in their lives for Kelly.

Although Max experienced lots of attention from both parents, he appeared to have difficulties in integrating his good and bad feelings. He probably saw himself as the centre of the world and produced unique achievements so as to have a special position. It was seemingly difficult for him to care about other people.

Patrick saw himself at the heart of a dangerous and threatening internal and external world in which no one understood him. His mother tended to manipulate him rather than to understand his pain, unhappiness, jealousy, and envy. Patrick repeatedly tried to provoke his analyst in the same way as he did his father and to irritate her until she became angry. If, however, he felt himself understood and emotionally affected, he would express this through physical proximity and touch. He seemed to be deeply convinced that he was unwanted and intolerable. 
Fifth dimension: explanations for orders as opposed to inflexible rules

With Kelly, both parents accompanied the setting of rules with explanations appropriate to the child's age. They would take account of Kelly's wishes as far as possible and try to come to a solution together. Compliance with rules was clearly important, whereby humorous hints were employed more often than sharp commands.

Max's parents also set clear limits, yet both parents seemed to have problems in insisting on compliance. Both considered themselves too tolerant and inconsistent with Max.

With Patrick, the parents' methods of education differed hugely. The mother attempted to use promises and stories to persuade Patrick to do something, although since these promises often were not kept, the validity of rules became unclear. The father appeared either to set up strict rules and insist on compliance down to the last letter (shouting, beating, mockery) or to make fun of Patrick if he did not do what was wanted. Patrick and his father very quickly became entangled in power struggles.

Sixth dimension: acknowledgement and praise or inhibition of abilities

With Kelly, her parents appeared to encourage a wide range of abilities, namely her intellectual, her musical, her dancing, and her theatrical talents. At times, it was not clear whether Kelly's talents were being encouraged or whether her mother and her father needed Kelly to cheer them up and distract them from their own worries. Kelly's play would then become excessive. She also used her charm and her humour to get her own way. Kelly got lots of attention from her maternal grandmother.

Max was greatly encouraged in his intellectual abilities by both parents. He had a large library of children's books and non-fiction that his parents often read to him. Writing and making things created a bond with his mother. He had acquired much knowledge that he used in order to be better than other children. His great ambition and his perfectionism made his activities seem less like play, instead giving him a somewhat serious air.

Patrick seemed to never know exactly whether praise from his mother was meant seriously or was being used to pacify him. 
He was deeply convinced he could not do anything well. His maternal grandfather liked being with him, making things and doing things with him, and in this situation Patrick showed skill. When playing ball with his father, competition was of foremost importance, his father wanting to do everything better, which made Patrick angry when he lost.

Seventh dimension: good social skills or socially withdrawn

Kelly was the centre of a group of children: she had lots of ideas, so that the children were happy to play with her. She was able to establish contact with the observer immediately and initiate activities to everyone's delight. Her cheerfulness and her carefree attitude were contagious.

Max tended to play by himself. He would observe the other children but rarely made contact with them. He did not joke and had no physical contact with them. It was only in singing that he was able to integrate into the community.

Patrick was an outsider who was rejected and made fun of, and in the end he refused to go to nursery school. In the presence of other children he was either afraid or he would threaten them. He often did not know what he should occupy himself with, since his expressive capacity was limited.

Let us return to the beginning of life to describe the many stages and functions babies and their parents must go through for a healthy development, and to understand where communication between parents and baby can lead to problems. We shall describe the development of the psyche-as distinguished from the body-and consider how the baby acquires his approach to understanding the world from the relationship with his parents.

\section{Birth: from the foetus to the newborn child, or from the imaginary to the real baby}

Birth separates the child from his mother. The long stage of pregnancy, a time of hope and uncertainty, of joy and fear, is followed by the short period of delivery, a time of pain but also of release for mother and child. The last stage of pregnancy is often quite arduous for the mother. The foetus, too, now has less space to move given its increased size. Emotionally, the idea of the womb as a protecting container changes to the image of a prison with the child locked in. Since antiquity-after 
Hippocrates and Galenus-it has been regarded as an irreversible fact in medicine that the child, at least in the first stage of birth, plays an active role, deciding himself when he wants to "knock on the door" in order to be let out by Mother Nature. The midwife is understood as a "doorkeeper" who, from the outside, helps the mother to open the womb when it is necessary. Emotionally, the first vital cooperation between mother and child takes place at birth, and it is only then that the child can be received by the mother (cf. Gelis, 1989).

If we consider birth as a cooperation between mother and baby, the question arises of what this signifies for the baby. He leaves behind the protective and nourishing placenta that gave him food and security, with a temperature precisely adjusted to his own body temperature, an endless provision of food, and never the frustration epitomised by hunger. When he comes into the world, the baby ends this existence within the mother, where he was kept warm and secure. Freud refers to "oceanic feelings", which he understands as the recollection of the feeling of happiness and security in the womb. The baby has no idea of what it means to be hungry, to be cold, or to feel alone. Once the baby has secreted the hormones that trigger his mother's labour, the world starts to move, violent contractions shake the entire system until he is finally pressed through the uterus and emerges. The child must manage to breathe within his first few minutes in order to live; otherwise he will die. "The complete change in conditions after the umbilical cord is cut probably leads to the disorganisation of any existing tactile and spatial structures of self-experience in the infant," to quote Krejci (1999, p. 24). The newborn child, however, only exhibits discomfort for a short time if he is received with love.

Thus for both mother and baby, birth represents a radical change and a loss of a familiar coexistence. At the same time, birth is something that is desired by both parties, since it is only then that the mother regains her body for herself and the baby has more space to move in. However, this dramatic change is so radical that it takes some time to be dealt with by mother and child and for the new relationship to become familiar: mother and child must rediscover one other once the umbilical cord has been cut.

Emerging from the protective shell of his mother's body, the source of warmth, comfort, and food, requires a considerable adjustment on the part of the newborn child-an adjustment, however, that follows from the foetus's experiences in the womb. Even while still in the 
womb, the child practises taking in amniotic fluids and draining them. The sound of the mother's voice, the beating of her heart, and all the inner sounds of bodily activities constitute a familiar environment for the foetus.

I assume the physical experience in the womb to be a major learning experience for the foetus towards its sense of body. Much is still unknown about this initial primitive "learning". Close observations of the foetus in the womb show an unexpected early motor and sensory activity. Comparisons of the movements of the foetus in the womb and after birth, as carried out by Piontelli, show a characteristic interaction between twins, one twin being the more active, the more mobile, while the other reacting more passively: films of the ultrasonic examination and recording of the movements of twins shortly after birth and at the ages of six months and one year confirm this constant characteristic for a given pair of twins (Piontelli, 1992).

The foetus is able to execute more difficult bodily movements, such as somersaulting in the uterus, than the newborn child can after birth. The foetus actively starts the process of birth at the appropriate moment by producing hormones. If the foetus has died, birth does not take place spontaneously but must be induced.

This nine-month experience of being held in a warm and soft membrane is referred to by Gaddini as "physiological learning", which precedes psychic learning as a differentiation of the experience of the body. This contact within the uterus can accordingly be interpreted as the experience of spatial limits. Since the foetus lacks intellectual knowledge about itself, the amniotic sac strengthened by the uterus wall becomes, in Gaddini's physiological-functional model, the basis for a fundamental knowledge of limitation that is present at birth. Gaddini clearly wishes to avoid the misunderstanding that he ascribes consciousness/ego to the foetus by stating, "Certainly we are, at this point, far from the possibility of even an initial mental self-image intended as having an interior space enclosed within its own borders, which separates it from a limitless external space; but the mental use of memory that characterizes the mind's learning from the very beginning acquires new dimensions with the birth process" (Gaddini, 1992, p. 123). The close interconnection of physical and mental functions and the differentiation of the psychic from the physical are to be assumed even before the foetus is separated from the mother at birth. Birth itself represents an increase of the process of the differentiation of the 
psychological function, since, according to Gaddini, it "is of necessity accompanied by intensified mental learning about physiological functioning". Despite the emphasis on the importance of the intrauterine experience, he still "subordinates the mind to the body" until after the second post-natal month of life.

Birth resulting from a "remarkable break", as Freud called it in 1925, brings with it a series of sudden and radical changes in the way the baby's body functions and an invisible change in psychic processing. Glaring light and cold as opposed to the constant environment in the womb, autonomous breathing, secretions, and excretions no longer correlate with the protective environment of the uterus. The mother's voice and the rhythm of her heartbeat are something familiar to the newborn child, while breathing, ingesting food orally, fluctuations in temperature are new and confusing impressions; so is hunger, along with breastfeeding - the epitome of satisfaction, associated with feelings of pleasure and the feeling of satiation as restitution of the intrauterine sensation of well-being. The fact that the mother can be called by the baby's crying, and the resulting satisfaction after feeding, represent experiences of successful communication. For Bion, this first experience of drinking at the mother's breast embodies the original form of human contact. It involves not only the sucking reflex but also the preconception of the knowledge about the way the baby's mouth fits the mother's nipple. Mouth and nipple represent for Bion (1962) the original form of linking, and thus are the starting point for thinking as the combination of perception and idea. The baby must rely on an external system, on a person who comes and picks him up, touches him and gives him the breast or the bottle. In his "The Origins of Psycho-Analysis" (1895) Freud assumes a physiological function of survival and the satisfaction of need that becomes communication. He says: "At first, the human organism is incapable of bringing about the specific action. It takes place by extraneous help, when the attention of an experienced person is drawn to the child's state by discharge along the path of internal change. In this way this path of discharge acquires a secondary function of the highest importance, that of communication, and the initial helplessness of human beings is the primal source of all moral motives" (1895, p. 317).

We cannot understand the situation of the newborn child without including the parents' emotional situation. For the parents, the birth represents the arrival of the new, real child. All the mother's thoughts 
revolve around the birth, about what the child's arrival into the world will be like. After birth, the child is separated from his mother "when the umbilical cord is ceremonially cut" (Gelis, 1989). This physical separation entails an intense emotional conflict on a number of levels. The first birth in particular represents a frightening situation for the woman: how is it possible that such a large thing can pass through the narrow birth passage? Will I recognise the labour pains? How will I handle this pain? Will the birth be normal or will there be complications? What will my baby look like? Will I be able to love it? Will it be healthy and completely formed? Surrendering oneself to the forces of nature is a threatening feeling. In addition, archaic ideas and fears are activated: Will my body break apart? Will I disintegrate?

The parents' fantasies about their baby, who gave the first indications of its character by moving violently or gently within the mother's body or reacting to stimuli such as music and noises, must now meet the test of reality. The end of pregnancy-associated by many women with pride and joy as the quintessence of completeness and unity with the foetus-occurs abruptly. Fear can arise at the thought of what might happen if the baby cannot leave the mother's body. Joy and pride over pregnancy can be transformed into threatening and claustrophobic feelings, into a sense of imprisonment, and also the feeling of total dependence on the baby. Feelings from the initial stages of pregnancy are activated-the fear of hurting the child, of damaging him or the fear of being killed or damaged by the baby at birth. Life and death are in fact closely related to each other during the act of birth, although the risk for mother and child has been radically reduced by modern medicine.

The newborn child is awaited both physically and emotionally by the mother and the father. Just as Gaddini interprets the limits of the womb as a functional model of the limits of the ego, parental ideas, hopes, expectations, and fears can also be interpreted as a "triangular space" (Britton, 1989, p. 86) within the parents enclosing the baby. This psychic space contains not only loving and positive feelings and ideas but also the parents' anxieties, worries, and cares. A relationship to the imaginary baby has already developed in the parents' minds, associated with hopes, wishes, fears, and expectations. This means that the newborn child already has an "emotional history". Is he a child for which the parents have longed for years - to which, after their wishes have been fulfilled, they have given the name "Desiree"? Is the baby unplanned but wanted? Has he been conceived violently in rape, signifying shame 
and painful humiliation for his mother? Is he the baby of very young parents who have subconsciously used the pregnancy as a means of escaping from their own parents? Parental motives for pregnancy are no doubt important for the baby but do not permit any forecasts about his further path through life: during pregnancy or the first few months of his life, an unplanned baby can become a great source of joy and happiness for his parents, entailing-as it were-a reconciliation with the baby who has forced himself into life against his parents' wishes. We all recognise how a baby influences his mother's and also his father's moods, ideas, and feelings. Eye contact, looks, gazes are of major importance. In the recounting of birth, focus is always on the first sight of the newborn child, followed by the sensation of the child on the skin and the first suckling at the breast. Eye contact exemplifies both the intimate limitation and extension to a third person. A baby looking into his mother's eyes sees not only the mother but also the mother's joy at his gaze. The baby assimilates the happiness in his mother's face as his own self-image: he sees himself in the same way his mother does. Winnicott speaks of the "shine in the mother's eyes" - but the baby also registers her worries, denial, and fear.

\section{Kelly's birth}

Parents asked about birth relate their impressions. Let us begin with Kelly, whose mother said:

Once she was out they put her on my breast, I mean I asked them to do so. She did not drink, you know. She cried a bit. I asked them not to cut the umbilical cord until it had stopped beating. They waited and then cut the cord. Then they rubbed it off and examined it in infrared light on the table.

Kelly's mother asked the midwife not to cut the umbilical cord until its pulse stopped, in order to provide Kelly the maximum sustenance for the start of her life. She emphasises that she asked the nurses to place Kelly on her breast. The father's description communicates more drama: "It was great, when they had placed her on her breast then they cleaned her and weighed her. I was given her to hold. That was wonderful. Not only because of the drama of which I just spoke, it was such a relief. I was so delighted, she seemed to be OK. I cried, it was really 
nice. The midwife said she had never seen a child who looked so much like her father. I said: 'No, please, don't say that she looks like me.' Fortunately she doesn't take after me, I'm happy for that."

Kelly's father appears not only to have helped his wife enormously in the physical sense, but also to have emotionally detected her worries and fear as well as her relief. Kelly's mother also emphasises how helpful it was to have him with her. He sat with his back to hers and warmed her back, holding her hand: he was "very good", as she said. When he held Kelly he cried, because he was so moved at holding his child in his hands. When the father is present, the birth is also a bonding experience for the couple and the newborn child-in which the father can also participate.

About the birth as a whole, Kelly's mother speaks with particular bitterness. She was surprised at her first labour pains-three weeks before the calculated date of birth, three days after the start of her maternity leave. She had planned to go to hospital, because this was recommended for the first birth. A birth at home never came into question. Kelly's mother provides a long and detailed description of the birth, the last part of which I quote:

I sat up on the edge of the bed, the doctor looked at me. I wanted to remain sitting on the edge of the bed. In any event when I sat up, I noticed that I could not get my legs down. This annoyed me and for this reason I said: “No, I don't want that, I don't want to give birth like this." But they insisted and I gave way. For this reason I was a little annoyed, but suddenly I felt the head. Short moments; since during the labour pains you don't really feel what's happening. As soon as I felt the head between the first and the second stage I thought I must change my breathing and I did. Nobody noticed. And then ten or twenty minutes later someone said: "By the way you can start pushing" [laughs]. It was really ... He [the doctor] did not see what was happening. And so I really had more pain than necessary but I thought I was doing the right thing. So I pushed and I was still on the bed in this terrible position that I did not want. And they did not encourage me to sit up or do any thing else. I found pushing very difficult. Then I said "I want to go home." [laughs] Then they said we must do an episiotomy. I said "No, I don't want that." I became stubborn and pig-headed. Finally they said: "Two more pushes, if you don't get the head out we'll do it [cut]." I said: 
"This wouldn't have happened if you'd let me sit up." Finally they had to cut me, but the worst was the sewing afterwards. That was the worst of all.

Still angry at the doctors' behaviour, Kelly's mother is planning to do things her way at a second birth. She also refused an injection to get the placenta out. She had to empty her bladder using a catheter, whereupon the placenta was released. She then had to wait a long time for a doctor to sew her up, experiencing this waiting as a form of humiliation, since everybody was walking past her. She was then occupied by writing down the precise time of the birth in order to be able to draw up an exact horoscope for Kelly, who was born at 11:12 am. With pleasure, she recounts how astonished the nurses were that she was already making a detailed horoscope for her daughter while waiting to be sewn up.

In Kelly's father's description, the focus is on Kelly's health. His presence at the birth went without saying, since he had accompanied his wife to the prenatal courses, where the husbands practised helping their wives at birth; one stage of birth was discussed each week, and there were joint exercises. He says:

I think, as far as concerns the birth, we had a false alarm the previous night, then we came back and then we went in again. There was a problem between three and four in the morning. The back of Kelly's head was so large that they could not get it out. For this reason they had to call a midwife who cut my wife. That was terrible. I hated the whole thing, it was horrible, it was frightful to look at ... As soon as we saw that Kelly was alive, it was OK. But when we saw the mess, the nurses and midwife worriedly looking at each other and blood everywhere and everything. My wife was cut very roughly with scissors, it was much more brutal than I had ever imagined. I don't know why it was, but it was OK. Everything was fine, but at the time it was not nice, not at all. It was horrible because we didn't know whether Kelly was alive. We hoped, but we weren't certain. It was only a few minutes but it seemed a long time, it was a horrible moment.

Description of critical moments during birth demonstrates the risk of every birth, the life or death of the child. It is impossible to predict the course of any birth, and only once the child is out and breathing 
is a positive conclusion attained; before then, great tension and worry prevail.

The emotionally differentiated description of a newborn child itself as sweet, with doctors, nurses, and midwifes as unfriendly, unloving, incompetent, and thoughtless, requires explanation. Naturally, we must first consider critically the actual conditions of birth in a hospital, the preparation and support for a pregnant woman. In fact, feminism and criticism of medical practices have led to many changes: giving birth in a lying position is now seen as unfavourable for mother and baby; giving birth in a kneeling, standing, or sitting position corresponds far better to the physiological needs of the mother (cf. Gelis, 1989, p. 189; Kitzinger, 2000, p. 168).

Birth represents the end of the first stage of life within the mother's body. In the psychological sense, the baby has a long history in his parents' minds. What is Kelly's history like? What were her parents' reflections before the egg was fertilised? How did the parents experience the pregnancy? What were their ideas of parenthood?

Kelly's mother describes the beginning of the pregnancy quite breezily, saying:

It was an accident ... We never spoke of having children. It was really strange, as soon as I missed my period, I knew ... I felt sick. I took a pregnancy test and woke him at seven and said, 'It's positive, and by the way I'm having the baby whatever you decide.' I knew that I wanted her, at that time.

Her description is so brusque that the decision to have a baby seems to be hers alone, not a joint one. The baby is described as something that she wants to have, that belongs to her. She also cites her age, twentyseven, as the reason she did not wish to wait. At the same time she still seems to have been happy at Kelly's father's reaction: he said he had always thought of having a baby with her and asked her whether she would marry him. They got married and went on honeymoon to Paris.

Queried on how the pregnancy had been for her, she replied spontaneously: "Great. I was very happy at being pregnant." She added that they had no sexual contact but that she was not concerned at this, since he was very considerate and tender. He massaged her legs every day and was greatly looking forward to the baby. She felt he wanted her to concentrate on the baby, and showed understanding for her situation. 
Kelly's father describes the pregnancy as a happy event, saying, "I was delighted, extremely delighted when I heard ... I assume that at the time it was delightful and at the same time ... it was a turning point for me, where I would have to discipline myself because I thought that I have to become devoted to the child, and less selfish. More aware of the child's needs ... When you have a child you have a life in your hands ... you have a responsibility."

His great responsibility as a father and the desire to fulfil this task well are his foremost thoughts. Kelly's father refers to the pregnancy as a turning point in his life, a new dimension that altered him. It happened at a time when he had begun harbouring the idea of becoming a father. Although his relationship with his wife became very difficult from this point, he considers the birth of his daughter the most important event in his life.

He describes the period of pregnancy as a very painful time:

So when she was pregnant, she was not really well and rejected me sexually. And we hadn't had sex all the time she was pregnant, and we didn't have sex after Kelly was born either ... My attitude was that if this happens because my child will be born, then it is a price I have to pay. I mean, the fact that she rejected me was not amusing but I accepted it as a part of the new responsibility.

What is remarkable is not only the variation between their descriptions, but also that Kelly's mother is unaware of how painfully her husband felt rejected. Later, he confides that he had always wanted to have sex with a pregnant woman. For him, this rejection was something he had to respect; he did not want to force himself on his wife. He speaks in detail about all the worries he had:

It was worrying as the pregnancy continued, you think, hopefully everything will be OK, the birth will go fine and the child will be OK, physically everything will be all right. That's a lot of things to worry about.

On the one hand, what Kelly's father says is true-all parents worry whether everything will be all right with their child. Presumably, his feeling of being so terribly excluded from marital intimacy contributed to exacerbating his worries. Kelly's father felt a relationship to Kelly 
as a foetus immediately after he had become aware of her existence: he could immediately imagine her, and found the ultrasonic examination fascinating. He also found it calming to see that physically everything was all right. Neither of them wanted to know the child's sex, but instead to be surprised. On the practical level, both took part together in introductory courses for parents and read many books about babies and pregnancy.

What does birth mean for Kelly as a point of departure? Initially, positive aspects seemed predominant: clearly, she was of huge significance for both parents. The pregnancy seems to have been the beginning of the end of their relationship as a couple, and the parents were divorced under dramatic circumstances, after a turbulent struggle for custody. What Kelly may rarely experience is a well-functioning couple relationship.

Since we consider the pregnancy as part of the newborn child's history, its emotional importance must be examined.

\section{Pregnancy}

Pregnancy represents not only a fundamental biological change in the body but also affects the psychodynamics of the pregnant woman's inner world. It stirs deep layers of the personality, since the woman's perspective shifts from the childlike to the motherly. In the woman's fantasy, unresolved conflicts with her own parents and unfulfilled hopes are revived both on the conscious and the unconscious level by the portent of an actual foetus growing in her womb, accompanied by her fearsboth of dissolving corporal limits and of invasive penetration. Unfulfilled wishes from early childhood and hopes, rivalry and the feeling of exclusion from the oedipal couple combined with early experiences of separation influence the way a woman deals with pregnancy. The major part of this internal restructuring remains unconscious and is in part symptomised by fatigue and exhaustion, a consequence of these psychological questions being suppressed and ignored.

How strongly early experiences are revived by pregnancy is shown by Oriana Fallaci (1979) in her book about Letter to a Child Never Born. She first describes how she became aware of a "you": "Last night I realised that you were there: a drop of life that has come from nothing", a revelation that was "a ray of certainty in this darkness" but at the same time "as if a bullet had been fired into my breast". The mother's own 
ambivalence is projected onto the child when she asks herself: "What if you do not want to be born at all? If one day you accuse me and scream at me: 'Who asked you to put me into the world?'" She subsequently speaks of her attitude to life: "Life is hardship, child. A war that repeats itself day by day, and its moments of joy are brief parentheses for which a horrible price has to be paid" (p. 7). She then asks the "drop of life" for a sign, an indication that it wants to live. Here she associates the discussion with the foetus with her memories of her mother and herself. "You know, my mother didn't actually want me. I began as a mistake, in a moment of another person's carelessness. And every evening, to stop me being born, she would dissolve some medicine in water and drink it with tears in her eyes. She drank it until the evening when I moved in her body and kicked her to tell her that she should not throw me away ... A few months later, I was rolling victoriously in the sun, but whether that was good or bad, I do not know" (p. 8).

The great emotional poles, her longing to become a mother and her fear of becoming a mother, are shared implicitly with the foetus. She is uncertain whether life for her child-to-be will be a gift or a burden. In this imaginary dialogue, we see how Fallaci expects her child to provide answers to her questions, to give her comfort and support as if their roles were reversed. Her internal difficulties and external events make it impossible for Fallaci to bear the child into the world alive, as the "child never born" in the title suggests.

I see pregnancy as a period of psychological preparation for the assumption of the new task and responsibility as a mother, entailing a leave-taking of familiar time structures both for the woman and in the couple's relationship. How radical the change is actually going to be can hardly be anticipated in the imagination of the parents-to-be. Giving the new baby psychic space in the parents' minds constitutes an important first step towards setting new emotional priorities. Pines talks of the first pregnancy as a time of crisis for the female identity, since it is a point of no return, irrespective of whether the baby is born or the pregnancy ends with a miscarriage or an abortion (1993, p. 60). This internal confrontation remains an essential point of reference for the rest of the woman's life.

If the pregnancy occurs during a period of psychoanalysis, I believe there is the opportunity to accompany this turbulent restructuring of the internal world with reflection. The psychic internal space that can result from the subject's reflective distancing allows her-under beneficial conditions-to understand the overwhelming conflicts 
revealed through transference with the analyst, and in the process she gains contact to her own vitality through expressing her feelings of aggravation, sadness, and loss. Raphael-Leff refers to an "improved accessibility of previous experiences and a more permeable awareness during pregnancy that can make the pre- or post-natal psychotherapy unusually profitable/successful" (Raphael-Leff \& Perelberg, 1997, p. 125).

The period of pregnancy has been considered by a variety of analysts to be a particularly important time in emotional terms. ${ }^{4}$ Helena Deutsch (1944) and others (Chertok, Bonnaud, Borelli, Donnet \& Revault D'Allones, 1969; Jessner, Weigert \& Fay, 1970) emphasise the massive regression during this difficult time. They argue that pregnant women are more in need of protection, more dependent, need particular attention, become more introverted and emotionally unstable, and have physical symptoms such as dizziness, nausea, a feeling of heaviness, gastric problems, swollen legs, and an increase of weight, all of which impair normal functioning. It is not quite clear whether these authors make a connection between the physical symptoms and psychic experience. Kestenberg (1956), however, emphasises the opportunity of an integrating force during pregnancy (Bernstein \& Warner, 1984, p. 21).

\section{Max's birth}

Max is the first son of a German woman, with an English father. They live in a gentrified district of London, in a one-family house with a garden. His mother describes his birth as follows: "Oh dear, the birth, [sighs] the birth was everything in one, terrible and wonderful."

She then relates that she had long considered how she wanted to organise the birth, whether it should be in the hospital or at home. There were many things to consider, including whether she would get a good midwife. She then decided against the National Health Service, she says, and chose a private midwife and a GP. She was aware that this went against the recommendations of the NHS, which does not advise home birth for the first child. She describes her feelings at the time:

I felt myself to be bursting with health and fit, and so I was in a good mood. I actually had dreams in which I simply breathed my baby out. I was very confident, I thought that nothing could go wrong. 
Here, wishful thinking can already be detected-a denial of the pain and effort to be expected, almost as if there was something in her that wished to avoid contact with the reality of the pending separation from the baby. The risks of which the health visitor had warned she ignored. She then describes the birth itself:

The strange thing was that I had extremely long and severe labour pains, not in the sense of complications [clears her throat]. But I had, I think, a day and a half and I was still not properly open ... I was exhausted and almost desperate by this time. The nice Australian doctor who was dealing with me was playing the guitar and was very relaxing. When he examined me he said: "You must go to hospital because you need a rest. You know, they could go on for another three days. Great pains but it's not opening." I was absolutely amazed and couldn't believe it. This was a sore point because I felt that whatever I did I wouldn't get this baby out, or it wouldn't come out properly. It was very, very frustrating.

She explains her resistance to going into hospital by the fact that her parents and her brothers were hospital doctors and she wanted to have nothing to do with them. In addition, her mother had been treated so negligently in hospital that one child had died and she had been unable to assert herself. She wanted absolutely to do it by herself, without a hospital. She then further reflects on her feelings during her attempt at a home birth and says: "Funnily, it was somehow not absolutely real, I had a nice midwife and a friendly doctor, but there was something unreal in the air. I could not imagine me really having a baby. I could not associate the pains with the baby. I was at home and then I was so exhausted, I had an injection (epidural anaesthesia) and immediately fell fast asleep. And within the next few hours I opened up entirely. So it must have had something to do with me, something in me that held it back."

She describes what happened afterwards:

The doctors were unfriendly and uncooperative. They were either reproachful or seemed to be waiting to have to do a caesarean. But the midwives were really, really good, very helpful. And they gave me the feeling, a feeling of reality. They helped me, as it were: If you can do it, then do it now and be happy. It sounds amazing but as soon as I knew I could really do it, I was confident ... I was surprised; it was the experience of my life. 
It was not until she was in the hospital that Max's mother seems to have come to grips with the reality of the birth-as if she did not want to believe that her baby was ready to separate from her and to have its own life. It was only when she slept, that is, when she relinquished control, that labour could cause the cervix to open, something she seems to have unconsciously resisted before.

Max's father describes the birth at home as initially a point of contention between him and his wife, but she prevailed. He allowed himself to be convinced by her arguments, found a good midwife, and then felt relieved.

The birth itself was very exciting. There was a very, very long phase of labour pains ... I think Max was born around 10.00 in the morning on Friday, and the first pains began on Wednesday morning.

The decision to go to hospital after all, to this "sterile, antiseptic hospital", was disappointing, and the birth was still pending. Max's father describes the doctors as unhelpful, which led to considerable tension.

Everything was cold and unfriendly; the doctors were making tactless comments.

He could see the baby's hair one hour before the actual birth, an indication of how long it took for Max to emerge.

Seeing Max in reality was "... a wonderful feeling. A truly wonderful feeling," says his father. "Immediately after my wife had had him, while she was being sewn up and the placenta was being dealt with, I would say within twenty minutes after the birth." For both of them, it was clear that the father should be present at the birth. "She very much wanted me to be there, I don't think there was ever any question about it."

Max's mother describes the joy of having him actually with her in great detail.

When Max came out they immediately put him on me, on my body, even before they had washed him, that was very good ... He did not need anything, he was just himself. His head was not squashed or anything. He was fine ... I spent a night in hospital: that was very good. It was a huge room with twenty mothers with 
newborn babies. You'd think the chaos would be terrible. But it was absolutely peaceful. There were many nurses and each baby was next to its mother's bed. I had him with me all night long, I think. I didn't sleep, I was so happy [laughs]. That was something very special, I felt myself so cared for amongst all these newborn babies. It was very peaceful. When a baby cried someone immediately came to deal with it.

After the positive birth, without any complications, Max's mother seems to have found the hospital situation calming because everything was structured. She was able to have Max with her all night long. The objective situation of a large ward with twenty mothers could be seen as a strain, but instead was experienced as the consolidation of a common feeling, as peaceful and secure. Ultimately, unlike her mother, she had had a natural birth with a healthy baby.

In both accounts we find a compartmentalisation into good and bad, the hospital being described as a threatening and unfriendly place. After the birth, Max's mother is able to reconcile herself to the hospital that helped her to actually press the baby out. Not even the large ward with many newborn babies constituted a strain for her; on the contrary, she appears to have shared her joy with all the other mothers. Having described the pregnancy as an inner, crisis-ridden restructuring, it is understandable that the internal forbidden thoughts, feelings of rivalry with one's own parents, and the ambivalence towards the baby were seeking a place where they could be accommodated. In a historical psychoanalytical examination of the relationship between the belief in witches, sexuality, and religion, Lyndal Roper came to the conclusion that a mother-to-be's internal "evil" elements resulting from unresolved conflicts with her own mother are often projected onto the midwife. The midwife then becomes the embodiment of evil, which in the middle ages culminated in their being accused of witchcraft and death at the stake (1997, p. 201).

\section{Patrick's birth}

The birth of Patrick, whom I have described as a child with great problems, practically devoid of any self-confidence, proceeded without any unusual incident. Patrick was a child who was wanted; his parents had been married for two years when his mother became pregnant. Patrick 
was born in hospital in a spontaneous birth. Both parents had been looking forward to the baby, their first. It was a natural birth without complications; in fact, since no interviews were held with the parents of the children who came to therapy, little is known about Patrick's birth other than its lack of complications.

\section{The physical capabilities of the newborn baby}

The physical capabilities of the newborn baby have been compiled by Brazelton in a "Neonatal Behavioural Assessment Scale" (NBAS), which is designed to evaluate the child's reactions and reflexes. An additional important aspect of the NBAS is to demonstrate to parents the astonishing abilities of the newborn child, thus refuting the preconception of a helpless bundle without abilities that is entirely dependent on adults. The newborn child is tested in all six states of consciousness: deep sleep, light sleep, drowsy, alert with bright look, eyes open with high motor activity, and fussy and crying states (Brazelton, 1995, pp. 21-31).

1. First, the newborn child is tested to see how it can filter out unpleasant stimuli.

An unpleasant stimulus-a torch-is shone for two seconds at the child's closed eyelids. He starts and begins to move. As soon as this reaction subsides, the torch is then shone a second and then a third time, up to ten times. The first stimulus causes the baby to start and move his entire body, twitching his arms and legs; normally, however, these movements become weaker with every repetition, so that with the fourth stimulus, he generally hardly moves at all. He breathes deeply and regularly, his facial expression is relaxed. The same procedure is carried out with a rattle and then with a bell. Normally, reactivity is reduced in order to filter out intrusive stimuli from the environment. Some children, exposed to particularly large amounts of stress during birth, can initially not switch off disturbing stimuli: they have a "raw" nervous system, but it becomes normal within a few days in a sheltered environment.

2. The transition from a state of sleep to the drowsy and alert states is observed and evaluated with a point score. If the baby switches only slowly from one state to the other and can persist for some time in a state of alertness or sleep, he is already exhibiting a most impressive ability to regulate his world. If he switches suddenly from one state of 
consciousness to the other, and is unable to remain in one state, it will need the patient help of his parents to regulate his behaviour. A baby who drifts helplessly from one state of consciousness to another is at the mercy of his sensitive and immature nervous system, and often must recover from the medicine that the mother has taken during the birth.

3. When the outer side of the baby's sole is stroked, the toes grasp towards the doctor's fingers. When the side of the foot is stroked the baby spreads out his toes in the Babinski reflex.

4. If the newborn grasps for the doctor's two index fingers, the doctor can slowly pull him up into a sitting position. The head hangs backwards, but the baby makes a great effort to get it into a horizontal position, employing his shoulder muscles. As soon as he is sitting, his eyes widen and he begins to look around, with the parents now typically in a state of amazement at the child's abilities. If the newborn's head begins to hang backwards and he proves unable to straighten it, his muscle tone is examined in closer detail. The reaction of the shoulders when the newborn is pulled up into the sitting position indicates how well the baby will react to the parents' attempts.

5. In order to elicit the walking reflex, the doctor leans the baby's upper body gently forward across one hand, planting his feet firmly on the bed. In a kind of slow trot, he will make a step first with one foot, then with the other. This shows parents the enormous developmental potential within this complete and tiny being. A baby who has lost blood during birth or has weak reactions needs special support measures.

6. The important protective reflexes are tested by placing a soft cloth over the child's eyes and nose. If the child both bends his head backwards and raises his hands to push away the cloth, we receive two indications that the child was carried to term and has an intact nervous system. If he was born too early or is still strongly influenced by the drugs that were administered to the mother, he cannot carry out these movements.

7. Touching one side of the newborn's mouth triggers the breast-seeking reflex, also known as the rooting reflex. The infant turns his head in the direction of the touch and his mouth looks for where he thinks the breast should be. If the doctor gives his finger to the baby to suck, the baby exhibits three reactions. The tip of its tongue licks the part 
of the finger that is nearest to the lips. The back of his tongue begins to massage the middle part of the finger, and finally the child will begin to suck the finger tip almost as far in as its oesophagus. With a healthy baby, these three mechanisms quickly become coordinated. With a premature baby, it takes longer; often, the baby cannot suck on a bottle and must then be fed through a tube.

8. If the newborn's head is turned to the side, he exhibits the asymmetric neck reflex and assumes a fencing-like response: when the doctor turns the baby's head to the left, the body turns away to the right and the left arm extends, with the right arm bent up towards the head. The baby is learning to carry out asymmetrical movements. Such reflexes are of benefit even during labour: contractions of the womb cause the child to turn his head to the side and thereby to trigger a series of reflexes. He bends and turns and, by stimulating the womb, plays a part in the delivery.

9. When the doctor holds a shiny red ball about 30 to $40 \mathrm{~cm}$ in front of the alert newborn's eyes, he gradually focuses on it. He follows the path of the ball to the right and left, and as far as an angle of $30^{\circ}$ upwards. The eyes follow the ball in a series of jerky movements and the head turns slowly from one side to the other. When the baby concentrates on a visual stimulus in this way, his entire face brightens; his whole body is involved. Seeing a human face makes the baby's own facial expression lively and attentive. The baby's reaction to a face is greater than that to any other object: his mouth curls and the upper half of the face exhibits mimicking movements as if he wants to imitate what he can see. The baby reacts to the human voice with great curiosity.

10. When the doctor strokes the side of the baby's spine while his hand holds the child by the stomach, he bends his entire body to the side. This swimming reflex, known as the Galant response, is due to our amphibian ancestors. If the child is placed on its abdomen, he pulls his legs under himself and starts to crawl. The crawling reflex causes him to raise his head in order to turn it and avoid the bedding, and he attempts to put his fist in his mouth before curling up into a comfortable position.

The reactions of the newborn child as described by Brazelton convey an impression of what the baby can do immediately after he is born. It should be noted that the newborn baby shows his strongest reaction to 
a human face and a female voice. Paralleling these physical abilities, the newborn child also has the emotional ability to form the first relationship with his mother by means of visual and physical contact, the sense of smell and hearing.

Films of newly born babies swimming in water like little fish, stretching their bodies out so that they can stand on the doctor's hand, cause us to reflect on the psychic unity, the ego of the newborn child. From work with disturbed children with chaotic inner worlds, we know that they have enormous problems coordinating their bodies. Their inability to think clearly or to organise their feelings is always reflected in their physical appearance: they are awkward, clumsy, and generally either appear repulsive or generate sympathy. In the course of analytical work, to the extent that they feel themselves understood by the analyst and begin to find linguistic expression and understanding for their feelings, their bodies also change. Their often slow growth is replaced by a boost in development; they may begin to climb on chairs and higher objects. Instead of keeping a fearful distance, falling over and injuring themselves, they begin to develop pleasure in their bodies. Brazelton's test for newborn babies impressively demonstrates the physical achievements that a baby is capable of making. Moving in a liquid clearly sets different conditions than moving in air; the border of the uterus is now gone. It is probable that this radical change- birth-is the source of deep fear of catastrophic change, a "fear of loss of individuality", and "trauma of birth" as it is called by Otto Rank (1924). The process of detachment that takes place at birth requires the child's mind to shift from one functional stage to another-as Gaddini puts it, "from the stage of non-integration to that of actual autonomy" (Gaddini, 1998, p. 42).

Emotional assistance in handling the abrupt change at birth is therefore of major importance. The transition from life in the womb to life in the world becomes easier for both mother and the newborn child if physical and emotional contact is made possible at the various levels of perception. The mothers questioned related how happy they were to be able to hold their baby in their arms, to look at him and to touch him: mouth contact and suckling re-establishes contact with the mother's body, contact with the skin reproduces the experience of warmth and limits, the mother's voice has already become familiar during pregnancy and aids the child in processing other sounds in its environment-both alarming and lulling. Sight and eye contact are of enormous importance, since the eyes and facial expression are capable 
of conveying quite differentiated feelings. Daniel Stern, in his Diary of a Baby (1991, p. 17), described the impetus of a patch of sunshine for the baby's "dramatic and emotional" encounter with the world. Tasting the mother's colostrums introduces a new quality, as does smelling the mother's odour.

What are the consequences for working with parents-to-be or young parents that result from this description of the emotional conditions of pregnancy and birth?

\section{Support systems at the time of birth}

Discussion of the beginning of life clearly shows that assistance and encouragement given to the newborn child must always include consideration for the unity of parents and child. During this sensitive time of preparation for the new baby, the mother-to-be requires emotional support. It is striking that prenatal preparations and support given to parents are primarily focused on the physical aspects of the adjustment. There are pregnancy exercises, breathing and relaxation training, information about healthy feeding, positions at birth, and the physical care of the baby. What is missing is assistance with the attendant emotional adjustment. It would be important to help parents prepare psychologically for parenthood, encouraging them to speak with their partners about conflicting feelings, fears, and hopes. Since every new family combines two different "family systems", these must be investigated: ways of dealing with children, everyday rules, standards and rituals, celebration of festivities, and conflict management always differ. The parents-to-be, who in many cases have only recently separated from their own parents, often wrongly assume that they can now start afresh. It would help if they were given support when they discover they have internalised aspects of their own mothers or fathers-even if they have always criticised or rejected such behaviour. The latent search for the image of what kind of father or mother they want to be should become conscious and discussed with the partner. It is often surprising and threatening to see what deep layers of personality pregnancy stirs up. This stirring of the inner world, however, also constitutes a major opportunity for personality development, for bringing to the surface unresolved conflicts with the parents' own parents. Pound and Mills (1985) warn against only considering the pregnant mother's current relationship with her mother, and instead argue in favour of including 
earlier stages of the mother-daughter relationship. The mother-to-be is influenced by the image she has created of her own mother. Pregnancy also represents an opportunity for setting the relationship to one's own parents on a new basis, entering a terrain previously reserved for the previous generation.

From parent-infant therapy, we know that early experiences of loss on the part of the parents-to-be, when not discussed or mourned, are frequently manifested as problems in the relationship between baby and parents. The early death of a parent or unreconciled and unintegrated conflicts with a parent are projected onto the new baby, who under the burden of the parents' projections produces physical symptoms that can be interpreted as a cry for help.

It can be greatly comforting to know that particularly during pregnancy, the mother- and father-to-be are exposed to a flood of mixed feelings. It helps to recognise that it is normal not only to look forward to the new baby, but also to occasionally hate the pregnancy, prefer to get rid of the baby, to fear being excluded and having no time for oneself and one's partner. Permission to feel and talk about jealousy and rivalry can contribute to overcoming the need to suppress these negative feelings. In fact, we know that men and women who can show these aggressive feelings or indirectly reveal them through their concerns about the possible deformity, death, or loss of the foetus, are emotionally more robust. Being allowed to admit one's positive and negative feelings has a cathartic effect. Surprisingly, joy and pride about the living being created by the parents-to-be can then be expressed more freely.

Another important dimension lies in providing help for a gentle transition from the life in the mother's body to the outside world. In the last 100 years, the baby has been separated from the mother immediately after the birth, often without any physical contact being permitted, and brought to a separate room. This practice in the United States is described by Montagu as follows:

As soon as the child has been born, the umbilical cord is cut, it is shown to its mother and then taken by a nurse to a room known as the "neonatal care unit", probably because the only thing that does not happen there is neonatal care. It is weighed, measured, its physical and other characteristics recorded, a bracelet with a number tied round its wrist and then it is placed in a small bed in which it can yell out its distress to its heart's content. (1971, p. 54) 
Precisely when the mother's bodily warmth and breast could give the baby a sense of orientation and the only link to his previous existence, he was separated-although this separation was in conflict with the emotional needs of both mother and newborn child: the mother wishes to view and get to know the product of her nine-month pregnancy and the efforts of the birth, to examine and feel his body, to feel his movements and his reaction to being held. The baby placed at the mother's breast uses his head to find the nipple to drink. One mother describes how her newly born child was placed on her breast while the umbilical cord was still connected and began to drink immediately. When he was finished with the right breast, he began to cry. Only when the father suggested placing the baby at the left breast did she do this. The baby drank the pre-milk and then fell asleep. The father's help was needed to effect communication between the mother and the newborn baby. We might also wonder whether the baby already has advance knowledge of the existence of two breasts.

Being able to touch the baby and hold him in her arms immediately after birth is also very important for the mother. This new manner of being together consolidates a psychosomatic bond; readiness to breastfeed is much greater in mothers who are allowed to keep the newborn baby with them and are not separated from him (cf. Richter \& Stauber, 1990; Uexküll, 1994).

\section{Notes}

1. Even a "neutral observer" will be emotionally affected by the parentinfant relationship, since it triggers violent feelings within him. Nobody can escape the phenomenon, since we were all-men and women alike-created in the womb of a woman. Even negative or objectionable images meant to prevent us remembering the start of our own existence, by for instance dismissing babies as unimportant, revolting, and a nuisance, are interpreted as a defence against these feelings, transforming them into their opposite.

2. The term "good enough mother" was coined by the English paediatrician and psychoanalyst D. W. Winnicott to indicate that no mother is only good, but that it is enough if positive aspects predominate (cf. Winnicott, 1984, p. 29).

3. The investigation "Infant Observation: A Follow-up Study" was supported by the Austrian Science Fund (FWF) and carried out at the London Tavistock Clinic. 
4. In my contribution I am thinking of female psychoanalysts, since my experience and discussion refer to the experiences of female analysts with pregnant patients. The literature known to me also deals with the transference to a female analyst. It would be particularly interesting to compare these experiences with the experiences of male analysts. 
CHAPTER TWO

The first year of life

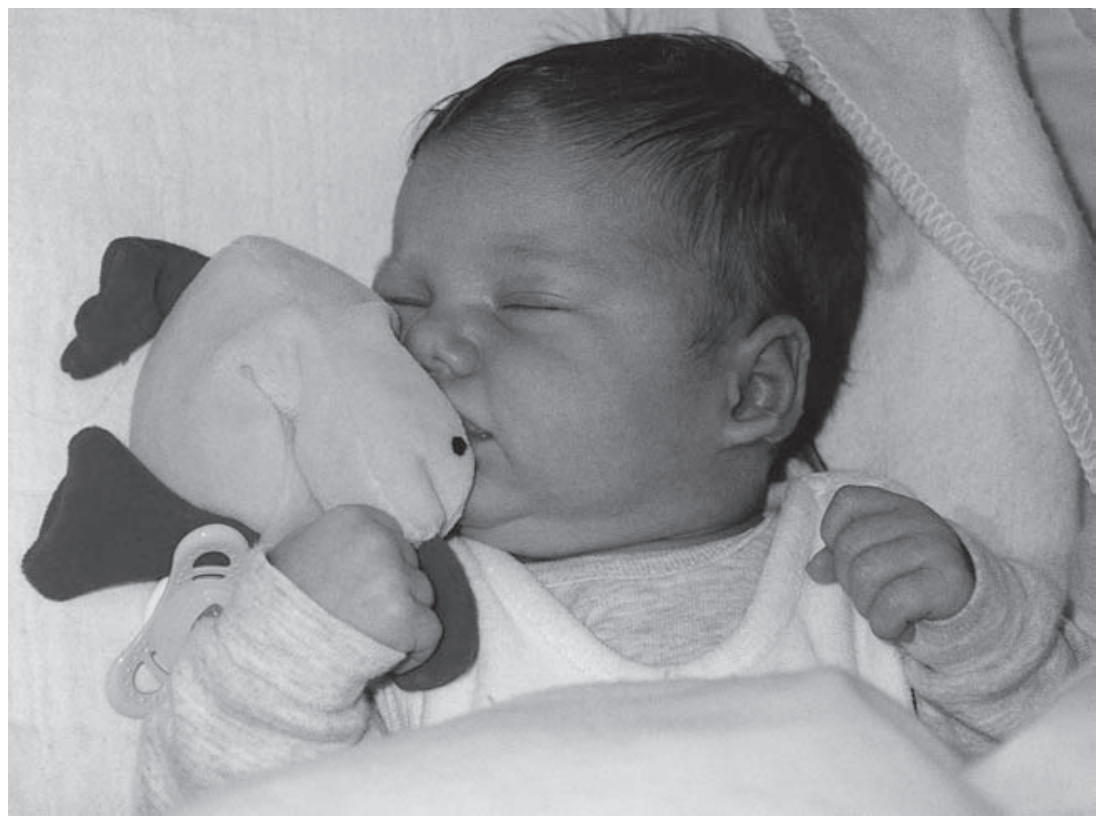





\begin{abstract}
A fter nine months of pregnancy, the new baby is now born. Before we examine the baby's dramatic physical and 1 psychological developments and his budding relationship to the parents, we should take a look at some of the tumult a baby causes in his immediate and extended environment. The birth of their first baby turns a couple into parents; it also turns their parents into grandparents. If the new baby already has older siblings, he will increase his family's size, with those siblings reconfigured into new positions. The reconfiguration of a family with its several generations and the new roles and tasks awaiting its members all pose real challenges for everyday life - but also spur a range of emotional transformations. Room must be made for all the things a baby requires in our modern society, such as a pram, crib, nappy-changing table and baby bathtub. It is astonishing and also confusing how many new objects are necessary in order to transport the baby from one place to another, keep him warm, and care for him. These objects are usually acquired before the baby's birth, often when the baby would already be able to survive outside his mother's body: symbolically, space is being made for the new living being. Even more crucial than these external preparations are the
\end{abstract}


psychological adjustments various generations of the baby's family have to make, in order to create mental space for him.

\section{Changes in the family through the birth of a baby}

The new baby makes his parents' parents into grandparents. As evident in this phrase, the new grandparents are not active participants in the process, instead simply waiting for their children's decision to have children of their own. Even if they have long wished for grandchildren, it is surprising what intense and contradictory feelings are elicited in grandparents when their wish is fulfilled. Realisation of that expansive, narcissistic wish to see their family perpetuated, attended by desires for immortality - to live on through their children and grandchildrenare accompanied by feelings that can seem quite threatening to grandparents. They must accept the fact that they are past the reproductive age, surrendering this position to their children. A grandmother's often unconscious wish of having a baby herself can be manifested in various ways, and so can her unconscious rivalry with her daughter or daughter-in-law. Grandmothers-to-be frequently describe menacing dreams where their daughter or daughter-in-law falls prey to some violent crime, and they must then adopt the orphaned baby themselves. I believe this and similar dreams, where grandparents must assume care of the baby, express their envy and unconscious rivalry with the mother, who is in their fantasy robbed of her baby. Here, we see an inner conflict delineated, with one side of the grandmother seeking to protect the mother, and another side begrudging her the joys of motherhood. Many people harbour the fear that when aggressive or shameful feelings become conscious, all positive feelings and the power to love will be annulled. In fact, the opposite is true. The more grandparents become aware of their unconscious desires for parenthood and their grief at the end of this creative faculty, the less they will be blocked in supporting their children as new parents. Enacting rivalry through dreams, or discussing it with a trusted person, usually is a welcome relief, also enabling the grandparents to reflect on the birth of their own children. Possibly there are things they now would like to have done differently or better. Connecting to earlier experiences makes grandparents more open towards helping their children with the multitude of new tasks now facing them. If feelings of rivalry and envy are suppressed, they are often transformed into actions meant to demonstrate 
that the "grand"-father or -mother are not yet "over the hill". New grandfathers occasionally remarry a younger woman, have a baby with her, or throw themselves so vehemently into their work or other duties that they cannot find time for their child's new family. Such men typically have great difficulty accepting the fact of their own age and are blind to the potential satisfaction their new role as grandfather could bring.

Similar turbulent emotions are often elicited in friends of a newly childbearing couple. Friends who themselves wish for a baby will feel a connection with the parents-to-be, sharing in their joyful anticipation and hoping to thus learn from their experience; their unconscious envy and rivalry are diminished by the hope of later having this same experience themselves. For friends who have already given up any hope of becoming parents, any participation at all in the approaching parenthood is often so painful that they might even break off contact with the parents-to-be.

Since we wish to examine more closely the feelings of parents and baby in various developmental stages of the baby's first year, his siblings' emotions are now described only briefly.

\section{Emotional reaction of siblings}

The newborn baby's siblings must deal with just as tumultuous feelings as their parents and grandparents. The younger a sibling is, the more painful it is to be ejected from his/her position and to surrender fantasised possession of the mother and the special status of youngest child. Children with other siblings have already had this experience, learning to share their territory, but earlier feelings of rivalry are once again activated. When children are still very young-under two years of age-they often cannot formulate their fears in words or in play, or cannot make themselves adequately understood. Anger, disappointment, uncertainty as to the future, and the conviction that their parents have created a new, superior baby all make for great inner tension in an older sibling - occasionally leading to the child running a fever shortly after the new baby's birth, with no somatic cause found. In this case, if the sibling happens to be staying with relatives at the time of the birth, he will likely be taken home immediately and thus recovers, with loving parental attention conquering the child's unconscious fears of being unloved and being excluded. The child learns that he will not 
lose his parents' love and that there is now room for all the children in the family. Objectively, this constitutes an inordinately difficult period, where any support from relatives or friends can be helpful. If parents are able to understand sibling fears and jealousy and to discuss them with the older child, he will feel accepted with his "bad" feelings. If allowed to participate in caring for the new baby-holding a bottle filled with tea or observing the mother changing nappies-and if the mother discusses the baby with him, the sibling can then identify with his parents, slowly building a positive relationship to the baby. Small babies begin very early to take interest in and react to their older siblings, observing them closely, soon smiling and becoming joyful when the older child draws near. The intensity of sibling jealousy certainly depends on the quality of the sibling's relationship to his parents-but it is nevertheless important to realise that every child is to some extent jealous and fears being superseded by the new baby.

\section{The emotional relationship between baby and parents}

The first year of life is of enormous significance for the baby's subsequent physical and psychic development. During this time, the foundations of the personality are laid, akin to the foundations of a house and of equal importance for its stability and structure. In the child's first months and years, his perception of the real world, his separation between inner and outer sensations, his thinking, and his relationship to the parents are all evolving out of raw, unintegrated feelings and perceptions. The parents or caregiver must aid the infant as he copes with his raw, primitive, and archaic feelings and somatic perceptions. Even though an infant already possesses a far greater range of abilities than was assumed for centuries, he still remains dependent on adults for his survival. He cannot feed himself or move from place to place, but instead is dependent on others to keep him warm, nourish him, and guarantee his bodily well-being. This physical care corresponds to emotional succour that, in bonding the infant to a love object, helps him orient himself within his own body and in the world at large. In the first three months, a "social birth" follows the baby's physical birth, where he builds a relationship to the world via his relationship to his mother or caregiver (primary object). In these dramatic first months, the infant can establish elements of structure and inner order if his mother succeeds in containing and comprehending his archaic fears and returning 
them in a modified form. We can compare this process to Egyptian mythology, where chaos and darkness are averted by turning towards order and light. We can say that the baby-who if unattended would starve and expire, a victim of his own overwhelming needs and fearsexperiences himself as threatened by chaos. Esther Bick expressed this needfulness and vulnerability in an evocative image: "When the baby is born, it finds itself in the position of an astronaut who has been shot into space without a spacesuit ... the baby's overriding fear is that it will either disintegrate or dissolve. We can observe this in the trembling of an infant when the nipple is removed from its mouth or when it is undressed" (1986, p. 296).

The astronaut's spacesuit, supplying oxygen and warmth, corresponds to the loving, emotional care the parents provide, with their physical and emotional containment of the infant. The oxygen an astronaut needs to survive and maintain his physical position in the atmosphere can be compared to a mother's capacity for registering her infant's feelings and demonstrating her understanding. It is important to realise that this phenomenon does not primarily involve physical care, but emotional responsiveness. By internalising his mother's nurturing, protective faculties, the baby develops a positive core in its psyche, a "good inner object", back to which he can constantly refer. At the same time, the infant's first encounters with chaotic forces remain embedded in the deepest levels of his personality, constituting a "psychotic core" that is normally subordinated by positive experiences.

It is of great importance that mother (and father or other caretaker) is able to be receptive to the infant's distress, including the fear of being attacked and dying, can take it in, contain it and by giving it meaning modulate it, making it possible for the baby to take it back into himself. Parents will be able to contain their baby's painful emotional states if they are in touch with powerful infantile anxieties within themselves, yet able to maintain a spirit of hopefulness, having faith in their own and the child's life-force to put against fear, terror and despair. Such emotional-spiritual strength conveys to the infant, on a feeling level, that there is something like a mental-emotional space within mother/father/caretaker that allows painful emotional states to be held, contained without going to pieces - they can be thought about ... If, on the other hand he finds his fright terror, despair, misery are not received, not 
understood by his caretakers, it leaves him with what Bion calls "nameless dread", unspecified, unthinkable thoughts which have continually to be expelled/projected into others. Some mothers / fathers/caretakers may receive the infant's communications but become so terrified that they feed back to the baby their own terror and despair, adding to his own. This is likely to cause him to be wary about what he takes in, physically and emotionally. (Salzberger-Wittenberg, 2013, p. 7)

René Spitz (1945), observing infants in orphanages who were optimally cared for physically but had no constant, emotionally accessible persons to form a relationship with, described a situation he termed "hospitalism", where this deficiency can actually lead to a child's death.

The baby's fear of disintegration is paralleled by his parents' anxieties that their child could die, or that they cannot possibly live up to their task as parents. Even though mortal dangers for mother and baby and mortality rates for both infants and mothers during or after birth have been greatly reduced through modern medicine, the first period of life nevertheless remains a highly vulnerable one. The newborn baby's body cannot yet master the tasks he faces, and the infant's initial fears are intense ones, including fear of death. The first three months of life are particularly sensitive. As the baby grows and if his development and emotional relationship with the parents proceed auspiciously, he enters a different stage of development. Therefore, we shall first examine his development during these first three months.

\section{The first three months}

The first days after birth are a difficult time for mother and baby; both must come to terms with their final corporal separation and loss of unity. The birth constitutes the first experience of separation for baby and mother. Being born, leaving the mother's body and beginning to live in the outer world is both an ending and a beginning. "The infant is likely to experience it as a 'catastrophic change' [Bion, 1962] which evokes catastrophic anxiety (terror) when separated from mother's body and coming into this so very different, unfamiliar outer environment" (Salzberger-Wittenberg, 2013, p. 17). Each new phase of life entails leave-taking from the situation preceding it, since new 
contingencies must be mastered. Even though this new phase offers more possibilities and potential for development, mother and baby alike must come to terms with the dissolution of their secure corporal bond, and alongside the joy attending a birth, this creates unconscious feelings of grief. This is what is meant by maternal post-partum "blues", since the mother-in spite of her joy over the new baby's arrival-is grieving for the loss of the total, definitive corporal bond she previously had with her child. This post-partum emotional instability occurs in the first three to seven days with $60-70 \%$ of all mothers (Herz et al., 1997, p. 284).

In its first three months of life, the newborn baby-if supported by a constant love object (mother, father, or other caregiver)-succeeds in employing his senses and distinguishing between his perception of inner and outer by developing a love relationship, an emotional bond. This undertaking may seem simple, but anybody who has had a baby knows that the first few months are enormously strenuous. This is not only because the newborn baby must be constantly fed, changed, washed, and carried. In truth, what makes this first phase so particularly strenuous is that the parents are exposed to the baby's raw, contradictory feelings and projections. The baby oscillates from moments of happiness, relaxation, and satiation to bouts of desperate crying that seem to engage his entire physical being and are often impossible to subdue. These oscillations between states of alert inactivity or calm sleep to desperate howling often occur without any buffer zone. Just as the reader might ask if such a tiny creature can truly be so desperate, unhappy, and full of destructivity, parents will ask themselves what they could have done to elicit such a sudden shift in the baby's mood. Here it is important to understand that each infant alternates to a greater or lesser extent between feelings of safety and the fear of disintegration. Just as in later life we are afraid of the "ceiling caving in", that we could lose the "ground under our feet" or our feeling of selfworth, a hungry, thirsty, sick, cold, or fatigued baby feels surrounded by persecuting forces both inside and outside himself. As long as he is unable to differentiate between inner and outer, he can quickly perceive himself as threatened. Phases of tranquillity, activity, and even deep sleep are unstable and can swiftly segue into anxiety. Dependence on love and care from a stable person is of central significance for the baby's physical and psychic development. Parents must understand that even with the most ideal care and devotion, the baby's swings 
between happiness and desperation, security and persecution will still occur; their response should be to offer the child a chance to overcome his disappointments, fears, and frustrations through consistent encouragement and love. Since the child is immediately confronted by a need to differentiate himself from his mother and master his fear of losing her, phases of desperation and fear are unavoidable. If good experiences have the upper hand, the child can internalise these and learn to calm himself.

Parents reading the above might infer that their mission is to supply unwavering love, caring, and understanding for the child. That would be a misunderstanding, particularly since parents are also subject to enormous shifts in mood during this same phase. They must not only manage their new situation, fraught with their own hopes and fears of inadequacy, but they are also containing the baby's fears and emotions. When parents succeed in calming a crying baby or feeding him, capturing his attention or coaxing him to sleep, this constitutes a reward for them, a "narcissistic gratification", confirming to them that they are adequate parents. However, when they fail to promptly calm their baby or guide him out of his desperation and fear, parents can quickly feel themselves desperate and helpless. This sense of helplessness can then easily proceed into rage, hate, self-reproach, and demoralisation. Parents who wish their baby never to cry, to be constantly happy and satisfied, swiftly find themselves at an impasse. The panicked screams of a recalcitrant baby have a penetrating quality that, without further ado, can subliminally endanger the parents' "adult" psyche: suddenly, they see themselves as helpless and attacked in a threatening situation. When a baby proves difficult to calm, almost every parent feels the impulse to scream-or scream at the baby. Losing control and screaming "I can't stand it any more, just be quiet", a parent may see a frightened baby cease crying for a second or two-only to resume with even greater desperation. Psychologically, it is easy to understand how the baby awakes such primitive feelings in each of us; the essential point here is for parents to discover a positive and calming agent in themselves, in order to pacify not only the baby but themselves. When parents scream back at their baby, they show he has destructively succeeded in making his (ostensibly) powerful parents feel helpless-and this only increases the baby's fear. Sometimes it helps when the parents recognise they have reached the limits of their self-control and then hand the baby to somebody else or grant him time to calm down by himself-the latter 
approach is often effective. It is particularly important for parents to understand that every father and every mother has moments when they hate their baby and, overwhelmed, wish to be rid of it-at least until they have regained their composure after an hour or two. For this reason, it is important for parents to have a support system: grand parents or friends who can help.

One crucial question is whether parents trust their baby to pacify himself alone-cry himself to sleep—given that he has received enough loving attention during the day.

I proceed from the assumption that experiences during the early years of life lay the foundation for the further development of the child's personality. How should we visualise this in concrete terms? An infant's initial experiences are somatic in character. Psychoanalysis has helped us understand that the first love between baby and mother constitutes a prerequisite for romantic love between man and woman later in life. In adult love, we recollect the psychic experience of baby-mother or baby-father love. The first love between mother and baby forms the foundation for an adult's later capacity to love; it is impossible to love without having experienced being loved. An unloved baby will find it difficult—although not impossible — to fall in love as an adult, and such a love is likely to be painful, characterised by a lack of satisfying unity between two lovers.

\section{Exploration of the body}

The analogy between experiences in the first months of life and their echo in romantic love is manifested through numerous phenomena. For new lovers, getting to know one another-not only their personalities but bodies-is an undertaking of major significance. The way lovers explore each other's bodies, gazing, touching, stroking, and commenting lovingly on every detail and anatomical peculiarity, shows great similarity to the way parents explore their newborn baby's body-touching his legs and feet, commenting on the way his toes, arms, legs are formed, the particular shape of his head. The individual shape of his eyes and nose are investigated and pointed out; parents repeatedly attempt to establish links and similarities between their infant's body and their own. Over time, they become acquainted with their baby's body, put his particularities into words. This intense preoccupation is of enormous importance both for parent and baby. The 
parents' affectionate, awed journey of corporal discovery means they are perceiving and experiencing the boundaries between their bodies and the baby's, through tactile love-and this signifies both the separation between distinct living beings and their joyful contact. Parents are, after all, "creators" (in collaboration with nature or with God) of this small miracle, the human being. When we watch parents interact with their newborn baby, they conspicuously seek eye contact with him. As the baby's body is lovingly examined and stroked, he seems to "wait" for this eye contact, devising a kind of rhythm out of that very state of expectancy. This leads us to a second analogy between lovers and the early relationship between parents and baby: a special quality of eye contact.

Lack of parental eye contact and of a loving interest in the baby's body induces in the baby a feeling of estrangement from his own body, which can later be manifested in poor motor coordination and clumsiness. In romantic love, close physical contact also expresses love and bonding; separation or physical unattainability is experienced as a painful deprivation.

\section{Eye contact}

Amorous body language entails the seeking of physical proximity. We recognise lovers by how they gaze silently into each other's eyes, how they hold their faces close, their special ways of speaking, kissing and embracing, holding hands, caressing each other's faces. In all other forms of adult interaction, a protracted gaze is considered intrusive or aggressive-taboo. A prolonged exchange of looks constitutes either a sign of great intimacy or the type of aggression preceding a fight (Stern, 2001, p. 219). The constant avoidance of eye contact is a typical sign of inner conflict or apathy, and has an irritating effect. Temporarily refusing to look at another person can be a kind of punishment, a la "I'm not going to look at you any more."

\section{The language of lovers}

The language lovers employ is also reminiscent of the first communication between parents and child. Parents speaking to their baby develop a "baby talk" characterised by high pitch, repetition, and rhythmic emphases. Lovers, too, develop a particular language, where 
certain words or gestures can acquire new meanings; facial expression becomes exaggerated, with mutual reactions following seamlessly, as if the two lovers are completely connected. Lovers also enjoy moving in synchronisation, by turns to and away from each other, in effect miming the symbolism of separation and reunification (see Person, 1988). Sharp noises or a loud, angry voice can make a baby cry.

The baby lies in its mother's arms, the mother approaches the baby's face to a distance of approximately $20 \mathrm{~cm}$ and gazes smiling into the baby's eyes. The baby is completely concentrated on the mother's gaze, gazing becomes its sole occupation, as if it would like to thus draw the mother even closer. When the mother slowly draws closer, her smile broadens and she touches the baby's nose with hers. Mesmerized, the baby gazes in its mother's eyes and opens its mouth in expectation, simultaneously grasping the mother's necklace and holding it. As soon as the mother's nose touches the baby's, the baby's smile also broadens, it opens its mouth and answers with a happy "Oh". While the mother gradually withdraws her head, the baby releases her necklace and continues to gaze at her expectantly. This is an expectant kind of energy-almost embodying a request for her to once again draw closer. The mother waits a bit, at the climax of this energy she slowly comes closer once again, rubs her nose twice with the baby's, it then "answers" twice with two single "Oh"s. Then the mother once again withdraws her head, she leans forward, kisses the baby on its forehead and rocks it, holding it close to her in her arms and humming a song. (Description of a sequence from the BBC video film Talking Cure on infant observation)

This brief scene lasts less than two minutes and yet depicts an intense, satisfying dialogue between mother and baby, complete with introduction, dramatic development, climax, and conclusion. Mother and baby are in harmony with each other. In this context, Daniel Stern coined the term "in tune" - to be in harmony.

It would almost require a video analysis to pinpoint the countless communications here exchanged between mother and baby. The positive tension is important here, a tension that devolves from both the feeling of being understood and of mutual understanding. When the mother is queried as to her feelings, she says: "Whenever he smiles at me that way, joyful fireworks go off in my belly." 
It is astonishing how early a baby can express love, caressing its mother's breast, reaching for her sweater, passing his hand over her face. In order to achieve harmony with the infant, the parent should exercise sensitivity when touching him; it needs time to adjust to eye contact and movement. Fast movements, shrill sounds, sudden shifts cannot yet be comprehended by the infant. Swift, rough movements that do not permit the infant to react in kind convey turbulent emotions on the part of the adult-emotions possibly imparting a sense of exclusion or rejection to the infant.

\section{Psychic development}

When speaking of the infant's psychic development during this early phase, I like to describe mental operations as analogous to bodily functions. The beginning of life is marked by a constant back and forth between states of disintegration and early integrative experiences. The newborn baby's personality structure is first established through early positive and negative experiences where his fears are assuaged or increased. The baby's first successful linking experience is between his mouth and a nipple (either mother or bottle). Bion posits the baby's emotional anticipation of the breast ("preconception"), becoming stronger with every real experience until it crystallises into a "conception". "We can represent this situation as the union of a preconception (innate expectation of the breast) with a realization (presence of the gratifying good breast) that gives place to a conception, characterized by its sense perceptual quality ... A union between preconception and experience form a conception-a way of thinking" (Grinberg, Sor, \& Tabak de Bianchedi, 1993, p. 52). This is tied to the experience of satisfaction. When the infant suckles, his entire organism is called into play; he bonds with his mother through eye contact, also attempting to grasp her clothing or her hand: all his senses are engaged. Suckling is bound to the feeling of relief, of satiation-hunger being something the infant has only been subject to since his birth. He suckles satisfaction, love, and security into his body, apparently ingesting this love and satisfaction along with his mother's milk.

On the other hand, if the baby experiences negative feelings such as hunger, boredom, or loneliness, he attempts to rid himself of them by kicking and screaming-so to speak, ejecting this annoyance from his body-at the same time sending a kind of signal, a form of 
communication. Freud linked an infant's fidgeting and screams to hallucinatory wish fulfilment, by means of which the infant attempts to rid himself of an increasing state of tension. It now becomes crucially important how the environment reacts to this message from the infant, whether his parents are receptive or not. If the mother is capable of containing the baby's feelings and understanding them, she then becomes a container for the fears and emotions overwhelming him. If she possesses the inner space to reflect on her child's feelings, simultaneously digesting these fears on a psychic level and returning them to the infant in a modified form, the infant then not only assimilates the image of a devoted mother but also her manner of transforming these primitive anxieties, by naming them and communicating them back. Bion describes this model for communication as the "container", that is, where the mother embodies a container for the baby's feelings (1962).

The intimate connection between physical development and emotional experience can be seen during all phases of corporal change, such as puberty, pregnancy, menopause, and aging. Alterations in our bodies outside our control subject us once again to primitive, archaic feelings that in turn trigger a profound increase in our sense of insecurity and persecution. The more stable our good inner objects are, the easier it is to surrender ourselves to these processes without feeling the need to combat them. During puberty, the body's sexual maturation-a revolution occurring without the adolescent's consent-elicits insecurity and fear. Our fear of growing old and of becoming an invalid is due to our potential loss of the independence we attained as children in feeding ourselves, in excretory processes, in cleaning ourselves-a loss that would render us once more as helpless as we were as infants (Teising, 2000, p. 7).

\section{The baby's personality}

The manner in which parents now react to their baby becomes crucial. Are the parents capable of seeing the baby as a separate entity? Can the mother view herself as a separate person when caring for her baby-or does she "weld" herself to the baby, constantly carrying him with her, not allowing him to calm himself or go to sleep on his own?

The infant's budding relationship to his parents is strongly influenced by how well they can recognise that he has his own personality and his own fate. Peter Fonagy has demonstrated how the parents' 
ability to truly see their newborn child becomes an important factor in the child's development. Parents support or hinder development by granting or limiting the baby independent space beyond their own close bond to him. Their fantasies about their baby influence their behaviour towards the child (Fonagy, 1996). When a mother proves incapable of allowing her baby his own independent existence, this creates enormous problems.

The personality and temperament of each baby varies already from birth. Approximately 50 per cent are characterised as "easy" babies, meaning they are fundamentally active and also adaptive. 25 per cent of all babies are considered to have delicate health (so-called "delicate babies"), with 25 per cent considered robust (Thomas \& Chess, 1977). Brazelton emphasises how crucial it is to react and adapt to the individual characteristics of each baby. One mother tells of her first child, an extremely sensitive daughter. When breastfeeding, she was easily distracted-any noise was enough to make her interrupt feeding, and afterwards it was difficult to encourage her to continue; bright light or a certain degree of motion in the room also rendered breastfeeding impossible. The baby required more than an hour for each feeding. When the same mother bore a son two years later, she was worried about being able to breastfeed him since she now had two children. Her son, however, was robust and his attention could hardly be diverted while breastfeeding: he was distracted neither by noise, nor by his sister's stroking his head, nor by her playing. He retained his mother's nipple firmly in his mouth, and, although he sometimes paused from feeding, he always maintained eye contact with her.

Individual differences among babies are an important factor in the success or failure of parent-baby relationships. For parents, the first weeks are occupied with getting to know their baby, and this includes comparing the imaginary baby they fantasised about during pregnancy with the real baby now before them. Notably-and luckily-the process of pregnancy enhances parents' capacity for then adapting to their baby and understanding it. The more parents are encouraged to understand their baby's character traits and responses, the stronger this early relationship will be. But every parent reaches his or her limits in understanding their baby. Particularly active and strong-willed children can be the pride and joy of energetic, active parents-whereas for more sensitive, timorous parents the same child can pose a threat, indirectly conveying to them that they are unable to deal with him. A quiet baby, 
who responds to attention relatively slowly and requires more time for making eye contact, may constitute a problem for worried parents, who might question whether their child is "normal". A robust baby may also lift his mother's confidence by independently finding a hold on her nipple when she holds it in the correct position, whereas other babies will need their mother's patient help retaining the nipple firmly enough. Usually, it takes several days before parents and baby achieve a trusting communication. Parents can usually only distinguish their own baby's crying from that of other babies after the third day. For certain sensitive babies, stimulation from different sources simultaneously can overtax them and make them cry; when exposed to excessive visual or auditory stimuli, they may become incapable of feeding. In this case, it is important to keep the baby in a darkened room without extraneous noise during nursing, when the infant requires its full concentration for breastfeeding.

Thus, success in creating an adequate understanding between parents and baby depends both on the baby's personality and also on how the parents treat him. Parents may handle their baby for the most part with love and empathy, or coldly and dismissively. How a baby is fed, cared for, how his parents play with him or sing to him, how they perceive and experience his crying and fears-all these factors play a role in the psychic development of his personality. A baby who is neglected or senses he is a burden to his parents, who respond to his crying by shouting at him or shunting him off to the side, develops differently from other infants. As noted earlier, empathetic parents can also feel over-challenged, but the crucial measure is whether their attitude falls within the rubric of so-called "good enough mothering". For the psychoanalytical perspective, however, not only emotional reactions from the baby's environment are of significance, but also the baby's interpretation of and reaction to his environment (i.e., parental treatment). A prominent English psychoanalyst described the varied reactions of children: "Something comes from the infant or child's own make up-how he responds to the handling he receives. Some infants and young children from very early on appear to respond to any disturbance or frustration with great anxiety, others seem to tolerate strain and difficulties much more easily, some will explode with rage very quickly, others are more patient, others will appear just to give in and withdraw" (Joseph, 2001, p. 182). These reactions vary because children experience events in varied ways. The need to wait can constitute an unbearable, 
infuriating frustration for one child, whereas a more phlegmatic child may tolerate the same situation without difficulty. Nevertheless, it is important to understand that this experiential variety also influences the images children form of their parents, in turn leading to a varied assortment of "inner objects", that is, inner images of the parents. The inner image of the parents is coloured not only by their actual behaviour, but also by the child's own emotional reactions. A child in a fit of rage can experience a mother who compels him to wait as cruel and cold, whereas a more patient baby would accept the same behaviour, as long as he is then picked up and held.

There has been much thought given to what sort of predisposition could contribute to early dysfunctions such as autism, where the infant totally withdraws from the world, or delusive, paranoid psychotic illnesses. We now believe that there is in fact a biological disposition manifesting itself in inordinate fear, massive envy, and destructivity, where desperation, hate, and violence dominate all relationships, combined with extreme vulnerability and the subject's need to exert control: everything not corresponding to his/her wishes is experienced as an unjust rebuff. In addition, we believe that such a child has also experienced an unfavourable environment-parents who reject or cannot understand his peculiar combination of sensitivity and vulnerability combined with his need for control, and/or a mother unable to assimilate the feelings the baby projects onto her (see Bion, 1959; RiesenbergMalcolm, 2001, p. 179).

In his 1901 novel Buddenbrooks, Thomas Mann depicted with great sensitivity how the disappointed expectations father Thomas Buddenbrook had for his son Hanno proceed to poison the father-son relationship. The father wished his much-longed-for progeny, Hanno, to be active and assertive, not delicate and sensitive. Thus in Chapter Seven, we read: "Thomas Buddenbrook was in his heart not in agreement with the essence and development of little Johann." The sensitivity and musicality Hanno inherited from his mother Gerda is a thorn in his father's side, alienating him from his son, as if these traits would embody a force inimical to the proverbial strong, practical man who strives for power and conquest through forceful deeds. The father's attempts to fight against this inimical force, which include calling his young son "Kamerad" and subjecting him to little tests at the dinner table, are unsuccessful. Hanno reacts with painful withdrawal-his shy glance does not even reach his father's face; he first remains mute and 
then begins to cry. "Does his dreamy nature", wonders the father, "not sometimes border on simplemindedness?" Gottschalch, in his analysis of the father-son relationship, points out that Thomas Buddenbrook projects his own weaknesses onto Hanno, weaknesses he does not wish to acknowledge since they represent a personal danger for him.

\section{Feeding: breast or bottle?}

Feeding the baby can be such an intensely pleasurable experience for mother and baby alike that we speak of the "breastfeeding couple". Mother and child also attain a close corporal bonding when the baby is feeding. It is important to see suckling not only as contact between mouth and nipple, but as contact between two bodies, via that sensitive organ which Montagu in this case likes to call the "mind of the skin" (Touching: the Human Significance of the Skin, 1971). Mother's milk is an ideal source of nutrition for the baby-no baby is allergic to it. It has many salutary effects: the proportion of protein and sugar is exactly correct; it is enriched with antibodies that strengthen the baby's immune system after birth, therefore reducing the danger of infection. A baby can almost totally digest his mother's milk, so that he need not even defecate every day, in contrast to babies who are bottle-fed. The first milk produced in the two days after birth (colostrum), as well as the early milk of the first eight days, are already optimal for the baby's digestive system: their composition is such that the baby gradually becomes able to digest their component parts, in particular their proteins. The closeness of this mother-infant bond is demonstrated by the so-called "let-down reflex". When the baby begins suckling, this contact activates nerve impulses on the mother's part that reach her pituitary gland, which in turn secretes a hormone called oxytocin. When this hormone reaches the glandular structure of the mother's breast, in turn stimulating the cells surrounding the milk glands, these glands then contract. That causes the milk to flow more copiously to the ducts behind the nipple thirty to ninety seconds after the baby has begun to feed. The same hormone also causes a contraction of the uterus and thus a swifter return to the normal state previous to pregnancy. The hypophyseal hormone prolactin, which stimulates the secretion of milk, may also be responsible for feelings of passive fulfilment and satisfaction (Lidz, 1974, p. 1951). Many mothers report a special quality of happiness during breastfeeding that can easily stand comparison to other 
feelings of physical pleasure. The baby also seems to experience great satisfaction. Anyone viewing the enchanted smile of a breastfed, sleeping infant would have no trouble comparing it to the relaxed expression of sexual satiation.

Breastfeeding requires a strong sucking action from the baby, which strengthens the musculature of his mouth but entails considerable effort-in turn leading to an even more pronounced satisfaction and relaxation when the baby is sated. Babies who have been breastfed tend to have superior diction later, since the muscles around their mouth are so well developed.

This will serve to describe the objective reality and the physical phenomenon of breastfeeding.

If we read a description of the physiological aspect of a baby's needs during breastfeeding and the possibilities open to the mother offering her milk, we seem to discover a state of ideal reciprocity. The mother produces the milk in her own body, the milk always is at the ideal temperature, its composition is optimal, the process is eminently practical, and can be done anywhere without any exterior aids. Everything seems wholly advantageous, eminently simple-almost like an advertisement for nature.

However, whether mother and baby attain a successful union in breastfeeding depends on the mother's emotional situation. It must not be forgotten that her relationship to her baby is coloured by her own experiences during early childhood; even given her deep wish to nurse her baby, conscious or unconscious fears are always in play.

Conscious fears centre upon the following questions:

- Will I produce enough milk, or will my baby go hungry?

- Will my milk be good and nutritious, or too thin—or even toxic?

The principally unconscious fears revolve around fantasised aggression on the part of the baby:

- Will my baby suck me dry?

- Am I still a woman while breastfeeding?

- Will the baby bite me or otherwise hurt me?

- Will breastfeeding damage me physically or psychically?

The crux of these fears can be formulated in the prototypical question a troubled mother asks herself: is the goodness in me strong enough so 
that I can nourish the baby and keep him alive, or are evil and rivalry in me so dominant that the baby will go hungry or even be poisoned? To the baby are attributed (mainly unconsciously) all the aggressive feelings the mother felt towards her own mother during her own period of nursing, back when she desired to steal all her mother's "secret treasures" out of her body. Accordingly, breastfeeding seldom functions successfully with a firstborn child from the very outset. The physical and emotional contact between mother and baby can be hugely enriching; but this also means that the mother's body is no longer hers alone, that she must take the baby's welfare into consideration when she eats, drinks, or smokes, just as she did during pregnancy. On the one hand, she is freer as a breastfeeding mother to leave the house with the baby, since she always carries its food within her body; on the other hand, she is newly dependent, since she requires the baby's cooperation for emptying her breasts of milk. In order to deal with their resulting contradictory feelings, young mothers need support and advice from midwife, nurse, obstetrician, and husband. The father's emotional support plays a major role. Is he able to allow his child such an intense relationship to the mother, a bond where he is excluded? Can he subjugate his feelings of rivalry and envy to his love for the child? Can he continue to desire his wife sexually or does he now fear her milk-dispensing breasts? As was seen in Max's family, the father was able to offer considerable support for his wife's breastfeeding of the baby: she actually became more desirable to him in her new capacity as breast-feeder. A father's responses can constitute either a supportive, mentoring, or a complicating factor.

We must not delude ourselves that every "breastfeeding couple" is happy and unperturbed. Observing how a baby is breastfed gives us insight into the relationship between mother and child. How does the mother hold her baby? Securely, calmly and firmly, or uncertainly, as if the baby were an egg she might drop and shatter? Does the mother make eye contact with her infant during breastfeeding or is she occupied with other thoughts and concerns? Is she touching her baby, does she stroke him and speak quietly with him, or is she emotionally distant? How does the mother put the baby to her breast? In breastfeeding, the baby's temperament is of equal importance to the mother's attitude; is the baby a good nurser, can he find the nipple by himself and make firm contact? In breastfeeding, it is crucial that mother and baby succeed in becoming truly acquainted, in order to develop a cooperative mode of 
nursing and solve impending crises together. Nursing support groups, where offered, are very helpful. And practical tips, such as found in Brazelton (1992) - for instance, his rule of thumb that nursing should last no longer than twenty minutes, and his observation that some children will drink so quickly that they are already sated within a few minutes-can help calm mothers' fears.

If breastfeeding is not possible for various reasons, the baby can be fed with a bottle. More important than the question of breast or bottle is the mother's emotional bond to the baby. It is important that she holds the baby in her arms during feeding and that she emotionally participate in the process, since it is not only milk but the mother's love that the baby is imbibing. A well-held baby can also absorb love and security with its bottle, whereas feeding without emotional contact imparts a flat quality to the mother-child relationship. It is less important whether a mother is occasionally occupied with other matters during feeding than that a basic quality of "good enough mothering" informs the mother-infant relationship, with positive experiences outweighing negative ones.

Here is an observation of a scene where a mother nurses her second son, just twenty-five days old:

Clemens is lying on his belly and begins to pull his legs towards his stomach. When he begins to complain, his mother takes him to her and decides he must probably still be hungry, because he hasn't drunk very much before. She sits down on a mattress and puts Clemens on the left side. His eyes are still closed, his mother puts him in a half-turned position into the crook of her arm and helps him gently with her hand to take the nipple into his mouth. He lies with complete tranquillity, as if he were still sleeping, but nevertheless drinks with a forceful, regular sucking motion. Occasionally there are smacking noises when he swallows air. The mother notices that she can use this time, while his older brother is sleeping, to devote her entire attention to Clemens. She bends over him, so that her long hair frames him like a picture, gazing tenderly at him and murmuring something to the effect of whether the milk tastes good or if he might still be hungry. When he has stopped drinking, she puts him over her shoulder, where he lays his head and again falls asleep. When he begins to move and fret again, she puts him to 
her left breast. He drinks and exerts pressure simultaneously. "If it won't come out on top, it will down below," says the mother. "You can hear it very loud," and she laughs. Clemens drinks and goes to sleep with the nipple in his mouth, a dreamy, sated expression on his face. The mother leaves him to sleep, she strokes his cheeks gently with one finger, bends her head down and gazes at him in wonderment. (Diem-Wille, 1992)

Here, we observe mother and baby in a scene of love where actual feeding is almost a background event. The mother cannot provide Clemens with as much attention during the day as she would like, since she also has to take care of her older son, who is quite jealous and illhumoured. Because of this, as she explains, she uses the time during the brother's midday nap and again in the evening to completely devote her attention to Clemens. Clemens seems not to ever quite wake up during feeding - as if his dream of the breast can continue on through a real experience of the breast. He is completely nestled in his mother's hair, lulled by her gentle voice and her finger on his cheek.

The mother-baby relationship can have a distanced and remote quality even during breastfeeding. Here is an observation of Michael. The mother tells the observer that, although it was agreed that her husband would care for Michael at weekends, she herself must take care of him every night, because her husband and his brother are currently starting a new business. She takes Michael out of his pram, although he is still very sleepy and has hardly made a peep.

"You can wait while I change the TV." Then she fetched a towel and settled herself down with Michael. He had stopped crying when she got up, and connected with her breast hungrily when she offered it to him. He sucked busily ... for several minutes ... Mother gazed at him in silence for a while and then said it was lucky they had a video-TV stopped at 12:00, and then there was nothing. With the video, she could watch TV at night ... She said it was nice when they all got home because they all wanted to hold Michael and she could have her bath and go to her room and shut the door ... Then she roused herself again, sat Michael on her knee and started patting his back. His head lolled to one side, and he dozed. (Rustin, 1989, p. 16) 
With Michael, feeding proceeds in an almost mechanical way; his mother appears unable to concentrate on him, she seems depressed, overtaxed, and exhausted. She complains about her husband, who offers her little support. She seems to consider her need to watch television as competing with Michael's need to be fed. In effect, she herself appears to need someone to take care of her. Apparently, she has lost contact with an inner image of the loving mother. Michael hangs on her like a chain—she merely tolerates his suckling. She seems to be at the outer limit of what can be demanded of her.

In order that we understand what deep effect an emotionally distant mother can have on the development of the baby's personality and his perception of his body, I would like to describe a related sequence from an analysis. Michael is presumably unable to establish secure emotional contact to his over-challenged, depressed mother, but he is physically well cared for and lives in a well-ordered family system. Since we have no possibility to observe Michael in his further life, we must depend here on hypothesis. It could be that he will feel insecure as an adult and never truly know who he is, whether his body actually belongs to him - this deep state of insecurity seemingly without foundation, since his external care seemed adequate. This type of malaise is by nature diffuse and difficult to grasp.

At any rate, these reflections should not give mothers a bad conscience if they cannot always give their undivided attention to their babies. That would constitute a misunderstanding, for here my focus was less on the relationship to a sometimes distant mother, but rather on understanding a baby who may virtually never feel himself accepted and fails to establish emotional contact either with his mother or anyone else. At the same time, it should be emphasised how important it is to help mothers understand the challenges facing them in the baby's first year of life, at the same time remembering that many young mothers are themselves emotionally overwhelmed and thus less able to make emotional contact.

Patient $\mathrm{P}$ began therapy due to her panic attacks. Her mother had fallen into a depression after birth; she was also worried that the baby girl might have some fundamental defect (she was thinking of Down's syndrome), only because she slept much more than her older daughter. During the course of analysis, $\mathrm{P}$ began to notice how uncertain she often was as to whether she was the person being addressed in a given 
situation. She related a conversation with her boss: "My boss came to me and began a conversation with me about the college. I noticed I had immediately assumed he wasn't interested in talking with me at all, but instead with my new colleague. Only when I realised this did I see how inattentive and absent I was acting, and how I was constantly glancing over to that colleague. My boss was actually speaking quite animatedly to me. Only when I realised that he wouldn't be talking to me if he didn't really want to was I able to engage in the conversation."

This brief scene demonstrates not only the patient's deep conviction that she could not possibly be an object of attention, but also an unconscious inner mechanism that she herself began to notice. Her behaviour was designed to justify her fears, with reality confirming her belief that nobody could truly be interested in her. In the moment she became conscious of this, she could assume the reins of the conversation again as an interested partner, trusting that her boss truly wanted to talk with her and devote his attention to her. In analysis as well, she was constantly fearful as to whether I was really listening to her: she felt unable to gauge my facial expressions and reactions to what she confided in me-just like a baby who must be constantly vigilant not to lose his mother's attention when she is occupied with her own thoughts and fears. P also reported a compromised sense of her own body: "Often, I run into objects, have poor body coordination, or don't even know whether I am hungry." For ten years, she had worked out as an athlete in order to get better in touch with her body, but only in analysis did she slowly develop a feeling for herself, her body, and its borders-and begin to develop a capacity for sexual sensitivity and pleasure. When she spoke with her mother about her lack of sexual desire, her mother merely recommended that she should sometimes simulate pleasure in order that her boyfriend not desert her.

Paediatricians' recommendations can be a calming influence, providing suggestions for how the mother can tell her baby is full, how he should best be held in order to burp him, and similar matters. Earlier, a rigid four-hour rhythm for feeding was standard, but this has been abandoned in the recognition that children develop individual feeding rhythms: the problem has shifted to feeding a baby according to his own specific needs. Some mothers no longer can tell which kind of crying can be interpreted as hunger and which indicates other needs. 
Often, the baby will be offered the breast even though he has drunk an hour beforehand, whereupon he demonstrates through his listlessness that he is not yet hungry again. As a general orientation, therefore, it may be helpful to establish an interval of two to three hours between feeds, with the rubric that a six-week-old baby should be provided with six feeds a day. It is also recommended to wake the baby for feeding just before the parents go to sleep themselves, in order to accustom him to a longer period of night sleep (see Brazelton, 2006).

\section{Sleep and going to sleep}

One major task the parents face is helping their baby handle his various states of consciousness. Can the parents trust their baby to go to sleep by himself, to pacify himself without help? Admittedly, the baby's temperament plays a large role here: some babies find it less difficult than others to sink into sleep from the waking or half-slumbering states. Often, however, a more decisive factor is the parents' divergent perceptions of their baby's behaviour and their subsequent reactions. A restless baby, whimpering fretfully and batting about with his arms and legs, will be assessed by some parents as a tired infant who needs more quiet in order to fall asleep. Other parents will decide the baby is actually suffering or lonely, and needs to be picked up and carried about. When the baby is picked up, he will most likely calm down, but although some babies go to sleep on their parent's arm, others soon become restless again. Carrying a tired baby about often becomes the beginning of an irritating, unsatisfying pattern of behaviour. Some babies, even though they just fell asleep on their parent's arm, start crying again when they are put back to bed, whereupon their parents believe they must pick the baby up once more-a cycle that can repeat several times.

The mother's desire for the baby to go to sleep on her breast or arm is matched by the baby's fantasy of perpetuating the harmonious existence he enjoyed in the womb. Even stronger here than the baby's fantasy is his mother's desire for omnipotence, for providing her baby with an idyllic, positive, nurturing world. However, in this case parents are forgetting another important task: the baby must be helped in developing his own abilities. The parents' movements, the rhythms of their arms and bodies, help induce the baby to leave his active period and proceed to the phase of sleep. Brazelton (2006) believes that all children have greater or lesser problems going to sleep; thumb-sucking, 
however, is a reliable aid any baby can turn to when trying to master these difficulties.

When the baby is carried about or allowed to fall asleep on his mother's breast, a dependency is created depriving the child of the chance to calm himself, to develop the confidence required to go back to sleep on his own if he should wake up during the night. If the baby falls asleep in his own bed, on the other hand, this then becomes a place of trust.

The sleep cycle shifts from phases of deep sleep to phases of light sleep or REM sleep (rapid eye movement), where the baby is dreaming. In this state, breathing becomes irregular and shallower; the baby makes searching or jerking motions and may wake up. Adults also experience these phases of sleep in a rhythm of four-hour intervals, but have learned to turn over (after a brief period of waking that they often later forget) and go back to sleep. Experts therefore recommend putting the baby into his crib after feeding and burping-when he is subdued but still awake-and then remaining close to him, speaking softly or singing. For the baby, his environment then becomes a trusted influence, and he can more easily make it through the night.

Parental help for the baby as he masters his frustrations from breast to bed will be most effective just after he is fed: the baby is sated and has absorbed warmth and attention along with his milk. However, the mother must be prepared to cut off this beatific, satisfying activity and offer the baby his chance to go to sleep by himself. Infants who are only able to fall asleep on their mother's breast usually have a mother who finds separation unbearably painful. "I can't stand it when the baby cries," is the explanation generally given. Maternal worries that the baby cannot bear such frustration play less of a role than the mother's own difficulties in breaking off her intense closeness with the baby, even though she realises it will resume four hours later at the next feeding. In these mini-separations, the father's help is of decisive importance. Can he encourage his wife or partner to relinquish the baby for this short period?

There are certainly individual differences between infants-hardy babies who can better bear frustration and pacify themselves, and sensitive babies who can endure frustrating circumstances only with difficulty. But in the latter case, a mother who believes she must shield her baby from any and all frustrations can be a recipe for disaster, since the baby will then experience even more difficulty developing confidence 
in his own capacity for mastering frustration. The mother who believes she must carry her infant about for hours for him to go to sleep can soon become a nervous wreck herself, because she gets angry (Brazelton, 2006, p. 61). A mother who allows at least a modicum of time for herself will then be able to look forward to being with her child again. Mothers who acknowledge both their positive and negative feelings towards the baby - and can discuss those feelings with the father-usually can tolerate their baby's crying better than mothers who are unable to admit their aggressive feelings towards their child. The baby's crying is then unconsciously perceived as part of a scenario where the overwhelmed, frustrated mother's rage at the baby's demands has already done harm to the child: every bout of crying is then perceived as an accusation of the mother's inadequacy (Daws, 1989).

A "good enough mother" can perceive both the positive and challenging aspects of her baby and will understand that the baby, too, must learn to accept his parents' limits, processing his frustration in smallish doses. For all parties involved, the motivation for teaching a baby to fall asleep alone is commensurate with the ultimate reward. Confidence grows that the baby can manage without his parents at least for a period of time, and develop his inner image of a good mother without requiring her constant physical presence. It is also reassuring for parents to know they have already given enough attention to their baby so that they can also take time for themselves.

It is important to know that most babies in the period from their third to twelfth week become "fussy" at the end of the day. Some 85\% of all babies in this condition cannot be calmed by being carried about, fed, played with, or otherwise distracted. Here are some of Brazelton's recommendations:

Go to the baby. Try out all the maneuvers you know to find out whether he needs anything. Pick him up and carry him. Feed him, cuddle, and change him. Give him warm water to help get a bubble up. But don't do too much. One you've reassured yourself that he is not wet, in pain, hungry, or sick, either use soothing techniques or let him be. The normal one to two hours of fussing can easily be prolonged into a four-to-six-hour ordeal if parents get too anxious and barrage the already overloaded nervous system with too much handling and stimulation. (2006)

These suggestions should help to forestall the kind of martyrdom for baby and parents that can arise when parents who cannot bear 
the baby's fussing then (commendably) try to soothe him. In one investigation, it was shown that children sleep longer and wake up more rejuvenated after fussing. Knowing that most babies undergo this phase should help parents pass through it more easily with their babies, without an undue burden being placed on the parent-child relationship.

Let us now see how both observers and parents in the families of Kelly and Max have described the first three months of these babies' respective lives.

\section{Development of the children Kelly and Max}

\section{Kelly's first three months}

As mentioned in the description of Kelly's birth, she already had her horoscope done at the age of one hour-in fact, while her mother was waiting to be sutured. Kelly was born three weeks before expected, in mid-August. She weighed almost four kilos (seven pounds four ounces), and had had a light case of jaundice. In the observer's first report, he described her as follows:

My first glance fell upon Kelly, who was lying asleep in her basket-a new-age style "Moses basket" standing in the middle of the room. She was lying on a yellow lambskin ... Kelly already had been asleep for four hours after her midday feeding, this was her regular daily rhythm. During the night, she apparently slept longer ... While her eyes remained shut, she yawned and let her mouth open, her tongue made motions as if she was tasting something. Her mother remarked that Kelly had scratched her own face ... While the mother was telling me about her birth, Kelly's movements grew calmer, as if she were reacting to her mother's trusted voice.

For Kelly, as for all babies, the mother's voice provides a centre of trust to grasp onto, calming them and seemingly "holding them together" emotionally. At first, it seemed Kelly wished to eject something unpleasant with her tongue. Her mother was lying near the baby carriage, in order to rest and simultaneously observe Kelly as she slept. A mother's tender looks to her baby constitute an important form of contact. An infant's appearance, its smooth skin, the soft fleece of its hair, its tiny nose and little ears exercise a stimulating effect on parents. The child is perceived and admired as a little miracle. Newborn infants prefer the 
human voice to all other sounds, and favour the female voice. Listening to her mother's voice seemed to have a soothing effect on Kelly and her perhaps unsettled thoughts.

Kelly's mother informs the observer how much she herself eats and how quickly time seems to have passed since her own mother came to take care of her and the household, enabling her to focus on Kelly in relative peace. She mentions how much she misses her work. She describes herself as very sensitive, potentially moved to tears by the smallest detail. One aunt gave Kelly a teddy bear she made herselfthe last one she could sew together, since she was growing too old to do so.

While the mother told me about the birth, Kelly opened her eyes, wrinkling her brow, and emitted a cry. Her mother continued to tell about her first days ... When the mother went to the telephone and talked, Kelly's face relaxed noticeably, since she now could hear her mother's voice better. She then moved back and forth restlessly and emitted another cry, which caused the mother to think she must be hungry. The mother took Kelly out of her basket and put her to the breast, whereupon Kelly grasped the mother's sweater tightly with one hand and sucked with a regular motion.

After only three days in the world, babies are capable of distinguishing their mother's milk from another mother's milk, as MacFarlane (1975) established in an experiment. Babies were placed next to cotton cloths dipped in various mothers' milk, and they turned towards the cloth suffused with the milk of their own mother. Regarding Kelly, we see that her mother adjusted to her wishes in breastfeeding, which quickly resulted in a four-hour rhythm. Kelly shows good appetite during feeding, good digestion, and is developing superbly, as her grandmother has observed. The grandmother's wish to play an important role after Kelly's birth seems to accord with the wishes of Kelly's mother to be cared for by her own mother; she gladly leaves the housework to her.

The observer describes nappy-changing when Kelly was seven weeks old:

As soon as her shirt had been taken off, Kelly went out of control. She lay in a diagonal curled-up position and cried insistently. The mother looked for a fresh shirt in the ironed laundry and said she would have to go find a new one ... When she came back, she said placidly to Kelly: "Why are you upset? I'm here, and here's a clean 
shirt ..." The mother then put the clean shirt on Kelly, with Kelly wiggling back and forth. She applied cream to Kelly's genitals, while Kelly protested this with a penetrating "Aaa". The mother now attempted to put a pair of pants on her, but Kelly had stretched both legs out straight and stiff. The mother asked her to bend her legs, but Kelly kept them stretched until the mother bent them for her in order to put on the pants. When she was done with dressing Kelly, the mother suggested to Kelly she drink from the breast in order to recover from her tantrum. When she put Kelly to the breast, Kelly took her nipple and sucked.

Although this is ostensibly a detailed observation of an out-ofcontrol baby, Kelly's reactions actually seem rather appropriate for preserving her emotional integrity while naked. Kelly's mother is emotionally accessible and is able to calm her down, maintaining a certain contact with Kelly's vulnerability and fear. Kelly seems to become more upset than her mother, who has sufficient confidence that she could bring the dressing process to a conclusion. I interpret the fact that Kelly can take the nipple immediately afterwards as an indication of her already internalised image of a good mother. The observer seems to have identified with the baby and would prefer that the mother shield Kelly from the painful, frightening experience of being disrobed, when he writes that "mother and baby are out of tune". At the age of twelve weeks, Kelly has acquired more confidence in her own skin and its function of holding her together. While being undressed, she maintains eye contact with her mother, blowing air out her mouth with comical noises that the mother imitates.

A view of Kelly's first months from her parents' perspective. The mother describes returning home after the birth:

I just wanted to go home. When I went out the hospital door, I thought: "My God, now I'm responsible for myself. Nobody will tell me what to do." But my mother came the next morning and saved me [she laughs]. Afterwards, I was anaemic and very tired. My mother said: "You're only going to take care of the baby," and she took care of everything else, cleaning, cooking, ironing, laundry. She stayed two weeks. It was great. Each afternoon, she encouraged me to lie down while Kelly was sleeping. That was a big help.

At this point, Kelly's mother was well able to accept the help her mother offered. She had left home in a stormy period at the age of seventeen, 
but now she seemed to enjoy being cared for like a baby. She was less able to accept help from her husband. When he wanted to change nappies, she became so impatient watching him that she eventually sent him away, and she could scarcely stand it when he took Kelly to him when Kelly cried. She said: "When she had gas, as all babies do, he put her on his chest, which she liked a lot, and she fell asleep. But I knew he would turn around and let her fall, that's why I couldn't sleep. And that's why I preferred to take her myself."

The fears of Kelly's mother seem to stem more from an unconscious feeling of competition with her husband than from actual experience. She would like to be the only important person in Kelly's life. Even in the moment she took Kelly away from him, she can see quite well that her husband would be prepared to do more for her. Kelly was then breastfed, which was a source of great joy and pleasure for them both. The mother commented:

I always wanted to breastfeed her. I loved breastfeeding. I mean, I enjoyed it. I didn't intend to stop it, because I believed it gives them a good start. She was a big, healthy baby and didn't like solid food until she was six months old ... I took her everywhere and nursed her.

In her description, it becomes clear that nursing was a major source of satisfaction, whereby she could demonstrate to the entire world what a wonderful mother she was and how superbly her baby was developing. The fact that Kelly was developing well confirmed to her that she was a good mother, one who could feed her baby well with nourishing milk-indeed, that she was the most important person in her daughter's life.

Kelly's father described this first period after the birth as hectic. Since Kelly was born three weeks too early, he was not yet finished with alterations to the house. Immediately after the birth, he rushed home to prepare the last room and clean everything up. For him, too, the presence of his mother-in-law was helpful. "She knows everything about babies that we didn't know. She gave us many good suggestions, that was extremely helpful. We were also both very tired."

He described himself as not particularly helpful, in view of the fact that he could not breastfeed Kelly. The only thing that calmed Kelly in the night was putting her to the breast; then she could fall asleep. "Unfortunately, we usually escaped to the breast," he remarked with 
regret. But for nappy-changing, he was there. "I must have changed more diapers than any other man on earth. Everyone was amazed that I did it so willingly ... I liked doing it, I couldn't understand how people find it so terrible ... You contribute to making the baby feel comfortable, it's good work."

Since Kelly's father was edged out of various areas, changing her nappies signified at least one meaningful task where he could contribute to Kelly's comfort. Being a father represented something very important to him.

It was wonderful and also educational ... The old saying, that the child is a father for the husband ... You don't acquire knowledge, but still you learn a lot when you have a child. You get to know yourself, you learn your own limits and how tired you can be but still function. I could understand why people have children at the age of twenty, instead of forty-one like me. They have more energy.

Both parents are interested in Kelly-indeed, she constitutes the focal point of their lives. "Kelly is the most important thing that's happened in my life, the thing that's satisfied me and made me most happy," said her father. Being a mother has become an essential part of his wife's identity. Both have respect for Kelly's personality. In spite of some difficulties in their marriage, they have remained steadfast in their loving parental role towards Kelly. Their love and humanity afford Kelly a good start.

\section{Max's first three months}

After an attempt at home birth, Max was born in the hospital after sixteen hours of labour. During the first observation, Max's mother is dressed quite comfortably, since she, as she says, spends "most of my time in bed".

The bedroom was dimly lit, Max lay in the middle of the double bed, which filled up the very small room. The mother lay next to him and talked softly to him, stroked his arms and legs. Then she moved her breast to his mouth, with Max smacking his lips. They lay that way for forty-five minutes, only interrupted by short breaks 
when Max fell asleep. When Max fell asleep, his mother stroked his cheeks tenderly. The social worker had called him a "potato eater" because he drank so intensely.

The observer records that Max's mother spent the first weeks more or less entirely with him in bed. Since Max's mother was highly critical of the strict four-hour feeding schedule her own mother had followed, she intended to feed Max according to his needs. In fact, it is curious that any baby could nurse for forty-five minutes long. There seems to exist very little space here between mother and baby. Is Max allowed to preserve his own space as a separate being? It is unclear who has real need of the protracted feedings and close proximity in bed. Is it really Max who wishes to nurse for such long periods, or rather his mother? Could it be that the mother's desires are projected onto the baby? Some confusion hovers over the question of who requires such closeness. The mother had told the observer that she was happy to spend the night in the hospital, because she had the opportunity to watch "the nurses calm the babies". This sounds almost as if the mother was grateful to learn from the nurses how to calm her own baby. Her own mother had miscarried several babies, and she seemed concerned that she would also lose her baby. This mother would like to devote herself completely to Max and his needs. Max had the same colour of complexion as his mother even at birth. Only after six weeks does his mother begin to write down feeding times and discovers-to her surprise- that Max drinks every three hours regularly during the day, and has a bowel movement every day at $6 \mathrm{pm}$.

In interviews, Max's parents gave a detailed report of the first three months with him.

After her enthusiastic depiction of the first weeks, Max's mother described a difficult time immediately following. Several times she referred to her troubled relationship with her own mother. Questioned as to how nursing was going for her, she answered: "My mother found it very difficult, she had various problems with it. I had no problems whatsoever, it was beautiful ... I was expecting problems, but there weren't any ... I could have breastfed him forever. I nursed him for a full eight months."

She seemed to experience her breastfeeding ability as a triumph over her mother, since she was so much better at it-as if nursing were a kind of competition. At the same time, her envy of her mother and other 
siblings seems to have played some role as well. It is if breastfeeding serves a double goal: to supply Max with milk, and also to demonstrate to her mother that she was the better mother of the two of them. Only in an incidental remark did she mention how she also felt quite "stuck onto", as if immovably chained to her seat.

The first two weeks were full of happiness.

We had a private midwife, who came to us the first ten days ... We had a good relationship, she was a great help. There were so many things I wanted to know, she was really like a mother figure for me ... I could ask her everyday things, like what I should do when he got a rash. She showed me a nice kind of baby massage ... Frankly, I found it very difficult when she left us. I was quite sad when she came only seldom to visit me.

Yes, I remember, the first week was a great feeling of happiness ... what I later found so difficult was his constant crying. Suddenly I had the feeling of being overwhelmed by violent irritation. I controlled myself, but I was angry as could be at the way he wanted things even when I thought I had given him everything, yet he wanted more.

Max's mother describes her emotional shifts between happiness and her deep irritation at not satisfying her baby. Presumably, the first week was so particularly gratifying and peaceful because she felt protected and supported by the presence of the midwife, who came one hour a day. Brazelton points out that particularly for women who have a tense relationship with their own mothers, midwives and paediatricians can assume this maternal function. This midwife seemed to also have given the mother a measure of security-she could assimilate the feelings the mother had had in her own childhood. Her eventual departure from the scene seemed to render Max's mother hollow and helpless, as if she had been abandoned. Presumably, Max was only tenuously established for her as a separate being, since she wanted him constantly at her side and offered him the breast when any kind of discord arose. We discover from her that Max could more easily calm himself when his father picked him up. The close proximity between mother and baby in the first weeks-when Max's mother was more or less constantly in bed-indicates her wish to be inextricably bound to him, as if she cannot accept him as a separate entity without great difficulty. Here, 
the baby massage technique the midwife had demonstrated served as a good solution. The massage could smooth over Max's sense of broken unity, which he experienced through his skin as the outward border of his body. It gave his mother the opportunity to experience a new form of manual contact with Max. Babies tend to enjoy the regular, loving motions of this massage, usually carried out under a warm infrared lamp. From the psychological perspective, the mother's massaging helps not only supplement the extremely close bond her breast has with the infant's mouth, but also offers a more clearly defined, more "separating" alternative bond, with the mother's eyes and voice also playing a supporting role.

Her husband took off two weeks from work to be with her and Max, assuming the cooking and other household duties. She did not directly interpret her own mother's presence as help-even though the mother came to London after Max's father went back to work-instead describing it as an "official visit" on the grandmother's part in order to "show her grandmotherly pride". However, her longing for maternal help and support could be read between the lines, as when she spoke of "not trusting" her mother-in-law's suggestions. She was, on the other hand, well able to accept her husband's help.

Max's father had difficulty in recalling the first month with Max. As extensively and animatedly as he described Max's birth, he still had few "clear memories" of Max's first period at home. He spoke of practical matters: taking two weeks of vacation to stay at home, learning to manage daily chores for the household. Asked whether his mother had helped out, he answered in the negative, in an almost indignant tone. Both parents had agreed that neither of their mothers should be asked for help.

I don't have any clear memories of the first months, except that I was very tired ... The first period was very fragmented, Max cried quite a lot, we thought he had colic. He was a restless baby, I'd say ... I remember thinking how fundamentally Max had changed everything. It plunged me into a world that was so different from the one before. And my time was taken up with a series of timeconsuming activities ... There was no continuity between before and after, everything was completely altered ... For me, it was an unbelievable confirmation of my manhood, of my adulthood, to be 
the father of a child in a family. So I think it must really have been a good experience.

The descriptions Max's father supplies have a strong air of control about them. He can hardly remember this initial period. During his wife's pregnancy, he apparently viewed everything as marvellous, even ideal, whereas the actual baby demonstrated to him his own limits. His decision-shared by his wife-to do without help from both their parents points to the tense relationship Max's father had with his mother. In emotional terms, Max seems to have rendered his father a "member of the adult world". The father was convinced he was infertilepresumably due to unconscious guilt feelings towards his own father. Max's birth and thriving appear to have rendered him a mature adult, capable of caring for a family.

"The devotion to the child was important ... I felt very vulnerable, that my identity was no longer under my control and that Max could not be protected."

Max's father tends to worry over his baby's health; he describes himself as an anxious father. He was afraid that Max could die and be taken from him. He felt grateful towards both Max and especially his wife for making the entire experience possible. Indeed, he pointed out that the baby has also enriched his relationship to his wife:

Our relationship was a bit barren, the "cannons had gotten rusty". Then came the pregnancy, that was very good. The events of his birth created a very strong bond between us. We felt very close to what we had experienced together. As a whole, it improved our relationship, it also intensified our sexual relationship. In the year after the birth, our sexual relationship was definitely quite a bit better than in the year before the pregnancy.

Max's father strongly emphasises how much having a child means to him and his wife. Having Max, caring for him, and watching him grow creates an important dimension and enrichment for the father's life and marriage, whatever fears accompany this new element.

Since we have no data for the first months of Patrick's life, we will instead describe another family, one that experienced considerable problems in the first three months after the baby's birth and therefore went into parent-infant therapy. 


\section{Children's progress in therapy}

\section{Troubles in the parent-child relationship: Lea and her parents}

This clinical material is based on analytic work with parents and newborn babies in the hospital, and takes into consideration both the foetus's learning ability and its capacity for self-expression while still in the womb. The French psychoanalyst Szejer describes the case of "Lea, the little girl who had no first name".

The mother had her child through a caesarian section, and under quite difficult conditions. She had wanted to become pregnant and then got twins ... later it was discovered that one of these twins was deformed ... and that it only had a slight chance of survival. The parents decided quite late-only two weeks before the expected birth - to carry out the foeticide [killing of the foetus]. The mother then insisted on a caesarian section so that she need not view the dead child. The parents could also not agree at first on a first name for the surviving baby, so that a birth certificate could not be issued. This difficulty in naming the child constituted a possibility for the analyst to offer the parents her help, which they were able to accept. Szejer's hypothesis was "... that the parents could not give their child a name because its dead sister had no name. She was in a certain sense a 'living corpse', and therefore the parents had an absolute need to name both children." (2000, p. 43)

Even before the analyst entered the picture, the parents had already named the dead child Sophie and its surviving sister Lea-perhaps because this problem was already taken seriously enough by the hospital to offer psychotherapy. The analyst describes her intervention: immediately after she entered the room, she told Lea (in the parents' presence): "Your sister Sophie, who was in your mother's belly, died. That's why you already could feel she wasn't moving before you were born. And that's also why you can't see her now, and won't ever see her again. You can keep your memories of her, but she won't be at your side anymore" (ibid., p. 44).

Szejer describes how astonished the parents were at her addressing the newborn baby, since doctors had only given them evasive answers concerning whether Lea would have any awareness of her dead sister. Three days later, Lea became critically ill; she had lost 
weight. In her as well, a deformity had been discovered-two of her toes had grown together. On the second visit the therapist said to Lea in front of her parents: "Lea, it seems to me that you wanted to be born, but that you haven't yet quite decided if you want to live, and that's why you're not eating. But in order to live, you have to eat. You have a deformity in your foot, but that's not nearly so bad as the deformity your sister had. You can't die of that, but you'll have to be operated on later, and then your foot will be completely normal" (ibid., p. 44).

After this, she suggested to the mother and nurses that they should lay Lea on her mother's belly, so that Lea could hear her heartbeat while feeling her skin. Lea's reaction is interpreted thus by Szejer: "Lea was deeply disturbed at this, the death of her twin sister prevented her from seeing herself as alive. In order to establish a safe connection between the time before and after the birth, she needed a connection to the tie before birth - this meant the taste and smell of her mother ... since her mother had been inaccessible to her in the first moments after the caesarian section ... this was the only way she could transform her grief over her sister to a 'force for life', instead of the morbid identification with her corpse" (ibid., p. 45).

Already a few days later, Lea had seemingly decided "to save her skin". She began on her own accord to breastfeed, so copiously that she was released two weeks later from the maternity ward (ibid., p. 45).

\section{Discussion}

First, it is important to note that the analyst's aid was useful to the mother in helping her to mourn for her dead child and truly accept Lea. Beyond this, opinions may diverge regarding theoretical explanations for the therapeutic intervention. In the analyst's description, her conversations with Lea focus on the significance of Lea's "taking the initiative" and deciding to live, whereas the analyst's close connection to Lea's parents-who had not yet been able to emotionally process their decision to kill the deformed foetus-is ignored. The parents attempted to repress the fact of the dead foetus from their consciousness, by not yet giving the child a name. The mother also wished not to see the dead child, and had the living child extracted from her body under full anaesthesia. At first, therapy was centred on understanding the mother's 
behaviour, her grief over her baby, her guilt feelings, and her sense of having created a deformed child. Only when the analyst herself could reflect on these interconnections was she able to articulate them. Even if her interpretations were directed at Lea, they were also intended for the parents. Interpretation is a way of describing events-or, to put it differently, the analyst helped the mother to face facts. Her offer of help in naming the twins seems already to have helped the parents select two names, one for the dead child and one for the living child. The mother's behaviour indicates she might view her body as something poisonous or dangerous, something she must protect Lea from-as if she were a murderess who would be capable of also killing the second baby. Presumably, she was afraid that the second child would have not only a deformed foot but also carry the same life-threatening deformity her sister had. When the analyst pointed out that Lea's deformity was comparatively harmless and correctable, this probably effected a transformation in the mother's attitude towards her surviving baby-as if she had previously been afraid to put her heart into mothering since she believed this child might also be soon taken from her. I myself know nothing of this mother's inner world, her guilt feelings, or fantasies of revenge. Nevertheless, I presume the analyst's interpretations helped the mother to experience her grief over the dead child and to assuage her fears of deformity, thus preventing her from further bombarding Lea with her own unconscious projections, so that Lea could then turn to her breast for milk. Daws shows how important it is with stillbirths and miscarriages to symbolise the dead infant's existence with a name and rituals of burial or cremation. This enables the parents to comprehend the loss of their baby and to grieve (1989, p. 240). Bourne and Lewis emphasise how difficult it is to grieve for a dead baby, since its death is in some sense experienced as a "non-event": the admixture of birth and death is confusing, painful, and alienating (1984, p. 31).

The French school of psychoanalysis based on Lacan, which concerns itself with the first experiences of the newborn baby, puts language and eye contact with infants at the centre of its therapeutic technique. Szejer writes:

It is the voice through which the baby finds its symbolic expression for others, because it is for him the means of representation, vocalization and address. Through the voices of other people, the newborn baby is transformed from a mere body to a being of symbolic import. Even more than the cutting of the umbilical cord, the voice 
marks its entrance into life. Only through the voice does the child's body become named, marked and prized. (2000, p. 37)

The voice, the marking of an infant with a name, signifies its entrance into society, into humanity, a process already concretely defined with the cutting of its umbilical cord. But this focus on language, I believe, requires further explication of the psychic space represented by speech. Together with Bion, I assume that at the core of communication between infant and mother is her emotional absorption of the baby's physically expressed emotions. A mother who has the inner space to assimilate the baby's feelings, reflect on them, and "digest" them, then verbalising them and returning them to the baby in a form he can assimilate, enables the infant his access to this verbalised description of his feelings. Communication is, however, not restricted to language: the considerably larger sphere of emotional communication is non-verbal. Through the non-linguistic emphases and rhythms of the voice, through visual expression, skin and eye contact, the baby can detect fine nuances that are decisive for the emotional significance of a word, the emotional quality of a voice. In clinical examples, we can clearly recognise the relevance of inner space, and of understanding problems of the mother-child dyad-both points of decisive importance for whether the baby reacts to an analyst's words.

\section{Therapeutic help before birth: Joseph}

In rare cases, the mother obtains therapeutic help during pregnancy, thus avoiding the much-feared and in fact pernicious post-natal depression. It is well known that during therapy or psychoanalysis, women are able to work through their wishes and fears, conscious or unconscious, of becoming pregnant, thus actually succeeding in becoming pregnant-as occurred with Max's mother. I will now describe the "emotional preparation" for Joseph's birth-his mother, here called A., had been "put" into analysis by way of her two-year-old daughter.

A. went into parent-child therapy because her two-year-old daughter Victoria was eating so poorly. According to her, she was forced to follow Victoria all day with a spoon, otherwise the child would eat nothing at all. At the first therapy session, I met a friendly, delicate but most proficient little girl, who investigated the room, immediately established contact with me and played by herself. I was struck by the mother's irritation when Victoria gave me wooden blocks to hold and asked for 
my help undoing a doll's apron. Her mother was in her sixth month of pregnancy and anxious that she would not have as much time for Victoria after the new child was born. When I asked her if she thought Victoria might starve, she answered like a pistol shot: "Yes. That's why I'm so afraid." While she told me how Victoria never had an appetite, Victoria opened the backpack, took out a plastic bag with grapes in it, and unambiguously asked her mother to open it: she wanted to eat a grape. Her mother reacted truculently, saying: "You won't eat it, you're just going to play with it." When she then nevertheless attempted to put a grape in Victoria's mouth, Victoria turned her head to the side and wanted to take the grape in her own hand. Reluctantly, her mother allowed her to do this; Victoria put the grape in her mouth and sucked on it, shifting it from one cheek to another. The mother then wanted to take the grape out, whereupon Victoria almost choked, since she was trying to swallow it as quickly as she could. When I pointed out how independently Victoria was playing and how much she would like to put the food into her own mouth, her mother perceived herself as criticised, once again reacting truculently: she remarked that her own mother said things like that too; for that matter, Victoria ate much better when she was with her grandmother; every time she was picked up from her grandmother's, she wanted to stay there forever, and wept inconsolably. In response to my interpretation that she was afraid her own mother could take Victoria from her, she nodded. It calmed her to hear she was the mother and could decide as she wished how often she would visit her own mother with Victoria.

In the second session, the mother said Victoria's eating problem had already practically solved itself; Victoria was able to communicate what she wished to eat. The main problem now was that A. felt such hate towards her own mother that she felt reluctant to bring Victoria to her for babysitting, although the mother's babysitting relieved her of a considerable burden. The fact that Victoria stayed up until 11 pm every night did not bother her-she enjoyed the evenings with her, since her husband worked in the next room until midnight.

Upon my commenting that she never spoke of the future baby, she shrugged her shoulders. "No, I never think about the new baby. It's as if I weren't pregnant. I don't feel anything." It became clear that she had not wanted this pregnancy. She had also been pregnant two years before Victoria, but had lost the baby. After six months she once again became pregnant, but it was an ovarian pregnancy. She was in a most 
serious condition and required an operation. At that time, she had also gone into therapy and had once again become pregnant. She was very fearful, was assessed as a risky pregnancy, and allowed to stay home from work, which she greatly missed. (She had planned to go back to work when Victoria was two years old and had been looking forward to this.) When she became pregnant, she reacted desperately and wanted to get an abortion. Her husband strongly wanted to have the new baby, but left the decision up to her. Since she also wanted two children, she was afraid to abort in case she could never become pregnant again. She felt absolutely nothing for the impending baby, and merely sat around at home; only Victoria could draw her out of her dejected state. When I observed her interaction with Victoria, it seemed laboured and dutiful. Victoria always turned to me first, and only if I failed to react would she ask her mother for help, or her mother would call her over in order to help her with something. At the end of the fifth session, it became clear how gravely she feared some impending chaos after the next birth - that she herself would collapse, with her husband and mother assuming care of the children. She then decided to begin a four-session analysis, as she feared post-natal depression.

Only in the first session of this analysis did it become clear how negative her image of herself and the world was. Indeed, she felt herself surrounded by enemies; her mother would take Victoria from her. She felt she had taken away her husband from another woman by pretending to be different from what she truly was: her husband loved "another woman", so to speak-the woman she had represented herself to be. Actually, she felt she should move out, and intended to do so either before or after the birth. She had already withdrawn from her husband and even from her beloved dog. Her husband had remarked that Victoria received $90 \%$ of her attention, he got $8 \%$ and the dog $2 \%$. She confirmed this to me laconically.

Her feelings regarding me and the analysis were contradictory. She was emotionally withdrawn, almost inaccessible, but at the same time she found the sessions too short-at the end of each session, she remarked how it had really only just begun. She felt compelled to enter analysis because she did not want to seek psychiatric treatment: then her mother would win Victoria over to her side completely. Working through A.'s deep mistrust of me and the world was an essential point in the analytic process. She was convinced that nobody could understand her. When, after one week, she could accept that she had her own 
space with me, she found herself more able to be happy about Victoria. After week two, Victoria for the first time ran over to her when she came to pick her up from her grandmother's.

Nevertheless, A. once again seemed to not truly understand she was pregnant. Her enlarged belly disturbed her: she had the impression her body was occupied by an alien force. She found it impossible to think about her baby, she felt only emptiness within her thoughts. She arrived punctually at each session and found our separation at the weekends painful. She recalled being oppressed by her brother when she was fourteen months old, and mentioned her fear of treating Victoria the same way. She was deeply afraid of impending chaos after the birth. She reacted very emotionally to my interpretation that she wanted me to keep the existence of her future baby alive through my thoughts. On the afternoon of this same day, she was able for the first time to shop happily for baby clothes, and also be friendly to her brother. Afterwards, she spoke of her fear of becoming dependent on analysis, just as she had been completely dependent on her mother before marrying. In the final week before giving birth, she reminisced about her poor relationship to her father, who was an alcoholic and never had wanted children; her mother suffered under this, frequently commiserating with A., the oldest daughter, who then proceeded to argue with her father. When he became sick, she was the only family member who visited him every day. Although they were unable to discuss their issues freely and completely, the father did say, "I made many mistakes with you." Saddened by his death, she was able to grieve over him. After this session she went for an ultrasound examination and for the first time saw the baby's face, which had until then been hidden from view. She became filled with an elemental joy and knew now that everything would be all right with the new son, although her attempt to select a name for him with her husband proved unsuccessful. She gave birth a week late-a spontaneous birth, without complications. After the birth she came to me three more times, but then broke off the analysis, claiming she could not manage the logistics with her two small children.

\section{Discussion}

In the first week of analysis it seemed A. had hidden herself behind a concrete wall, difficult to reach, alienated from her environment. Only the prospect of completely sinking into the dejection that was already 
causing her to sit in one chair for hours at a time, staring vacantly at the wall, could evoke true fear in her. She wanted not to lose Victoria, who presumably represented her vital self, fighting to remain in the world and not sink into depression. The fact that the second child was to be a son seems to have brought up unresolved conflicts with her dead father, as well as suppressed jealousy of her younger brother, evoking feelings of both fear and guilt. Her fear of her own dark side was so great that she decided not to continue analysis after successfully giving birth. It also required considerable time before she and her husband could agree on a name-Joseph-for their new son.

\section{From the fourth through to the twelfth month}

In the period from the end of the third month to the end of the first year of life, the infant has developed far enough so that he ingests not only his mother's milk but also solid food, and can move about on his own-crawling, sliding, rolling, or carefully attempting his first steps. He can make himself understood through noises, tones, and gestures, not only to his parents but to other adults. He can demonstrate his feelings clearly through affectionate hugs, furious bouts of crying, pushing, and grasping. He can now sleep for longer periods or even through the entire night, and occupy himself alone with various pursuits. Thus, he has evolved from a competent but needy baby into a "miniature human".

Here, I will set out to demonstrate the development of the emotional relationship between parents and baby regarding certain essential aspects, seen in terms of the baby's personality:

- Acknowledging the baby's personality

- Body care and independent mobility

- Development of the baby's psyche

- Feeding, nursing, and weaning

- Sleep and sleeping problems.

\section{Acknowledging the baby's personality}

Recognising the individuality of a baby's personality entails recognising a You-another human consciousness. I have already discussed our basic assumption that the baby arrived in the world expecting to find someone to psychically care for him and provide him with a certain level of emotional understanding (Bion, 1962). The development of the 
baby's personality can be understood as a "psychic birth", by necessity predicated on the existence of another person. Winnicott calls this relationship between mother and baby a "mutual recognition" between persons who recognise each other as both distinct and of essential value. Only this mutual acknowledgement-a kind of emotional reactionmakes "our feelings, intentions and behaviour meaningful" (Winnicott, 1971). In relationships that barely allow for this sort of recognition, there remains a feeling of emptiness, meaninglessness, lifelessness. The writer Peter Rühmkorf (2000) expresses the feeling of an empty, meaningless life in the following poem:

It's not worth it

Being born for a bit of food,

To forget the tubercular neighbour

And his shrieks of the tooth.

It's not worth it

After supping to stroke the hard husks

In the clutch of counting fingers

That then praise some god

And flatter him he's just.

It's not worth siring sons

We're them all right,

Glib and well-shaven

But beasts by night.

It's not worth it!

Look for the sense.

Be fruit, seed, mulch.

No profit immense

In the clutch of counting fingers.

In this poem, Rühmkorf shows that a sense of meaninglessness in life is rooted in acquisitiveness and possession-and in going through the motions without truly being in harmony with ourselves, functioning only in an external sense, devoid of life and joy. Hope and meaning depend on our becoming "fruit, seed, mulch": being something as opposed to possessing something. How is it possible to reach such a feeling of emptiness and meaninglessness?

An essential factor is whether parents can accept their baby for what he is, and whether they can assimilate or contain his still unmanageable feelings, holding them in trust, so to speak. Winnicott speaks of 
the central significance of mutual recognition between two separate persons. Bion calls this fundamental relationship a "containment" - the storing of a child's feelings within his parents. In our European culture, attaining a realistic view of any baby means discarding widely accepted assumptions and prejudices that serve only to distort parents' perceptions and thus acceptance of their actual baby. One extremely limiting prejudice is the assumption that children are "innocent", that anything pernicious in them must be due to the environment, lack of parental love, or other deficits. Another prejudice is the view of children as asexual, and a third is underestimation of their cruelty — and curiosity.

\section{Children's "innocence"}

In my opinion, the idea that children are inherently innocent embodies a longing parents harbour and then project onto their children. We long to see a newborn baby as pure and exclusively good. The baby born to parents bound in a loving relationship is seen as a symbol of their love and closeness, a symbol the parents seek to idealise and protect. In their hands, the parents now bear the hope for a better future, untainted by the pain, problems, and guilt adults have brought upon themselves. We would like to discover every variety of beauty, hope, and perfection in the baby that constitutes our mirror image. The fact of having given birth to a healthy baby serves to quell fears of our own evil and destructivity, seeming to prove that goodness and creativity have the upper hand in us, that the uterus is a safe place, that sexual intercourse is virtuous and generates something new-embodied in the birth of Jesus as the definitive Christian symbol of hope. Conversely, the birth of a handicapped baby can appear to be a divine punishment upon its parents, heightening their fears and sense of failure instead of lending them the compassion and fortitude they need for the difficult task facing them.

In contrast to this mindset, it is a relief to recognise that a baby is furnished with good and bad feelings from the beginning, that he sees himself as the centre of the world and wishes to control everyone else within his orbit-without taking his parents' needs into consideration. A baby is not only forlorn and dependent, but also mercilessly dominating. The phrase "her/his majesty the baby" expresses this condition well. Aggression is not merely a response to neglect or deprivation, but a basic component of the baby's emotional constitution. 
Some readers may ask themselves how consciousness of a baby's darker side can help in parenting. I believe it crucially relieves parents of the impossible challenge they may have set for themselves to provide the baby exclusively with happiness and security. It is helpful to know that a baby who bites the nipple during breastfeeding is expressing a spectrum of emotions-on the one end, happiness at receiving milk, love, and security; on the other, envy and hostility to the mother's monopoly on potency and nourishment. The mother need not then ask herself what she has done wrong, but instead might comprehend just how difficult it is for this little baby to always be on the receiving end. The baby who just bit its mother may well then interrupt his feeding and turn to her, gazing with particular fondness, smiling, or expressing thanks through some gentle sound-and the mother can understand this as an attempt to repair the pain just caused by the bite.

If a baby is screaming and his parents can comprehend his desperation and fear, can remain calm and express the baby's feelings in words, this helps the baby understand that the fantasies triggering his attacks of rage and his subsequent fear of having destroyed everything do not correspond to reality - that the parents remain unharmed and still love it. When parents realise that the phases of rage their baby has, whether over his inability to control his world or over issues of separation, are normal and are an aspect of the baby's maturing and development, they can react more serenely. However, when they fear there could be something gravely wrong with their baby, or believe his exasperated howls signify dissatisfaction with them as parents, a vicious circle has begun. Instead of registering and comprehending the baby's feelings, the parents might start to feel criticised-even persecuted-by him, then becoming angry at the same child on whom they have lavished so much time, love, and attention. Their frustration and disappointment can make it all the more impossible for them to understand and help their baby distinguish between fantasy and reality. A baby's outraged screaming might remind his mother of her own mother, for whom she could never do anything well enough-and she might then develop similar feelings of surliness or apathy towards her own child. Perception of the child then becomes increasingly skewed, with the baby now no longer simply unhappy or fearful, but transformed into an image of mother's own dissatisfied, complaining mother. A father who feeds his son, changes his nappies, and carries him around may be reminded of his own tyrannical father, for whom he was never good enough, and he may therefore feel dictated to by his baby; accordingly, the son is 
experienced as a powerful continuation of his father's father. Selma Fraiberg (1980, p. 164) calls this phenomenon, where a child is perceived as representing the conflicted relationship between his parents and their parents, a "ghost in the nursery". Unconscious, unresolved conflicts with the parents' own parents are then projected onto the baby, distorting the parents' perception of reality.

If, however, the parents' relationships to their own parents are mostly positive, they can find strength in similarities their baby has to those parents or to other family members. This then creates an even more positive attitude towards the baby in that he reminds his parent of his grandparents or uncle/aunt. One could speak here of a "helpful ghost in the nursery"-for instance, when the baby's burbling reminds his parents of his grandfather's musicality.

Recognising a baby's destructive and dominant wishes also can help the parents say no. Parents who never say no do not make their baby happy but instead fuel his unrealistic fantasies of omnipotence, thus hindering development of the child's sense for reality and the borders between him and the world. Parents who trust their child in small increments to take care of himself-to pacify himself or go to sleep alone, perhaps with the aid of his thumb-enable their baby to develop trust in himself and to incorporate his positive experiences as elements in this process. Such a child will then be able to better cope with future frustrations, and become more tolerant.

Just as problematic as the parents who try to fulfil their baby's every wish are those who always say no and return their baby's destructivity to him by screaming back, putting him roughly in his bed, shaking or even beating him, thus offering the baby no other alternative but to submit to their imperatives. The child receives the impression his parents are omnipotent, and that he is forbidden to do anything outside their will. Summing up, we can say that the struggles inherent in recognising a baby's personality alter both parents' and baby's feelings of omnipotence. The essential point here, as Winnicott says, is to find a judicious balance and to consider the needs of both baby and parents (1971).

The baby as an asexual being

Babies' presumed innocence entails the notion of an asexual being. Often, this assumption is based in religion-as if the creation of an asexual being would constitute a positive achievement, with the subliminal implication that sexuality and pleasure are something bad. Anybody 
willing to precisely observe the behaviour of babies and small children will not fail to notice their moments of sexual excitement and pleasurethe intense physical excitement while drinking, the male baby's erection while being changed, a girl's ecstatic cavorting (Taylor, 1999, p. 29). The ecstatic sexual interest very young children have in their own bodies, their genitals, and the bodies of other children is manifested through both looks and grasps. Some parents report that their baby boys show sexual pleasure during washing and oiling of the skin at a few months' age and take every opportunity to grasp their penis, often with such force that their parents fear they will hurt themselves. Babies' excited jumping on their parents' bed, accompanied by wild shrieks and laughing, is not hard to identify as their imagination of what their mother and father do at night. Siblings often enact even less ambiguous fantasies of their parents' sexual union, with one child lying on top of the other and both laughing excitedly, then disappearing under the blanket. Above all, the noises children hear at night can be confusing, since expressions of pleasure and excitement are similar to those of panting and even of pain. One student observed large birds in the zoo emitting throaty sounds. A five-year-old girl, who had at first observed these birds with great interest, made similar noises that began sounding more and more sexual, then answered by the birds. These throaty sounds quickly became louder and more intense, the adults turned away in order not to watch, and the whole family swiftly exited the bird house. Adults have difficulty accepting children's interest in sex.

One mother described the lusty, freewheeling game her four-and-ahalf-year-old daughter and her two-year-old son played in a children's wading pool for a half hour one summer, proceeding as follows: the girl stood up in the water, grasped her vagina and said, "I have a lippy!", then sat down so that water sprayed all around. The boy laughed loudly, stood up and pulled vehemently at his penis, saying, "I have a pippy!", proceeding to sit down so that the water sprayed. Both laughed, looked each other over, until again the girl stood up and pronounced her slogan once again, followed by the brother. It was a playful approach to the nomenclature of sexual difference, and we can interpret their wild splashing as an indication of the pleasure component in sexuality. Freud traced an adult's later exploratory interest in the world, discovery, and invention back to sexual curiosity, which first is directed towards the child's own body and that of its mother, and then quickly is broadened to include the entire world. 
At the same time, it is important to distinguish the different quality of early sexuality from sexuality as experienced in puberty. Even when children later play doctor or explore each other's bodies, the rules of the game keep their play within a protective frame. The great interest children of all ages have for animals and animal films is often increased through their sexual curiosity, since animals exhibit their sexual behaviour freely; both sexual union and birth are often depicted openly in such films.

Just as we recognise that there exists a form of sexuality in children, it is all the more crucial to protect the child. The respect for the special nature of child sexuality and the knowledge that children can so easily be seduced should serve to indicate the particular need for protecting them. The crossing of sexual boundaries between child and adult is a traumatising experience, since a fundamental border is damaged. Instead of a child being protected and loved by an adult, the victim of sexual abuse experiences deep emotional and psychic confusion. Often the abuser is a family member with whom the child has a more or less loving relationship, someone who lacks respect for this corporal boundary and abuses the child for his/her own sexual needs. Parents very frequently overlook the disturbed, often peculiarly exaggerated or withdrawn behaviour of their children who are sexually abused.

\section{Cruelty and curiosity of children}

Implicit in the idea of children's innocence is the assumption that destructivity, cruelty, greed, hate, envy, and jealousy are not innate components of the child's nature but instead reactions to neglect, separation, and unfortunate environmental circumstances. This assumption can become an enormous burden on the parent-child relationship. Every temper tantrum, instance of greed or megalomania is then felt to be an implicit criticism of the baby's inadequate environment, proof thereby of the parents' shortcomings. Accordingly, parents often believe they must devote even more attention, time, and love to the baby, since they assess its "bad" feelings as the response to an unworthy environment. The pressure parents put on their child to not exhibit feelings such as jealousy, hate, envy, or cruelty often leads directly to the child's becoming convinced he is bad. Children then attempt to conceal all these "bad" feelings, ashamed of them. Psychoanalysts believe, however, that the appropriate task for parents is to help the child name 
and understand these feelings, thoughts, and fantasies. It is essential to differentiate between thoughts, fantasies, and actual behaviour. A child who says he would like to send his little sibling back or throw it in the rubbish is confiding an inner conflict to his parents. A shocked reaction on the parents' part, such as "We mustn't say such things" or "I don't want to hear that again, shame on you" leads to the child concealing such feelings, often to repression. But the impulse remains, and it then becomes more probable that the older child "unintentionally" pushes his younger sibling so that he falls down the steps, or puts dangerous objects in his pram. Openly discussing these wishes enables access to the child's fears and the threat of dislodgement the new baby represents. The child then has the chance to talk about these feelings instead of committing truly harmful acts. The clear distinction between behaviour and fantasy constitutes an important aid for the child towards integrating the darker parts of his personality and understanding that everyone is both good and evil. When parents help their child accept his malicious feelings, he can then show his loving side as well, for instance by helping the baby, washing or feeding it. One could say that the human psyche moves between both poles, respectively described by Goethe (1793): "Noble is man, helpful and virtuous" — and by Patricia Highsmith (2010): "Every person carries within himself all evil that ever existed." Both sides are equally important. Curiosity and the hunger for knowledge ride on the wings of aggressive ambition. The insight that a baby is capable of love, gratitude, and joy requires amplification: anger, envy, hate, destructive rage, and annihilation are also there to be mastered.

Curiosity and the wish to look inside everything-into the mother's body and all inner spaces that symbolise her body, such as boxes, suitcases, or chests-are important basic elements in the baby's drive towards knowledge. A baby requires a portion of aggression in order to investigate his environment, as we see when we observe a small child playing, eager to take everything apart, unscrew and examine it.

Parents' fundamental attitude towards their child is manifested in all aspects of life, in caring for the baby's body, feeding him, how he sleeps and plays. Parents, too, must learn how to deal with emotional separation, closeness, and distance, while helping the child slowly learn to exercise some degree of self-determination-dimensions where the quality of parent-child understanding, or mutual respect, becomes apparent. 


\section{Body care and independent mobility}

When the phrase "mutual understanding" is applied to the motherinfant relationship, this remains a relatively abstract rubric if we cannot track it in concrete interaction with a baby. I have already emphasised that physical developments are particularly interwoven with psychic developments in the first year of life, and this includes the manner in which parents care for the baby. "Respect" or recognition manifests itself through care of the baby's body and the feelings there elicited. The manner of body care and development of independent mobility up to and including walking are also of significance. A baby must be nappied, cleaned, rubbed with baby oil or cream, bathed in the evening, and put to bed. These activities offer a time for conversation, singing, caressing. The baby becomes acquainted with the world via the hands of his mother or father, and through their voices, which hold him together emotionally. The calm words a baby hears-perhaps merely the mother's description of what she is doing to him-accompanied by eye contact, serves to show he is loved and appreciated. Emmi Pikler, a Hungarian paediatrician with psychoanalytic training, emphasises the significance of responding to a baby's temporal rhythms. She calls her book Laßt mir Zeit ("Give Me Time") (2001), and points to the importance of letting a baby develop his own mode of movement, unfettered by parental ambition-on his own impetus and according to his own abilities Emphasis on the importance of a parent's state of mind during changing or bathing the baby does not mean they must set impossible demands on themselves. On the contrary, a mother who has just hurried home need not rush immediately to her baby, but should first take sufficient time to wind down; even if the baby is already crying, the mother may be well advised to grant herself a moment to catch her breath, only then turning her attention to the baby. If loving parents are certain that they have given their baby sufficient attention that he can now console and occupy himself alone, this becomes a major relief; they can acknowledge that the baby does not require twenty-four-hour attention, and that their own needs are equally important.

If the mother/father can take time to give the baby their undivided attention for even a brief period, then his hunger for love and communication will be satisfied. In the first phase of romantic love, which has its roots in this early phase of life, we experience that the most important thing in life can be another human being. The first 


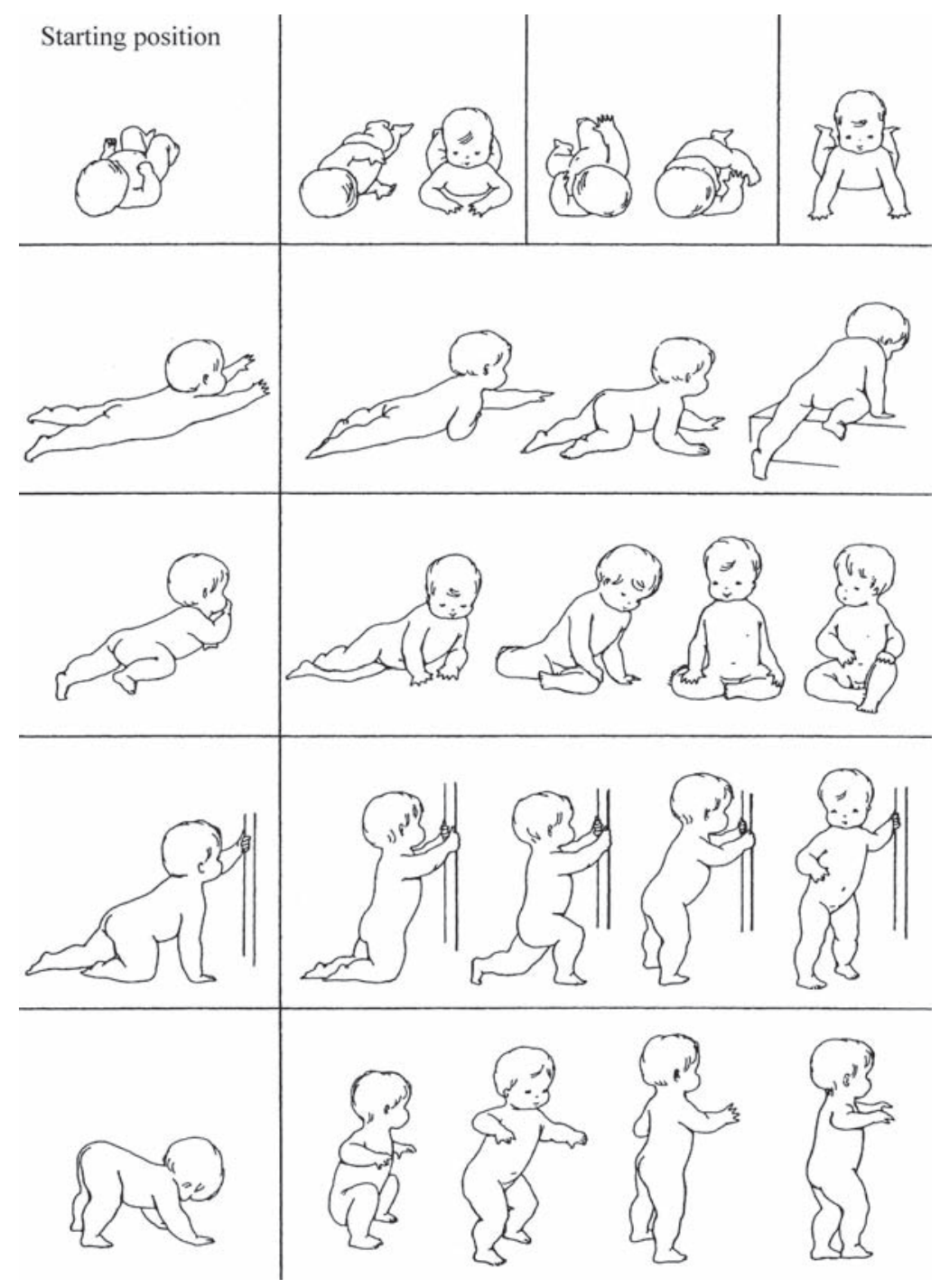

Figure 3. The series of independent movements from the baby's own initiative (Pikler, 2001).

love relationship is between mother and baby, a state of happiness of paramount importance for later phases of life. A successful relationship between mother and infant does not mean they are constantly together or that she devotes herself to the baby all day long. It is sufficient if her 
attention to the baby is complete while she is actually taking care of it, so that the baby can then be trusted to occupy himself alone, to assimilate his impressions of the world: his own body, his fingers, the colours of the curtain over the window, the light shining through it.

The basis for entering periodically into emotional contact with the baby, which in turn makes possible phases of separation and independence for the infant, is an inner flexibility on the mother's part. Moments of separation and temporary parting occur constantly for the motherchild dyad. Just as with feeding, where it is important to differentiate between hunger and other needs and to not constantly be sticking something in the child's mouth, it is also important to alternate phases of time spent together and time spent apart. Even during phases of separation, the mother's / father's thoughts are with the child. Carrying the baby around constantly or clinging to him makes for an insufficient alternation between closeness and distance, giving rise to conscious or unconscious negative feelings on the parents' part—of being overtaxed, sucked dry, deprived of free time-which are then imparted to the baby. He no longer knows if he is truly protected in his mother's arms or if her aggravation and rejection have the upper hand. In order to make sure he is indeed protected, he then wants to be carried around even more, and neither mother nor baby can be pacified. One mother spoke of her "crybaby" who could not stand to be without her for a minute. He could only go to sleep against her body; she could not even get dressed, stayed in her nightgown all day long, and had reached a state of complete desperation.

It seems necessary here to once again emphasise the elementary significance that the containment of an infant's feelings by his parents has. When I speak of "independence", I do not mean parents should leave the infant to himself most of the time in his cot or baby basket. What is required from the caregiver is psychic and emotional accessibility-a watchful gaze that registers the infant's movements and his attempts at contact, empathises with his joy or frustration, observes him, encourages him without unduly seizing the initiative. As Pikler believes, the infant learns "during the course of its developing mobility not only to turn over on its stomach, not only to roll, crawl, sit, stand or walk, but also how to learn. It learns to occupy itself alone, to find interest in something, to try things out, to experiment. It learns to overcome difficulties. It learns joy and satisfaction, the manifestations of success-which is the result of its patience and independence" 
(1982, p. 35). As important as Pikler's concrete suggestions for parents are, she also neglects one significant dimension: the emotional relationship between parents and baby. Indeed, we can assume that the attentive interaction between adult and baby, when the caregiver is attuned to the baby's responses, can also evoke loving and friendly feelings in that caregiver. Pikler founded an orphanage based on her principles, principles she primarily developed for nurses in the orphanage. In a research project on the children growing up in Pikler's orphanage, it was shown they were eminently capable of forming emotional relationships, later scrupulously planning when they wanted to have children themselves, since they wished to offer them a truly secure family. In contrast, a study of children from other orphanages showed that they tended to repeat their own histories, typically having babies as teenagers, at such an early age that they were unable to raise them themselves. Bowlby (1951, p. 95) emphasises that children who in infancy were raised in orphanages later typically embark on casual sexual relationships that result in offspring just as neglected by their mothers as those mothers themselves earlier were. However, "... of the 73 girls ... originally raised in Pikler's orphanage, none had an illegitimate child $\ldots$ among the 100 we studied, there had not yet been a case either of criminality or of unwillingness to work" (Pikler, 2001, p. 25).

Granting the baby freedom to develop his own mobility means that his uniqueness is recognised, and faith is placed in his development as such. Some babies can already hold their heads up at an early age. Some first manage to sit up via a sideways squat, some can crawl on their hands and knees, others slide forward in a sitting position.

Some children approach standing up from a "bear" position (hands and feet on the ground), others manage this from a kneeling position without additional support, still others hold onto an extraneous object for support. It is not important how wide the baby's repertoire is but rather how securely it executes its motions. Observing their baby, parents can derive important information on its personality, its character, its stamina and threshold of frustration. It is of little help when parents believe they must train their baby to execute certain specific movements, manipulating it into various positions. This indicates an impatience or ulterior ambition on the parents' part, resulting in the baby's increased dependence. When parents are truly involved in observing their baby, this conveys their confidence in it and their pleasure in its day-to-day progress coordinating its body. Their belief in its abilities makes it easier for the baby to develop its relationship not only with its own body, but 
with its environment and those very parents. If parents sit on the floor near their crawling baby, this by itself can bridge the distance between them as the baby actively seeks and then finds proximity to adults. Simply observing the baby constitutes a significant form of contact between parents and child, allowing the child to experience closeness to its parents without having limits placed upon its independence.

Regarding the question of belly position versus back position, Pikler emphasizes the greater freedom for the baby to discover its own hands and move its legs when in the belly position, as seen here in Figure 4.

a) The baby familiarising herself with her own hand in the abdominal prone position (Pikler, 2001).

BEA

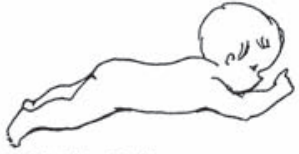

Age: 9 Weeks, 2 days

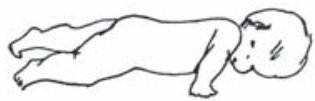

10 Weeks, 2 days

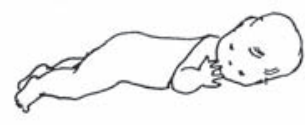

9 Weeks, 6 days

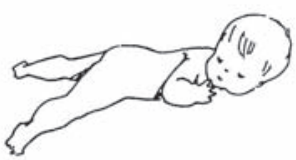

12 Weeks, 2 days

b) The baby familiarising herself with her own hand in the back prone position (Pikler; 2001).

MONI

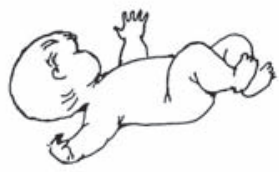

Age: 6 Weeks, 3 days

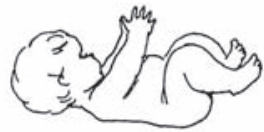

8 Weeks, days

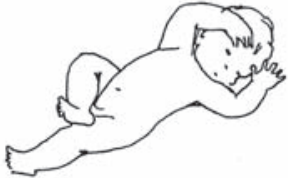

7 Weeks

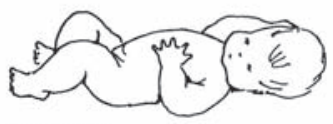

9 Weeks

Figure 4. The baby familiarising herself with her own hand in the abdominal and back prone position. 
When instead of understanding a baby, we merely talk about him without establishing emotional contact-when we cannot accept and assimilate his positive and negative feelings and his fears-the result is a sense of loneliness for the baby. The essential factor here is not the parents' interrupted physical presence, but rather their ability to enter into emotional contact with their baby. If a baby is given a cold shoulder by his parents, he can withdraw into a world of his own devising and eventually prefer fantasy to a world as cold and inimical as Rühmkorf described in his poem. If emotional contact is fundamentally defective, a baby tends to withdraw more and more. In these cases of unsuccessful or unattempted contact between mother and baby, we speak of a lack of emotional containment.

\section{Development of the baby's psyche}

Starting with the fourth month, a qualitative change emerges in the parent-child relationship. The baby becomes more active, less fearful, more patient; he now has the ability to remember, and also to smile. For his parents, the baby's first smile is a major, happy milestone. The baby shows ever more clearly that he can differentiate between trusted people and strangers. He has become more psychically "compact", less vulnerable, less prone to emotional "disintegration".

Parents describe this qualitative jump as a relief. They are now certain of their ability to keep their baby alive. The baby has gained weight, with dimples of fat and round cheeks; he can now produce more differentiated sounds of pleasure ("Ooh"s, expulsions of air, throaty noises) in addition to crying and whining.

This new quality in the relationship devolves not only from the child's psychic maturing, but also from the fact that he now attributes both good and bad traits to one and the same mother-viewing the loving, present mother as good, and the absent or critical mother as bad. This reduces a baby's fears, since he is now able to remember: behind the image of the bad mother, so to speak, the memory of a good, friendly mother remains alive. Piaget speaks of "object permanence". Simultaneously, the baby begins to see itself as a person with good and bad aspects; Piaget speaks of "subject permanence" (Piaget \& Inhelder, 1951).

In this phase, the child is faced with new demands. Because of teething, his mouth-until now a locus of pleasurable sucking and, 
together with his skin and ears, an assimilative organ-becomes a locus of torturing pain. An inner disquiet arises, presumably due not only to pain caused by newly emerging teeth, but also the baby's concerns over his maternal object and his own self. Integration of good and bad aspects also gives rise to issues regarding the loved one (object) and the self (Winnicott, 1965, p. 93).

The child learns to understand that his mother and father have an existence independent from him, in that they are not under his omnipotent control. Seeing that these adults have indeed survived the baby's rage and destructive fantasies constitutes an important step towards his distinguishing between fantasy and reality. In a radio programme for the BBC, Winnicott provided the following explanation: "If a baby cries in a state of rage and feels as if he has destroyed everyone and everything, and yet people round him remain calm and unhurt, this experience greatly strengthens his ability to see that what he feels to be true is not necessarily real, that fantasy and fact, both important, are nevertheless different from each other" (Audard \& Grosz, 2000, p. 2). We can take these reflections one step further: parents' measured reactions can be a crucial factor in helping their baby understand that his fantasised attacks, rage, and fear that he has destroyed everything are not borne out by reality-that the parents have remained unhurt and loving.

The baby's self-image, too, has altered: "The previously omnipotent I shrinks down to a realistic size," as Krejci (1999, p. 97) sums up. Feelings of grief and longing arise, as well as a wish to restore the object (father and mother) that was damaged in the baby's fantasy. Melanie Klein pointed out the great significance of the capacity for repairing real or fantasised damage. This possibility for grieving and reparations constitutes an important basis for the creative process. A baby who has just pulled wildly on its mother's hair or bit her can then smile sweetly at her or caress her. It is important that parents are able to accept these gestures of reconciliation and reparation and are not so insulted that they turn away-or sink to the infant's level, perhaps even biting back.

Recognition of the special closeness existing between his two parents also strengthens the baby's acceptance of his own psychic reality. Already quite early, during his first year of life, the baby makes clear he wants undivided attention from both his mother and father. Simultaneously, he begins to perceive the special quality of his parents' relationship, and attempts to place himself between them-often quite demonstratively-establishing himself at the centre and separating 
them from one another, if only by inches. Bion sees a child's ability to view his parents as a sexual couple as an important model for bringing together divergent elements in thought, giving rise to something new.

\section{Feeding, nursing, and weaning}

The baby's heightened interest in his environment-both audible and visual stimuli-also alters the nursing situation. The baby is now more easily distracted by movements and sounds. Many mothers experience this new factor as emotional rejection: suddenly, it seems everything else is more important to the baby than them. At the same time, eye contact during suckling and the baby's grasp on his mother's sweater or fingers can now become more intense. Many mothers worry whether they have enough milk for their baby. Earlier, it was recommended that mothers pump out some of their milk, as if the needs of mother and baby could not reliably balance each other.

After four months, the baby is able to ingest nourishment other than milk. Eating from a spoon calls for new abilities: taking solid matter into the mouth and then swallowing it, instead of merely sucking. This enterprise is at first unsuccessful, and must be practised in small steps. As a physical capability, it parallels a new emotional independence on the baby's part.

The father, who was almost completely excluded from nursing, can now assume an important position in feeding. One father who had already longed to give his son nourishment offered him a spoonful of baby food, on which the baby sucked slowly, then suddenly fell asleep in mid-feeding-just as he had during breastfeeding, something that made the father very proud. For his parents, feeding the baby solid food represents a farewell to the exclusivity of breastfeeding, a step in the direction of the child's ultimate independence.

The question of weaning

There are a great many different forms of weaning, ranging from an almost casual lessening of meals at the breast to an abrupt stop. There is no form of weaning that is a priori correct; each baby-mother pair develops the form that suits it. Sometimes a mother believes her baby is weaning himself, in that he shows a decided affinity for solid food 
and wants the breast less often. Experiences the mother herself had as a baby are kept alive through memory and feeling, determining her behaviour at such a deep level that they are hardly accessible to her consciousness. If these were happy experiences, they set ostensibly "instinct-secure" behaviour into motion, and the mother will have little problem in adapting to the baby's wish for more independence and less dependence on the breast, thus weaning him in stages. One mother related that her daughter almost imperceptibly started eating more and more solid food-but she nevertheless consciously kept on breastfeeding her in the morning and evening for several months, since the activity of nursing was so important to both of them.

Mothers whose own mothers had great problems with nursing and weaning have a very different experience. B entered parent-small child therapy with her son, almost two years old, because of her problems weaning him. She said weaning had also been difficult with her older daughter; she ended up going to her own mother's for three days, during which she weaned her daughter "while my mother and I took turns carrying around the baby". She simply denied her daughter the breast, so that she was forced to drink from the bottle. She and her daughter had suffered greatly under this, and now the mother wanted to do things differently by her son. When I later asked her if she knew how her own mother had handled weaning, she began to cry. "I always had a difficult relationship to my mother. She was convinced that her milk was bad, was poisonous. She breastfed my sister, who died when she was three months old. My mother is convinced my sister died because her milk was poisonous. When I was born, my mother only breastfed me for two months and then switched quickly to bottle feeding, in order to save me. I always ate poorly, which she also attributed to the poor quality of her milk. She didn't even breastfeed my younger sister at all, in order to protect her."

Presumably, the weaning of B's second child stirred up the great burden her older sister's death represented, and her own guilt feelings. At the same time, her mother had conveyed to her that people should solve their problems on their own. A.'s decision to seek therapeutic help indicates her longing for a mother/grandmother figure who would listen to her and take her problems seriously. It was as if she required permission to find out what was best for her and her son.

Weaning constitutes an important step towards maturity-one that can only be accomplished by mourning the corresponding loss in 
intimacy. At the same time, however, it represents the starting point for a new experiential dimension. Consumption of solid food offers the baby a variety of new sensual experiences-different substances with new tastes, colours and forms. Not only the baby's mouth, tongue, and lips are called into play but also his sense of touch. Rice can be made into balls; peas, corn, or carrots can be grasped and rolled. Anna Freud pointed out the link between food and a baby's interest in his excrement. Her advice was to first allow the child to grasp solid food with his hands, respecting his exploratory impetus. "Infants and small children already accompany passive feeding with certain hand and finger movements that indicate an impetus towards activity ... that is focused on handling of the food, playing with it, and spreading it around ... if this is tolerated by the environment, the anal pleasure derived by this contributes greatly to pleasure in eating" (1946, p. 1056). Parallel to this, the mother can also be feeding the baby with a spoon, and later the baby may feed her with a spoon, switching roles.

Feeding can easily degenerate into a power struggle between mother and baby, if the baby's pleasure in eating and his independence are compromised.

\section{Sleep and sleeping problems}

The infant's development also alters his sleep patterns. Between four and twelve months of age, the infant usually has only two sleep phases during the day and can sleep through the night. This applies to a variety of sleep periods-Brazelton (1992) speaks of eight to twelve hours, Daws (1989, p. 11) specifies the period between midnight and $5 \mathrm{am}$. At any rate, this comprises at least two four-hour phases, which also means that the baby has learned to go to sleep on his own if he wakes up. In these phases of light sleep, he might move restlessly, slide to the edge of the bed or cry somewhat, but usually his eyes remain shut. In an investigation (Moore \& Ucko, 1957) it was found that $70 \%$ of three-month-old babies, $83 \%$ of six-month-old babies, and $90 \%$ of oneyear-old babies could sleep through the night. The age of five months seems to be a cut-off point, after which it becomes much more difficult to help a baby with sleeping problems to go to sleep on his own. It is recommended (Brazelton, 1992, p. 103; Spock \& Parker, 1998, p. 522) to develop a go-to-sleep ritual with the baby after feeding - reading to him, singing, caressing him (avoiding, however, active games) in order 
to subdue the baby. Experts advise against leaving a baby alone in bed with his bottle as an aid to going to sleep on his own. Every baby needs to be held and touched during feeding, and in addition, leaving a baby alone with the bottle is quite detrimental to his tooth development; the bottle itself acquires a significance it never would for babies who are held while being fed. If a healthy four-month-old baby is still being fed during the night, this cannot be due to his physical needs, but rather to a learned pattern of behaviour that is preventing him from sleeping through the night.

When a one-year-old baby wakes up in the morning, he is easily able to occupy himself alone-practising his singing, holding conversations with himself, imitating the chirping and crowing of birds.

\section{Developmental history of the children Kelly and Max}

\section{Kelly's development between the fourth and twelfth month}

When she was four months old, there was a major change in Kelly's life, since her mother started to work again part-time. Her maternal grandmother moved in for several weeks until she found a suitable house nearby. The health visitor also suggested giving Kelly solid food, which her mother tried only once, then abandoning the attempt.

Watching Kelly with her babysitter, the observer described how sorely Kelly missed her mother's breast. "Kelly seemed quite uncontrollable in her troubled state and in her desperate search for the breast." Kelly's mother nursed her immediately after arriving home and in the morning after she awoke. The observer interpreted this continued breastfeeding as a compensation for the mother's long absence during the day. But we can also understand it as an indication that both Kelly and her mother had need of the intimacy afforded by breastfeeding - and that Kelly might not yet have a secure inner object of a good mother. Perhaps Kelly's mother also required this atmosphere of peaceful trust that nursing supplied her. Did Kelly perhaps unconsciously know just how happy she made her mother when her need for the breast became so urgent? Could breastfeeding have been providing Kelly's mother with a substitute for the kind of mature sexuality she was lacking? The observer described several instances when Kelly's mother felt somehow rejected due to Kelly's chewing on her teething ring or bib. At these times, she told the observer Kelly preferred these things to the nourishment she 
offered her, and that Kelly might possibly also prefer her father to her. "Kelly insisted on receiving the breast immediately after her mother came home from work." Perhaps this supplied a certain satisfaction to Kelly's mother-that she possessed something nobody else could offer Kelly.

Already from the first time nine-month-old Kelly received solid food, she was also allowed to hold a spoon in her hand, attempting to stick it into her baby food, stirring it, and raising it to her mouth. Kelly was greatly pleased when she became more skilful with the spoon, alternately putting a spoonful into her mouth and then into her mother's. The mother opened her mouth and let Kelly feed her, helping Kelly with one hand to get the spoon in. She exclaimed how good the food tasted. Kelly laughed happily and then opened her own mouth in order to stick her mother's spoon in. Eating can thus turn into an enjoyable game, alternating the roles of "feeder" and "feedee" as with Kelly and her mother.

Here, we see Kelly's mother taking Kelly seriously, accepting her wish to assume the mothering role.

Kelly was also greatly interested in her mother's body. "Kelly plays with her mother's body, she hides her face in her mother's bosom." Later, we read: "Kelly played with little figures in a box, which she opened, putting them in and taking them out."

We can interpret this as demonstrating Kelly's interest in discovering the box's contents-and perhaps also her wish of discovering what her mother's body contains.

In situations of separation, when both parents left the room, Kelly was able to express her feelings clearly:

When both parents left the room, Kelly looked after them with consternation and emitted quick urgent calls, until her mother asked her father to come back. When the father sat down next to Kelly, she immediately calmed down and looked from her father to me.

This description recalls the test administered by Mary Ainsworth, called Strange Situation, where the reaction of one-year-olds to separation from their parents was measured in a laboratory situation. Kelly's reaction would be attributed to a securely attached child. Such children demonstrate their anger, irritation, and fear, and they cry because they 
know their parents will not desert them-trusting them to react to their crying and then return.

\section{Social contact}

Early on, Kelly had to adapt to various adults taking care of herfirst another mother with her own child (Kim) of the same age, later a babysitter. "Kelly is very interested in the other baby ... as soon as Kim came to her, Kelly-who could not yet walk-pulled herself up. In general, Kelly enjoyed the presence of other children and played a great deal with them." Could we see this as evidence that Kelly was stimulated by Kim's presence, starting to walk at the age of one just as Kim did? Through the observation, we see that Kelly can develop and be stimulated by new situations presenting her with new possibilities. That would seem to be a good basis for learning and discovery. In fact, the observer described how Kelly, interested in everything, subjected every object to exact and careful investigation.

"There was also a lot of rivalry. It was usually Kelly-at least in the first weeks of this arrangement with two children-who had a toy in her hand that Kim very much wanted to have. Kim tried to take it out of her hand. At first it seemed Kelly didn't mind whether Kim took something from her. But soon Kelly developed a strong resistance to having these objects taken away, whether it was a book, a soft doll, or a game."

Naturally, Kelly had the advantage of being within her own secure home and was playing with her own toys. She seemed to learn how to assert herself, holding on to the objects that belonged to her instead of crying when trouble arose. She presumably saw Kim as an invader in her kingdom, also sharing the babysitter with her.

Her maternal grandmother was an important person for Kelly; the relationship was described as "warm and uncomplicated". The observer wrote: "I remember how the grandmother came home, picked up Kelly, and read her a book with so much imagination in her voice that Kelly was completely enthusiastic. There was such a difference to the rather insecure attitude of Kelly's mother, who saw it as a personal insult when Kelly would lose her desire to be read to." The grandmother seemed to be a lively woman with a good sense for fantasy, which she shared with Kelly. 
Kelly had many toys and was happy to play alone; she had inner resources she evidently could summon, and her parents gave her room to do so. When she could crawl, she went into every corner of the living room, with her mother remaining in the room watching her.

The sequence where Kelly first moved independently away from her parents is described in detail by the observer:

Kelly crawled away from her mother in the direction of the living room. Before she reached the threshold, she stopped and turned her head in order to look over her shoulder at her mother. The mother smiled at Kelly and looked at her expectantly: "Well, what are you doing now?" she asked. Kelly turned her head once again, towards the living room, raised one hand, and moved one knee carefully forward. In the midst of this movement, she stopped and turned her gaze once more towards her mother, who went on observing her. With an abrupt decisiveness, Kelly changed direction, turned to her mother and crawled swiftly back to her. The mother spread her arms out, waited until Kelly had reached her, picked her up and said laughing: "You're a little escapee!" She gave Kelly a kiss on her hair and took her up into her lap. Kelly cuddled against her mother, but then after a few minutes wanted to get back on the floor to play some more.

This scene shows the attraction the new room she was crawling towards held for Kelly. Yet her glance backwards also expresses fear and the wish to return to the security of her mother's lap. The following week, the observer described how this time, Kelly paused only briefly at the threshold, looking around and then crawling into the living room with a happy squeal. From a fearful little girl seeking protection, she had become an explorer of unknown realms.

Kelly seems to be respected as an autonomous person and encouraged to make her own experiences. She also has a good many children's books, and all three adults like reading to her, thus supplying her with both stimulation and challenge. From the observer's description:

Kelly was a smart, lively little girl, with great attention for her environment. She has blonde hair and blue eyes. She is thin and flexible. She investigated every corner of the room while playing. Her smile is broad and friendly. She has a contagious laugh and sense 
of humour. She found it fun to include adults in her games or have a book read to her while sucking her thumb contentedly. Often, she was absorbed in her play, she sat with great concentration and played.

Her powers of concentration as well as her independence are indicators of a stable personality. Her interest in exploring objects and spaces demonstrate her curiosity and exploratory drive, where she also can carefully integrate her wish to discover inner regions. Both parents seem to have supplied Kelly with a lively environment that draws out her abilities to symbolise and play creatively. Her father, who loves music, often plays or sings to her.

\section{Kelly's development from her parents' perspective}

Kelly's mother emphasises how much Kelly liked sleeping on her sheepskin. "She slept there from the day we got back from the hospital ... and it became her portable bed. Wherever I went, I rolled it up, could put it anywhere on the floor and she went to sleep then ... When she got older, she put the sheepskin over her face and put her thumb in her mouth. She slept that way until she switched to her bed at Christmas."

Kelly's mother understands Kelly's need for a constant sleeping environment and for sucking her thumb when she goes to sleep.

The mother continued breastfeeding Kelly until she was two and a half years old. She related with pride how Kelly rejected the solid food advised for her at four months, and would only take mother's milk.

"I took her everywhere with me. I fed her in the chamber of commerce in London, in train stations, or at professional meetings ... She was never a problem. I put her in a carrying bag. That was what I really loved, carrying her around. That was easy. She could sleep for hours in the cloth."

The long period of breastfeeding seems to have expressly suited Kelly's mother's own needs. Particularly after she had begun to go back to work, she enjoyed this close contact in the mornings and evenings. She was very glad of her employer's offer to return to work, since she had been worried whether she was still remembered there. "I'm sure like many women who stop work for a few months, I was afraid of losing my identity and becoming a baby machine." The employer's offer 
furnished her the secure knowledge that people valued her work and that she did her job well. She was generally satisfied and said: "The first months, as long as everything was going well with my husband, I felt I had it all: my job, my career, my husband. Everything was OK, I felt very good."

This period constituted a phase where Kelly's mother had the impression she "had" everything. She was an admired mother with a husband, a professional career, and a baby that was developing well—exclusively on her milk. She described her mother as a great source of help, someone she could trust overnight with Kelly. She could also appreciate that her husband was of great aid, encouraging her to read and further educate herself. Her life sounds so completely positive, even carefree, that it could represent a victory in hypothetical competition with the masculine principle: she now enjoys both sides-the attributes of both the masculine and feminine principle.

This same period was difficult for her husband. "He had to work a lot, there was the threat he would be out of a job, his mother got cancer and died."

Kelly's father describes this first year as a major change in his life. Particularly since his relationship to his wife had deteriorated during her pregnancy and she also refused him sex for a time after Kelly's birth, the baby now constituted "a new focal point" in his life. He went so far as to suspect his wife wished only a baby, without a husband, and was merely using him. He entertained no ambitious goals for Kelly, instead wishing her to be "self-confident ... I didn't want her to be a daddy's child, but a self-confident, balanced person, who could be herself opposite everything."

He characterised himself as a tactile person, who liked physical closeness. He also liked to touch Kelly, stroking her as a baby and playing with her; he carried her often and was enthusiastic about her development. Being a reliable father was important to him; Kelly should always be able to come to him. He was surprised how much she changed from week to week. As a father, he wished to encourage and further every aspect of her personality.

His opinion was that a baby learns many things through habit, and for this reason rituals and rules should be so strongly developed and established that punishment would not be a necessity. Observing how Kelly found her own ideas for playing and included other children in her games was a source of great pleasure to him. During the observation 
periods he was seldom at home, so that the observer only met with him twice during the course of two years.

\section{Max's development between the fourth and twelfth months}

Max was not an easy baby: he cried a good deal and would wake up several times during the night. Each time he woke he was offered his mother's breast, because she believed he could not otherwise go back to sleep. When he was nine months old, his parents attended a motherinfant counselling in order to grant themselves longer periods of uninterrupted sleep at night. Max's mother was advised to stop feeding him at night, whereupon he managed to sleep for five hours at a stretch.

The observer describes Max at four months in the following scenes:

When I arrived, Max was lying in his corner in the kitchen, somewhat elevated on a pillow, while his mother made dinner. He lost his rattle and complained softly. When I put it in his hand, he lost it again. The mother told me that he could hold things correctly now ... In the next thirty minutes, I was witness to a growing "conversation" between Max and his mother, from piano to fortissimo. Max's mother was cooking and approximately two metres away Max lay on his pillow. Max seemed not to find that too great, but it was bearable and he communicated his discontent in a fashion that absolutely had the quality of sentences, commentary, exclamation, and questions, questions his mother answered every time. In this conversation proceeding back and forth between Max and his mother, Max became more and more frustrated and tense, although he wasn't crying yet. Finally he succeeded in calling his mother over to him. She picked him up together with the pillow, talked to him and put him then in his baby's chair, which was very close to her. Max was now calm and took up the "conversation" again, while his mother kept contact with him with her right foot. But after five minutes, Max couldn't stand it any more, he began to yell in aggravation, flinging his body backwards and roaring. The mother asked him whether he could stand it just a bit longer until she was done. When he continued to cry, his mother took him out of the chair. Max was immediately calm, his world seemed to be in order again. His mother held him at her hip. Max was very interested in her cooking and he observed her every hand movement. 
This little scene shows how responsive Max is to his mother's voice. For her part, she not only supplies him general answers to his "questions" but understands his various sounds as discrete pronouncements, each of which has to be answered in turn. Max apparently wishes to come closer to his mother, but she manages to make waiting tolerable for him. When they come closer and she touches him with her foot, this suffices only for a few minutes, until he manages to completely close the spatial gap between them, then observing precisely all her movements as she prepares a meal for his father. Max's mother provides him with support to endure his small frustrations while the fulfilment of his wish to be as physically close to her as possible is temporarily postponed. In this half hour, his mother grants him attention in a pre-linguistic form, as he practises self-expression through a variety of sounds.

Through several observations, we learn that Max became calmer as soon as his father arrived home.

Max was sitting in his baby's chair when his father arrived home. In the moment Max heard the door open and his parents say hello to each other, his behaviour changed: he sprang to attention. But he continued looking at his mother in surprise, who said laughing: "Don't look at me. Your father just got home," pointing to her husband, who stood before Max and looked at him attentively. Max looked at his father, smiled and answered his father's greeting with a friendly smile.

Max's father does not immediately rush to him, but can wait until his wife points out his arrival to Max and Max can connect the sounds his arrival makes to him as a person. Max also remains calm while his parents converse with each other. As soon as his father leaves the house in the morning, he begins to "chatter".

During another observation, we learn that Max was "... cranky and unhappy, but became completely calm as soon as his father arrived home and picked him up."

In the observation of Max, we can see that on a variety of levels, his mother understands him well and has established contact with his feelings, although she has difficulty retaining space for herself in other areas. Max's mother reports that Max cried through one complete therapy session. She seems to find difficulty in preserving space between herself and Max, and also in enlisting a babysitter's help during her therapy sessions. 
When Max became four months old, his mother began to look around for a babysitter, since she would be going back to work in two months; she taught in a school for children with special needs. In preparation for this separation, Max's mother began to partially wean him. "The mother had no problem switching Max from the breast to the bottle during the day. At six months, Max received three meals a day with a spoon, which he consumed with great appetite. In the night, she breastfed him when he woke up, which was usually three times a night ... Sometimes it was painful to observe how desperately Max sought the intimacy of breastfeeding, while his mother acted as if she did not notice this, or ignored his pulling on her sweater, insisting on feeding him either in his baby's chair or not at all."

This weaning process was also difficult for the observer. During the day, Max's mother seemed to hold firm, but at night she let him have his way, with the result that he never developed a proper sleep rhythm. Only when both parents were exhausted from their fragmented nights did they seek professional advice.

Feeding Max with a spoon is described in detail:

Feeding him with the spoon always happened with Max leaning back in his baby's chair. His mother crouched down next to him on the floor, in a position that didn't always look comfortable. She never fed him on her lap or in any other position until he was eight months old (and old enough for the highchair). The reason to feed him in the leaning chair seemed to have been that that way, nothing would get dirty, since Max could neither grasp the plate nor the spoon. Each spoonful was always already prepared for him before he had swallowed the previous one. Each time, the spoon was put neatly into his wide-open mouth, after it had been "cleared" by the mother putting it in her own mouth "to make sure it isn't too hot".

The mode in which Max's mother chose to feed him reveals her mixed feelings. On the one hand, she would like to afford Max a measure of independence from her breast, on the other hand she prevents him from touching the food himself and putting it in his own mouth. Feeding involves not only the ingestion of nourishment but also autonomy and power. In the position Max's mother adopted, the only possibilities open to Max are opening his mouth and allowing a spoonful of food into it, or else turning his head away. Indeed, it is somewhat confusing for the observer to detect who is being fed, since each spoonful is first 
put in the mother's mouth before wandering over to Max's. The process is somewhat reminiscent of the feeding of birds, where the mother bird first has the food in her beak before it is offered to her chicks: here, Max's mother controls the situation and is active, with Max retaining little mobility in his prone position. As we learn, it is Max who here effected a change through his protests. The observer writes:

When Max was eight months old, he began to protest more and more strongly against his leaned-back position while being fed. Finally his mother countered with the question: "Are you already a big boy?" which marked the switch to being fed in the highchair. During the next months, his mother continued to attempt leaning him back in the baby's chair, but Max finally asserted himself and made it clear he would not tolerate being leaned back and passively fed.

This observation conveys the enormous power residing in small babies craving independence when, through sheer stubbornness and endurance, they eventually make their mothers allow them to feed themselves with their own two hands. A child's own wish to become big and independent is an enormous help in his upbringing. Even when Max's mother attempts to keep feeding him passively three times a day, Max knows how to foil her. He protests more and more vehemently, turns his head away, makes it more and more difficult for her to lean him back, until his mother finally accepts his wish to sit up. Yet, as we can see, the mother continues to devise ways to prevent Max from learning how to feed himself:

His mother tried to prevent Max from playing around with his food by giving him toys to distract him while she fed him. Normally this was a container where wooden blocks could be placed one by one, just as his mother fed him spoonful for spoonful. Feeding seemed to mean distracting Max from what was happening, so that his mother could sneak spoonful after spoonful into his mouth. But Max was often only prepared to open his mouth when he could simultaneously put a wood block into the container.

When Max places his block into the container, he becomes the active party - as if it his job is to feed the container-and only then does he allow his mother to put something in his mouth. 
Max loves to play with water and sand, and spends a great deal of time watering garden flowers with a small pitcher, pouring water in and out of it.

At eleven months, he begins to walk, after enthusiastically making his way from object to object using only his arms.

\section{Max's development from his parents' perspective}

The first three months with Max constituted a major change for his mother: she spoke of a "fundamental transformation in my life, basically very positive, in many areas very positive". Only when Max was four months old and she went out for the first time at night did she notice how she had almost imprisoned herself with him up to then. She said: "I went out for the first time four months after I had Max ... We went to the theatre and I saw all these adults standing at the bar talking to each other. Had that been going on the whole time I hadn't been around? I was completely astonished, as if I couldn't believe that the world hadn't fundamentally changed."

Her inner transformation through motherhood and the new family is so overwhelming that she is shocked how everything in the outside world remained unchanged - as if the world itself would indeed have been transformed because of her new child. This confirms how deeply rooted her fears of bearing an unhealthy, unhappy baby and of being an unfit mother must have been.

This point in time, when Max became four months old, was also the time when Max's mother began to consider what her return to work would be like. Originally, she wanted to immediately take up her full work schedule, but after her actual experiences with Max, she preferred not to leave him alone that often and was able to arrange her teaching for only two mornings a week. She found a very nice woman, almost fifty, who herself had an eleven-year-old boy and whom she described as "motherly". "She was a warm, wonderful woman and I felt very safe in leaving Max with her. When she quit after a year, I was very upset ... I wanted her to stay on." The therapy Max's mother was undergoing at this time helped her acknowledge her own longing for a mother figure-not only for Max, but also for herself-and thus find a suitable person. The relationship to her mother remained quite tense. (The relationship to the babysitter she later found, a German woman, turned into something of a friendship.) 
Max's frequent crying and yelling seems to have had a physical basis: he was thought to have a chronic bladder infection. "He was susceptible to illness. From the age of six weeks on, he constantly had a cold, with difficulties breathing. He breathed so loud and snored so that we couldn't keep him in our bed, because I couldn't sleep." The first year was fraught with worries over Max's health. The actual problem was discovered through pure chance. The mother described this:

During our first visit to Germany, when Max was five months old, he had an accident-he fell out of a narrow bed and we took him to the hospital. And there we found out about his small kidney ... completely by chance. He got antibiotics then, to keep the second kidney uninfected and healthy. Since then it's been OK, he's healthy.

Only after this diagnosis, made through chance circumstances at the hospital, could Max be treated with antibiotics; his urinary tract infections ceased and he then cried less often.

Max had a notably positive effect on the relationship between his parents. The mother described it in the following way: "Max made a big difference. We both had a relationship to him, we both loved him and wanted him to be with us. As if it had taken him to give our relationship a final form ... We are both very caring people ... And our sex life also became better. It is truly astonishing, there are all these terrible tales of people who didn't have sex any more after the birth, that after the birth everything was gone. With us, it was much better ... After the birth, after a month, we carefully had sex. I felt much freer. That was a big difference to my girlfriend, who needed a few years to be herself again. I felt I came back to being myself very quickly."

Regarding this important subject-the difficulties many couples have revitalising their own relationship after the baby's birth-it is significant that for his parents, Max constituted an enrichment of their connubial relationship, and that their joint relationship with him created a new, fascinating bond of common experience. Max's mother was in psychotherapy during his first year, and this seems also to have helped her reduce some of the tensions arising from her cramped, guilt-laden relationship to her own mother, and live her own life.

Joint worries over Max, who was a relatively difficult baby, seem to have been handled by the couple in a harmonious fashion. "My 
husband wanted to participate in mothering Max. It was as if we asked each other: 'Can I hold him now?' But there were also times when we both had had enough, when we had to get up ten times during one night."

Max's mother's ability to let her husband participate in caring for the baby apparently created an additional bond between the two parents.

She described in detail how the two of them solved the problem of Max's waking up three times within one night:

When he was nine months old, Max still was waking up three times a night, and because of that we went to a sleep clinic. They said more or less that he had gotten used to being taken out and being carried around for going to sleep and that he didn't know how to go to sleep on his own. We took the work away from him, so to speak. So we introduced a strict program, staying with him, but having him fall asleep by himself. We put him in the crib, he screamed as if he would never stop ... We stayed in the room and spoke a little bit so that he knew we were there but wouldn't help him. It was difficult, we felt we were being cruel.

This course of training proceeded excellently, and after one week Max could go to sleep on his own. His parents only felt able to leave him to his own devices when they acknowledged that they had actually been performing a service for him he should learn to do for himself. Since carrying him around and feeding him had become a fix point during these nine months, all parties experienced the change in this pattern as painful.

Max's father emphasised the difficulty of Max's first six weeks, when both parents were exceptionally tired since Max cried so often before his kidney and bladder problems had been diagnosed. His kidney had presumably often been inflamed, although both parents had attributed his high temperature to colds. Max was a restless child. His father changed his nappies often and enjoyed doing so. For him, having a child meant a form of confirmation: "I had my work, a constant work that extended over many years. Now the child was there and I thought, the most important elements of my life make sense together." The great satisfaction Max afforded his father also seems due to his feeling that he had metamorphosed from a sterile man into a fertile and successful 
father. The news of Max's kidney defect was so shocking because Max's father feared that Max, who made him so happy, could now be taken away from him. He became aware of his own fragility and vulnerability; aside from anything else, Max was his only child.

Both parents seem to now love each other all the more, and feel more gratitude towards one another, since the father also views his wife as the mother of his son and she him as father of her son.

These descriptions from family observation will now be followed by additional examples: Julian, from a young-child/parent therapy, and Malcolm, who only entered analysis at the age of nine, but whose first year of life was replete with trauma.

\section{Developmental history of the children in therapy}

\section{Difficulties in the parent-child relationship: Julian}

A prominent psychoanalyst, Annette Watillon-Naveau (2001, p. 24 ff.), has described therapy for a family with a small baby: Julian and his parents.

"He was five weeks old when his parents turned to a therapy, since he was always crying. Julian was sleeping in his Maxi Cosi when his parents put him on my couch. The mother took off his jacket and the baby opened his eyes. In the night, he slept six or seven hours in his parents' bed, but during the day he dropped off now and again for ten minutes. He was breastfed five times a day, he would wake up then and could scarcely be subdued although his mother tried everything, carrying him around and rocking him. When she had finally calmed him and wanted to put him back in his bed, he started desperately crying again. She couldn't even manage to take care of her own needs such as eating and dressing herself. While the father was describing Julian's difficulties, Julian remained calm. But when his mother again began talking, he started to whimper. Then he gave a shrill scream. The therapist said she had never heard such a shrill, penetrating cry before, and showed great concern. She told the baby she saw how he was suffering. Then the mother stood up and asked if she could take Julian out of the room, whereupon the therapist answered that the mother would know what was best for her baby."

Julian stayed on his mother's arm for the whole hour of therapy, crying sporadically. He was a baby his parents had most definitely 
wanted to have, and the birth had proceeded without incident. Seven years earlier, the mother had had a miscarriage. Three years earlier, another baby, a girl, had died shortly before being born due to a pulmonary oedema: she was suffocated in her amniotic fluid. During the pregnancy with Julian, his parents made sure to have the amniotic fluid examined, thus calming their fears. After Julian's birth, his mother was convinced that some calamity would befall him. The therapist interpreted: "As if you had no right to a living baby?" "Exactly," answered the mother. "Exactly, I don't deserve one." When the therapist enquired why she felt that way, the mother told a long story of two earlier abortions. She saw the first of these as justified, since although she had already known her husband then, she was still very young. The second abortion, however, was the source of much self-reproach. Her husband was not yet divorced at that point, and that was why they decided to postpone having a baby.

Her mother had compared Julian's penetrating cries to the cries of a person drowning. Julian's mother immediately made the connection to her daughter's death: she could imagine what it had been like for her baby to drown in amniotic fluid. She added that she had long ago forgotten this and only just now thought of it again. The therapist suggested considering whether Julian's crying could have some connection with the death of her daughter. The mother answered: "Sometimes, when I look at him, I see the face of the dead baby in the facial features of my son."

In that same moment, Julian stopped crying, became relaxed, and went to sleep in his mother's arms. His mother also became calmer and seemed somehow to soften. Julian's crying then diminished and disappeared within the next few days.

\section{Discussion}

In this case study, the therapist describes a young mother who had been unable to work through her unconscious guilt feelings and fantasies of punishment for her two previous abortions. Presumably, the death of her daughter inside her own body confirmed her expectation of deserving punishment. Since these feelings must have been unbearable for her, she was unable to reflect consciously on them, instead projecting them onto her son, Julian, who collapsed under this burden and cried. Only during the night, while his mother was also sleeping, could he 
relax and sleep himself. During the day, he was apparently bombarded by his mother's unconscious projections. His grandmother and the therapist recognised the unusual character of Julian's cries and could describe this verbally. By understanding and working through these terrible feelings once they were expressed, Julian's mother could then also discuss the previously inaccessible feelings she had regarding her two abortions.

This phenomenon-that small children show a direct reaction when their mother is given a hearing during therapy and her fears, aggressions, and desperation are addressed-is encountered frequently. A young boy, Robin, who was also clinging to his mother, only then left his mother's lap and played when she described her sorrow at the inexplicable disappearance of her father when she was thirteen years old (Diem-Wille, 2000). For this reason, I like to speak of small children in parent-child therapy as "catalysts", because they render visible major problems their parents bear with them (see here Watillon-Naveau, 2001).

This clinical material shows the therapist putting her observations of parent-baby interaction to use, sharing them with the parents and thus enabling them to see their baby through a fresh perspective.

One example of this was a mother who went into therapy with her baby because he constantly wanted to be fed; during a session, the therapist observed how she interrupted the baby's calm, concentrated playing to practically force a bottle into his mouth (see Dornes, 1997). It took the mother's astonished acknowledgement of this observation for her to see that the real problem lay in her own distorted perceptions. She had been truly convinced that the baby was hungry. Afterwards, she could discuss the hunger she had as a child for the attention her mother was not able to grant her.

I would like to offer another example demonstrating how an early problem in the parent-baby relationship can manifest itself only later, when the child is nine years old, making it far more difficult to resolve than when it actually arose in the first year of life.

\section{A battered baby: Malcolm}

Malcolm's mother was informed by his teachers and day-care staff that his aggression and impudence was intolerable. He was fighting 
with the other boys, and once even pushed another child in front of an automobile that could only brake at the last minute.

When his mother appeared for a preliminary session with me, she had the air of a lost little girl who needed help. She told me her nineyear-old son, Malcolm, was the oldest of three children. At home, his behaviour veered between fearfulness, nightmares, and aggressive, brutal treatment of his two brothers. He would wake up during the night screaming, unable to pacify. He dreamed of an all-consuming monster. In a drawing test, he depicted himself as a small rabbit. As a baby, he very often cried, and his father believed the mother was spoiling him when she picked him up. She herself had been very young when she had Malcolm, with little notion of babies. The father already beat the baby brutally at the age of four months, shaking him and hitting him against the wall. He also beat her. After a hospital stay, she reported her husband to the police; her husband went to prison and was subsequently deported to his native country. When she later visited Malcolm's father, Malcolm screamed and cried each time the father came into the room, running for protection to his mother's arms. This conduct provoked the father, who tried to exorcise Malcolm's behaviour with more blows. The mother then returned to London. During reconciliation some months later, she again became pregnant and returned to England, where she had her second son when Malcolm was fourteen months old. Her third son was by another man from the same country as Malcolm's father. After his return to London, Malcolm was unable to eat, in fact unable to swallow; he struck out around him and was generally disruptive.

In the first two therapy sessions, Malcolm was an eager boy, wanting immediately to play with the toys there as if he might be taking some kind of entrance exam. He impressed me with his swift powers of comprehension and his ability to express his feelings. In drawings, he depicted his family as flowers-his mother, himself, his brother, and his little brother. Then he turned the paper over and drew a row of monsters holding hands. When he attached the drawing to the window, the monsters could be seen through the friendly flowers showing what monsters are hidden behind the friendly surface. He said: "That's my family." In response to my interpretation that behind the friendly flowers appeared the monsters who threatened him at night, he agreed. He seemed relieved that somebody could see both these sides at once. 


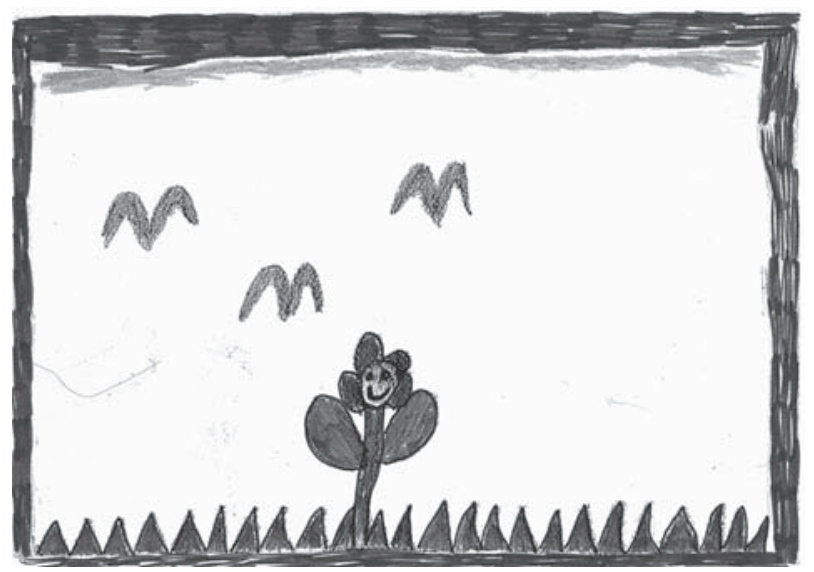

Figure 5a. Malcolm's drawing of his family as a friendly flower.

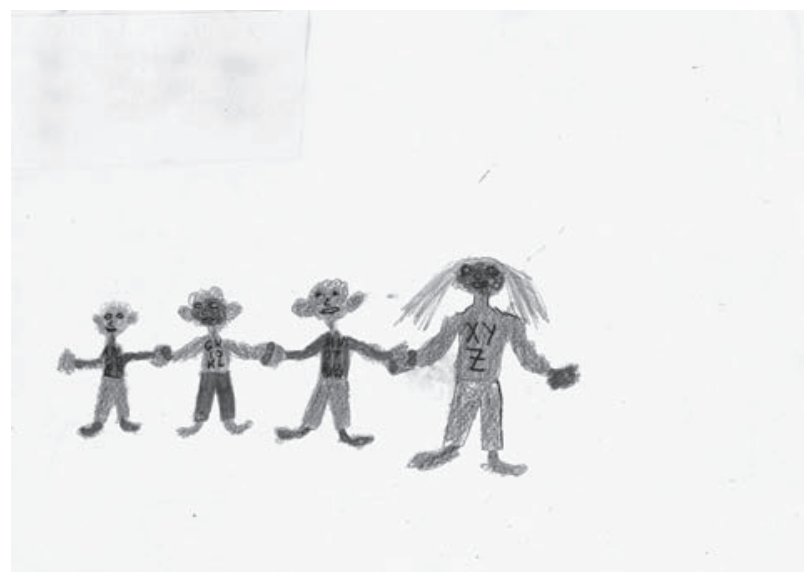

Figure 5b. Malcolm's drawing of a row of monsters holding hands.

Malcolm showed that behind his uncontrollable destructivity and violence there lay helplessness and fear, often causing him to sink into apathy and dejection. According to him, therapy would be a good idea since he often had problems breathing in the springtime.

The therapy took a dramatic course. Almost as soon as Malcolm could see he had a secure place here, his cheerful façade collapsed. He sat with his head on the table as if turned to stone. My understanding of how desperate and lonely he must feel and how withdrawn he was, 
since he had virtually no hope anyone could understand him, broke through to him. He believed that instead of forty minutes, only fourteen had passed.

After this, there came a phase where he fought to possess me exclusively for himself. He demonstrated great jealousy of all other children, and wanted to lock me up in my office, sealing the doors shut, keeping me in chains until he came back the next day. At the same time, he executed an artful series of splits: he jumped around on the couch, performing somersaults and other daring feats, to excite my admiration and express his erotic desires for me.

Already after the first week, Malcolm's mother could observe a great change in him. He learned well at school, receiving only high grades. At day-care, there were no more complaints.

In therapy, however, his violence increased, due on the one hand to the separations from his analyst at the weekends, on the other hand to the fact that his mother now had a new boyfriend, who had moved in to their apartment. The couple's very visible and audible sex disturbed and excited Malcolm. He jumped on the couch until he was covered with sweat, wanted to take a shower in my office to wash his "dirty feet". Before our Christmas break, he fell into a rage, marked up the entire wall with brown crayons, writing derogatory words such as "handicapped", mocking and insulting me. His confusion between sexuality and violence was also reinforced through outer impressions, since his mother's new boyfriend had now been badly injured in a knife fight and was currently in intensive care. When disappointed-such as when he had forgotten the cable for his Game Boy in the bus-he collapsed, crying like a three-year-old child, inconsolable and determined to run away.

At home, there emerged a new phase where he became depressed and said he would prefer to go to a children's home. He asked his mother why she had had him at all; he saw his life as dark and hopeless. At the same time, his performance at school remained excellent, and there were no disciplinary complaints.

Then, there began a phase where he tried to provoke me to hit him. He made huge holes in the wall using a chair, scratched the doors up with scissors. He rejected my interpretation that he wanted me to hit him the way he himself had been earlier hit. He also could not feel his own rage, saying, "No, I'm happy" as he raged on, until I took the destructive objects away from him. His destructivity escalated; at first, 
it had an erotic component, since he forced me into physical contact as I took the scissors out of his grasp. Later he was like a madman, completely deranged: he destroyed not only his toys (the ruler, his beloved cars, his ball, his block) but also furniture - a chair, a standing lamp in the entry room, the light switch. His toys were ruined. I had to put the wooden building blocks away, after he tried first to break the windows with them and then to throw them at me.

When Malcolm's mother came to me with her new boyfriend during this phase, Malcolm became sick, he vomited, and had diarrhoea (without, however, fever), because he was so afraid that I would discontinue treatment of him and inform his mother of his rages with me. The mother's boyfriend was completely astonished at how Malcolm had been able to change. He was convinced that Malcolm would become emotionally inaccessible in one or two years. The mother felt guilty because she had been unable to protect Malcolm better during his first two years. After this, Malcolm turned friendly and grateful. Presumably, he had never experienced that anyone had not complained about him to his mother. But when I prevented him from destroying the other children's drawers, he again fell into a rage. His aggression mounted, he wanted to strike me with a cushion, and became uncontrollably furious. His face was full of cold hate, his movements like a ritualised orgy of blows. I was supposed to experience how he had felt back in the time when he was beaten and tied up. Like a wild beast, he screamed, "I can't speak" and raged on. He spat at me, sprayed me with water, wanted to flood the entire room, was beside himself when I interpreted to him that he wanted everything to have his smell. He also broke his own drawer; the few toys remaining to him were now contained in a plastic bag.

Now I was the one who was afraid before every session, who had no idea what he would do next. He was completely unpredictable. I confronted him with his destructivity and offered to help him reflect on whether he wanted to destroy his therapy here or give himself a chance to let me help him. Very impressed, he whispered: "I only have a very tiny chance."

This session constituted a turning point. He tried to funnel his aggression into playing with the Game Boy, and asked for new toy cars. When I gave him four new cars, he was visibly moved. It was now possible to reach him emotionally and address his fear of what would happen if he completely lost control of himself. He could no 
longer remember what he had done when he was in his rages. He said, "Yes, once, when I didn't want to leave at the end of the session and you made me go, I flipped out." He had seen and experienced how his mother preferred men who were "wild". Her current lover was tender, but also often wild: he sometimes pinched her, so that she ran away shrieking. Malcolm had expected I would like him when he was raging and unpredictable.

\section{Discussion}

In his first year of life, Malcolm was abused physically_beaten and tied up-and presumably also verbally. He had no stable good inner object. His floods of fear, hate, helplessness, and lust for vengeance are still at a primitive level: he can neither express them in words nor symbolically. He then becomes the evil, punitive, torturing father whom he so fears. His mother also hit him, since he cried so often. When he himself becomes the violent father, I am meant to experience the feelings he had as a beaten, tortured child. At the same time, he feels himself responsible for the failure of his parents' relationship, consequently behaving in such a way that he must be punished. Only the emotional connection to me as his therapist and his wish to possess me exclusively for himself clear the way for his recollection of a positive inner object and his need for contact-which nevertheless only surface sporadically. The derision and mockery he heaps upon me are something he often experienced himself when he was made fun of as a foreigner, black, or a "stinker" on account of his dark skin and kinky hair.

Presumably, both parents were overburdened by their own emotions after Malcolm's birth and could not work through their own feelings of rivalry. Malcolm's mother was the oldest of three children their mother had had at short intervals. After ten years, Malcolm's mother could no longer stand her family and simply ran away, growing up with her father and stepmother-who rejected her from the beginning. She hardly had contact any more to her own mother. She became pregnant because she was "naïve" and wished to leave home. Malcolm's father was passionately in love with her; he was a musical person with a zest for life, a marvellous dancer. When he was jealous, he reacted furiously, forgetting everything and striking out around him.

Malcolm's father came from a family with ten children. He was the oldest and was beaten often and brutally by both parents. Most of his 
time was spent with his grandmother. He could not bear watching when Malcolm's mother affectionately nursed the baby or carried him around. He demanded she leave Malcolm alone when he cried, ostensibly in order not to spoil him, but in reality because he was so envious that Malcolm had a mother who cared for him.

In this case study, we see how deep a mark the wounds of Malcolm's maltreatment left on him-so deep that he felt unsure whether he could put his "tiny chance" to use.

\section{Theories on the psychic development of the baby}

The following discussion aims to link everyday experiences with small children to psychological theories on the earliest developments in young children. This overview of the most important psychoanalytic developmental theories is meant above all for readers who wish to put the theoretical concepts they are already familiar with into a context together with other theories. Thus, I will try to describe the four basic theoretical positions on their own terms, in order to then present mutual criticism from other standpoints.

This book seeks to consider a variety of lesser-known investigative approaches to the first years of life. In addition, I wish to provide an informative overview of various concepts that further a deeper understanding of the mother-infant relationship, as well as the genesis of the psyche during infancy.

Various ideas regarding the existence of a baby's personality bear not only a theoretical influence but also affect daily behaviour. The mother's experiences during birth are marked by implicit assumptions she has concerning the new baby. Does she already attribute to him a personality? Or is he a bundled object that can be put down and picked up according to convenience, without its feeling anything? The mothers' description of the births of Kelly and Max show how important it was for them to have their baby physically close to them, becoming acquainted with this new person, investigating the baby's body, caressing the baby and simultaneously checking that every physical feature was completely formed. Max and Kelly were greeted as persons and given a decisive welcome. In contrast, descriptions of obstetric practice in 1950s US hospitals depict the baby treated as a bundle-cleaned, examined, and separated from his mother, as if the mother and baby had no need for physical contact with each other. The baby was handled 
as if he had neither feelings nor sensibilities - as if adequate treatment consisted in bringing him to be fed every four hours.

If we consider attitudes towards children through various historical epochs, a depressing picture emerges: infanticide, restriction of infant movement through various devices, child beating, sexual abuse, and routine separation of the child from his parents (Badinter, 1980; deMause, 1974). It would exceed the limits of our study to examine in detail Badinter's problematic thesis-that "mother love" only emerged as a concept in the final third of the eighteenth century, since previously, upper-and middle-class children were handed over to the care of nurses (1980, p. 113).

As opposed to other animals, the human mother and baby look at each other directly after birth. The child's searching look meets his mother's (or father's) eyes, establishing contact from a being that reacts to stimuli, drinks at the breast, and can be pacified by his mother's voice. The mother and father look at their child, caressing him and speaking to him as if he can already understand them. The infant's ability to express feelings physically is inborn. His parents attempt to understand and interpret these expressed feelings, thus employing a concept of a You: a being with whom they interact, whose reactions they comprehend as a kind of answer to the attention they turn to him. This first "conversation" with the newborn baby, generally considered by the layman a normal event not in need of special interpretation, has led to a variety of concepts in psychological analysis.

Since 1930, several important psychoanalysts in the Anglo-American countries turned their attention to early developments in the first years of life. In London, Melanie Klein's work with very young childrenfrom two and a half to three years-led to the formulation of important assumptions concerning the emotional development in the first year of life. In discourse that became quite heated after the death of Sigmund Freud, disciples of Melanie Klein and Freud occupied themselves with the varying theoretical concepts on personality development in the first year of life as well as with varying techniques of child psychoanalysis ("Controversial Discussions", King \& Steiner, 2001). ${ }^{1}$ In a psychoanalytically oriented infant observation according to techniques developed by Esther Bick, child therapy trainees attempted to observe infants in their natural environment-within their family and in the interaction with their parents-over a period of two years, in order to study their development. Winnicott, a member of the "Independent Group"2 
between Kleinians and Freudians, was also involved in this discourse, developing several notable contributions, for example, the concept of a "transitional object". Bowlby was more strongly oriented towards a biological concept of development centring on the emotional "attachment" between mother and infant, with particular attention given to experiences of separation, death, and loss in the parents' own lives.

The results of René Spitz's empirical research on the early years of life revolutionised the understanding of infant care and orphanages. In a study published in 1945, he demonstrated the emotional deprivation experienced by orphanage children who were only cared for physically, without being given the opportunity of building a stable emotional relationship to one caregiver. He called this phenomenon the "hospitalism syndrome", something that could lead to a child's death. In his essay "Hospitalism", Spitz focused on the child's expressive affect in the second year of life, such as social smiling, or the "no-gesture", which he saw as manifestations of advanced structural development as well as the ongoing integration of previous behaviours.

In France, a line of research developed around Lebovici (1983) leading to a mode of mother-baby analysis where the unconscious projections of the mother onto her infant could be examined. This approach was further developed by F. Dolto (1984), Eliaheff (1994) and Szejer (2000).

In the USA, Freud's concept of "primary narcissism" was extended, in particular through the theory of "symbiosis and individuation" developed by a group centring on Margaret Mahler. Selma Fraiberg, in Ann Arbor, Michigan, concentrated on research into the first relationship between mother and infant, and developed her own mode of parent-child therapy with deprived mothers and babies which she called "psychotherapy in the kitchen" (1980).

New impulses can currently be found in the empirical infant research centring around Daniel Stern, Brazelton, and Craemer, which has led to new insights through videotaping of infant activity.

In Germany, Lichtenberg and Kächele are prominent examples of researchers who attempt to provide empirical evidence for infant activity, summarised by Martin Dornes in the well-known book Der kompetente Säugling ("The Competent Infant"), 1993.

In my explanation, I will try to make effective use of important insights from varying branches of research, aiming to understanding the infant's early relationship to his primary caregivers, mother and 
father. The sometimes considerable controversies in the field are only mentioned briefly in order to demonstrate the varying range of the theories.

Among these aforementioned positions, there is lively discussion concerning basic concepts and their relevance to psychoanalytic practice; a distinction is made between a "clinically reconstructed infant" (through free association in a psychoanalytic setting) and an "observed infant" in empirical research.

Psychoanalytic theories do not comprise a closed system: although they are all indebted to the same roots-the basic assumption of an unconscious, of multiple motivations for one behaviour, the great significance of the first years of life, and the ambivalence of feelings-they differ in how they describe individual phenomena in language. In some cases, there exist differing conceptual descriptions for the same phenomenon. Sometimes, insights and clarifications are formulated from a particular perspective and then find broad recognition. The reader who is less interested in various theories concerning the first phase of development can proceed to the following chapter.

The attempt to comprehend a newborn baby's psyche on a theoretical level has led to a widely divergent range of theories and hypotheses. Researchers are in agreement that we can only attempt to form plausible assumptions, since there is no direct access to the subjective experiences of newborn infants and conclusions can only be drawn from their observed behaviour. I will here outline the four most important concepts.

All the varying concepts regarding infant development during the first three months agree in one respect: one point in time-two to three months after birth-is regarded to be of key significance. In addition, all theorists agree that nobody can know what an infant experiences: scientists and researchers can only develop theories and assumptions, furnishing them with a plausible basis. Even the most exact observation-whether through an observer's eyes or with the help of video-cannot supply a direct view into an infant's feelings, sensibilities, and perceptions. It is only possible to draw conclusions from the infant's observed behaviour regarding his ostensible feelings. In particular, there are divergent views on the significance of aggression, as well as the infant's ability to enter into relationships with others.

I wish to describe here the most important divergences among four concepts, ranging from Melanie Klein (the British psychoanalyst), 
Anna Freud, Daniel Stern (empirical infant research), and John Bowlby (attachment theory). In order to make the various standpoints clear, a certain amount of schematisation is unavoidable. This short explanation is intended to have an introductory character into various psychoanalytic theoretical traditions, motivating the reader towards further and deeper study.

Primary narcissism and symbiosis with the mother in Sigmund Freud, Anna Freud, and Margaret Mahler

Trying to formulate Freud's psychoanalytic concept of development for the early years of life, we soon see that his psychoanalytic theory does not constitute a closed, consistent system, but that he continually modified and developed "models of the psychic apparatus" his whole life. Joseph Sandler and his co-authors divide this process of conceptualisation and modification into three phases (Sandler, Holder, Dare \& Dreher, 1997). In the first phase, Freud proceeds from an affect-trauma theory, where he assumes an actual traumatic event occurred during childhood (a seduction) that constitutes the root of neurosis (Freud \& Breuer, 1895d). Instincts, along with their vicissitudes and defences against them, later acquired more meaning for Freud (1915c). In the second phase, Freud proceeds to a topographical theory, further developed through dream interpretation, the "royal road to a knowledge of the unconscious activities in the mind" (1900a, p. 608). He differentiates between the unconscious, preconscious, and conscious systems, the dynamics of which originate from instinctual drives and wishes acting "from the inside out" in the form of fantasies (1900a, 1905d). The third phase is centred on the two drives Eros and Thanatos (death instinct) $(1920 \mathrm{~g})$ together with the structural theory of the id, ego, and superego (1923b). In Freud's discourse, the conflicts and compromises between these three psychological systems are now brought to the fore.

Freud bases his theory on three sources: clinical experiences from his analytic work with patients, self-analysis, and literature, including myths of "primitive peoples". His clinical experience and self-analysis lead him to the basic tenet that sexual desires are an essential impetus for psychic events. He proceeded from a broad understanding of sexuality he called "psychosexuality", denoting sensual pleasure, originating from various body zones or organs. Freud calls the energy underlying sexual or sensual pleasure "libido". Personality development depends 
on psychosexual development-the way we deal with libidinous desires, blocks, and conflicts. Freud worked with adult patients and did not undertake any systematic or continuous observation of children or infants. Although according to Freud, the way a three-year-old child (and his parents) handles the oedipal conflict constitutes the core of neurosis, he emphasised the central significance of the early, "preoedipal" years of life. The significance of the mother as first love object, also determining the basic pattern of personality and quality of later love relationships, is also emphasised by Freud in several of his written works.

Freud's writings on development during early years of life stem from his second and third phases. He discusses the first year of life in "On Narcissism: An Introduction" (1914c), written during this second phase. The concepts of narcissism and object love, however, later evolved into a much more complex form, with the important factor of identification now extended; this later made possible a modern conceptualisation of borderline and narcissistic personality disorders (Sandler, Holder, Dare, \& Dreher, 1997, p. 142). ${ }^{3}$

The idea that not only the object but also the subject can be libidinally invested (cathected) is formulated by Freud in his "On Narcissism". Freud assumed that a state of primary narcissism (love of oneself) was predominant in the baby well before object love comes into being. The deriving of sensual enjoyment is practised at first through auto-erotic activities at erogenous zones, predominantly the mouth and lips. Freud writes:

At the dawn of psychic life, the ego emerges furnished with drives, and partially able to satisfy those drives on itself. We call this condition the state of narcissism, the possibility of autoerotic satisfaction. The outer world at this time carries no interest and is seen indifferently as regards satisfaction. Thus, the ego merges with sensuality, the outer world with indifference. (1915c, pp. 134-135)

The "purified pleasure-ego", as Freud called it, is cathected with the baby's entire libidinous energy. "Originally, at the very beginning of mental life, the ego (self) is cathected with instincts and is to some extent capable of satisfying them on itself. We call this condition 'narcissism' and this way of obtaining satisfaction 'auto-erotic'. At this time the external world is not cathected with interest (in a general sense) and 
is indifferent for purposes of satisfaction. During this period, therefore, the ego-subject (self) coincides with what is pleasurable and the external world with what is indifferent (or possibly unpleasurable)" (1915c, pp. 134-145).

Object love is here understood as the investment (cathexis) of the object with the subject's libido. To love a person is described as the libidinous investment of that person (the object), but Freud thereby implies that the image of that object or its recollection is invested with energy - thus already entailing a form of psychic representation. A portion of the subject's libidinous investment is applied to the object and the object is included into the subject, which is illustrated by Freud in his image of the amoeba. "We can thus formulate the image of an original libidinous investment of the ego, later transferred to the object, which however remains basically where it was and stands in relation to the object investment as the body of a protoplasmic organism does to the pseudopods it has emitted" (1914c, p. 76). Nevertheless, there remains a "residual narcissistic investment" of the subject, and therefore a balance is preserved-similar to the image of a joint container: "... the more of the one is employed, the more the other becomes depleted" (ibid.). In a variety of situations, such as the state of being in love, the object is invested with an excess of libido and the subject goes hungry. With paranoia, the investment of the outer world and objects is reversed, and flows back into the subject's own personality, a state characterised by Freud as "narcissism". Megalomania is thus not a new phenomenon in the subject's life, but an enlargement or extension of a previous condition.

Freud describes primary narcissism as a phase preceding both the formation of the ego and the object relationship, and characterised by auto-eroticism. In order to hold conflicts at bay, the baby employs a kind of filter blocking out irritation and overwhelming stimuli. Freud was also of the opinion that narcissism and psychosis are rooted in a developmental stage that precedes a mature object relationship. The infant seeks the satisfaction and pleasure his mother's breast can provide. If this is not available, the infant can seek it —at least in the short term-in "hallucinatory wish fulfillment" (Freud, 1900a, p. 539), by remembering satisfaction already experienced during nursing and appending that to his state of need. Freud also spoke of parents who not only reanimate their unfulfilled desires through their baby but also seek to actually fulfil them through the baby. 
Although in Freud's second phase-his topographic theory-the subject's behaviour and experiences were considered to be products of instinctual wishes from the unconscious, then modified and censured upon their emergence to the surface, the third phase-his structural theory-lends more weight to outer reality as hindering or displacing the expression of drives.

Clinical psychoanalytic experiences from his work with patients caused Freud to undertake modifications in his topographic model, which then led to a new concept-his structural theory-in his The Ego and the Id (1923b).

Freud assumed that only after an infant is six months old can we speak of his having an ego. One portion of the id undergoes modification and becomes the ego, whose primary function is self-preservation and the acquisition of the capacity to simultaneously adapt to the pressures of the id and the superego, and the demands of reality. The ego assumes the function of delaying instinctual discharge and of controlling it by defence mechanisms. The third agency, the superego, was seen to develop as a sort of internal residue of early conflicts with authority figures (father). It transports parental and cultural values, and the child's own ideals. A large part of the superego and the ego, and all of the id, were seen as functioning outside consciousness. Previously, the baby only had access to a filter defending him from unbearable stimuli, a protective shield ("Reizschutz") (Freud, 1920g): it reacts exclusively according to the pleasure principle, in that it seeks satisfaction and functions according to the primary process.

I have already pointed out that Freud assumes a phase of "primary narcissism" at the beginning of life, preceding the love for other persons, "object love". From the beginning of life, Freud believes, a baby seeks to avoid displeasure and achieve pleasure. He describes the mouth, mucous membranes, tongue, and lips as erogenous zones, activated by drinking but also by "ludeln" (approximately, "pleasure-sucking"). The baby's pulling on his own or another person's ear, carried out with full concentration, serves this same purpose (Freud, 1905d, p. 87). Today, we would attribute the same significance to the skin, which is stimulated through touching, stroking, or other movement, as Montagu (1971) describes in Touching: the Human Significance of the Skin.

In his famous paper Three Essays on the Theory of Sexuality (1905d), Freud supplies a schematic narrative for the typical course the sexual instinct takes from childhood on. To avoid misunderstanding, it is 
important to emphasise that expressions of sexual desire in the child and in the adult are subject to the same kind of modification and evolution as human beings in the history of their species. Originally, the small child has a positive attitude to the products of his body, innocent of disgust or shame. He enjoys displaying his body and is also interested in other people's bodies, not differentiating between genitals and other body parts. Only through the process of civilisation has humanity experienced a shaping of its common affect, and during a child's upbringing he learns to develop a sense of shame and disgust of the forbidden and the hidden. Freud called the child's innate inclination "polymorphousperverse", since the unimpeded interest in excrement, urine, looking at and displaying the human body is reminiscent of sexual practices that have been termed "perverse". The great significance of body excrement, however, is unconsciously preserved by the child who regards his stool as a gift to his mother, or by adults making it a sign of trust to move their bowels in a particular place. Indeed, in normal development these early forms of sexual pleasure remain sources of pleasure, but are later subordinated to genital satisfaction. What is called "foreplay"-tender, loving sexual actions-provides an essential contribution to loving, pleasurable sexual unification. This includes kissing, licking, sucking, gazing and caressing, stroking, displaying, playful hiding and seeking, capture and subjugation. The more both lovers can implement from their fantasies, the more pleasurable sexual confluence can become. When the playful aspect of foreplay is lost, the sexual act becomes a technical act, often a mere performance without tenderness-and most likely a sign of early disturbances.

If developmental phases are fraught with conflict, however, sexual interest can remain fixed in one developmental stage and never attain the mature form of genital sexuality (Freud, 1905d, p. 136).

Freud calls the earliest phase the "oral phase", since the mouth-with its sucking and stimulation of both the mouth's mucous membranes and skin-is among the most important erogenous zones. In the second year of life, excrement and retention of the stool, which then evolves into a significant source of pleasure, become an important theme. The "anal phase" is reflected in the child's preoccupation with expulsion and retention of faeces. Only in the third, "phallic" phase does Freud deem the genital region the centre of attention. In all these phases, all senses — sight, hearing, smell, and taste, as well as touch (i.e., the skin)— participate in pleasure. 
Freud's thesis that small children do not yet know shame or disgust is generally considered valid. His corollary to this-that the evolution of shame and disgust corresponds to an evolution in human historywas deepened by Norbert Elias in his The Civilizing Process (1969). Examining texts containing rules for behaviour by early Renaissance writers such as Erasmus, presented a precis of behavioural rules for eating, drinking, spitting, bathing, etc. as they evolved through civilisation, and then placed this in the context of various political hegemonies. Mario Erdheim (1984) contends that the satisfaction of pleasure is not renounced through strictures of the civilising process, but rather relegated to the unconscious.

This basic tenet of Freud is so broadly acknowledged that it has made its way into the received wisdom of everyday life. For parents, it is important to know that the child's interest for all products of his body is neither unnatural nor cause for concern, but a sign of behaviour not yet falling under the rubric of "civilisation". By the same token, the small child enjoys playing with both mud and food, forming them, pressing or smearing them, until he learns to differentiate between these materials.

Anna Freud's concept of "developmental lines" as based on the structural model

In 1965, Anna Freud published a consistent theory of development based on Sigmund Freud's structural model and his concept of biologically determined, successively interdependent developmental phases. She speaks of psychic "developmental lines" that normally determine a child's development and are built on each other. These "developmental lines" are a way of describing a psychic process of integration and drive organisation, organisation of the ego and superego in the psychic apparatus, where these rubrics can then be used to measure normal or pathological development. "Progress on this ladder is in every individual case the result of interaction between maturing processes among drives, ego and superego, and their alteration through environmental influences, i.e, a combination of maturation, structuralizing and adaptation" (1965, p. 67).

Anna Freud began analytic work in the early 1920s in Vienna with children in their latent period, between six and eleven years (A. Freud, 1927, p. 14). ${ }^{4}$ At that time, she contended that small children could 
not yet develop transference neurosis because they were in reality still dependent on their own parents. She therefore recommended an "introductory phase of analysis" in order to afford insight into the child's illness and for the therapist to "slip into the child's trust" by allying herself with the child and demonstrating her ability to help himeven with "devious" methods and "forcing" herself on a child who felt he could do without her (ibid., pp. 11-13). She emphasises the significance of dreams, daydreams, and the child's drawings, all of which she then interprets (ibid., p. 37). Should a negative transference take place, by which she means a transference that is unpleasant for the therapist, "... we will then defuse or weaken it as soon as possible" (ibid., p. 48), since in addition to the analytic component, there is always an "intentional component of education" (ibid., p. 47).

After her emigration to London, Anna Freud began to write detailed reports from the wartime orphanages "Hampstead Nurseries" between 1943 and 1945, focusing on children who were separated from their parents for long periods. She herself, however, did not take particular pains to include these detailed observations into her theoretical work, and they became more or less forgotten.

The typical psychoanalytic developmental line proceeds from the state of infantile dependency to adult love life. The lines of development-which extend between the beginning and the end points of development-are described as "from irresponsibility to responsibility in body management", "from egocentricity to companionship", "from the body to the toy and from play to work" (A. Freud, 1965, pp. 64-87). In the pre-oedipal phase of the first three years of life, Anna Freud distinguished between four lines of development:

1. At the start of life, there exists a "biological unity" between mother and child where narcissism is extended from the mother to the child. The child includes the mother in his "narcissistic milieu" (Hoffer, 1952 quoted by A. Freud, 1965, p. 68). Freud also concurs with Margaret Mahler in her distinction between an autistic and a symbiotic period, characterised on the one hand by separation anxiety and on the other by the urge towards independence.

2. In the phase following this, "love according to the form of support" or the period of the "part object" (Melanie Klein) is of central importance, as a precursor of the object relationship. The object serves the satisfaction of needs, and is "intermittent and fluctuating, 
since object cathexis is sent out under the impact of imperative desires and withdrawn again when satisfaction has been reached. In a pacified state, the individual returns to narcissistic libido attribution" (ibid., p. 65).

3. Only after this phase does Anna Freud identify object relationship in its true sense, since the libido is now constantly fixed to a certain person, a phenomenon termed "object constancy": "... the stage of object constancy which enables a positive inner image of the object to be maintained, irrespective of either satisfactions or dissatisfactions" (ibid., p. 65).

4. Prevalence of an ambivalent relationship to the object, marked by anal-sadistic wishes, that is, libido and aggression towards one and the same object: "... the ambivalent relationship of the preoedipal, anal-sadistic stage, characterized by the ego attitudes of clinging, torturing, dominating and controlling the love objects" (ibid., p. 65).

After this come the oedipal phase, the period of latency, pre-puberty, and puberty.

Fonagy has expressed regret that Anna Freud's comprehensive observations from the orphanage, which she compared to experiences from child analysis, did not find their way into the developmental lines (2001, p. 66). Tyson and Tyson (2001) also point out that Anna Freud later declined to avail herself of the richness and clarity of her early writings. Anna Freud's main significance and contribution to analytic theory, nevertheless, lay in her study of inner conflicts and defence mechanisms, seen not only in an intrapsychic context but as developmental conflicts-thus acquiring a transitional character. Problems of development were seen in terms of libidinous phases, with various fixations and regression occurring during various phases.

Margaret Mahler: symbiosis and separation-individuation theory

Margaret Mahler belongs to the pioneers of research into early childhood development. She proceeds from Freud's concept of primary narcissism and develops the concepts of "separation" and individuationtwo complementary intrapsychic stages of psychological birth. For several decades, her theory of development was the most decisive influence on understanding early childhood development for Freudian 
psychologists and ego psychologists in Europe and the US, with the exception of the Kleinian group.

Her work with psychically severely deprived children (benign and malignant cases of childhood psychoses) led her to ask how intrapsychic structures were formed in normal mother-child relationships. She attempted to answer this through lengthy and elaborate long-term studies in the naturalistic setting of a playroom (Mahler \& Gosliner, 1955).

For early development, Mahler proposes separating the phase of primary narcissism into two sub-phases. In the first weeks, the child is unable to "perceive the mother as agent", and thus is situated exclusively in the stage Mahler describes as "Normal Autistic Phase" (1979, p. 16). Referring to one of Freud's images, she compares this closed psychic system to a bird's egg, where autistic needs for nourishment can be fulfilled (ibid., p. 13). Next, the child begins to be aware of his mother indistinctly, but there is no sense of individuality. Mahler then speaks of a "Normal Symbiotic Phase" from the age of three months (ibid., p. 13). With Freud, she assumes that the infant possesses a "protective shield", allowing him to remain attuned to himself and hindering his perception of his mother and other people; she posits a selective indifference or avoidance of human stimulation on the infant's part. As Mahler writes, the infant's symbiosis with his mother entails an "illusory idea of a shared border of two individuals who are in reality separate" (ibid., p. 15). During the third month, a "body-ego" begins to emerge with two instances of self-representation-one turned inwards towards the body's interior, and one demarcating a boundary between the body and the outside world. The inward-directed instance of self-representation is the point of departure for a "sense of self"; the outward-directed instance demarcates a border between the self and other persons (objects). Through his relationship to his mother as primary object, the infant then becomes acquainted with the real world of objects. He uses the mother as a point of orientation. This is why Mahler assumes learning is only possible from the third month of life on, whereas in the "quasi pre-historical phase of magic hallucinatory omnipotence, the breast or bottle are part of the self" (ibid., p. 18). This normal autistic phase is characterised by Mahler as a "forerunner". The concept of "mother-child symbiosis" is founded on observations of child behaviour-but interpreted symbiotically, since the child behaves as if he sees his mother as a "dual unity", including the child within herself (Mahler \& Gosliner, 1955). According to Mahler, the child sees 
his mother as a need-satisfying extension of the self. Only through the child's differentiating between satisfying and unsatisfying experience can he slowly develop the idea that there exists something other than this symbiotic dual unity. This symbiotic behaviour is manifested in a particular response to the mother's laugh, with the mother's conscious and unconscious attitudes forming an important basis for the concept of self and the object.

According to Mahler, the Separation-Individuation Phase emerges at the age of four to five months, and is divided into four stages: 1) differentiation; 2) practice; 3) rapprochement; and 4) consolidation of object constancy. Separation describes an inner psychic process where the child separates himself from the dual unity with his mother. During this, an object relationship evolves, entailing an inner representation of the mother as distinguished from self-representation-thus the origins of the inner conviction that it is possible to exist autonomously and independently from the mother.

\section{Phase 1: Hatching}

Between the sixth and seventh months, the child shows great interest in the world and seems eager to break out of the symbiotic unity.

\section{Phase 2: Practising}

Between the tenth and fifteenth months, the child tries out his cognitive and motoric abilities and, employing them, is able to create or also bridge a spatial distance to his mother. The child nevertheless requires psychic proximity to his mother in order to "tank up emotionally", particularly when he is tired or feeling unhappy. The small child is at the apex of his fantasies of omnipotence. "The child's belief in its own magical omnipotence ... is still accompanied to a considerable degree by the feeing that it shares these magic powers of its mother" (Mahler, 1979, p. 26).

\section{Phase 3: Rapprochement}

Between the fifteenth to eighteenth and twenty-fourth months, the child attempts to live out his contradictory wishes of being with his mother (symbiotic unity) on the one hand and his wish for autonomy on the other hand, leading to inner crisis and increased separation anxiety. He becomes aware of a separate individual (his mother) and thus, so to speak, a separate individuality. Because of his new cognitive 
development, the child slowly becomes aware that he cannot control his mother, then actively attempting to achieve closeness to her; his separation anxieties increase. When a child becomes aware he is not omnipotent, he attempts to seduce or control his mother through charm and terror.

\section{Phase 4: Object constancy}

"Object constancy", similar to Jean Piaget's "object permanence", describes the phase when a child understands his mother has a separate identity and is truly a separate individual. Between the twenty-fourth and twenty-sixth months, the child succeeds in constructing and consolidating a constant relationship to his mother on the level of a stable internal representation (internalisation). He can now retain a stable psychic relationship to his mother, even when he is angry at her or is separated from her for a given time.

This differentiated concept of phases of separation and individuation makes it possible for a clinical psychoanalyst to reconstruct the preverbal development of grown patients. Mahler's observations were derived mostly from middle-class families.

In response to the criticism that infants express curiosity, desire for stimulation, pleasure in mastering tasks, and in establishing contactalready from birth on-symbiosis theory was modified. Instead of the "symbiotic phase", Pine $(1990,1994)$ suggested "symbiotic moments" occurring particularly before and after feeding. In other moments, the baby would be eminently capable of differentiation between self and objects. Baumgart (1991) views "symbiosis" as a clinical concept, a narrative schema aiding a patient to conceptualise his or her wishes for fusion. Thus, the concept does not necessarily describe an actual developmental phase occurring between the ages of two and four months, but is rather a metaphor allowing access to the patient's psychological past.

Criticism of the concepts of "primary narcissism" and "normal autism"

Joseph Sandler comments on Freud's description of primary narcissism by remarking that "We can assume that narcissism exists from the moment that the infant has a rudimentary awareness of himself, even though he or she may not have differentiated the primitive 
perception of the object from himself" (Sandler, Holder, Dare \& Dreher, 1997, p. 144).

The relatively simple image of a well, filled with libido waiting to be ladled out-meaning the ego goes hungry while its subject is in love, and cathexis is withdrawn from outer objects during states of paranoia-has been proven insufficient and misleading, according to Sandler.

Melanie Klein also criticised Freud's concept of the newborn infant remaining in a condition of primary narcissism for several months (1952). For her, this "implies a condition where-apart from the libido-no impulses, fantasies, fears and defenses exist and no connection to an object ..." (ibid., p. 83). Segal and Bell find the same concept conspicuously unsatisfying, adding that in his essay Freud has reached the limits of his drive theory, whereas "... his writings implicitly convey a lively consciousness of an inner world" (2000, p. 197). In psychotics' state of narcissistic withdrawal, they execute a "withdrawal to internalized objects", as Segal and Bell write (ibid., p. 210): from birth onwards, some form of connection to another human being (object) must be said to exist.

Experiments from empirical research, where newborn and older infants react to movement or can distinguish their own mother's smell, are seen as contradicting the concept of "normal autism".

Daniel Stern's chief criticism is directed at clinical reconstruction of the past through narratives from adult patients and older children: there have been no actual long-term investigations of babies that focus on the hypothesis of "normal autism" or primary narcissism (1985, p. 23). Stern considers these theories both retrospective and pathomorphic, since they proceed backwards in time from an understanding of psychopathology in a later phase (ibid., p. 19). Dornes voices reservations regarding the "reconstructed infant" he finds in Freud's and Mahler's models, since both construct a "myth" and describe the infant via concepts from adulthood (adultomorphism) (1997, p. 24).

\section{Object relations theory in Melanie Klein and Wilfred Bion ${ }^{5}$}

Melanie Klein: rudimentary core ego from birth onwards

Melanie Klein's understanding of early child development came from her clinical work with very young children. From these "early analyses", 
she derived important insights through her precise observations, which in turn led her to new theoretical concepts as she attempted to understand what she had observed. Klein understood her analytic theory as a logical extension of Freud's ideas, remaining "in Freud's footsteps", so to speak. She succeeded in an innovative fashion in bringing together essential concepts from late Freud-such as the death instinct and the psychic structure formed through identification-with her deep understanding of the contradictions inherent in Freudian theory. Klein's achievement is the "discovery of the child as an object sui generis", as Claudia Frank (1999) put it in the subtitle to her book on Melanie Klein's first child analyses. The new technique of child analysis, where Klein understood children's play as a form of free association and comparable to adult dreams for expressing feelings and thoughts, provided her with clinical data she employed convincingly in her theories. To put it simply: just as Freud discovered the unconscious and the child within the adult, Melanie Klein discovered the baby within the young child and the adult. She managed to integrate and further develop the Scottish psychoanalyst Ronald Fairbairn's theory of object relations (1952) together with Freud's late structural model. Fairbairn contended that the individual primarily seeks a relationship to one person-in psychoanalytic terminology, an "object" - rather than being ruled by drive wishes. Employing the concept of unconscious fantasies, Klein was able to reconcile these seemingly opposite rubrics. "Unconscious phantasy, for her, was shaped both by the drives directly and by internalized experiences with others which had in turn been constructed and modified by the drives and by yet deeper layers of phantasy and earlier levels of experience" (Black, 2006, p. 9). Emphasising the significance of early relationships in object relations theory led Klein to shift her interest towards development-theoretical questions.

This shift of attention to the pre-oedipal phase was the impetus for Klein's concept of the rudimentary ego from birth on, existing as a "core of the ego" (Klein, 1946, p. 180). As explained above, she diverged from Freud on his concept of primary narcissism and postulated that the newborn baby already achieves contact with his mother and the outer world. Klein (1946) believed that the newborn baby has a primitive ego, vacillating between a state of disintegration and relative coherence. In a primitive fashion, he can distinguish between I and not-I, also experiencing positive and negative feelings and fantasies of intake and expulsion. After his safe life within the womb, where he never experienced 
hunger and was always kept warm, the baby is born into an unknown world where he is subjected to powerful needs (such as hunger), raw impulses, fears, and manifestations of life/death forces. Here, his situation is dominated by the fear of disintegration and his wish to be held, to be in contact with the nipple, hair, eyes, and hair of his mother in order to feel complete and held together.

The "paranoid-schizoid position" and the "depressive position"

Kleinian theory does not devolve from consecutive phases or lines of development, as in the two Freuds; instead, she speaks of two basically divergent positions that retain their relevance during the course of an entire life. With the term "positions", Klein means modes of experiencing, that is, the manner in which we experience impulses, fantasies, and fears as well as our defences against them-"positions" that determine how we behave towards the world, ourselves, and other people. She calls a baby's early, archaic mode of experiencing the "paranoid-schizoid position", and the later, mature mode of experiencing the "depressive position". These two positions involve differing qualities of fear, forms of defense, and object relations. In this connection, Klein takes up Freud's theory of the death instinct, nevertheless understanding it in a clinical sense, connected to an object, and less in the biological or philosophical sense. She speaks of an "interaction of life and death instincts as expressed in love and hate" (Spillius, 1994, p. 333). "Where Freud thinks that the Unconscious contains no idea of death or annihilation (Freud, 1923b, p. 57), Klein (1948) thinks '... there is in the unconscious a fear of annihilation of life' (p. 29). For Klein, this fear of annihilation is the primary anxiety, more basic than birth anxiety, separation anxiety, or castration anxiety" (Spillius, 1994, p. 333). The emphasis on sadism derives from Klein's analytic experiences with very young children, who expressed massive sadistic fantasies in their play, subsequently feeling guilt. These insights from child analysis caused Klein make a link to the sadistic impulse in early childhood and led to her assumption of a fear of annihilation existing from birth on, as the expression of the death instinct.

The paranoid-schizoid position

The normal paranoid-schizoid position is characterised by a rapid shift in emotional states, and dominates the earliest phase of life, the 
first three months. Moods oscillate between love and security in the presence of the object (mother or caregiver) and fear, hate, and rage in its absence-interrupted by phases of sleep and other activity. These first three months are characterised by the persecuting fear of inner annihilation, projected outwards. According to Klein, hunger is not only a feeling of "there is no food here" but induces a subjective impression that "the object is letting me starve". It is important to remember that every verbal description of this type of baby's feelings is inherently misleading, since it puts something into words that actually occurs in the form of corporal sensations. These images of a primitive ego differ from the perceptions of an adult observer and are therefore somewhat liable to false description. Isaacs (1952) assumes that these first events are experienced in the form of corporal sensations, then linked to dynamic impressions - sight, sound, surfaces, touch, taste, and smellbefore they are linked to words. Klein assumes that the psyche reacts to the fear of annihilation with schism and projective identification. The child splits his positive and negative feelings and projects them in his fantasy onto an object, inhabiting a world where both the object and subject are invested only with either extremely negative or idealised positive aspects. There is at first no recognition that positive and negative aspects of the self or object belong together. These aspects of one person or of the self are termed "part objects". The first part object is, according to Klein, the mother's breast, whereby "breast" signifies not only a source of nourishment or the stilling of a need, but a source of love and life.

By accepting the quality of his relationship to parts of the outer object (voice, eyes, breast, skin of the mother or the father), the baby can gradually construct an inner world, accessible to his ego and standing in some relation to the outer world. In his actual experience of being nourished, the newborn infant experiences the intake-into-self of milk, love, and the mother's warmth. Feelings of omnipotence are characteristic for the paranoid-schizoid position.

In her essay "Envy and Gratitude" (1957), Klein adds an important element, speaking of original envy as a constitutive factor. The good part object is envied and then attacked. In cases of excessive projective identification and massive envy, so much guilt over the fantasised destruction is created that it leads to pathological confusion in thought (see Rosenfeld, 1975). 
In analogy to bodily functions and their mastery, Klein posits a psychic model: assimilation of nourishment becomes the assimilation (introjection) of feelings, elimination or vomiting becomes emotional expulsion (projection), the closing of the eyes becomes denial, physical withdrawal becomes rejection. Krejci summarises this analogy as follows: "The correspondence between concrete assimilation and expulsion as an expression of oral and anal drive impulses on the one hand, and introjection and projection as processes on the psychic levelwhich by the same turn are linked to oral and anal drive impulses-is paradigmatic" (1999, p. 37).

The varying character of psychic experience in the first three months of life was clearly formulated by Melanie Klein. In this first period, the infant begins to build a relationship to the important people in his environment, although this relationship is founded not on the entire person, but on partial aspects. The mother's voice, her face, her nourishing breast are linked to satisfying and loving experiences and thus experienced as "good". These partial aspects of a person-"partial objects"are assimilated into the infant's inner world as a product of his actual experiences and his fantasies, in psychic processes that are somewhat analogous to the bodily processes of assimilation and expulsion-that is, the "good inner partial objects" do not represent real experience, but are constantly modified by the infant's fantasies, wishes, and primitive feelings. These links to the good, loving aspects of the mother and father give rise to an image of a good, peaceful, and sheltering world where the baby feels nurtured and protected. Here, it is important that this positive sensation is not only linked to the baby's time physically spent with his parents, but also to how the baby, having assimilated these satisfying experiences, can now forge an imaginative link to his good inner partial objects-in order to calm himself and go to sleep alone, for example.

The infant's state of fear, desperation, and imminent disintegration seem completely separate from this positive, peaceful world. The mother's absence, the state of separation from her is experienced as evil and persecuting. We can assume that the infant perceives the feeling of hunger not as a part of his body, but as an inimical sensation originating from outside his body. In concrete thinking, these negative and threatening feelings are accordingly brought into connection with part aspects of the mother or father, who are then experienced as "bad". 
Presumably, another aggravating factor is that the infant experiences these good and bad aspects as "partial objects", separated from each other, and thus now fears that all his good connections have vanished. The nourishing breast (when absent) can thus be transformed into a bad, dangerous breast. In understanding what violent feelings, hate, and destructivity are activated in the infant, we should keep in mind that the small child sees himself as the centre of the world and wants with all his might for his wishes and thoughts to be immediately fulfilledfor instance, access to the breast, which must belong completely to the infant, under his total control, with no feeling for the needs of others or that the mother cannot or will not be accessible at all times. With this kind of absolute wish, needs can never be completely fulfilledthere always exists a greater or lesser frustration that can be borne only in increments. At first, this impatient state of insatiability elicits rage with every delay or impediment, although babies certainly differ as to temperament: some are more patient than others. In addition, the loving attention a child receives will eventually help him to wait for the fulfilment of his wishes. Thus, a howling infant might turn away from his mother's breast, his limbs distended, crying desperately, until his mother succeeds through her patient caresses in lending him the confidence he needs to take a "good", milk-filled breast into his mouth.

This inner mechanism of separation into good and bad aspects is called "splitting", an early form of defence in which we nevertheless remain well versed our entire lives. The wish to separate the world into exclusively good, idealised persons or areas and the "realm of evil" is based on these early experiences. Accordingly, in the persons, ideologies, or intentions characterised as good, we must not see negative or limiting aspects. Everything bad is then relegated to the hostile intentions of political opponents, foreigners, or Jews. In fairy tales, we find the absolute separation between good and bad aspects embodied in figures such as the good fairy, the affectionate king, and the evil witch or the envious stepmother. And just as the baby separates his environment into good and evil, he experiences himself either as good, friendly, and full of love or as bad, dangerous, full of hate.

Klein believed that the maternal breast and maternal body, as well as the parents' sexual intercourse, are goals for fantasised attacks through destructive impulses. The child then feels himself attacked by the part objects he projects onto the breast and his parents' sexual intercourse. In child analysis, Klein observed that children would draw a monster 
or depict in playacting what she then interpreted to be a "combined" object-in Klein's extrapolation, a hostile mother who had incorporated the father's penis.

The depressive position

Klein believed that the quality of object relations and fears become altered in approximately the third month of life, when perception of part objects moves to that of whole objects. The child now manages to integrate good and bad aspects of the object and to know that the good and bad mother is one and the same person. Accepting this new idea that the bad mother, attacked in the child's fantasy, is the same person as the loved mother unleashes an extremely painful process entailing a "depressive fear", as Klein terms it. This fear consists of a mixture between concern for the object, the fear that it has been irreparably harmed, guilt feelings, and the child's feeling of responsibility that he has caused the damage. The child wishes to repair the object destroyed in his fantasy. How strong his guilt feelings are depends on the actual condition of his mother. If she is in a good condition and can empathise with her child's problems, this will decrease the child's fear of his own destructivity and strengthen his confidence in rehabilitating the object. If the mother is in a bad condition and if she is incapable of understanding her child's conflicts, the child sees himself as responsible and his fear is increased. The rehabilitation can nevertheless be sought in a manic or compulsive form, accompanied by denial, triumph, and contempt. If these defensive forms of fear cannot be sustained, the child withdraws once more into the archaic split of the paranoid-schizoid position. A salutary way of moving beyond the depressive position is for the child to internalise a stable, positive object, which then forms the core of the self and the basis for the ability to love.

Recognition of the fact that ostensibly good or bad aspects belong to the same person, the mother or father, proceeds gradually and constitutes an important step in development occurring in the period through the third month of life. To the extent that the child can see his mother and father as good or bad, he also begins to see himself as a person who harbours good and bad thoughts, feelings, and fantasies. His fear is thus diminished, and separate parts of his personality can be gradually integrated.

Klein views the period of development following the first three months, that is, between the fourth and sixth month, as an important 
qualitative shift in the baby's basic psychic experience. Her emphasis on the child's fantasy life, supplementing the classical understanding of drive energy, opened a new dimension: an inner world populated with inner images of the persons (objects) from the child's life, positioned in relation to one another. The baby's fresh abilities of recollection and selective attention, and the mastery of improved expressive and bodily coordination leads to a lessening of fear and an increased feeling of security. The baby begins to feel concern for others. An important concept is that of "reparation". The child seeks to repair damage he caused his mother or father in his fantasies. Previously unknown feelings of compassion and regret, pangs of conscience, grief, and longing arise. The mother, who can now be seen as both good and bad, is outside the sphere of the baby's fantasised omnipotent control. The baby's ego, hitherto perceived by him as omnipotent, is now reduced to a realistic size. Through the ebbing of his fantasised attacks, he emerges into a more realistic perception of his parents: they are no longer as distorted, neither idealised nor demonised.

Klein also assumes that in the first year of life, the child already perceives the special relationship between his father and mother. She connects her concept of the depressive position to Freud's Oedipus complex, maintaining that the beginning of the depressive position coincides with the beginning of the oedipal conflict (1940). When he recognises this special bond between his two parents, a bond different in quality from his own bond to the parents, the child gains a new perspective on his own psychic reality. Being excluded from the parental couple - who have the capacity to create new babies-is painful, but also opens a new psychic space in the child, in turn enabling him to think in a generalising way. The child experiences his parents as a couple, who reflect on the child and love him. He thus assimilates a model for thinking about himself. "The capacity to envisage a benign parental relationship influences the development of a space outside the self capable of being observed and thought about, which provides the basis for a belief in a secure and stable world" (Britton, 1989, p. 87). This concept of an early oedipal phase in the first year of life has been criticised and dismissed, although the father's significance in the first year of life is now acknowledged.

The discovery of these two differing inner modes of experiencing enables therapists to understand early psychic disorders previously inaccessible to analysis and treatment-psychoses representing a 
stagnation in these early forms of experiencing. Violent mood swings, deep confusion between inner and outer, acute panic and hostility, followed by massive provocation and exorbitant demands, omnipotent fantasies, and attempts at domination can be understood as typical characteristics of psychotic illness, which is the reason why the concept "paranoid-schizoid position" was devised to describe them. It is a "position" because it is not based in one developmental phase that later shifts to another phase, but rather in a "sensibility": a form of experiencing, retained in a latent sense even when it is replaced by a more mature form. This more mature form enables the subject to think in categories differentiated beyond the black and white, to respect the needs or wishes of other persons in addition to his/her own, and take responsibility for his/her own actions. This mature form of thinking and feeling is called the "depressive position". The terminology is perhaps unfortunate and can easily lead to misunderstandings, as if it meant a pathological, depressive state. However, the intention is to describe an acceptance of one's own good and bad components, responsibility for loving, and aggressive impulses together with the possibility of atonement. Nevertheless, attainment of this mature form does not constitute a final stage; rather, it is thought that we shift back and forth between the two positions, tending in phases of crisis, separation, and conflict to revert to archaic forms of thought.

This view of the beginning of life, where good and bad aspects, love and hate, envy and gratitude, destruction and enrichment converge in the psyche, elicited great indignation. The "innocence of the child" was seen to be under attack. However, there is no other theory that explains the causes of deep psychic disorders. Although evil always bears a special attraction for us and brute force, crime, and destructivity have always found a place in familial, political, and economic life alongside love, encouragement, and altruism, it is difficult to accept that both sides-"eros" and the "death instinct"—are elements of the psyche from the very outset. Adults have a compelling need to see a newborn infant as pure and innocent.

\section{Wilfred Bion}

In the 1950s, Bion developed Klein's theories considerably further. ${ }^{6}$ He took up the concept of projective identification and developed 
a theory of thought, where he proposed three models towards understanding the process of thinking (Spillius, 1994, p. 341).

The first model is concerned with unconscious fantasy, in Bion's terminology a "preconception", which is used to test reality. Similar to Kant's postulation of an a priori form of perceiving time and space where thinking is possible, Bion (1962) proceeds from a hypothetical knowledge of the emotional bond between subject and object, whose $u r$-form is embodied in the linking of the infant's mouth to the mother's nipple. The baby seeks to discover whether his fantasy, proceeding from an innate opinion (preconception) corresponds to the realisation of that fantasy. In the progression from an image of the breast to a thought, Bion-like Freud-considers the experience itself to be a "realisation", in that the experience of a real breast, together with the preconception breast-mouth, leads to a "conception" - in other words, thought.

The second model focuses on how the infant deals with frustration or a negative reality, when there is no breast available to still hunger. The child's response depends upon his ability to handle frustration. Klein believed that the child experiences an absent breast as a bad breast, since the unconsciousness knows no negation. Bion advances this thought further. The absence of a loved object spurs an emotional experience that Bion believes is the starting point for thinking, since in fantasy a hallucinatory wish fulfilment (Freud) placates the baby's needs. With Ferenczi (1924), Bion assumes that during his first sleep, the satisfied infant imagines himself back in his previous existence, his mother's womb. If the child can tolerate frustration, he can transform his frustration over the absent breast into a thought. Through thought, the child comes into contact with his fear, and can gradually realise he is frustrated because the good object is now absent and may or may not return. However, if the child cannot tolerate the frustration caused by his absent object, he cannot develop the thought of the transformation from the bad object to an absent but good object, and instead the absent object is experienced as a concrete, bad object, then repulsed through omnipotent projection. Thinking and symbolisation cannot develop under these conditions.

The third model is focused on the "formulation of the container and the contained". Bion adopts the concept of projective identification from Klein, drawing a distinction between normal and pathological projective identification. In his psychoanalytic work with psychotic patients, Bion discovered that they made statements they themselves 
did not understand; it then fell to the analyst to make something of this "disjointed stuff". Bion developed a concept of infant intellectual development based on Melanie Klein's ideas. He believed a baby has feelings or needs-from without or within-he cannot deal with. He attempts to expel or "breathe out" the part of his body that experiences these feelings or needs, to reject it through urination or crying. Bion called these parts "beta elements". In what direction do these projected experiences go? It is clear that there can be no development or emotional growth without modification of these raw feelings. The child behaves in such a way that he elicits those very feelings in his mother of which he wishes to divest itself (Bion, 1962, p. 114). The projective identification is a fantasy of omnipotence, but it also leads to behaviour that can elicit the same sensations in the mother. If the mother is emotionally stable and empathetic, she can assimilate these feelings.

To the extent that she is emotionally capable of absorbing these feelings, she will take them in, modifying them through her powers of understanding. This capacity the mother exercises is made possible through her love for her baby, her "reverie", her dreamy attention. Inasmuch as it has the quality of an activity, it belongs not to the mother, but instead is common to both mother and baby and useful to both. What the mother does with the feelings projected into her corresponds to a psychic "digestion" of the baby's raw feelings. The mother thus becomes a "container" for the baby's fragmented feelings. This psychic activity of the mother, occurring unconsciously, is compared by Riesenberg-Malcolm (2001) to birds who first masticate food for their babies before putting it in their beaks. The baby absorbs not only those experiences, now put into words, but also absorbs the manner in which his mother perceives her task of psychic digestion. This digested form of experience, which the baby than can introject, is termed "alpha elements" by Bion. Alpha elements constitute the basis for learning from experience, for knowledge of reality. Bion calls the mother's ability to transform beta elements into alpha elements her "alpha function". The child not only can now introject the transformed alpha elements, but also gradually the transformative function itself, thus acquiring the beginnings of his capacity to tolerate frustration and to think.

If the mother is so preoccupied with her own turbulent emotions that she is unable to assimilate the experiences her baby emits, if she turns away from her baby in irritation and incomprehension, then these feelings of hers boomerang back to the baby, challenging him beyond his 
limits. When containment cannot take place, this can also be due to the child's intolerance and envy of his mother, for the things she is able to do that the child cannot. The child feels empty and flat (lack of containment). If, however, the mother herself is flooded by feelings of defeat, aggression, abandonment, and misfortune, she not only rejects those feelings that the baby has projected into her but also imposes her own feelings into the baby (parasitic containment). Challenged beyond his limits, the baby then expresses this in somatic complaints, as with Julian and his sleep disorders or in the extreme anxiety of Malcolm.

The same function the mother executes when she "digests" her baby's raw feelings is also attempted by the analyst in therapy, taking in what the patient says in raw form and rendering it understandable to the patient through an interpretation. De Masi (2003) points out that Bion's idea of the unconscious as a function that transforms thoughts and feelings (the emotional unconscious) was a precursor of neuroscientific theories. He writes: "Startlingly, Bion thus anticipated the neuroscientific theory on the unconscious that ascribed it the function of working through feelings" (p. 15).

This concept of "containment", effectuating the transformation of undigested beta elements into alpha elements, is a valuable element in theories from many different schools. The model of container/ containment integrated the realms of feeling and thinking into a theoretical framework.

Inspired by Melanie Klein's elaborated theory on early development, Esther Bick invented an ingenious method of psychoanalytic infant observation which constitutes an essential building block in the training of psychoanalysts and psychotherapists in London. Before the students work clinically with patients, they observe a baby's development in his first two years within a clearly defined natural setting at home. In the weekly one-hour observations in the family's home, the interaction the parents and others have with the baby is observed in detail, with great significance given to description of the baby's corporal, facial, and acoustic expression. The observer is meant to register events of outer reality, but on the other hand also consider his/her own feelings, moods, and fears evoked during the observation process, thus helping to detect primitive fears in him/herself and becoming sensitised to phenomena of transference and countertransference (Bick, 1964; Rustin, 1989).

The weekly seminars, conducted under the tutelage of a psychoanalyst, then focus on carefully formulating hypotheses on the development 
of the baby's inner world as it is being formed through unconscious fantasies and real experiences. Throughout this two-year seminar experience, utilising descriptive notes from baby observations, the observer develops not only an enormous sensitivity for emotional processes but also a precise mode of observation-often in spite of his/her own quite painful reactions-which is of manifest help for clinical practice (Sternberg, 2005).

Criticism of the concept of a rudimentary core ego from birth on

The chief butt of criticism has been the concept of the infant's destructive impulse, of original envy. Klein's ideas were held by her critics to be absurd and not demonstrable, and her texts were difficult to read (Spillius, 1994, p. 324).

The concept of the death instinct has been contested or dismissed by many psychoanalysts. Bowlby (1979) objected to how Klein attributes little or no importance to the child's actual environment.

Although some results of empirical infant research have supported Klein's and Bion's postulation of an active newborn infant, objection has been made to the presumption of an infant's ability to fantasise and dream or his ability to construct a relationship to another human being (mother). Dornes objects to the presumption of unconscious fantasies in the infant, calling Klein a "romantic for the concept of fantasy" who proceeds from an "idea of soulful body processes" (1997, p. 100). Although Dornes accepts the primitive nature of fantasy-which Isaacs (1948) attempts to describe as non-verbal, non-visual, and corporally experienced-he can only see it as a "matrix of images/fantasies that are inherent in sensation". At the same time, Dornes emphasises the advantage this concept of unconscious fantasy offers in avoiding a Cartesian body-soul dualism (1997, p. 101, footnote).

Daniel Stern writes: "I would guess that the idea of innate or primary fantasies is not necessary, because ... the infant will so quickly form representations of those experiences that his nature leads him into" (1995, p. 80). He proceeds to add that "One can, of course, call this aspect of his nature 'preconceptions', but these are not fantasies." Stern reverses chronology when he says that the child's contact with the world results in representations whose subjective aspect later shapes the child's fantasy world. He has difficulty with the concept that an innate knowledge is inherent in the body and its impulses, with 
corporal sensations accordingly experienced as a form of postulated (fantasised) actions.

\section{Daniel Stern: empirical infant research}

As a psychiatrist, Daniel Stern attempted to link developmental theory with psychoanalysis by making detailed analyses of mother-child interaction in the first three years of life. His line of research bore impressive results. At the centre of his approach was the attempt to provide videotaped support for observations of a child's early development. His basis was empirical research and not, as is usual in psychoanalytic tradition, clinical data from therapy or analysis. In a critical distancing from Freud's drive theory, Stern takes exception to the method of reconstructing a person's early development out of clinical data from analysis. Instead, he sought to understand, through observing an infant, how a human being becomes "human" (1985).

Empirical infant research centring upon Stern and Cramer proceeds from a psychoanalytically oriented understanding of the personality, but does not focus on observation of everyday situations. It defines six corporal states of the infant, whereby the fourth, that of "alert activity", is considered the optimal basis for learning and interaction-that is, a phase during which experiments can be carried out. In the first weeks after birth, six different psychic and corporal states of the infant are distinguished from each other: 1) regular sleep with closed eyes and regular breathing; 2) irregular sleep with movement of the limbs and face; 3) sleepiness: the eyes are open, but there is no other activity; 4) alert activity: the eyes shine and follow moving objects; 5) alert activity with diffuse motoric movement of the entire body; 6) unrest, expressed by crying (Mussen, Conger, Kagan \& Huston, 1990, p. 103).

In his first book, The First Relationship, Infant and Mother (1977), Stern describes the results of his research, in the process deepening our understanding of empirical details, the structure and the various quality of mother-child interaction. Through analysis of video recordings, Stern can analyse the tiniest changes in the baby's facial expression and the mother's expressive reaction to it, in terms of dramaturgy, length, and intensity. Stern analyses vocal pitch and dynamics, the length or (when mother or baby feel under pressure) avoidance of eye contact. Many rubrics for describing mother-child interaction are expressed in musical metaphors: an "in tune" mother and child, their vocal pitch and rhythm, 
the choreography of their movements responding to one another, or the mother's touching of her baby as a rhythmic game accompanied by the baby's joyful vocalisations. Escalation or de-escalation in play, joyful excitement, or over-stimulation are characterised as "moments", where learning occurs. These socially "lived" experiences are stored in episodic or explicit memory.

Stern believes that the child's subjective world comes into being through his interaction with his mother. The initiative for this can come from the mother or the child. The various possibilities for contact include facial expression, looks towards or away from each other, the mother following the infant's gaze or vice versa, smiling or expressions of pain, and hand motions (1977, pp. 9-49).

In his book The Interpersonal World of the Infant (1985), Stern devises a concept of "self-awareness" which he defines as a central organising principle of the infant's emerging psyche. Stern's focus is the structuring of the self through schematisation of experiences. His critical attitude towards the psychoanalytic developmental theory of Spitz, Anna Freud, and Mahler, which he finds redundant and far too narrow (Stern does not take Klein's and Bion's object relations theory into consideration), causes him to develop a new conceptual system that emphasises subjectivity and intersubjectivity, not intrapsychic rubrics. Stern proceeds from the basic assumption of a self that long precedes selfawareness and language $(1985$, p. 6). This self encompasses the "senses of agency, physical cohesion, continuity in time, having intentions in mind" (ibid., p. 6). Stern attempts to demonstrate his assumption of a preverbal subjective life and experience through experimentation. Since the infant cannot respond verbally to questioning, he is shown objects-for instance, the faces both of a woman and of his own mother-and his preferences are measured, that is, which face he looks at longer. The (temporal) length of the infant's gaze is seen as proof of his ability to differentiate between the two faces. Stern distinguishes between four different phases of the self and social relations: he calls the period between birth and two months the "emergent self", between two and six months a "core self", a "subjective self" between seven and fifteen months, and finally a "verbal self" (1985, p. 11).

In the early phase of development through the second and third month, babies are able to relate various sensory perceptions; they can differentiate between lifeless objects and faces. Infants are curious-they seek social contact. The basis for this notion of the active infant, seeking 
contact to persons, objects, colours, and patterns, comes from empirical experiments. The babies' "answers" were given in the form of behaviours such as sucking, looking, or turning their heads in the direction of a towel drenched with their mothers' milk. The experiments were carried out exclusively during the phase of "alert activity" (Wolff, 1966). Stern postulates that a baby experiences inner organisation-both the emerging process and the results thereof-in a fashion he calls a "sense of emerging self". He believes babies are already born with a strategy for collecting information (1985, p. 61).

The baby's experiences are "unified and global". "They take sensations, perceptions, actions, cognitions, internal states of motivation, and states of consciousness and experience them directly in terms of intensities, shapes, temporal patterns, vitality affects, categorical affects, and hedonic tones." Babies order these impressions and perceptions, with an inner organisation emerging that later becomes the self.

Investigation into the interpersonal world of these subjective perceptions, where the perception of self, of other, and of the world are closely interwoven, forms the crux of Stern's research. The "sense of self with other" is seen as parallel to a "sense of self" and to a "sense of the other".

The concept of "schemas-of-being-with"

An important goal in empirical infant research was to investigate "schemas-of-being-with" - to document how the mother's inner images (representations) are manifested in her observed behaviour. Stern (1985) also focused on the infant's (presumed) subjective perspective in his interaction with the mother or caregiver. ${ }^{7}$ Stern extends the significance of the mother-infant relationship to encompass the totality of human relationships, of intimacy and trust over the entire course of development. Fonagy concludes: "[Stern] describes these relationships as the stuff of all human connectedness, intimacy, and trust throughout development, and sees the ability to engage in them as essential to mental health" (2001, p. 118). If the baby can experience the mother's feelings towards him through her behaviour, he will then assimilate his mother's quality of feeling, and this introjection determines the type of inner images he has about himself and his relationship to his mother. The types of interaction between mother and baby are described in terms of "schemas-of-being-with". Stern writes: "A schema-of-being-with is 
based on the interactive experience of being-with a particular person in a specific way, such as being hungry and awaiting the breast or bottle or soliciting a smile and getting no response" (1995, p. 19). This is influenced by many elements: the mother's own schema of herself, her image of the infant (schema of the infant), her relationship to her husband (schema of the husband), and to her father (schema of the father), as well as her relationship to her own family (schemata of the mother's family). Daniel Stern proceeded from the general assumption that these inner images are manifested in both the mother's behaviour and the infant's observed behaviour. Together, they form the "parent-infant interaction" (1995, p. 77). Together with his wife Bruschweiler-Stern, Stern describes this process from the mother's perspective in the book The Birth of a Mother (1998).

In an empirical investigation of a mother and her three-year-old twins, Stern attempted to understand how the mother's feelings and attitudes towards her two children influenced her interaction with them (1971). Stern noticed that one child, Fred, was often morose, bursting into tears while both the children were playing with their mother on the floor. The other twin, Mark, continued playing happily with the mother. When the mother's attitude towards both sons was investigated, it was discovered that she had already experienced Mark as an active, lively baby in her womb-apparently, like her own personality-whereas the quieter baby, Fred, reminded her of her husband, with whom her relationship was currently tense. A video "microanalysis" of their playing showed a difference in behaviour: "The mother acted differently toward gaze aversions during face-to-face play, depending on who performed it. If Mark averted his face, the mother accepted this signal as a temporary cutoff and either looked away or stayed still. If Fred averted his face, the mother did not accept it as a cutoff signal and moved closer to him, as if to force a fuller contact but succeeding only in forcing him into a position of greater aversion" $(1995$, p. 44). With every round of growing closer/pulling apart, the mother and Fred became more frustrated; Fred became agitated, finally bursting into tears.

In order to understand this microanalysis, we must know that previous microanalyses of mother-infant play had already shown that infants and small children show their temporary inability to assimilate new sensations by the direction in which they look or turn away. For adults to react sensitively to the infant, they would have to tolerate a short pause, look away, and then wait until the infant once again turns 
to them. Such pauses last only a very short period, often less than a minute, but are enormously important emotionally since they afford the infant psychic space to digest his impressions and to decide himself when he wants to resume playing. Often, parents do not even register these brief interruptions on a conscious level. Normally, as soon as the baby has psychically processed the stimuli, he turns back to the adult, making eye or body contact.

The important lesson from this case is that no process in maternal and infant behaviour is one-sided, but that actions are linked to one another, with the mother's behaviour influencing the baby and vice versa. In this case, the mother was also observed tolerating short interruptions with Mark and reacting sensitively to them. Mark thus was able to retain independence, resuming contact with her on his own accord. With Fred, harmony was broken. His mother could not accept his turning away and consequently moved closer to him, which made him turn away even more vehemently and avoid her, which presumably made the mother feel rejected. This mother was not aware of her own behaviour: only when she could effect a transformation in her inner attitude, where Fred was assessed as phlegmatic, could she react appropriately to his behaviour.

Although Stern believes he diverges from psychoanalysis, criticising Klein's concept of the "inner object" and Bion's notion of transferring maternal fantasies to the baby as "mystification" or "magical thinking", there are areas of agreement between them. Of course, Bion, Klein, and Fraiberg all proceed from the assumption that the mother expresses her attitude towards the baby-devolving from her fantasies - through her behaviour, facial expression, vocal pitch, and tactile sensation. This is why a one- to two-year psychoanalytically oriented observation of the parent-infant interaction is part of the psychoanalytic curriculum in London. A good capacity for observation is an important indicator of later psychoanalytic skill.

Precise examination of mother-child interaction bore rich fruit in Stern's parent-small child psychotherapy. In his book The Motherhood Constellation (1995), Stern discusses various clinical orientations and provides numerous clinical examples. In his first impressive body of research, he described a baby's reaction to his depressed mother, using video analyses of filmed interaction. The baby, who had previously experienced an empathetic mother, attempts to spur his depressed mother to activity through particularly demonstrative contact. Stern describes 
mothers who attempt to overcome their own passivity by responding with forced friendliness, in turn eliciting an apparently enthusiastic reaction from their baby that is presumably just as false-thus documenting Winnicott's "false self" in ascendant form. Fonagy believes the child identifies with the distorted representation his mother has of him, finally complying in a "false form of togetherness with the mother".

\section{Criticism of the concept of empirical infant research}

Precise observation of mother-child behavioural interaction has made a valuable contribution to understanding how an infant's psychic development progresses in both normal and pathological forms. In particular, babies' ability to actively contribute to the forms of this interaction has been impressively demonstrated using empirical examples. A common criticism of Stern focuses on his narrow conception of psychoanalysis, which does not take into consideration the "significant modification and new formulation of psychoanalytic theories of development" (Tyson \& Tyson, 2001, p. 104). In addition, Tyson and Tyson find Stern's new meta-language to be a "new professional jargon" with "occasionally quite confusing metaphors". It is regrettable that Stern does not incorporate the object relations theory, since the concept of an inner world, the intrapsychic events of unconscious fantasy, fears, and imagination are thus neglected.

The question of the origins of a self remains open (Metzger, 1999, p. 388). As Fonagy points out, description of a gradually emerging self seems to focus more on a corporal self than a "mental" self (1996, p. 107). Any feelings of dependency, rage, and frustration are omitted from this picture.

The point Stern regards as his most important contribution-his focus on the relationship between mother and baby from the very beginning of life-is not new. The baby's egocentric attitude would seem to necessitate some recognition of another person's existence, something that "... the followers of Klein, using her intuitions and hypotheses and observations, have claimed for more than half a century. But it is significant that in his paper Stern quotes Stein Braten but makes no reference at all to Klein," as Riccardo Steiner remarked (2000, p. 8).

The main criticism of Stern involves the short interval of time transpiring in his experiments-the phase of "alert activity" - which, although considered optimal for the learning process, could hardly 
be adequate for measuring babies' essential feelings and moods. Particularly during feeding or crying, the infant is subjected to his own extreme affects, wishes, and fantasies, which Stern for the most part excluded from consideration. The question of which important affects become significant for other phases of crying, nursing, or sleeping remains open. Another principal objection concerns interpreting a baby's behaviour-for example, sucking, looking, or moving his headas inner experience.

For this reason, Stern's results, seen in terms of affect, come off as flat and superficial, since deeper feelings are not included for consideration. Notably, empirical infant research ignores results from psychoanalytic baby observation (Bick, 1964; Miller, Rustin, Rustin \& Shuttleworth, 1989) that have been carried out for the last sixty years. In his book The Motherhood Constellation, Stern puts forth a false understanding of Bick's form of baby observation as a "therapeutic function", terming it a form of therapy (1995).

A principal criticism of empirical infant research is formulated by Green, who draws a distinction between the psychoanalytic conception of intrapsychic conflict and the observed interaction between mother and baby $(2000$, p. 66).

Fonagy speaks with great appreciation of Stern's work, but criticises a lack of terminology for aspects of child behaviour that could be linked to a given behaviour in adulthood-which would make possible genuine longitudinal observations of children through their adulthood. "Whilst Stern's observations are well operationalized in terms of mother-infant interaction and infant development, they lack operationalization in the context of adult behavior, and therefore longitudinal studies based on Stern's framework have rarely been attempted" (2001, p. 121). For Fonagy, the lack of integration among Stern's essential theoretical concepts, his "schemata of ways-of-being-with" and the "internal working models" constitute other weaknesses (ibid., p. 121).

\section{Bowlby's attachment theory}

The theory Bowlby developed proceeds from the assumption that the essential, genetically influenced emotional bonding between infant and mother-seen by Bowlby as based in an innate need for attachmentis connected to the mother's physical presence. This inborn instinctual pattern is just as essential as the infant's oral gratification. 
Bowlby's insight is indebted to animal studies, especially that of Nobel prizewinner Konrad Lorenz, who succeeded in proving through experiments the phenomenon of "imprinting" - the fixed recognition of a mother-as an inborn behavioural pattern for grey geese. Similarly, the infant is attributed an inborn tendency to seek physical closeness to a person who provides him with warmth, protection, and nutrition, thus taking away his fear of separation, hunger, and loneliness. Such inborn behavioural patterns constitute an evolutionary legacy (Bowlby, 1969). Bowlby distinguishes between five types of behaviour that are formed during the process of maturation: sucking, crying, smiling, clinging, following/seeking. In this context, the infant sees his mother as a "secure basis". Accordingly, Bowlby views early separations from the mother as highly problematic. He began investigating infant experiences of separation, where he attributed great significance to outer reality: he sought to put the attachment theory on a scientific basis, with a biological foundation. According to Bowlby, attachment comes to pass via a biological feedback loop that activates certain behaviours between mother and child. However, the child's object is not the mother as a person, but the preservation of her physical closeness, later supplemented by the psychological goal of security. Early separation from the caregiver thus constitutes an interruption of the social bond essential to life.

The significance of early loss due to death or separation constitutes a further important point in attachment theory, taken up by Bowlby from Melanie Klein.

\section{The basis for inborn behaviours}

As in behavioural research, Bowlby proceeds from the assumption of an inborn instinct the baby has to seek closeness to his mother, as can be observed with animals. Bowlby initially emphasises the biological character of this instinct. The quality of attachment to the caregiver can vary. Extrapolating from experimental situations, Mary Ainsworth, a colleague of Bowlby, was able to develop a measurement scale that distinguishes between secure, insecure-avoidant, insecure-ambivalent, and disorganised/resistant attachment patterns, outlined below in more detail (Ainsworth, Blehar, Waters \& Wall, 1978).

Whetherachildachievesa"secure", "insecure-avoidant" or "insecureambivalent" bond depends on the mother's sensitivity and empathy, according to Bowlby. The environment is assessed in terms of the 
parameters secure/insecure. The mother's interaction with her baby encompasses every aspect of life and is not confined to feeding, pace discussions of breastfeeding versus bottle-feeding in the 1950s and 60s. In the terminology of attachment theory, the concepts "dependence" and "independence" are replaced with the concepts "attachment", "trust", "loss", and "self-esteem". Instead of the rubric of an "inner world", with its unconscious processes, drives, oedipal wishes, fantasies, or inner conflicts, proponents of attachment theory speak of the concept of "internal working models" for the world and the self. These working models are constructed by every individual according to his/ her experiences, then determining his/her expectations and strategies, according to Bowlby (1979, p. 143).

This radical dismissal of psychoanalytic concepts-and especially of Klein's understanding of the inner world and unconscious fantasies as they emerge in the transference in the psychoanalytic session-was caused by a fundamental disappointment Bowlby had in his psychoanalytic teachers. He underwent analysis under Joan Riviere, a close colleague of Melanie Klein, and-as his biographer Karen reports (1994, p. 44) —was struck by a tangential remark in one of her essays: for her, the role of the environment was "virtually zero". Bowlby's misunderstanding of psychoanalysis led at first to a total rejection of inner psychic processes. The question of how people undergo qualitatively various emotional relationships is a "correct question" posed by psychoanalysis, but psychoanalysis provides the "wrong answer", since it attributes development to the "satisfaction of certain drives, e.g. nourishment for small children or sex for adults", Bowlby writes (1987). In astonishingly provocative language, Bowlby spoke at the annual meeting of the U.K.'s Institute of Psychoanalysis in 1957 on "An Ethological Approach to Research in Child Development"; as an analyst, he criticised Freud's "conceptual system of the dynamic unconscious" as unreliable, incomprehensible, and unscientific, and then spoke extensively on the behaviour of the herring gull, the stickleback, and the chaffinch. He only briefly discussed the application of ethological concepts to research on child behaviour.

Bowlby saw the sources of insecure attachment particularly in maternal depression, early separation, or insufficient sensitivity on the mother's part. According to him, the most important impetus for internal working models comes from the baby's expectation of access to his primary caregiver. The self as internal working model develops 
according to how accepted or rejected the child feels himself in his mother's eyes. A child who feels rejected by his mother sees himself as valueless, unworthy of love and flawed.

In the meantime, attention has shifted from the description of behavioural systems to the mental representations of attachment and "internal working models" (Fonagy, 2001). Key points of criticism, such as neglect of the infant's fantasies, his wishes and fears during the genesis of inner representation, were answered. The implicit emphasis on mutuality for working models of the world and the self has led to a fruitful extension of attachment theory by analysts such as Baldwin (1992) and Fonagy (2001), and psychotherapists such as Main (1991). "Internal working models" are now understood as a mixture between external perceptions and inner fantasies. In their 2002 book Affect, Regulation, Mentalization and the Development of the Self, Peter Fonagy, György Gergely, Elliot L. Jurist, and Mary Target attempt a synthesis between attachment theory and object relations theory. Attachment is here no longer the goal per se, but serves to enable the child to understand his environment, his own mental state and that of his caregiver-all subsumed under the rubric of "mentalization". Mentalising becomes a central point of social development, with the question posed: how does a child become able to understand the emotions of another person, his close environment, and his own emotions?

The "Strange Situation" as research method in attachment theory

An important motif for Bowlby's development of attachment theory was his criticism of psychoanalysis as giving insufficient consideration to actual observed situations and to empirical research. Bowlby's American colleague Mary Ainsworth developed a test that could measure the quality of attachment a nine- to eighteen-month-old baby has to his mother. She provided a useful mode of measuring attachment, based on observation, to supplement Bowlby's abstract and rather theoretical attachment theory. Grossmann and Grossmann refer to her as the "mother of attachment theory", who succeeded in the "practical application ... through field work with the Ganda in Uganda" (2003, p. 8). A model was found in the test that behavioural researchers Harlow (1958) and Hinde (1982) developed in animal experiments with chimpanzees, where they measured the chimpanzees' behaviour towards artificial chimpanzee "mothers" constructed out of wire. Since 
the "Strange Situation" is the best-known test devised for examining patterns of attachment, we will describe it here.

The Strange Situation procedure comprises a twenty-minute long "arranged" situation where one parent is in the same room with the stranger (Ainsworth, Blehar, Waters \& Wall, 1978). The mother (or father) is then requested to leave the room for three minutes, leaving the child with the stranger. After the mother (or father) returns, and after a short interval, the parent again leaves the room for three minutes; shortly after, the stranger does the same thing. After this, the parent returns to the child.

The eight steps in this experiment are:

1. Parent and child enter the room.

2. Parent sits quietly, responding if the infant seeks attention. The third person joins them.

3. A stranger enters, talks to the parent and gradually approaches the child with a toy.

4. The stranger leaves the infant playing and then tries to interest the infant in toy.

5. The parent enters, the stranger leaves quietly and the parent waits until the child settles; then the parent leaves again.

6. The infant is alone.

7. The stranger comes back and repeats episode 3 .

8. Parent returns, stranger leaves. Reunion behaviour is observed.

The entire course of events is recorded on video, with particular significance ascribed to the child's behaviour during separation and at the parent's return. If the child becomes distressed, the experiment is broken off and the parent returns earlier. Subsequently, the video is evaluated. Two aspects of the child's behaviour are observed: the amount of exploration (e.g., playing with new toys) the child undertakes, and the child's reaction to the departure and return of the parent. Categories of attachment patterns were devised —at first three, then later four:

Secure Attachment ("B"): These children are unhappy at separation. When the parent returns, they go to him or her, let themselves be consoled, and then go back to their play.

Insecure-Avoidant Attachment (" $A$ "): These children show few signs of distress when the parent leaves the room, and do not react to the mother 
or father particularly after the second, more stressful separation. They remain watchful of the parent and inhibited in their play, treating the stranger similarly to the parent.

Insecure-Ambivalent/Resistant Attachment (" $\mathrm{C}$ "): These children are highly distressed when the parent leaves the room. At the parent's return, they alternately cling to the parent and push them away. Their play is inhibited.

Disorganised/Disoriented Attachment (" $D$ "): This small group shows a range of confused behaviour, or stereotypical movements when the parent returns, including "freezing" and rocking. Lack of coherent attachment strategy.

This test has by now been employed in numerous empirical studies in various cultures and is recognised as a valid, reliable measure (Holmes, 1993, p. 105). In the middle-class Baltimore Study, made by Ainsworth, Blehar, Waters, and Wall, $66 \%$ of the children were securely attached, 20\% insecure-avoidant, and 12\% insecure-ambivalent (the fourth category " $\mathrm{D}$ " did not yet exist). Cultural tendencies were also observed-in the USA and Western Europe, there was more insecureavoidant attachment " $\mathrm{A}$ ", whereas in Israel and Japan the proportion of insecure-ambivalent attachment " $\mathrm{C}$ " was higher. A child's emotional attachment to his mother can have another quality than to his father, and many researchers therefore recommend that both parents take part in child care.

With the help of the Strange Situation, empirical research succeeded in reversing firmly held prejudices, for example, that working mothers achieve an inferior attachment compared to stay-at-home mothersalthough the quality of care seemed to constitute an important factor (Mussen, Conger, Kagan \& Huston, 1990, p. 187).

In order to measure parental behaviour as related to attachment, Main, Kaplan and Cassidy (1985) developed a semi-structured interview - the "Adult Attachment Interview" (AAI)—for measuring the parent's internal working models. The interview was conducted similarly to a first therapy session, where the "unconscious should be surprised" in order to stimulate it into self-reflection (Main, 1991). Interviewees are first requested to supply five adjectives for their childhood relationship to their father and to their mother, and to describe typical family constellations and scenes: how they behaved as a child 
when they were excited or upset; which parent they felt closer to and why; whether they had felt rejected or threatened; why they think their parents behaved as they did; how the relationship to their parents has changed over time; and how their early experiences have influenced their current life.

The interviews are audiotaped, transcribed, and then ordered according to eight categories: loving relationship to mother, loving relationship to father, role exchange with parents, capacity to recollect memories from their childhood, anger at the parents, idealisation of the relationship to the parents, denigration of the relationship, and narrative coherence. After this, an assessment is made according to four qualities of internal attachment patterns: "autonomous", "dismissed", "preoccupied" and "unresolved/disorganised". Here, not only the content but the quality of the discourse is important: openly expressed, coherent, and characterised by an inner cohesion, as with the "autonomous" parents-or short, incomplete, and fragmented, with the tendency to idealise the parents in childhood recollections, as with the "unresolved/disorganised" parents.

This possibility of measuring a child's attachment patterns to his parents has proved a boon for empirical studies. In a broad investigation of couples during pregnancy, Fonagy researched their own attachment patterns with the help of the AAI in order to predict the quality of attachment to the baby (Fonagy, Steele, Steele, Moran \& Higgins, 1991), with the same families subsequently tested six and twelve months after the baby's birth.

Such attempts to order complex and manifold relationships into four categories of attachment patterns are undoubtedly useful for research questions, but for case studies, a classification into four categories has often proven problematic: in understanding the particular, unique relationship one baby has to his parents, this test instrument has not proved to be a particular enrichment (Datler, Trunkenpolz \& Funder, 2002).

\section{Criticism of attachment theory}

Bowlby's theory has been criticised as reductionist. Above all, his comparison of human beings with grey geese irritated his colleagues: "What is the point of analyzing a grey goose?" asked Hanna Segal provocatively (1989). Although Bowlby was active as a psychoanalyst, he attributed almost no significance to inner reality, the oedipal conflict, or 
fantasy. The clinical examples he included came from the work of his colleagues, since he saw himself mainly as researcher and administrator. In a chapter on Bowlby and the inner world, his biographer Holmes writes: "Dreams are nowhere to be found in his work, and he is, for the most part, concerned with observable behavior rather than with the inner world" (1993, p. 127).

The assumption that internal working models constitute a linear depiction of outer reality does not adequately explain clinical experience from psychoanalytic practice, where the strictness and cruelty of a child's superego and its distortion of the picture of his real parents become so evident. In contrast to Freud and Klein, Bowlby did not take the individual differences in babies' personalities into consideration, since he saw attachment as a reaction to a child's real experiences. Holmes, an important proponent of attachment theory, remarked: "It is worth noting that Klein, like Freud, assumes that there may be constitutional differences between infants, a point which Bowlby tends to overlook" (ibid., p. 131). In addition, the few clinical examples Bowlby includes are not particularly convincing. He attempts to demonstrate that the causes of a patient's psychic problems only proceed from real experiences. Bowlby describes the family history of a mother inclined to inexplicable episodes of aggression, struggling compulsively against her impulse to throw her eighteen-month-old son out the window and commit suicide: she came from a family fraught with bitter parental quarrelling, where the mother had made several suicide attempts from which she had been saved by her daughter, Bowlby's patient. In conclusion, he writes: "My reason for supplying with this brief outline is that it describes certain pathological processes I find typical. Patients who suffer under strong and apparently inexplicable fears of being unloved, being abandoned or of the death of a person close to them, usually or perhaps always are reacting to real situations they were once in: sometimes far in the past, sometimes quite recent, often both" (1980, p. 50). Here, Bowlby excludes the psychoanalytically relevant line of questioning regarding what influence real experiences had on the development of the inner world and the formation of the transference relationship with the analyst.

Through this exclusion of the child's or patient's inner reality, Bowlby avoids discussion of the way she or he handles longing, aggressions, envy, and rivalry. In attachment theory, the child's developmental disorders are regarded as a consequence of the mother's insufficient 
sensitivity or accessibility. Criticism has also been made of the implicitly normative assertion that the mother must be amply accessible during the child's first year of life, since this criterion has been perceived as an implicit rebuke to working mothers, for example when Bowlby writes that "... in the first year of life ... a person, whoever it may be-and usually, this is the mother-is capable purely through his or her presence or immediate accessibility of supplying the conditions enabling to exploring the world with confidence" (ibid, p. 50).

Perhaps the controversy in the 1950s and 60s among "psychoanalytic schools" from Melanie Klein to Anna Freud served as an additional impetus towards extending their lines of questioning (but not necessarily their conclusions). This can be seen in Bowlby's research on war orphans in Anna Freud's "Hampstead War Nurseries", where with his colleague Robertson he investigated the effects of early separation from the mother; on the other hand, Bowlby underwent his student psychoanalysis with a Kleinian analyst, which may have led to a conflict in loyalties.

In a critical assessment, Fonagy (2001) expounds his view that the aspects of temperament and personality in the baby, neglected by Bowlby, constitute an important dimension (p. 25). A meta-analysis of sixty-six investigations, which together involved over 4,000 infantmother dyads, where attachment was investigated, showed a level of correlation that is "small by any standards" (ibid., p. 26). The quality of maternal care, reactions to corresponding stimulus and stress, warmth, and synchronised interaction can be regarded as indicators for a secure attachment (Belsky, 1999). However, other types of maternal behaviour, for example, intrusive, overstimulating or controlling behaviour in the context of insecure-avoidant attachment, have only been correlated to a statistically negligible degree.

The wide dissemination of attachment theory can presumably be attributed to the fact that behaviourism could not explain the complexity of human interaction between mother and child. The exclusion of deeper dimensions-sexuality and the death instinct, fantasy and the dynamic unconscious-has undoubtedly facilitated the theory's reception.

\section{Summary}

This short overview of the four contemporary psychoanalytic theories of development demonstrates their various basic frames of reference. 
For the sake of clarity, I described what they have in common and where they differ. Freud considered the object pre-eminently in the framework of drive expression, as a means of satisfaction. The Oedipus conflict was central for him, and he emphasises his incomprehension of the nature of pre-oedipal development (1931b). It can be seen that theories of early life are based upon Freud's comprehensive theoretical edifice-drive phenomena, affects, and the formation of intrapsychic structures.

Discussion of the significance of outer reality, that is, concrete interaction between persons (mother-baby), versus the inner world, the intrapsychic dimension of individual experience (fantasies, wishes, envy, aggression) involving other persons, has led to further development and differentiation in psychoanalytic theory. Kleinian theory and techniques developed from a terminology of "part objects" to a very concrete language of "the good/bad breast", the "persecuting penis", all of which Klein linked in a fresh way to clinical material. Many of her colleagues, it must be said, employed these physical-corporal interpretations in a routine, forced manner. Spillius emphasises that today, analytic interpretations are linked more strongly to physiological functions such as "... seeing, hearing, thinking, evacuation. Together with the increasing emphasis on function, concentration on the 'total situation' of the patient's immediate experience in the transference during analysis often leads to discovery of deeper layers of meaning, some of which may be seen to be based on infantile bodily experience" (1994, p. 351). Instead of the paranoid-schizoid and depressive "positions", these are understood as forms of thought and feeling, as "states of mind".

Some of Klein's hypotheses about small children, particularly the assumption of a rudimentary capability to differentiate between self and other, appear confirmed by empirical infant research. Stern writes:

Infants begin to experience a sense of an emergent self from birth. They are predesigned to be aware of self-organizing processes. They never experience a period of total self/other undifferentiation. There is no confusion between self and other in the beginning or at any point during infancy. They are also predesigned to be selectively responsive to external social events and never experience autistic-like phases. $(1985$, p. 10)

More dialogue and cross-pollination between psychoanalytic theories and empirical infant observation and attachment theory would be desirable. Psychoanalytic hypotheses on child thinking and feeling 
should be consistent with empirical findings, and empirical research would be enriched by taking psychoanalytic concepts of development into greater consideration. For example, the valuable contributions from Esther Bick's technique of psychoanalytic infant observation have been little considered. Even within the Kleinian school there exists only a subgroup that concerns itself with infant observation, and attempts at correlation between clinical analytic work and psychoanalytic observation have been only sporadic (Rhode \& Klauber, 2004; Rustin, 1989; Waddell, 2002; Williams, 2003). In this discussion of the early years of life, we should aim to render Kleinian theory fruitful in actual observation, and to describe clinical examples from child analysis in illustration.

\section{Notes}

1. The controversial discussions between Anna Freud and Melanie Klein, which took place between 1941 and 1945 in the British Psychoanalytical Society, count among the most profitable and fruitful encounters for the development of psychoanalysis. (King \& Steiner, 2001).

2. The "Independent Group" sought to develop an independent body of theory that would not be fully indebted either to Melanie Klein or Anna Freud in content.

3. In the monograph of the International Psychoanalytical Association "On Freud's On Narcissism: An Introduction: Freud Today. Turning Points and Controversies", 1991, the conceptualisation of narcissism is extensively discussed.

4. In the introduction (p. 4) to the English (1974) and the German (1980) versions, viewing her work in the context of a complete edition, Anna Freud wrote that these comments required "modification". The reported age of the children in analysis was corrected: their ages had actually ranged from two years to early or advanced puberty.

5. A thorough description of developmental theory in Freud, Klein, and Bion with regard to the genesis of the body ego, feeling and thinking, and psychosexual development, is provided in my book The Early Years of Life. Psychoanalytic Developmental Theory According to Freud, Klein and Bion (2007).

6. Other important proponents of Klein's thinking such as Hanna Segal and Herbert Rosenfeld can here only be mentioned in passing.

7. The idea of describing development from the baby's perspective (Stern, 1977) is continued and developed by Stern in his book Diary of a Baby (1991). 
CHAPTER THREE

The second year of life

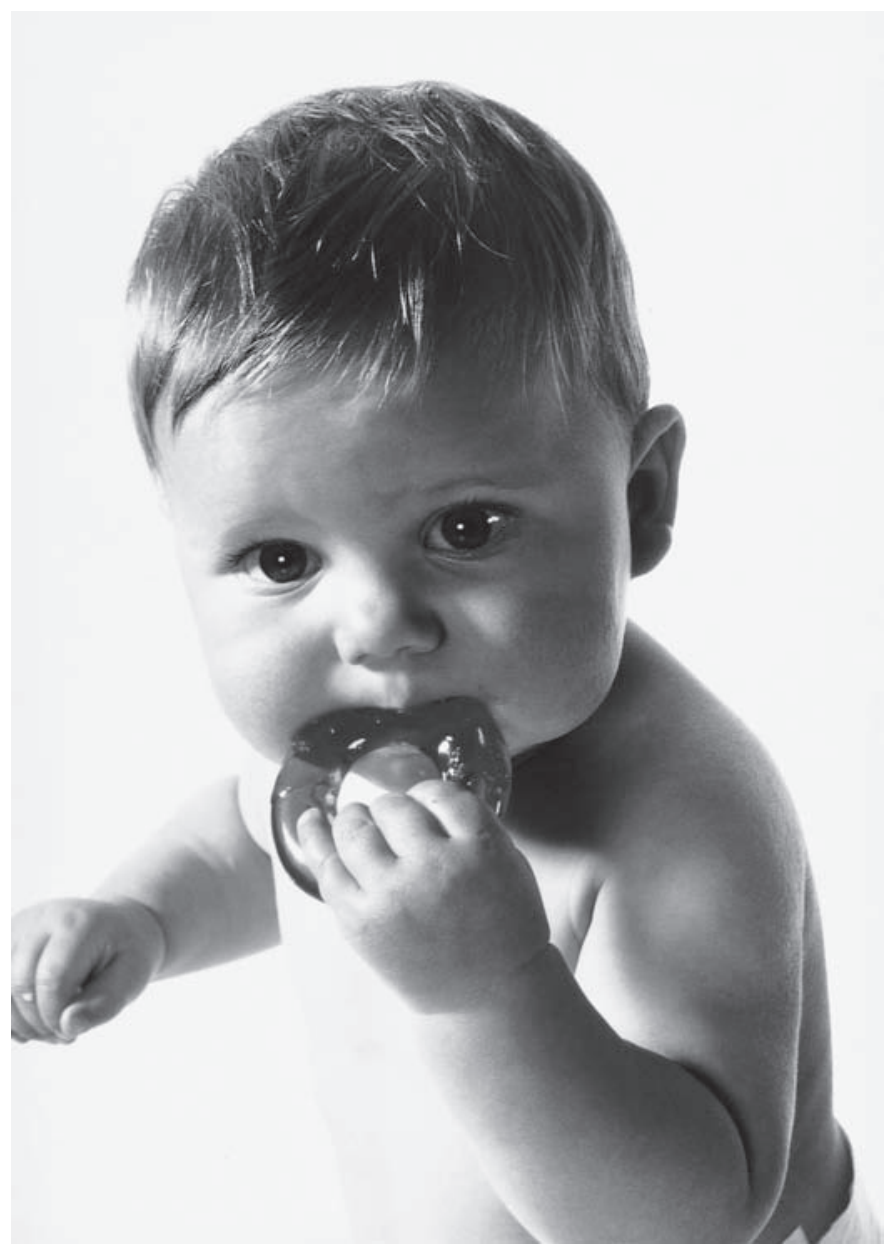



$\mathrm{I}$ n his second year of life, the child gains a new perspective on the world from the standing position. Since he also can use language, he is able to make himself understood in a more differentiated way, describing and demonstrating his wishes and emotions. He can express his inner feelings and experiences through play and symbolically. Through his new physical and psychic capabilities, he acquires independence and can do things on his own: he becomes a "toddler".

In this section, I will try to view the world from a toddler's perspective, in order to gain insight into his feelings and what lies behind his behaviour. We must bear in mind that in spite of his two new capabilities-standing upright and language-the two year old has not yet established psychic stability: on the contrary, particularly when he is tired or fearful, he can veer rapidly between optimism, independence, and infantile helplessness. Many parents have difficulty empathising with these mood swings, and tend to place too many demands on their child since he understands and cooperates so well during good phases. When a child is well rested and active, the world is an exciting place waiting to be discovered, and he investigates mysterious objects in daily life with great seriousness. When a child feels needy 
and small, he wants nothing so much as to be lifted by his parents back to a sheltered, secure place.

I would like to describe paths of development for the second year of life in terms of the following rubrics:

- The urge to walk

- Independence and separations

- Children's play

- Discipline and order

- Acquirement of language

- Toilet training

- Development of sexual identity.

\section{Paths of development in the second year of life}

\section{The urge to walk}

The small child, who has heretofore achieved motor skills by crawling, now learns to stand up and walk. The way this transition is accomplished varies from child to child. It is fascinating to observe each child mastering this challenge in his own way; the point in time also varies-some children already can walk at eleven months, others only at eighteen to twenty-two months. Some parents become uneasy when their child has not yet made attempts to stand up by the time of his first birthday. If the child is active, attentive, and mobile, there is no cause for concern. He might already be expressing himself through a variety of sounds and yet still be moving on all fours, might understand everything he hears, and fetch objects for himself but still only start standing up several months later. The transition from crawling to walking can be quick or can take weeks, studded with numerous disappointing attempts where the child falls down through his own incompetence and becomes angry. The best support parents can offer is to grant their child his own individual timespan, allowing him to make his own experiences on his own as far as possible. Ambitious parents who spur their child to start walking before the child is ready actually hinder his capacity for learning. Such a child will then tend to require a helping hand, and may never learn how to grasp onto objects in the room for support.

From his standing position, the child now views the world through a new, more adult perspective. He can fetch his own toys; his hands 
are free to hold objects. He can reach objects that are further up, so that parents may have to relocate them to safe places in the kitchen and living room. The child's delight in these new capabilities goes hand in hand with his delight and pride in walking: he is constantly in motion, practising and perfecting his new ability.

With a child who has just learned to walk, a short trip to the supermarket becomes a voyage of discovery that can last four times longer than it otherwise would. Every level must be climbed, each entryway requires inspection. A leaf lying on the way is picked up and examined, or put in the child's mouth. A small bug excites as much attention as dog faeces. A garage ramp represents an invitation for the child to mount and descend it over and over, tying to master this skill even while repeatedly falling down. The parents are faced with their own balancing act-honouring their responsibility to protect their small child from accidents while granting him enough space to experiment and investigate. Before any expedition, parents should assess whether time will be limited-in which case it is advisable to bring the baby carriage - or if extra time can be allowed.

On a psychic level, the experience of independence also affords the child a feeling of greater self-confidence. For some parents, especially mothers, their child's increased independence is a relief, but this is nevertheless often tinged with a sense of regret for the loss of the unique intimacy between mother and baby.

\section{Independence and separations}

In the second year of life, the small child discovers not only his environment, but above all the meaning of independence, of being a distinct person with his own will. He seeks to get his way with his parents and fights for his own ideas, simultaneously observing parents and siblings with great precision, aspiring to emulate and mimic them. Accordingly, objects from daily life become far more interesting than the child's own toys. A child watching his mother cook is happy when he can open the bottom drawer of the kitchen cabinet, extracting cooking utensils, pans, and plastic containers. Since he now can walk alone, he can decide how close or far to his parents he wants to be. He can toddle into his own bedroom - or back to the kitchen or living room when he feels the need for his mother or father. The child's premature aspiration to do everything on his own with his still limited skills often makes for frustration 
and anger. The wish to get away from his parents quickly segues into fear of abandonment. When a child runs away, inducing his mother or father to run after him, I see this as a playful test of whether they are truly following and looking out for him. Here, the child is testing his own freedom, but also testing whether the mother or father will catch him.

One could also say that in this phase, the small child has become simultaneously more and less dependent. Parents complain of their child now crying every time they leave the room. It is important to understand that in this short phase, the child's increased autonomy can also increase his fear of being abandoned. Parental empathy will help phase out this behaviour quickly. "Training" the child to be alonefor instance by shutting him alone in a room, only to have him cry or scream-will merely increase his fears, not his confidence in being alone, therefore making the child even more dependent and giving him the impression the world is a dangerous place. Small children are grateful when their parents help them be independent. One mother told how she had taught her fourteen-month-old daughter, who constantly wanted to climb up on a chair in the kitchen, how she could do this unassisted. The daughter then pushed the chair with all her might to wherever the mother happened to be in the kitchen, pulling herself up onto it and helping wash vegetables, make dough, or cook. This "training" only required twenty minutes. Brief expressions of encouragement and praise from her father and mother then turned each time the daughter climbed onto the chair into a pleasurable experience.

I would like to demonstrate how important it is to encourage a child's independence, through observations of two related scenes.

"The one-and-a-half-year-old Michi has discovered that he can take out pieces of a wooden puzzle with a handle. He laughs and tosses one piece at a time on the floor. The mother, who is reading a newspaper next to him, glances at him from time to time and throws him encouraging looks. She seems to recognise what joy he has in his active role, taking the animals and figures out and flinging them away. The mother accompanies each fling by saying 'bums', which elicits a proud laugh from Michi. When they are all lying on the floor, he crawls towards the wooden pieces to pick them up and place them in his mother's hand. The mother smiles at him, saying 'Thank you' each time. Michi smiles back at her, and by the third time begins imitating her 'Thank you'. 
This interaction is so interesting for him that he in fact picks up all the wooden pieces. The mother draws his attention to pieces that lie further away, pointing with her finger and saying: 'Look, the train is still lying over there.' By the third time, Michi has discovered that piece and retrieved it. When the mother has all the pieces in her hand, she stands up and goes over to the puzzle. Turning to Michi, she says, 'Look, Michi, now I'm putting the pieces back in. This is a doll carriage,' then putting that piece back in. With the locomotive, she imitates the noise a locomotive makes: 'It fits in here ... and this is a cat. What sound does a cat make?' Michi watches each movement his mother makes, and imitates the locomotive noise. When asked about the cat, he answers 'Meow.' She praises him and imitates his meow. Michi takes one figure out of his mother's hand and puts it into the lower left corner. The mother positions the piece so that Michi can put it in himself. She praises Michi and describes for him what he is doing: 'Yes, that's the locomotive, it belongs in here.' When all the figures are in, Michi is allowed to take them out again."

\section{Discussion}

Observation of the mother and child reveals their close harmony with each other. The mother encourages Michi's activity without ever compelling him to do anything. She is able to wait until he himself is ready to put a puzzle piece back in. Through her verbal encouragement, thanking him for picking the pieces up, all his actions receive appreciation, which in turn motivates him to longer stretches of this activity. The mother shows her son that each thing has its place, has a name, and can make a noise. Bringing her attention and empathy to bear, she expands Michi's attention span; he is eventually able to retrieve all the pieces, even those hidden ones. He devotes his attention to the way objects are formed and starts to recognise the discrete positions they fit into, thus perceiving the entire form of the puzzle, with the figures fitting their forms just as his activity "fits" his mother's attention. Every time, he hears the same name for the same figure and a noise he then attempts to imitate, helping him forge the requisite connections and-laterrecognise words more easily, in turn enhancing his verbal development. At the same time, he experiences his mother's loving attention, her joy and her pride in what her son is already capable of. 
From another observation, this time of a toddler the same age as Michi with his father:

Little Bob grasps the handle of a puzzle piece carefully with this thumb and index finger and pulls it out. He seems surprised and pleased that this works. He studies the piece, and looks over to his father, who is reading the newspaper. When the father does not return his son's glance, the son throws the puzzle piece across the room. The third time he does this, the father looks up briefly, murmuring severely, "Don't throw things around that way," but remains seated. When Bob nevertheless throws the pieces around more and more wildly, the father stands up reluctantly. "No, we don't just throw things around the room," he says in a strict tone of voice. The father tells Bob to pick up the pieces, but Bob does not comply. The father then picks up the pieces himself and suggests that they play together. He holds each piece up to Bob, names it by its name and expects Bob to put it in its proper place. "Where does the locomotive belong?" he asks Bob. When Bob puts the piece in the wrong place, the father corrects him. With the third piece, Bob loses his patience, he pushes the puzzle away with his foot, which irritates the father.

What has been conveyed to Bob through this encounter? He discovered it was not possible to comply with his father's prohibitions. His father only reacted after Bob became noisy. Bob's main impression was of his father's dissatisfaction at Bob's inability put the pieces back better. Bob is alternately not granted recognition, criticised, or overly challenged.

When a child who cannot yet do or understand so many things nevertheless demonstrates a hunger for independence, this places high demands on his parents. The child has discovered that he can get his way, that he can say "No". Often he will say "No" to things he likes to do, and make decisions even when they are false. But every false decision constitutes a potential learning experience. It is easy for parents to become caught up in a power struggle or to overestimate their child, presenting him with choices that challenge him beyond his capabilities. Often, parents exacerbate this situation by offering their child various options for what to eat at breakfast or which clothes to put on that day. A child who is offered either a glass of cocoa or juice or tea may not yet be capable of choosing among them. If he points to one of the things 
proffered, he might then push the very glass of cocoa away he had just wished for, then reaching for his mother's glass. A glass of cocoa that is presented as a matter of course, accompanied by a cheerful commentary on how good it will taste, is easier for the child to accept.

The certainty that no small child will voluntarily go hungry, but will at some point eat something, can help to relativise the power struggles frequently involved in feeding. Certainly, parents' basic attitudes and experiences they themselves had as children play a large role. Parents who were forced to eat when they were children themselves and can recall their attendant feelings of rage and helplessness will presumably opt for putting smallish portions of food on their child's plate, then allowing him to take more for himself.

Even though their vocabulary is quite limited in the second year of life, children succeed in expressing themselves with surprising subtlety-and asserting their independence. Here are two examples from an observation of Karl, twenty-one months old:

Karl came from his room into the kitchen, where his mother was occupied with cooking lunch. He climbed onto his chair, sat down, and said—without being asked anything_-"Yes." When his mother failed to react, he propped up his arms on his elbows, moving them simultaneously towards the table, nodded, and said "Yes! Yes!" in a friendly tone of voice. Now his mother looked towards him, observing him with a smile, and then in fact asked him a question: "Are you hungry, Karlchen?" He looked at her and said again, "Yes." She explained that the food would be ready soon and described the things remaining to be done. Karl did not let her out of his gaze, observing her every instant and reacting with great pleasure when she was finally done and gave him his bowl of soup with a spoon in it. He immediately took the spoon and ate his soup, with part of it ending in his mouth and another part back in the bowl.

Here, one derives the impression that Karl was not only interested in receiving his food, but in being understood-almost as if he was testing whether his mother would react to his signals. Children are not only constantly and tirelessly exploring the world, but are also sharp observers of social interconnections. We often discover children enthralled in their study of adults or of other children, negotiating with each other or solving some conflict. Through observation, they absorb not only 
facts but also emotional patterns of interaction, modified through the prism of their own feelings and fantasies. In play and in dreams, both cheerful and disturbing scenes are then re-enacted or worked through. Now follows another observation of Karl a few weeks later, while his grandmother was preparing dinner:

Karl had a bowl of squash soup sitting in front of him. With considerable appetite, he attempted to eat it. He held the spoon very low and tried hard to get the soup into his mouth, but when he raised the spoon he turned it in such a way that almost its entire contents fell out. His grandmother sat next to him and ate her own soup, nevertheless observing her grandchild at the same time. In an inconspicuous fashion, she tried to get the spoon with soup in it into his mouth. As soon as she got close to his mouth with the spoon, he closed his mouth and turned his head away. Shaking his head, he also refused her suggestion of alternately taking a spoonful from her and by himself. As soon as she put her own spoon away, he again tried to eat, but with no more success than before. The grandmother refrained from comment, giving him a sceptical look. When she shortly thereafter once again attempted to put a spoonful of soup into his mouth, he closed his mouth, put his own spoon away, and closed his arms over his chest. His message was unmistakable: either he should eat alone or not at all. When she accepted this, nevertheless continuing to look at him, he turned to her and said in a bold tone of voice: "Eat!" The grandmother had to laugh, since this sounded like a reproof of an adult and she was now placed in the role of the child who refused to eat correctly. When he had spooned out half his soup using his own techniques and it was clear this would continue for quite a while, his grandmother suggested putting his rice into the soup. Karl accepted this suggestion, he pushed the bowl closer to her, and she put a large spoonful of rice into it. Karl could consume this mixture of soup and rice by himself without effort and with obvious pleasure. His grandmother also seemed relieved to have discovered a compromise.

Karl's mother had never forced her children to eat, simply trusting them to eat when they were hungry. Karl's sister, two years older than he, ate with obvious enjoyment-one could see how good food tasted to her. As a baby, Karl had drunk so rapidly that he frequently spit up 
a bit of milk afterwards, and his mother was often unsure of whether he was actually sated. Already at a very early age, he wanted to eat by himself and evinced great stubbornness in this. In the scene we saw, Karl succeeded in unequivocally showing he wished to eat by himself or not at all. Possibly he wishes to be just as independent as his older sister. When his grandmother observes him instead of herself eating, he speaks to her in a bold tone of voice he must have heard from his mother or father. Subsequently, he in fact manages to make his grandmother accept his independence.

Sometimes, however, accepting a small child's wish for independence is difficult, for example when he refuses to put on his mittens or gloves on a cold day. Apropos an observation:

Karl sat in a duvet in his carriage, with his two years older sister holding on to it as his mother was pushing him. The mother tried to make both children put their gloves on. Her explanation-that it was cold out and their hands would get red and start to hurtfailed to convince them. She breathed out into the cold air, to show Karl how chilly it was. When she took his hand, he resisted, shouted "No" and took his hand away from hers. Several attempts by the mother were unsuccessful, until she became more and more irritated and finally gave up, since he kept taking the mittens off immediately. After fifteen minutes, when the sister's hands were already red from cold, she asked her mother to help her put on the gloves. Now the mother and daughter together put each finger into the gloves. Karl observed this procedure with great interest. When the mother was done, he stretched his hand towards her and said "Me too." His mother praised him and, relieved, put his mittens on him, which he accepted without resistance.

The description shows how difficult this phase in the child's second year is for parents to manage. Frequently, matters are involved that cannot be open to discussion: often the only possibility is to pick up a child who has refused all explanations and attempts at playful persuasion and, in spite of all his cries of protest, carry him away from some dangerous situation. When a child takes his gloves off for the umpteenth time, pushes something away or protests, it helps to remember this is a phase that will later pass. Rebellion-staking out the boundaries between self and environment-is a necessary phase of 
transition leading to autonomy. No parent would want a child to be a compliant "robot" (Spock \& Parker, 1998, p. 257). Often, older siblings are of help, since the younger child then sees more clearly that the same rules hold for all; emulation of older siblings constitutes an important motivation.

These examples demonstrate what a challenging time this second year is for both parents and child. Accordingly, much is made of the child's "negativity", the "obstreperous phase", or the "terrible twos", but this is also a fascinating period of development during which children learn an enormous amount; acknowledging its inevitability may help parents and other caregivers avoid being trapped in power struggles and instead consider a range of alternatives, keeping in mind they often must reckon with the child's protests. This phase of boundary-staking results in the child's stable knowledge of who he is, and yet it is a period fraught with fears. If the parents let themselves be lured into power struggles with their child, it is often difficult to find a pathway out. Parents are then often reduced to mainly uttering commands, in such curt phrases as "Come on!", "Do it!", "Just go!", “No!", "You just wait!", “Get away!", “Out!”, “Come along!”. In my psychoanalytic work, children as young as two-and-a-half play father and child with me, commanding and then terrorising me, swinging from impatience to scorn, pressing my head into a pillow in attempts to force me to sleep; they yell abruptly, becoming completely red in the face, threatening to go away and leave me alone or lock me up in the room. Naturally, a mother or father will inevitably sometimes lose patience and begin yelling. The question is whether this is then followed by some form of reconciliation or explanation, so that both child and parent can manage or master such threatening encounters. Ernst Jandl and Inge Meyer-Dietrich draw us closer to the child's perspective:

\section{quiet poem}

listen, you don't talk and eat. don't talk with your mouth full. now the grownups are talking, not the little ones. shut your mouth, deadbeat. if you're a poem, it's the quiet part. small as you are, you may be smart. or if you're dumb, at least be silent. 
look up, how beautiful above, you donkey,

the blue sky.

Ernst Jandl (Gelberg, 2000, p. 44)

\section{Rage}

Mama, today you're stupid.

Mama, you're dumb!

I could throw you in the trash,

The big one down in the run.

Bang! I put down the lid

And sit myself on top.

Only when you stop screaming

Will I open it and stop.

Mama, don't look at me so!

I can't help what I do.

You bug me so much

What's the matter with you?

Now I'll shout as loud as you

And you'll listen to me, too!

Inge Meyer-Dietrich (Gelberg, 2000, p. 134)

Often parents do not notice whether or not they themselves stick to the rules they have devised. In "Rage", we are confronted with a reversal: a child speaks to his parents as he has been spoken to. When parents address their children with respect, this constitutes an important regulating influence. Would they be outraged or insulted if their child spoke to them as they do to the child; would they deem it impudent and unacceptable? As important as it is to establish rules and rituals and to be consistent in holding children to them, the most important consideration is what example parents set for their children. One three year old was observing his grandfather, who shortly before had instructed him not to speak with his mouth full. When the grandfather himself began to speak with a full mouth, the child said in just as sharp a tone: "Don't talk, first swallow!" When the parents laughed, this indeed gave the grandfather food for thought.

Parental threats often throw children into anxiety, since they truly believe they might be thrown out with the trash, left alone at home, be shipped off to an orphanage or elsewhere. 
Children's play offers access towards understanding their inner world, expressing as it does a child's wishes, fears, and images of himself, his parents, and the world.

\section{Children's play}

Play is just as important to children as eating and sleeping. It has great significance for child development, since it constitutes a means of expression-a language-for the child's state of mind. Through play, a child explores both the world and his feelings as he comes into contact with that world. He can express his joy, fear, and destructivity. The preservation of a playful approach to life into old age is an expression of vitality. When a child is unable to play, if that activity is inhibited, this indicates severe emotional problems and/or retarded intellectual and emotional development.

Interaction between parents and baby-sound imitation, tactile contact-forms the foundation not only for play, but for the child's consciousness of himself as a separate person. In the second year of life, play between parent and child often consists of naming and pointing out various parts of the face. Where is your mouth? Where is Mama's mouth? These questions, together with the pointing gesture, delineate the difference between mother's and child's mouth. At the same time, the child acquires the ability to name parts of both his own and his mother's body. The fact that abstractions such as mouth, nose, and eyes not only describe the child's mouth but are applicable to anyone is imparted through play. Evidently, games of grasping and holding have not only physical but cognitive ramifications.

The seriousness and concentration of a child at play are palpable and impressive. He investigates every kind of object, attempting like a scientist to explore their diverse functions. Covers, switches, containers, pots-all of which the child can knock, strike, push to and fro, open and close-are of interest. Balls, buckles, and keys are set into motion, inserted, and retrieved: the aim is to discover what happens when one object is put together with another object. Thus, a pea is dropped into the juice, a ball is put into a box, and a stone into a shoe. Particular attention is given to any object the parents also use, such as the telephone, the remote control of a television, the mother's handbag, the father's key chain. This kind of play, which parents occasionally find senseless, has great significance for the child. Fairy tales and children's stories 
also depict this childish approach to the world-in Winnie-the-Pooh, we read of the two presents Eeyore the donkey receives for his birthday.

The melancholy donkey is especially sad because at first nobody has thought of his birthday. Winnie the Pooh decides to give him a pot with honey. But since he loves honey more than anything else, he cannot help but eat all the honey up himself. Then, however, Winnie has the consoling idea of giving Eeyore the empty pot, since he could keep things in it. Piglet wants to give Eeyore his balloon, but while he is walking he stumbles and the balloon bursts—so he gives Eeyore the burst balloon. First, Piglet gives Eeyore the remains of the balloon and then Winnie comes and ... :

"It's a Useful Pot," said Pooh. "Here it is. And it's got 'A Very Happy Birthday with love from Pooh' written on it. That's what all that writing is. And it's for putting things in. There!"

When Eeyore saw the pot, he became quite excited.

"Why!" he said. "I believe my Balloon will just go into that Pot!"

"Oh no, Eeyore," said Pooh. "Balloons are much too big to go into Pots. What you do with a balloon is, you hold the balloon-"

"Not mine," said Eeyore proudly. "Look, Piglet!" And as Piglet looked sorrowfully round, Eeyore picked the balloon up with his teeth, and placed it carefully in the pot; picked it out and put it on the ground; and then picked it up again and put it carefully back.

"So it does!" said Pooh. "It goes in!"

"So it does!" said Piglet. "And it comes out!"

"Doesn't it?" said Eeyore. "It goes in and out like anything."

"I'm very glad", said Pooh happily, "that I thought of giving you a Useful Pot to put things in."

"I'm very glad", said Piglet happily, "that I thought of giving you Something to put in a Useful Pot."

But Eeyore wasn't listening. He was taking the balloon out, and putting it back again, as happy as could be ... . (Milne, 1973, pp. 80-81)

It is often difficult for adults to realise what could be so desirable in a broken balloon or an empty pot, in fact so desirable that three animals can be perfectly happy. Milne shows how receptive children are 
to consolation and reconciliation: they can even appreciate a gift gone wrong.

Parents who believe children ought to busy themselves with their own toys forget the fundamental meaning of children's play: developing acquaintance, confidence, and mastery regarding the outer world. Every object from daily life is new to the young child and of interest. It is therefore advisable to structure the living space into a safe environment for the small child, who wishes to touch, grasp, and put everything in his mouth. In addition, the child investigates his own body, sticking his fingers in his ear, nose, and genitals, with the parents' bodies also of great interest-how they eat, wash themselves, their body care, and excretions. The child is as yet innocent of disgust, finding virtually everything interesting.

Play has great significance as a means for expressing feelings. Zulliger (1970) has spoken of the "healing powers in children's play". In play, a child can show his affectionate, tender feelings, caressing and holding a stuffed animal or teddy bear. When he hurls the same stuffed animal away or topples a tower, he can express his destructivity. I would like to describe an example of how one seventeen-month-old girl expressed her rage and desire for vengeance towards her parents-who had gone away for the weekend-in play.

The little girl was playing with a wooden Noah's ark, whose roof could be taken off, with two human figures and various pairs of animals at the back of the ship. She put the house onto the ship, put the roof on top and put some of the other animals together in pairs. Then she found the two human figures, whom she called papa and mama. She opened the roof, took the crocodile out, put the two human figures inside, saying "Go to sleep." After a few seconds she put both crocodiles with the parents and left them that way, with a satisfied look on her face. Her grandmother, who had been watching her play, said that the two crocodiles with papa and mama had dangerous teeth. The girl briefly made a face, knitting her eyebrows together and sticking out her chin. She let the crocodiles inside and turned to another game.

It seems to have provided ample satisfaction for this little girl to imagine the crocodiles impeding her parents' sleep, punishing them for their going out by biting them. A kindergarten teacher described the purifying, healing role of play for working through difficult experiences with one child who had had a traumatic experience: 
Maria had a phase lasting several weeks where she built with blocks strictly according to colour and shape. If somebody wanted to put a different coloured block on top of a tower, Maria took it off immediately, saying, "No, blue block." When she helped wash salad ingredients at home, she also insisted on putting the tomatoes in their own bowl, in order to separate them from the lettuce.

Knowledge of the girl's recent history revealed that she had been sexually molested. During this time, she avoided red blocks and only wanted to have yellow, blue, and green ones. Her parents tolerated her wishes for several weeks, until she began to mix the colours again.

In this developmental phase, separation from the mother, whether active or passive, constitutes an important theme. Observing his oneand-a-half-year-old grandchild, Freud came to understand how he dealt with this kind of separation. In Beyond the Pleasure Principle (1920g), he wrote of how long it took before his grandchild's "mystifying and constantly repeated activity betrayed its meaning":

The child had a wooden reel with a piece of string tied round it. It never occurred to him to pull it along the floor behind him, for instance, and play at its being a carriage. What he did was to hold the reel by the string and very skillfully throw it over the edge of his curtained cot, so that it disappeared into it, at the same time uttering his expressive "O-o-o-o". He then pulled the reel out of the cot again by the string and hailed its reappearance with a joyful "Da" ("There"). This, then, was the complete game-disappearance and return. As a rule one only witnessed its first act, which was repeated untiringly as a game in itself, though there is no doubt that the greater pleasure was attached to the second act. (p. 15)

Through play, the child could symbolise his mother's disappearance with the wooden spool. However, it is not the mother/wooden spool that deserts the child, but instead the child hurls the spool away-that is, he is active. He can also then retrieve the mother/wooden spool when he chooses to. In play, children succeed in working through painful experiences.

One game for children in their second year, common to many cultures, consists of first hiding the mother's face and later the child's. Through a cloth or other object, the mother hides her face or the father his, and asks: "Where is mama/papa?" After removing the cloth, the adult then says "Da" or "Peek-a-boo." The child observes his mother closely and 
crows with joy each time her face reappears. The pleasure of this game is that the baby experiences himself as a separate person, who can tolerate separation from his mother for a short time and keep his memory of her alive. In this context, the timing of the mother's reappearance plays a major role. If her disappearance is too short, the game becomes boring. If the time period lasts too long, the game collapses; the child becomes fearful and cries. The small child's confident laughter is tied to an increase in tension devolving from his fear of being abandoned, a tension then resolved through the child's own liberating laugh and joy in reunification. Here, the extent of parental empathy lies in recognising the point before a child's capacity for bearing his mother's absence is overstepped. Concealing the mother's entire body overly challenges the child, since she then becomes an absent mother. Winnicott pointed out that in every game there is an element of fear. When adults play with children, it is a good idea to take a cue from the child's own actions, with an eye to what he reveals of himself through play.

It is sometimes difficult to detect the border between helping a child and letting him try out something for himself. Parents who help their crawling child retrieve an object he cannot yet reach for himself are bound to disappoint him when they put something in his hand, since he would prefer to have got the object himself. Parents who become impatient when their child cannot manage something immediately may assume the child must also be frustrated; they forget how many fundamental new activities he must explore and practise. Here is an example from observation:

R. was playing with her thirteen-month-old daughter. A stuffed rabbit was put on a chair in such a way that Tessa, the little girl, could only see its face. She quickly saw in this a chance for a game and smiled at the rabbit, but before she could get to it, her mother took the rabbit and gave it to Tessa, saying, "There, give it a kiss." Tessa showed her irritation at her mother's solicitous behaviour by pressing the rabbit closely to her, only to hurl it away in a wide arc. A few minutes later, Tessa again showed clearly how frustrated she was by her mother's over-eagerness. She was sitting by a box full of blocks. With great care, Tessa selected one block which she then placed on the floor. She was just about to select a second one when her mother rapidly took two more blocks out of the box and built a tower, which Tessa then struck, crying out loudly. The mother then 
understood what she had done, put the two blocks back in the box, and said "Sorry". (Steiner, 1992)

Instead of observing her daughter learning how to select a series of blocks by herself, mother $\mathrm{R}$ reacted impatiently and wanted to show her how to build a tower. By doing so, she impeded her daughter from gaining this experience for herself. When, as often is the case, parents wish to accomplish something faster and better than their child, they undermine his self-confidence; he will then want his parents to do things for him, since he never gained faith in doing them himself. When we observe parents and small children playing together, we often see parents correcting their children, thus depriving them of space to learn in. Often the parents' critical behaviour is unconscious, with the best intentions of "helping" their child. In such a situation, the other parent frequently constitutes an important corrective factor by suggesting his / her partner leave the child to his own devices and not overly instruct or correct him. Often, unconscious behavioural patterns from the parents' own parents are repeated.

Mathias was playing a block game with [his daughter] Lisa, and every time she was about to put a block into the wrong spot, he took it away from her and put it in right. His wife then asked him why he didn't let Lisa do it herself. He later said: “Then, a light went off in my head. I had to really ask myself. That was exactly the way my father had done it with me, it wasn't what I wanted." (Beck, 2002)

Mathias further explained how as a child, he would want to help his own father at his work. He had hardly begun when his father would take the tools out of his hand and show him just how the task could be accomplished faster or better. Usually, the father would then do the task himself. Mathias then felt first hurt and then irritated.

From Mathias's descriptions, we can see how much it helps him when his wife draws his attention-in a friendly tone-to some particular behaviour of their daughter. He is able to use this chance for self-reflection. In infant observation, we often hear how a child uses his time spent alone to do things by himself that the parents prevented him from doing.

Another important function of children's play is to create order and structure. Just as the young child wishes to know how something 
works, where it fits, in order to create an inner order out of a multitude of impressions, the child's play is a kind of practice laboratory. Games have rules. In a game, the child can pretend to create a world, where hr re-enacts situations he has already experienced. Children often develop creative rituals-similar to those common in various societies-such as the way to meet a family guest:

To greet an eagerly expected guest who had just rung up on the intercom, the two-year-old girl ran towards her across the stairs. When she saw her, she laughed, said "Hello Grandma!", showed her joy through enthusiastic cries, sprang from one leg to the other, and then was carried into the apartment before her grandmother.

A similar ritual is enacted during state visits, when the host proceeds towards the guest as far as the aircraft staircase, demonstrating respect with music and the proverbial red carpet.

The young child attempts to discover inner order-and for this, he needs to accustom himself to patterns of outer order. He places value on putting objects back into their accustomed places. Parents are meant to tell the same story exactly as they did the day before. When the grandmother slices strawberries differently than the mother, the child may implore her to conform to the way he knows. Often, parents have no idea what a drama it becomes for children when things are done in an unfamiliar way, since their sense of order is then violated.

At the beginning of the second year, social connections to other children are not yet clearly defined. Children in this age group play alongside one another, observe each other, run after each other. From the middle of the second year on, they start to imitate one another. Interacting with other children, the child learns to hold on to his own toys. He learns to express contradictory feelings through play, like Tessa, who first holds her stuffed rabbit tightly and then throws it across the room.

A further theme dealt with through play is the separation from the mother and father. The child runs away, wishing to be caught by his parent. Archetypal patterns of running after and catching the child embody a pleasurable reversal of active and passive modes.

\section{Discipline and order}

In his second year of life, the child's daily rhythms tend to conform to those of his other family members. Adaptation of the baby's sleeping 
and eating patterns requires special explanation: this process is seldom peaceful or harmonious. Even children who have up until now had no problems sleeping now find it more difficult to go to sleep. They wake up during the night and require calming words from their parents. Stroking the child or speaking calmly to him, holding his hand, will help him get back to sleep. Even when he has had bad dreams and is fearful, he can revert to a placid state through his parents' presence and listening to their voices. One father recounted how, when he called "Everything's OK, just go back to sleep", his child was pacified. It is less advisable to take the child out of his bed or feed him, since he will quickly accustom himself to this and wish to continue the habit. More helpful are rituals-a fixed sequence of events before going to bed. Quietly reading or singing to the child after his bath, feeding him, and dressing him convey a sense that the child should now prepare himself for sleep. Children's usual remonstrations against going to bed are also linked to their unwillingness to relinquish their mother to other family members.

As important as it is to give children an opportunity to explore the world of objects, they also require clear limits. If the rooms where a child moves about are set up so that fragile objects are outside his grasp, possibilities for conflict are limited. Nevertheless, there remain enough perilous areas where the child must be protected and have limits set on him. Many parents confuse this setting of limits with punishment or a surfeit of control. Recognising that a child is only capable of holding to restrictions to a limited extent, the parent must emphasise certain important limitations. Even when a child is allowed to play for an extended time in his bath, the bath must eventually come to an end. Some parents place their hopes in obtaining the child's agreement, but this often is unsuccessful. The child's protests can be experienced by his parents as rejection or attack. Many parents repeat their suggestions so often that they themselves become irritated, giving loud vent to their anger. Instead, parents should understand that often, their child is not yet capable of insight into the situation, and should try to bring him to the desired behaviour with a calm but determined tone-simply lifting him out of the bathtub, for instance, even over his protests. It is of great help that small children are so easy to distract. Pointing to a colourful red ball, a light, or an interesting movement will soon divert the crying child's attention. If, however, parents are drawn into a struggle or harbour guilt feelings for forcing their child to do something he does not want to, they may find it hard to find a practical, neutral tone. The child 
will learn more easily to accept certain limits when they are pointed out in a friendly, casual voice. However, the process of setting limits is inevitably tedious and protracted for any child.

For parents and child, this learning process is painful but necessary, since it is at odds with the child's egocentric world view. The child sees himself as the midpoint of the universe; every object exists for the child to touch, stick in his mouth, eat, or throw away. In Winnie-the-Pooh, this egocentric attitude is depicted affectionately:

One day when he was out walking, he came to an open place in the middle of the forest, and in the middle of this place was a large oak-tree, and, from the top of the tree, there came a loud buzzing noise.

Winnie-the-Pooh sat down at the foot of the tree, put his head between his paws, and began to think.

First of all he said to himself: "That buzzing noise means something. You don't get a buzzing noise like that, just buzzing and buzzing, without its meaning something. If there's a buzzing noise, somebody's making a buzzing noise, and the only reason for making a buzzing noise that $I$ know of is because you're a bee."

Then he thought another long time, and said: "And the only reason for being a bee that I know of is making honey."

And then he got up, and said: "And the only reason for making honey is so as I can eat it." So he began to climb the tree. (Milne, 1924, pp. 3-4)

Egocentricity is a normal attitude for the small child, and through their wiles, parents are the ones to introduce a new, diametrically opposed attitude: they want their child to learn to accept there are things which belong to his parents or other persons, things the child cannot have. Great patience is required to teach the child that certain objects-electrical sockets, hot ovens, or parents' possessionsmust not be touched. Verbal explanations or repeatedly saying "No" have far less long-term effect than simply moving the child away and distracting it with something else. In some cases, one can teach children how to interact carefully with plants, for example, only allowing them to smell or touch them delicately. When parents respect their child's own "No" in certain situations and also give his wishes a hearing, they can expect the child to accept their rules for important areas. 


\section{Acquirement of language}

In the child's second year, the development of thinking and understanding can be observed from day to day. Language represents a new medium of communication and exchange, since words possess common meaning. In the book How Babies Think, Gopnik, Meltzoff \& Kuhl (2001) proceed from three hypotheses: "First, that babies possess considerable knowledge from birth on. Second, that they are born with an extremely powerful capacity to learn. And finally, that adults seem to be 'programmed' to teach babies exactly what they need to know." When parents speak, sing, or play with their baby, these forms of communication familiarise it with the rhythms of language. Speech is associated with being held lovingly, and experienced as emotional connection. At the age of six months, babies can already point to an object. By this time, they can phonate every sound needed for all languages of the world. At nine months, they can distinguish between the sounds of one language and another, for instance, English and German (ibid.). A baby's first words consist of putting together syllables such as "Mamama" or "Dada". The child develops a kind of nonsense language, experimenting with the intonations of "words" and "sentences" and imitating adult language. Anna Freud (1944) emphasises the child's pleasure in producing these sounds. Cooing noises after breastfeeding express satisfaction and well-being. To spur a child's sensitivity to language, parents try to teach him words such as "bow-wow" for a dog's bark or for the dog itself, and corresponding words for a car, train, or other objects. "Through onomatopoeia, concepts and feelings are reproduced in acoustic and linguistic symbols" (Kohlheimer, 2002 , p. 20). The pleasure in playful nonsense language is resurrected in adult nonsense literature. But two-year-old children are also capable of appreciating the humour in Dadaistic poems. As illustration, here is a poem by Hugo Ball known to have brought children to enthusiastic laughter:

Ele mele mink mank

Pink pank

Use buse ackadeia

Eia Weia weg

Enne denne

Dubbe denne

Dubbe denne dalia 
Ebbe denne dalia

Bio bio buff

(Quoted in Jacoby \& Berner, 2001, p. 15)

The humour here lies in the similarity of words used in the poem to actual language, just as a child imitates adult language without yet finding the correct words.

The child learns words with which he can express his wishes, such as "still", "also", and "no". He understands practically everything that is said to him. Often, parents underestimate their children, believing a child who cannot yet speak cannot profit from explanations. Particularly with separations and farewells, it is important to prepare the child and not simply steal away, instead explicating the departure through a ritual of farewell, replete with waving and kisses. Parents who prefer to slip away unobtrusively might think they are sparing their child (or, more likely, themselves) from the pain of separation. In reality, their actions can render the child insecure and fearful: he can never know when they will be staying or leaving. Saying goodbye and discussing the impending absence help clarify the distinction between presence and absence.

When limits must be set, explanations are also helpful, even when parents cannot yet expect their child to follow rules immediately. The mother and father are intermediaries between the child and the world. Equally as important as explaining and describing the outer world is giving names to the child's feelings, in order to help him clearly distinguish when he is sad, happy, angry, hungry, or tired. Counting rhymes, songs, and children's poems help the child to associate language and rhythm in combination with movement, such as "Ten Green Bottles", "Old McDonald", or "Humpty Dumpty".

The extent to which children's poems and songs express contradictory feelings, love and hate, safety and death, is demonstrated through a close look at their texts (see Rollin, 1992). One lullaby with an ostensibly pacifying effect is actually about danger and death:

Hush-a-bye baby, on the tree top, When the wind blows, the cradle will rock. When the bow breaks the cradle will fall, Down will come baby, cradle and all. 
Such songs presumably have a cathartic effect for the mother, since next to her devoted love she can also express unconscious hate and death wishes towards the baby as usurper and absolute ruler (see Winnicott, 1949).

Similarly, the text of the playful German rhyme "Hoppe Hoppe Reiter" depicts a horseback ride, with the rider screaming, falling down, and being eaten by ravens. Since the game based on it involves a compromised action-an ostensible falling down, but with the child then caught by his father or mother-the parents can express their negative feelings towards the baby solely in symbolic fashion, thus integrating these into their feelings of love. In Brahms's song "Lullaby and Good Night", the child will be awakened the next day: "Tomorrow morning, if God so wishes, you will wake once again." Here, too the threat of death is immanent.

Communication through "language is a two-edged sword" (Stern, 1985, p. 162). On the one hand, it makes wishes, information, states of mind, feelings, and experiences comprehensible; on the other hand, it necessitates the distinction between experiences and things that can be named, inevitably rendering some areas of our experience more difficult to communicate. As a medium, language emphasises the abstract level, making subjective, personal, and ineffable experiences harder to integrate, as Stern (ibid., p. 163) contends.

When the child reaches eighteen months, symbolic play and the naming of objects with words begin to develop. In fantasy, objects represent human beings and can be fraught with positive, negative, or frightening aspects. A wooden block can become the father, which is then either lovingly put to bed or used to furiously hit or punish someone. The child's magical thinking hinders the distinction between symbolised object and real object. An object that is assigned a dangerous symbolic meaning, such as that of the vengeful father, may appear to the child to be truly dangerous. Words, too, can be experienced as powerful and acquire magical properties. Children also tend to understand inexplicable events in the outer world as consequences of human actions.

Piaget described his eighteen-month-old daughter as she watched him make clouds of smoke with his pipe (Piaget \& Inhelder, 1951). She had also already observed that there are often veils of mist over mountains and clouds in the sky. From her remarks, it then became evident she believed her father also caused the mist on the mountains and the clouds in the sky with his pipe. 
The father is seen as a powerful giant, whose actions are of great import. The analogy between pipe smoke and the morning mist inspired the child's hypothesis that there was a causal link between the two. Piaget calls this worldview "egocentric", whereas in psychoanalysis it is termed magical thinking (Fraiberg, Freud). Only gradually does the child begin to test such hypotheses against reality.

At one and a half years, the child begins to perceive and study discrepancies between his own wishes and those of other persons. Gopnik describes the reaction of his one-and-a-half-year-old son, who was eating pineapple and spat it out since he did not like the tasteobserving, however, that the adults were eating it with pleasure. He summed up his observation by saying, "Pineapple: yucky for me but yummy for you." He had just recognised his taste diverged from other people's taste, and this profound insight made a great impression upon him (Gopnik, Meltzoff \& Kuhl, 2001). For children, precise observation and gazing out on the world are activities of major significance. Some parents become concerned when their child "isn't doing anything, just looking". During the course of such "looking", important thought processes are occurring: hypotheses are being formed, tested, and compared with experience. When a child learns to distinguish his own feelings and behaviour from that of other children (and their parents), he has accomplished a vital step in his development. He also begins to discover corollaries to this general principle-for instance, that he may do things with his grandparents that are not allowed at home.

\section{Toilet training}

Assessment of the correct point in time to begin toilet training has changed within the last forty years. Although forty years ago it was common to put a baby on the potty at the age of nine months, this has now shifted to the end of the second year. Brazelton's criterion, for example, was the child's ability to control his body when climbing up and down steps unassisted, one foot ahead of the other. The recommended method consists of waiting until the child himself wishes to sit on the potty or the toilet. Since he interests himself in everything adults do, seeking to emulate them, he should also express the wish to go to the toilet or potty; if put under pressure before this, he could come to attribute an exaggerated significance to stool or urine, wetting 
or defecating in his bed or smearing his faeces about. During a child's second year, parents are better advised to endure the impatience of grandparents or friends, granting their child the time he needs. The second year also has the disadvantage of being a period when children are striving for autonomy: toilet training can easily become a power struggle. If the child opposes his parents' wish to sit on the potty and deliver up his bodily excretions, their response can swiftly turn to pressure and belittlement. The child-exposed, under observation, and powerlessmight then experience his bodily excretions and his entire body as dirty and repulsive, compelling him to feel ashamed. "Out of a feeling of self-control without loss of self-consciousness proceeds a permanent feeling of autonomy and pride; out of a feeling of muscular and anal incompetence, from the loss of self-control and the inordinate participation of the parents arises a permanent feeling of doubt and shame," is how E. H. Erikson (1959) summarises the two poles of opportunity and danger in this developmental phase. ${ }^{1}$

Even when the small child is not made to sit on the potty, he develops a marked interest in his body and the products thereof during the second half of his second year. Some children begin to find a place to be alone during defecation. A full nappy is unpleasant for some children, and they accordingly demonstrate to their parents they want their nappies changed. For others, this is a pleasant, warm feeling, and they are reluctant to surrender their full nappies. Some two year olds bring their parents a nappy and lie down in the changing position. Bowel movements become significant events: other activities are interrupted and the child takes on an "introverted gaze". Urination also gains in meaning, linked to pleasure. Looking at the stream of urine, the resulting puddle, urinating in the bathtub interests both boys and girls. Delivery and surrender of bodily contents becomes emotionally significant. In the child's imagination, everything leaving his body acquires a major meaning, whether positive or negative. In fantasy, the contents of the bowel become something of import, a gift to the parents, a means of marking terrain or a weapon. Freud spoke of the significance of the anal, and called this phase the "anal phase", when sexual pleasure is fulfilled through stimulation of the anal mucous membranes. Anything similar to bodily excretions, such as any liquid that can be sprayed or poured out, and any material that can be kneaded, excite the child's attention. Playing with water and sand affords the child excellent opportunities for forming, kneading, and smearing. Finger paints and 
paper satisfy not only creative impulses of painting and modelling but also the pleasurable impulse to smear.

\section{Development of sexual identity}

In contrast to purely biological sexual apparatus, female or male sexual identity is acquired. The basic understanding of a human being as having feminine and masculine attributes was termed by Freud "bisexuality". This means that every human being has feminine and masculine attributes and that sexual identity is not set by nature, but only over the course of psychic development. Thus, there is a tension between biological equipment and the psychic experience of one's own body as masculine or feminine.

Investigation of the world begins with the child's own body as well as that of the mother, and with fantasies concerning the contents of the mother's body. The baby grasps at his own hand, pulls, pinches, and scratches his own face, sticks his finger in his nose and ears. In a similar manner, he grasps the ears, nose, spectacles, or breast of his mother, sticks his finger in his mother's or father's ear or nose. When naked, he investigates all his orifices and genitals. The difference between his own body and the opposite sex excites particular attention during the second year of life. The child wishes to be present while his parents care for their bodies, wants to follow them to the toilet, in order to observe every variation. Since the maternal body-and the question of how babies can originate within it-are of great interest, both girls and boys also wish to have a baby, which caused Melanie Klein to speak of a "femininity phase" for girls and boys. "In the castration complex of girls and the femininity complex of the male, there is at bottom the frustrated desire for a special organ of conception, pregnancy and parturition" (Klein, 1928, p. 190). This thirst for sexual knowledge constitutes a significant impetus towards intellectual development. In role-playing as well, when children play mother or father, they show they can attribute gender, with the opposite gender still retaining its attraction-so that the small boy also wants the biological equipment for having a baby, and the small girl also wishes to possess a penis that can be grasped and that can produce copious, wide-ranging streams of urine. Development of a conscience, as a means for dealing with what is allowed and what is forbidden, massively influences the young child's weak ego during this phase. In the child's fantasy, actual prohibitions and parental rules 
are transformed into cruel, implacable imperatives. ${ }^{2}$ In play, a stuffed animal or a doll is punished strictly, beaten, or thrown away, often shocking parents who have taken care to never hit their child. Children may also apply inflexible, cruel rules to themselves, which can later lead to self-castigation and shame if not ameliorated during subsequent developmental phases.

Freud proceeded from the assumption that young girls have no consciousness of genitals, perceiving an absence-in contrast to the boy's penis - on their own bodies. Since the 1920s, female psychoanalysts have shown through clinical observation and observation of small children that young girls do in fact have a concept of their own vagina, and paediatricians have reported retrieving small objects out of girls' vaginas (Chasseguet-Smirgel, 1964; Fleck, 1977; Horney, 1923, 1930; Klein, $1928,1933)$. The young child experiences his parents as a couple capable of making a new baby, which to a certain extent must exclude the child. Already during his second year, the child develops an idea of his parents as a couple linked through a particular (sexual) kind of bond, thus excluding the child from their relationship. At the same time, the child's idea of the parental couple who reflect together on the child creates a psychic space, which in turn becomes a model-in analogy-for selfreflection (Britton, 1989). A foundation is thus laid for self-reflection, observing oneself from a distanced position and reflecting on one's own behavior. The child's wish to break this special intimacy of parental togetherness, his jealousy and pain at being excluded, and his fear of being superseded by a new baby, are in conflict with his loving and tender feelings towards his parents. The child would like to thrust himself between the parents while they are kissing, exchanging caresses, or simply sitting close to one another. He would then be at the centre, the sole recipient of both parents' attention. At the same time, the child needs to experience that his parents will remain together in spite of the child's jealousy, still providing him with love and attention. Often, sleeping problems can be traced to the child's unconscious wish to disturb his parents' communion by crying, thus inducing them to come over to his bed. Children have a great sensitivity for detecting changes. Here is an example from parent-young child therapy:

The parents came to therapy because their nineteen-month-old daughter, who had always slept well, had now become difficult. The mother was in a state of total desperation, since Susi had 
become a "total terror", in that she would not go to sleep. The night before, she was so upset and screamed so furiously that she vomited the entire contents of her stomach. Both parents agreed not to let themselves be terrorised, and they decided this time to let her cry, as they had read in a book called Every Child Can Sleep. Only in the morning did they notice that their daughter had again vomited. The parents were shocked at how stormy and "hysterical" their hitherto cheerful and docile daughter had become. Apart from short phases during teething, she had always been able to fall asleep on her own. Now, the parents had no idea what to do. They perceived themselves as complete failures. Asked how it could have come to this point, the mother related that it had all actually begun when they had returned from a two-week vacation in Greece. During this vacation, they had all three slept together in one room. Susi enjoyed the presence of both parents, was cheerful and happy, frolicked in the water and didn't even want to come back onto land. For the three of them, it was their first vacation together. The parents did miss their usual time alone together, but had made a clear decision for a family vacation. The change after their return from the vacation was presumably too abrupt for their daughter. In further talks, it emerged that the return from vacation was simultaneously the point when the mother began work again. Three days a week, she came home only at $4 \mathrm{pm}$. In addition, the mother had stopped taking birth control pills for the last two months, since she wanted a second child.

The mother was at first surprised at my lack of concern over Susi's vomiting, or that I failed to criticise her as an uncaring parent, since she had taken the vomiting to be a sign of deep disturbance. Susi's "terror" and her screaming fits had reminded her of her own sister: it was not possible that Susi could have got this behaviour from her. "I can't tolerate this, how are things going to go on from here?" she said anxiously. My observation that Susi could be expressing wishes and fears through her behaviour at first calmed her. The parents could now reflect and understand that their daughter might perhaps feel expelled from the family's centre through the loss of her parents' constant presence in vacation, through adjustment to a nanny, and possibly the parents' interest in having a new baby.

Through her behaviour, Susi caused her parents to see themselves as failures and doubt their parental abilities. 
In the second therapy session, the parents told me their panic had subsided, since they now could better understand the contingencies and ramifications of Susi's problem. They could perceive her crisis as a short-term problem. In the days following the first session, the mother had allowed Susi more time to go to bed, allowing her to go to sleep on the sofa in her arms; as the mother said, "She needs more body contact right now," On the fourth day, Susi could once again go to sleep in her own bed, with her mother sitting at her side, holding her hand. The parents were also now happy since the mother in fact had already become pregnant.

We see in this example that Susi was overwhelmed by her inexpressible fears and created a situation that caused the parents to experience her feelings. By comprehending the elements of the situation and putting themselves in their daughter's position, the parents could then grant Susi the possibility for once more learning how to sleep alone. The catalyst for this crisis was perhaps not only Susi's behaviour, but the new pregnancy, which had possibly brought unconscious rivalry between the parents to the fore. Through the prospect of a second child, early unexamined conflicts with parents' own siblings and their feelings of rivalry are activated, which in this case could have led to a lessening in the parents' sensitivity to Susi.

Now I shall turn to the process of further development in the two families of Kelly and Max, in order to demonstrate how their second year of life progressed.

\section{Developmental history of the children Kelly and Max}

Kelly in her second year

Perspective of the observer

When Kelly was four months old, her mother began to work two days a week, alternating with Kim's mother in caring for the children, since Kim's mother was also working two days a week. When Kelly was ten months old, a nanny was hired.

The observer describes a play sequence when Kelly was thirteen months old:

While the nanny was out of the room making tea, Kelly looked around, looked at me, and then discovered her cup on the floor. She took it, looked at me again, and smiled. She examined the cup 
for a while, then put it down on the floor and picked up a small toy figure while smiling at me. When the nanny returned, Kelly looked alternately at her, at me, and at the figure. She approached the toy I had given her for her birthday-it was the "Pop Up Pets" set of figures-but kept the other figure in her hand. The nanny encouraged Kelly to play with my present, but Kelly only turned the buttons on it around. The nanny pushed the toy that should hold the figure closer to Kelly. Kelly put the figure in it, took a little hat, first put it on the figure and then on her own head. She laughed confidently and then put the little hat back on the figure. Then she cast away the hat, took the figure, and pushed it under the platform it had been standing on. The platform had a door that Kelly attempted to open and close. She tried to take the figure out, but her hand got stuck. The nanny showed Kelly how to open and close the little door, then took the figure, put it back, and pushed a button to move the figure away. But Kelly was not interested in this; instead, she took the same figure and put it in a box where there was already another figure and shook it. Then she turned the box over, pressed her face into the opening and turned it back and forth so that it made a noise.

The observer comments on the scene as follows: "Kelly seems to strongly identify with the little figure ... Kelly is alone, she first looks at her trusted cup. Her play with the figure that seeks a container has an intensity, as if she is investigating something she herself would like to enter, a fantasy of entering her mother's body again." Kelly is indeed finding a secure, protected space for this figure, as if fulfilling a special wish. The second figure, already in the box, could be understood as a symbol of the other child who is being taken care of together by her mother or the child's mother.

Children's play, the great concentration involved, and the seriousness of the undertaking, is often not taken seriously by adults or dismissed as "mere" playing. Consequently, the importance of play for dealing with separation or extreme emotions is overlooked.

The observer reports that Kelly was still being breastfed at the age of eighteen months, in the morning and evening. Together with a young boy of the same age, Kelly was looked after by a nanny. Her mother was considering how to end breastfeeding. She seemed embarrassed at accommodating Kelly's wish to be breastfed; on the other hand, breastfeeding appeared to be a compensation for her absence during the day. 
On the whole, Kelly behaved well with the nanny; she did what she was told. The nanny had the privileged position of being the first to observe Kelly's steps in development ... when the mother arrived at home, it was interesting to observe how she had problems controlling Kelly, not because of any weakness on her part, but because of Kelly's strong wish for the breast.

The observer registers how difficult it is for Kelly's mother not to be the first one to observe Kelly's steps in development, since she is away during the day. When the nanny established a closer contact to Kelly, the mother often felt excluded. Perhaps the long period of breastfeeding served to tranquillise both Kelly and her mother: it was something they alone could share. Was Kelly's wish for the breast also related to her having unconsciously perceived the mother's need for Kelly to take care of her and make her happy? This would mean that Kelly is developing a capacity to console her own mother and give her life emotional meaning. In fact, Kelly is now behaving in a relatively adult and reasoned manner. The extent of the mother's vulnerability is demonstrated by how quickly she feels rejected when Kelly prefers a teething ring to the food her mother offers her.

The observer has noticed how excited Kelly is by the presence of another child. Compared to the other child, she is much livelier and more curious. At the end of her first year, according the test results from maternal counselling, Kelly is several months ahead of her age in terms of mobility and her reactions, whereas in her language skills she is adequate. On the test, Kelly was not able to find an object covered by a cloth.

During Kelly's second year, her paternal grandmother became ill and had to have an operation. The grandfather had shortly before died of cancer.

Kelly was already at a young age an actress. Her mother noticed how determined and independent she was. She attempted to situate herself at the centre of attention by making faces and funny noises, in order to receive recognition through smiles and laughter ... her mother described Kelly's coquettish manner of looking in the mirror, putting on hats or dressing up ... she wanted to be a "little lady".

The observer later interpreted this behaviour in the following sentence: "In the description of Kelly as an actress, there is an implication 
of something unreal, a distance between fantasy and reality." Does the description reveal Kelly's generosity and openness or also a theatrical element? Does her behaviour demonstrate a wish to cheer up the adults and entertain them? This analysis is supported by evidence of the paternal grandmother's illness and hints of an increasing marital crisis. One could formulate the hypothesis that Kelly has the tendency to shield deep feelings, loss, and separation behind hyperactivity and excited play. That would enable her to exercise her abilities and talents both in a constructive and defensive manner. The danger could be that she feels responsible for her parents' emotional well-being.

Kelly seemed to be encouraged and constructively challenged by both her parents, her grandmother, and the nanny. Let us now examine her parents' description of Kelly's development.

Kelly's parents' perspective

Kelly's mother described the two-year-old Kelly as "conventional", similar to her grandmother. Kelly was a very feminine girl. The mother said:

Kelly loved clothes. I dressed her in pants and strong colours, red, green and bright things. I wanted not to stick her in pink things and flowered dresses, but my mother bought her those kinds of things. And in spite of all my efforts, she became a typical girl. She loved dolls and loved putting on pretty dresses and having a pretty hairdo. She even wanted to wear earrings ...

Kelly's mother seems to take Kelly's love for pretty dresses and dolls as a criticism of herself. For the mother, career and family also seem to be an "either/or" proposition, as if a woman could not develop both aspects of herself. Kelly's attempts to put everything back in its correct place also were experienced by her mother as criticism. It seemed not to occur to her to attribute this love of order to Kelly's process of establishing of an inner order. Since she emphasised Kelly's similarity to her own mother, she felt threatened and controlled from two sides. It is almost as if she finds Kelly's love of order suspect. She said:

Especially when she was little, you couldn't put anything where it didn't belong. I mean, Kelly put it back. Or she told me, that's the wrong place. 
As empathetic as Kelly's mother is in many areas, she finds it equally difficult when she recognises something in Kelly that reminds her of her own mother. She also seems to be envious of Kelly for the great quantity of attention that her mother gives her. She said that her mother had not moved to London for her sake, but rather to be with Kelly, treating her grandchild very differently from how she had treated her. "She never spoiled me the way she spoiled Kelly. Kelly is allowed to do things I never was. She is much gentler with her than she was with me." In this statement, we can perceive her pain at being undervalued, since Kelly's mother had felt disadvantaged in comparison to her own brother.

During Kelly's second year, her parents' marriage collapsed. Kelly's mother emphasised that the marriage's failure had nothing to do with Kelly, but rather with their sexual problems. In contrast to her husband, who felt sexually rejected by her, Kelly's mother had no consciousness of being desired by her husband. Quite on the contrary, she attributed their lack of sex to her husband's professional burdens. He struck herand she remained with him because of Kelly. She said:

He hit me several times, once when my mother was in the house. I hadn't told her anything about this, and she was truly, totally shocked. I had had a short affair with another man. That was the reason things became so difficult. I met him several times, and my husband found out. I ended the affair and didn't see him again. But my husband didn't believe me. Then he tapped my phone, to record all my phone conversations ... the day I found that out, I thought, this man is capable of anything. You know, he's unpredictable ... I couldn't eat ... for months, I couldn't sleep properly ... then I said to myself: "No, I'm leaving him! The house is less important than my safety." ... One Friday evening, when he was away playing with a jazz band ... as soon as he was out the door, I packed everything into three bags ... and we left ... I left him a note on the night table explaining everything.

She left him without any warning, taking Kelly with her. After several weeks, she then moved to her mother's, in preparation for returning home after her husband had moved out of the house. She left her husband in a manner similar to how she had moved out of her parents' apartment-where she had lived together with her mother 
and brother-as a teenager. Back then, she had felt locked in, because she was never allowed to go out. She described this in the following words:

As a teenager, I was rebellious and felt myself imprisoned ... after I moved away from home, I behaved as if I had been let out of a cage. I had a lot of difficulties ... My mother didn't know about any of this. I left her a note on the kitchen table with the message: "Mum, I'm moving out on Saturday. I know you won't agree, but I can't stand it any more. I know you think I won't make it on my own, but I will anyway." After this, she didn't speak to me for a long time.

From her narrative, it cannot be discerned whether her father had also left the family in such an abrupt fashion. Kelly's mother had a close relationship to her father and had suffered greatly when he left the family, back when she was very young. Perhaps she was now jealous of Kelly, since the father was very affectionate to his daughter.

Kelly's father had already told how his wife had rejected him sexually since the pregnancy, and that he had tried to accept this. He characterised the break-up as one of the two most significant events in his life: "Having Kelly was the most satisfying experience, and getting divorced was the most horrible experience in my life." Under no circumstances did he want Kelly to grow up without a father. He had done everything to avoid the divorce: it was such a terrible process. With the divorce, he felt himself brutally ejected from the apartment, from the family, from stability itself. He took great pains to preserve his close relationship to Kelly. After the separation, they gave up the nanny, and Kelly came into the care of a child-minder.

I used to pick up Kelly in the morning and bring her to the childminder. Before, I usually walked with her in the park. In the car, we told each other stories ... After six months—one day, without any reason-when we were in the park feeding the ducks, she came to me, put her arms around my neck, and said: "Daddy, I love you, I miss you so much!" I thought it's worth it. It's OK. That was the point when I knew that my efforts had borne fruit. Until this day, I hadn't got one sign.

His identity as Kelly's father seemed to play an important role for him. He spoke affectionately of his own father, to whom he had a close relationship, as a friendly, wise, and kind man. Many things he now 
did with Kelly, such as reading books and making music, he had done himself with his father. When he himself was a child, his family moved to Australia, where he felt lost and alien. The divorce had presumably reactivated these feelings of being foreign and homeless. Regarding his drinking and abuse of his wife, we must rely on speculation. He himself was ashamed of his eruptive jealousy and violence. We cannot know whether or not he unconsciously experienced the denial of sexual contact during his wife's pregnancy as a tacit accusation that his destructivity represented a danger for the unborn baby. The exclusion and jealousy seem to have hurt him deeply and brought him into a rage. Both parents nevertheless agreed that the marital quarrels and divorce battle should not be conducted over Kelly. The infant observation also continued on into Kelly's second year, with the observer also visiting Kelly at her grandmother's. The fact that the infant observation could be continued throughout all these problems demonstrates a mature quality of parenting from both Kelly's father and mother. Kelly's mother found it hard to accept how important Kelly was for her husband. She tended to view his visits more as an attempt to revive his relationship to her than as a sign of paternal devotion to Kelly.

Kelly's father set up a room for Kelly in his apartment, where she spent one day each weekend. However, he realised that the relationship with a father who did not live in the same household would acquire a different quality. Regulation of visiting times was painful. "I remember when I picked up Kelly the first time at the weekend, I had to have her back exactly at 6:00 in the evening. This feeling was dreadful. As if I were in a prison where you're only allowed out for a short period, where you're being told you aren't good enough to be together with your own child." He also realised that not being with her father constantly constituted a deprivation for Kelly as well. He was most concerned over this. At high legal cost, he obtained a flexible visiting schedule. He paid alimony and kindergarten costs. Both parents tried to never speak ill of each other to Kelly.

\section{Max in his second year of life}

From the observer's perspective

The observer watched Max playing his favourite game two weeks after his first birthday. She wrote that Max, since he was able to walk, liked best to play with water or sand. He could clearly express to his mother 
his wish to play with water. He climbed the steps to the bathroom without help and even managed to flood the bathroom floor through a sieve. The observer described one scene:

We were in the kitchen, and Max made complaining sounds in order to show he wanted to climb up on the chair next to him. His mother put a little stool next to the chair so that he could get up by himself. However, that wasn't what he wanted. He stood next to the other chair and whimpered. His mother stood behind him and tried to understand what he wished to express. Finally she understood. She helped him then to push the chair in the direction of the sink. When Max noticed that his mother had understood him, he stopped whimpering and put his full concentration into pushing the chair. First he stood next to the chair, then he walked around it in order to push it most efficiently from behind. When he was at the sink, his mother put the little stool next to it so that he could climb up himself. She filled the sink with warm water, and Max glowed with satisfaction. She handed him a wooden spoon and turned back to her cooking. Max seized the big plug for the sink and bit around it until the rubber ring came off. After he had attempted several times to put the rubber ring back on, he let it drop and pulled the other plug out. The water ran out slowly, and he put the plug back in successfully. His mother had now noticed what he did, and filled the sink back up with water. But Max now wanted to get down without turning around and using the little stool. He took his mother's hand and simply 'walked' off the chair, half falling down. He wanted to be held by his mother and watched what she was doing. After a while she put Max on the ground and gave him a bowl with raw, washed potatoes. Max put each one in his mouth, with his mother protesting loudly and saying, "Give them to me!" taking them from him one after another. The same game was repeated when Max took things out of the refrigerator. His mother allowed this, but asked him to give her each thing back, which he did willingly.

In this scene, Max is able to show very clearly what he wants, although he cannot yet talk. He is active and wishes to push the chair towards the sink by himself. An object such as the plug is examined on several levels-it is grasped, put in the mouth, bitten, and taken apart. His attempt to repair the plug is unsuccessful. He can bear this frustration 
and then tries to take out the other plug. Like a scientist, he examines the consequences of taking out the plug: the water runs out. He then succeeds in putting the plug back in, and the water level remains constant. When his mother wishes to intervene helpfully, his game quickly collapses. Max wants to get away quickly: he catapults himself out in such a way that his mother has to hold him. Later, when he is taking things out of the refrigerator, Max keeps in close contact to his mother, who names each individual object and then receives it back from him. It must also be remembered that Max has a problem with his kidney and urination. Perhaps this is the reason that water and emptying it bears such a large significance.

His predilection for playing with water is mentioned often. When in the sand, he plays with water; he waters the flowers just as his mother does. At fourteen months, he is observed filling an empty bottle with water over a remarkably long period. He seems to be occupied with questions of space, of fullness and emptiness. The filling of his body through eating and its emptying through urination and defecation are important, pleasurable bodily sensations. In playing with water, Max can control and test everything.

Weaning is done very carefully and slowly. Max was already weaned during the day and switched to solid food at the age of six months. In the night, however, he was given the breast up to three times in order to calm him, until his parents visited a sleep clinic; during the day, he also was still allowed a short "pull" on the breast, to which he helped himself. Max would go over to his mother, climb up on her lap, pull up her t-shirt and suck for a short time on her breast, at which his mother would laugh. Then he climbed back down from her lap. During a friend's visit with the friend's young daughter, who was the same age as Max-nineteen months—but still being breastfed, the following scene was depicted:

Max was very quiet and hung onto his mother, while the other child took centre stage with her lively, cheerful playing and running around. While we were all sitting on the floor, Max pulled on his mother's t-shirt. His mother seemed not to notice this and tried to distract him with a piece of bread. Shortly thereafter, however, she permitted Max to open her shirt, take out her breast and suck. She then held him up and put him on her lap like a baby, without his letting go of her breast. 
The breast seems for Max to be a locus of retreat and solace. Perhaps he is afraid of the lively girl playing in his territory with his toys: he wants to be the little baby again, held by his mother. The mother, too, seems to have a hard time taking leave of breastfeeding.

We were told of the final weaning when Max was twenty months old. The observer described him as "uncommonly skilful" at eating. She wrote:

He ate on his own, leading the spoon towards his wide-open mouth with regular motions and without spilling even the smallest bithis skill with the spoon was impressive. He had developed a particular relationship and love for his pacifier.

He differentiated between the "big" one and the "other small" one. When he went to sleep, he had to have one of them in his mouth and the other in his hand. He passed through the phase of weaning in six weeks, avoiding his mother's breast, which he called "schnucki". At times, he spoke with great unease of "schnucki kaputt". "He didn't even rest on my breast," reported his mother. During this phase, broken objects excited his special attention. He pointed particularly at crying children at the playground or those shown crying in a children's book.

Max himself seems to have undertaken the project of weaning. His mother had called the short phases of breastfeeding that he took "snacks". These snacks now became less frequent. His ability to eat on his own seems to have given him so much self-confidence that he could afford to relinquish the breast. Apparently, he is afraid he has made the breast—his "schnucki" — "kaputt", thus avoiding any physical contact with it. Both his pacifiers seem to have been an ersatz for the two breasts he gave up: he needs two, one in his mouth and one in his hand. Max transfers his grief over the breast outwards, he notices every crying child and points to all sad babies in his children's books. His mother can allow him his independence and her implicit rejection by him, although this is accompanied by a certain grief when she says that he no longer even rests against her breast. His great interest in broken objects expresses his concern over the object he has damaged in his fantasy. His wish to restore damaged objects, to glue or put them back together, demonstrates his capacity for reparation. He presumably harbours the fantasy of having damaged his mother and being able to repair her. 
Max had often experienced how his mother could become angry with him and still not reject him-she was able to "make up". In one observation, we read of a "quarrel" - a conflict between mother and Max-and how he was allowed to express his anger and irritation. Here it becomes obvious that Max's anger was also manifested in his treatment of the observer:

When I arrived, Max's mother opened the door for me, turned around, and went back into the kitchen without one word of greeting - which made me insecure and confused. It turned out that I had "picked a bad moment", since she had just had her first major confrontation with Max. She had forbidden him to run about with the big meat fork. She told me, "He ran at me and hit me several times." She had just arrived home from work a half hour before. She was making dinner. She gave Max-who was whining-a drum in order to distract him. Nobody was talking and the atmosphere was very tense, very unpleasant. I wished I didn't have to be there.

The mother put Max into his highchair and gave him his dinner. But everything she handed him-his plastic plate, his spoon, his cup-soon ended on the floor. Even when she didn't hand him the cup, he nevertheless managed to get it onto the floor. Each time Max leaned over to look at the mess on the floor, with a mixture of concern and satisfaction. Each time, his mother came back to pick everything up again, offered him food, filled up his cup silently. Max didn't eat more than a few spoonfuls and after fifteen minutes, his mother put him back on the floor. He immediately ran into the living room, while his mother sat down to eat her own dinner. I felt torn, not knowing if I should follow Max: at the same time, I didn't want to leave his mother alone. Shortly thereafter, Max came back, opened the refrigerator, taking out the objects carefully and then either putting them back or giving them to his mother or to me. Then he climbed up on his mother's lap. She let Max sit there for a short period, then she put him on the floor.

The starting point for the conflict is that Max's mother would not allow him to run around with the big meat fork, since this posed the danger of someone getting hurt. For Max, the meat fork was an object of fascination: carrying it around made him strong, potent, as powerful as his mother. He could not bear the frustration of being denied it, fell into 
a rage, and hit his mother, something he had not done before. For the mother, this was unacceptable. Now she, who had got up three months long in the middle of the night for Max, had carried him about when he cried, played with him, and given him so much attention, was being "thanked" in the form of blows. Her childlike side has been deeply wounded and insulted, so much so that she could not even greet the observer, instead opening the door to her in silence. Still, she was capable not only of not striking back, but of giving Max his food in spite of the way he had treated her. His hurling down of the food did not provoke her to yell at him; she kept picking up the objects he cast down. However, when he did not eat much of his food, she put him back on the floor-thus granting herself the luxury of eating her own dinner in peace. Max's taking things out of the refrigerator then tapped into a game between mother and son that had often been repeated with great pleasure, into which the observer was now also drawn. It took on the quality of "let's be friends again" and proceeded from Max. His trust that his mother was once again "friends" with him grew, and now he climbed up on her lap. The mother did not push him away. However, as soon as he sat on her lap, she put him down-so that she could eat in peace, but also in order to communicate her lingering irritation with him. Max could accept this and played alone for a while, until he once again went over to her. I interpret the fact that the observer stayed with the mother as a sign that she felt the mother's lingering hurt and thought the mother must have been grateful for her presence. This scene shows how well Max has already assimilated his inner image of reconciliation and restitution. The mother, too, can set clear limits, show her irritation and yet accept Max's reconciliatory offerings from the refrigerator. With many parents, their adult selves collapse during such a confrontation with a small child, when he bites or hits his parents: they bite or hit the child back. For small children, this constitutes a double threat. Not only have the parents suddenly bit or hit, but the children also believe they have made their parents angry through their own rage.

\section{Max's development from his parents' perspective}

Max's mother wished to do many things-particularly in the areas of food and toilet training-differently than in her own childhood: for example, she was always put under great pressure to eat everything on her plate. When Max began playing with his food, his mother understood this as a sign that he was full, and he was then allowed to get up and go 
play. Her own toilet training had been a traumatic process. When both her brothers were born, a nanny arrived who wanted to toilet train her at all costs within one and a half weeks. The nanny struck her when she made a motion in her nappy instead of the potty. Nobody protected her from this "dragon".

With Max, I didn't do a thing. I didn't even want to know how you're supposed to toilet train children. I let him do it the way he wanted ... I did nothing at all, he truly did it for himself ... He had nappies on, until they were dry, until he could say: "Where is the potty?" But he did this on the early side ... he was less than two years old.

Max's mother has access to her childhood feelings; she remembers how she was put under pressure and her sense of humiliation. She wants to grant Max freedom with food and with his bowels, sparing him what she had to endure. A further difference is her allowing Max to express his feelings, his anger at her. "I was never permitted to think-and certainly not to say-that I hated my mother." She detects a similarity between herself and her own parents, in that she also feels the impulse to manipulate Max-particularly while he could not yet speak. "I have difficulties with direct confrontation, although I try for it," Max's mother said self-critically. She and her husband had decided not to interfere in their child's life as much as their own parents had.

Max's father spoke of his irritable, bellicose mother, who was quite overwhelmed by the challenge her many children posed, and whose fits of rage he feared. He tried to keep himself under control with Max, and characterised himself as a gentle father. He had experienced his own father as a generous, musical man, ineffectual in prevailing against his wife. Max's father was unhappy as a child and is now in touch with his childhood feelings. He saw himself as a bad child. This negative self-image was compensated for by his compositional ability and his love for music.

I am an attentive father to Max, just as my own father was. Sometimes I get angry, which my father never did. Max has more freedoms than I did ... We don't control what he does. Partly, because he's an only child ... I think it's bad when we allow him to do so many things, but sometimes that's easier than having a fight ... We allow him to do more than is good for him ... We could have set more limits for him, but both our parents were too strict. 
We let him do and have what he wanted, when he wanted to hear another story, didn't want to eat something, or didn't want to walk so far ... Above all, I tend to be on the gentle side.

Max's father reflects extensively on his duties as father. He is overjoyed to have a child: it is like a compensation for his having given up music in his youth. To tell Max something directly and frankly is difficult for him. He perceives Max as rather spoiled; however, he cannot bring himself to become a stricter father.

After describing the two families of Kelly and Max, I return to Patrick, the child I described in Chapter One. Many of his problems seem to now be manifested in his second year of life. I should like to show how Patrick demonstrated these problems through play in his psychoanalytic sessions.

\section{Patrick's development in psychoanalysis}

Patrick's parents had agreed to an analysis in order to help him deal with his nightmares, his fits of rage, and his position as an outsider. Patrick's analyst attempted to understand his playing and what he said as expressions of his inner conflicts. In the feelings the child developed for his analyst can be seen the same patterns that he has towards his "inner objects", the inner images he has made of his parents in various phases. Burdensome memories are, so to speak, reconstructed through feelings transferred onto the analyst. Like most parents who put their child into therapy, Patrick's parents had not described any unusual experiences with their child. Often it does not occur to parents that their child needs help. With Patrick, too, it was his kindergarten teacher who drew the parents' attention to his emotional difficulties. In the ensuing discussions with the parents, individual instances of early developmental problems came up. Patrick's birth and his first few months were not unusual. His birth had been a spontaneous one; he nursed well and slept. He was already toilet trained at one and a half years, without pressure from his parents. Outer events apparently contributing to his difficulties included his mother's subsequent pregnancy, as well as Patrick's serious-in fact, life-threatening-intestinal infection in his second year.

I should like now to describe Patrick's psychoanalysis, which helped him sort out the problems of his inner world. To this end, I shall summarise various scenes that occurred during the sessions. 
In the first months, it was important for Patrick to orient himself, to know when he would be coming to me and when there were no sessions. In psychoanalysis we proceed from the principle that the child can bear the truth, that the truth is in fact healing if we can impart it to the child in a form he can comprehend. Therefore, there are no pedagogical reproofs, distractions, or promises; instead, the psychoanalyst must have the courage to accept everything the child himself might bring to the process. In Patrick's case, this was a chaotic inner world, in which phases of clear thought and speech also alternated with phases of thoughtless, cruel destruction and hopelessness. He was impatient and could not stand frustration. If he did not immediately succeed in some enterprise, he threw the object on the floor, destroyed it, or began to strike out wildly. Then, it seemed his inner world also lost all structure and collapsed. This was why the temporal structure of the sessions, which took place on three consecutive days, was of great significance. His psychoanalysis began after Easter, but was interrupted at the beginning of June by his family's three-week vacation and in July by my own five-week vacation. At the end of the first week, I asked him whether I should write down for him when he would be coming again. When he assented, I wrote down his sessions in a home-made calendar, with the days where he had a session in one colour and the sessions cancelled due to vacation also clearly marked. This calendar acquired a central meaning for him during the first three months. At the beginning of each session, he took it out of his drawer and made a circle around that session. The weekends and interruptions were difficult for him. Patrick's mother tended to make him promises and tell him stories in order to forestall one of his fits of rage. These promises, however, were only seldom fulfilled, so that Patrick hardly had any trust in such statements any more. When he was in a rage or demanded that a promise be kept, his mother often told him he was tired and made some excuse why the promise could not be fulfilled. His love for his mother tended to make him believe her, only to be disappointed anew. For some time he played the role of mother with me: he would tell me something that was not true and then laughed with schadenfreude at my disappointment. With our roles thus exchanged, many rituals of cruelty were enacted between us.

At the outset, he transformed the game room into a chaotic space, making it into a dirty, repulsive place with his broken crayons, torn paper, water sprayed about, and scribbles on the wall, so that the 
children after him or my husband might slip and hurt themselves or depart in horror.

From the very outset, his fantasies of new babies played a key role, whether they came from his mother or ostensibly from me. In the playroom, children are allowed to express their feelings, they are neither admonished nor punished: instead, psychoanalysis tries to put these processes into words. When Patrick for the first time felt taken seriously with his feelings, with his hate and jealousy of other children and of my husband, he was then able to talk about them. He showed me how the next child after him would fall on the wet floor and hit his head; demonstrating this, he himself fell to the floor as if in punishment. At the same time, he could also show me how important the sessions were for him, how cold he felt and how cosy it was in the room. When he felt understood, he would touch me with his foot as if accidentally, lean on me in passing, or look deeply and searchingly in my eyes. When I indicated to him that he should come close to me when he felt understood, his destructive behaviour immediately ceased. He asked me to help him put his things back in his drawer. Patrick assumed I was exactly like him. When he left the room a mess and then found it clean in the next session, he assumed that I would also forget everything that had passed. He seemed to be saying to me that nothing was of significance since it could always be cleared away. He could then make another mess and the entire world was stupid, without meaning or structure; in such a world, the significance of his actions would be ignored. But when he experienced that although I as his analyst would clean up his mess and put his playthings away safely from the other children, he still could reflect on his motivation for making the mess and keep emotional contact to it; he too began to ponder the matter. He also began asking questions and expecting answers. It seemed to calm him that I saw how often he was completely overwhelmed by something terrible, and at the same time could see how vulnerable he was and angry he became when he was laughed at or humiliated.

In a meeting four weeks later, both parents were deeply impressed how Patrick's fits of rage had completely vanished. He now participated in kindergarten without any problems. Visibly moved, Patrick's mother related how he now could talk about his feelings when he was sad or joyful. She tried to prepare him for decisions. Patrick came to her, put his arms around her neck and said, "Mommy, I love you." That was the first time this had happened. He also had less trouble parting from 
her. He also played "loving his sister", where he would embrace his little sister, although so tightly that she quickly broke away.

In analysis, Patrick showed he felt small and powerless and had little hope of becoming as big as his father. Patrick's father, who had at first thought therapy unnecessary, changed his mind when he saw Patrick's fits of rage disappear. As Patrick's behaviour became less wild and uncontrollable, his father could talk about his fear that Patrick's relationship to him could become as difficult as his own relationship to his father. He had been unable to talk with his father: he had been so humiliated and cruelly treated by him that he now could not imagine discussing anything with him other than his love-hate. Thoughts of his childhood were so painful that he was completely unwilling to discuss it. Often he felt at his wits' end since Patrick reacted neither to yelling, blows, or being shut in his room.

At the beginning of Patrick's second year of analysis, the fine structure concealed behind his apparently unmotivated destructivity became visible. Right after summer vacation, Patrick reminded me that I had promised him a new ruler, since he had broken two others. He seemed much more mature and was certain that the sessions would continue. He often began constructing a house, into which he invited me. We should be quite equal, without any difference between us. Later, he built one house for himself and one for me. These games had a constructive aspect, but sometimes also a touch of falsity, of pseudo-friendship, for instance when he wanted me to play the part of a kitten. His jealousy kept breaking through when he wanted to fill the whole space with "pee-pee", so that everything would smell of him and he would make big holes in the wall. His destructivity was concealed behind the "task" of looking for gold. Often, it was important for him to keep both levels covered: he put on an act in order that I wouldn't notice his true underlying intention.

Step by step, he gained more access to his feelings of insignificance and panic over his self-perceived stupidity and powerlessness. Often he was afraid that the absence of something meant it was gone forever. In play, he was the father who should "help" me, who was the small child or baby. But this help consisted in telling me what to do with a threatening voice, and he was quick to become impatient and pressure me, saying, "Come on, let's go!"; then, without any warning, he would scream at me until I was cowering. In these cases, his face turned completely red and he roared in a loud voice. When I asked how I was to 
react, he told me to be afraid and cry. My reactions seemed to increase his rage and shouting, until he then stopped.

The special quality of Patrick's relationship to his father unfolded through further play. Here some scenes from a therapy session:

First, we were fishing, then his mood changed and he became aggressive. He demanded that I insult him: "Shitty Patrick, he shat in his pants!" When he was unable to do something, he said "Shit"; when something exciting occurred, he had to go to the toilet. Later he became the small baby who had soiled his pants; I should be the father who changed his nappy. Patrick played this scene quite realistically, lying down on a baby's changing table; I was supposed to say: "Lift your bottom," and put something under it as a nappy, then fastening it. I was supposed to put him to sleep as his father, his mother being dead. In play, he climbed out of the bed in the middle of the night. I as his father should find him, yell at him, and punish him. This game was laden with great intensity. Patrick was not satisfied with my mere simulation of yelling and hitting him. He became excited, took my hand, and tried to hit himself with it. "You have to hit me hard, harder!" Since I did not do this, instead expressing verbally how I (as his father) was upset, he began to hit himself with his own hand. "That's how to do it," he said.

In numerous sessions, he demonstrated how successfully he upset both himself and his father, drawing his father into his cruel games. His fantasised couple consisted of a man and a child who were bound together in a pleasurable yet intimately cruel way. The child was in control: Patrick had it in his power to provoke his father to a state of extreme rage and indeed to complete helplessness. Patrick derived great satisfaction from this. My goal was to make it clear to him that he was the active agent in this, able to make his father punish him. He did the opposite of what his father demanded, or acted as if he had not heard him. In a role play, he showed me how he did this. "Don't you hear me?" he screamed, as his father. Sometimes he sat in the car ready to drive off, and I as the child was supposed to nag him until he really seemed about to drive away. I then had to scream in horror and run after him in terror. His pleasure at inducing rage in his father was thus quite obvious. Patrick succeeded often in tempting his father into acts of violence. 
In the next discussion with the parents, the father told me that he had now distanced himself from disciplinary questions, leaving this to his wife. Patrick had now begun to build houses with his sister, with his father assigned the role either of mailman who brought the two of them their mail, or policeman. The parents thought Patrick was already cured; in kindergarten, he played with more sense of fantasy than most of the other children. Despite this, they let him still come to analysis for his inner changes to become stabilised, as I suggested.

In the phase that followed, he often came to me like a small baby, lay down on the table, and said how cold and dark it was. I interpreted to him that he knew today was a postponed session and everything felt different from normal. When I understood how angry he was at me, he got up and wanted to play more, after going to the toilet. He showed what a relief it was for him to do something familiar to him, such as construct a house. He and I should exclude everyone else. He had brought with him an empty rocket hull, which he threw around in the room. I was supposed to be the small, fearful baby. I interpreted to him that he wished to show me he had felt discarded by me over the weekend. In play, he was the powerful adult, who could always throw rockets around, and I should be afraid and cry. He also showed me how hurt he was that I had left him alone over the Christmas holidays. He achieved access to his explosive feelings, and then wanted to destroy everything. Patrick could make contact with his feeling of not being able to do anything right. He began to try to do things on his own, develop trust in his abilities, and ask my help when he could not manage something alone. At the beginning of psychoanalysis he hadn't wanted to do anything alone: his refrain was "You do it".

At the beginning of psychoanalysis, Patrick was an awkward child, often teary-eyed, with a dull facial expression that rendered him rather unattractive. He slowly became more lively. In the sessions, he began to climb up on the table, to take it into his possession along with the room. He climbed from one windowsill to another, wanting at first to be held by me, but soon able to manage this without help. He jumped from the table onto the floor and became more and more skilful. In kindergarten and in the playground, too, he had shed his timorousness. He was now one of the ones who climbed all the way to the top of the jungle gym, which pleased his mother greatly. By clearly naming and sensing thoughts and feelings, he discovered solid ground and a method 
of overcoming obstacles. During a skiing vacation with his parents, he was allowed to learn snowboarding and was better at it than his athletic father. Since then, he also "snowboarded" in the therapy room with a stool or chair. His ability to think and to have affectionate feelings also altered his facial expression. In place of the cold, often cruel or timorous expression, his eyes could now express affection or sadness. He was now able to use his intelligence, which had often been shrouded by his inner chaos, and he was attentive, perspicacious, and quick on the uptake. His rivalry with his father-in transference to my husbandhad a threatening quality. Before Krampus Day, he spoke of his fear that Krampus would take all bad boys and kill them. After this, he drew numerous Krampuses to decorate every window of the playroom and to weaken the destructive power of Krampus. In numerous scenes, Patrick demonstrated how his ego had become stronger and that he was increasingly able to integrate his aggressive and friendly feelingsand to placate Krampus. In his drawer, Patrick was hoarding a variety of objects: he placed three paper towels at the start of each session in the drawer; newspaper cuttings he had found in the waste paper, threads, remains of pencils, chestnuts, and motley fragments filled his drawer to overflowing. As he achieved increased inner clarity, he began to clean out his drawer, tidying it and then putting the contents back in an orderly fashion, clearly telling him how I could aid him.

He began to take me for long trips on his "snowboard". But jealousy and hate still broke over him when he found a tiny piece of plasticene, tape, or string from another child. He played at hospital, where I was the small patient who was afraid and he was the doctor who gave me huge injections and pushed my head down by force. Once, he wanted to cut open my stomach in order to take everything out of it. Then, I was supposed to be the person who wet her pants, whereupon I was mocked and laughed at as "Shit-Ms.-Diem".

In the next meeting, Patrick's parents told of his hospital stay when he was one and a half years old, where it was necessary for four men to hold him down in order for the doctor to give him an injection. Due to a serious intestinal infection, he then had to wear nappies. His explosive diarrhoea had so scared him that he fell into a panic and would not stop yelling. He was very ashamed to have to wear nappies again. He imitated his father, who then called him "Shit-Patrick". The birth of his younger sister, at this same time, irritated him, as if it were a confirmation that he was unwanted due to his badness and dirtiness-as if this 
were the reason his parents had wanted a new baby. That was the point at which his frightening dreams had begun.

In the ensuing sessions, ghosts from his nightmares came to life. I was supposed to be the small child who woke up in the middle of the night and heard strange noises. I must then be completely petrified with fear, and he a ghost who scared me. I should then call for Mama. Or, we sat close together and listened to the threatening noise that he imitated. When I then linked these noises to what Papa and Mama do at night (sexual intercourse), he agreed and said that was dangerous. But he wanted to go into the bathroom to see what they do. Peering and listening were of great importance, bound up with his fear and the ghosts.

His traumatic hospital experiences became the focus of one therapy session. Patrick had kneaded blue, red, and green plasticene into a brown uniform mass. He then turned a radiator next to the table all the way up and asked me to come with him into the house, that is, under the table. Patrick climbed on the table, put little pieces of the brown plasticene on the radiator, and watched how it began to run down the radiator as it slowly melted. When I then interpreted his wish to fill the whole room with "poopoo", so that everything would stink of him, he nodded and said: "Yes, that's how it should be." He took bigger pieces for melting. He demonstrated how it should grow bigger and bigger and then asked me to stop it with a paper towel. However, since I was not fast enough, he himself took a sheet and demonstrated how I should do this. He emphasised how important it was not to touch the plasticene in any way. I linked this to his fear that this "diarrhoea" could be dangerous. He became more and more excited, laid large amounts on the radiator and demanded that I stop it, in which I was only partially successful: I was meant to see what it was like to be unable to stop this mass of diarrhoea. I asked whether this could be similar to the time when he was in the hospital with this dangerous, unstoppable diarrhoea. "It was like an explosion," said Patrick ominously. I interpreted that his explosive diarrhoea could have made him afraid of becoming completely broken. He nodded. When I asked him what it was like back then in the hospital, he said in an emotional voice that it had been very painful. Perhaps he had considered it a punishment for his angry thoughts over his sister in his mother's belly, I added. After a short pause for deliberation, he said in a calm voice that we could now turn down the radiator. Patrick took out clean paper towels and put together the larger pieces of plasticene 
for me to make a ball out of, since he would need this later. He cleaned off the radiator meticulously, at first asking me to help him, but upon reconsideration deciding to do it alone. He worked at this with great concentration. Since I had made him conscious of his interconnected fantasies, he felt understood and also felt he understood himself. After this, he was able to clean everything up with great care.

Although there was constructive development through the course of the sessions, elements of his destructiveness and jealousy emerged continually, where he spat on me, kicked me, tore the spectacles from my face in a fury and wanted to break them. His mood could swing harshly; I always had to be on guard. However, he gained more control over his hitting and pushing. When I could understand his mood swings and link them to his own experiences, his aggression was transformed into gentleness; he put his head in my lap. He began to draw pictures of himself. He was very skilful playing ball. He strove to win by a large margin; either he or I wrote our points down, and he was usually the winner.

He was able to express his wish that I be his third grandmother, always accessible to him, yet was also able to see that there would come an end to our contact. He was able to show his grief concerning the end of the analysis. Over the course of several sessions, he made a candle out of wax that he had brought with him, and also little candles out of rope, which should serve as mementos to the many sessions.

\section{Discussion}

His serious infection-necessitating a hospital stay-together with the birth of his sister, seem to have hurled Patrick into a crisis at the age of one and a half. Although he was already toilet-trained, it was necessary for him to use nappies. His inability to control his bowels transformed his body and himself into a dirty, repulsive hull of which he felt ashamed. Patrick apparently saw his illness as a punishment for his feelings of jealousy. Mockery from his father-who saw him more as a younger brother than as a small son-caused his fragile ego to temporarily collapse. He was seized by rage and panic, screamed and raged to such an extent that almost nobody could pacify him. His guilt feelings led him to fantasise a punitive world of ghosts and monsters, added to the threatening sounds coming out of his parents' bedroom and bathroom, which he linked to his aggressive fantasies. He was continually 
withdrawing into an anal, destructive fantasy world. He derived the greatest pleasure from the provocations of his father, who willingly played the role of the evil, sadistic, mocking punisher. His faeces constituted a powerful instrument; his full nappies, which he often did not want to surrender, were for him laden with pleasure. Patrick's father, who was excellent at sketching, felt compelled to outdo his son in their competition: Patrick had no confidence that he could ever learn to draw as well as his father. The father also always sought to win when they played ball. Only slowly did Patrick develop a certain amount of selfconfidence that he was allowed to do things his own way.

At the same time, there was a healthy part of his personality which psychoanalysis was able to build on. Patrick could build on the positive experiences in his first year of life: his world retained its essential structure; he had not had a psychotic breakdown, and did not withdraw into a private world like an autistic child. He tried to see if he could find security with his analyst. Through my steady patience with him, I represented a world where there was somebody concerned for his well-being. Patrick had the concept of an inner object, someone who could think of him. As soon as he could use analysis as an environment where he was free to show his terrible fear, describe the ghosts who haunted him, and exhibit his explosive jealousy, he could continue on at home and in kindergarten without attacks of rage and frightening dreams. A loving relationship to his mother seemed to soon outweigh his previously distorted image of her. Patrick now no longer needed to defend himself against his own feelings with attacks of rage, but could express his sadness or joy, longing or disappointment in a differentiated fashion. Although he still often burdened himself with the exorbitant demands of an exacting conscience, his ego had become stronger. He began to show concern for other people. With his father, he remained passive and wished to be inspired and motivated by him to play. Since his fears had lessened and he could counter the image of his repulsive body with a positive selfimage and increased self-confidence, he now became much better at having friends and resolving conflicts through negotiations instead of through violence and blows. Patrick remained vulnerable and susceptible to provocation.

His relationship to his little sister improved: they could play together for hours. When Patrick was sent to his room by his parents as punishment, he asked his sister whether she wouldn't like to play with him 
there and they then went together to his room-the parents remaining where they were, with mixed feelings.

In case studies, we may ask to what extent the environment is responsible for the child's problems and disorders. Authors such as Alice Miller, Bowlby, and Kohut give the impression that the parents are always at fault. I believe, however, that it is important to perceive mutual influences and help the parents understand their problems with their child. Discussions with the parents also serve to help them reflect together on their child's behaviour in order to understand him. Here is an example from the conversations with Patrick's parents: Patrick's father said Patrick's meaningless screams drove him crazy, since Patrick's fury increased until the father resorted to drastic punishments. I asked him to give me an example. The father thought for a minute and then told of how he had been with Patrick in the living room and asked him to close the door. After he had said this several times, he lost his patience and closed the door himself. Patrick, instead of then leaving him in peace, began to cry bitterly and opened the door again, which made his father furious. When the father once again closed the door, he locked it, so that Patrick could no longer open it, whereupon Patrick fell into a tantrum, rolling on the floor, and screaming at the top of his voice. At the time, Patrick was two years old and could understand what the father was saying to him. When I asked the father how he could explain Patrick's behaviour, he at first had no idea. I asked what had happened just previously. Then the father related that the three of them had been spending time together peacefully, until his wife went over to the neighbours. At first, Patrick had not cried. Only now did it dawn on Patrick's father that Patrick had perhaps believed the mother could only come back through the balcony door, and that was the reason he so desperately wished to keep it open. I asked him whether he had discussed with Patrick the fact that his mother also had a key with which she could unlock the balcony door. Only gradually did the father now begin to link Patrick's outraged crying with Patrick's possible fear that his mother could not get in again when the door was locked. It then occurred to Patrick's father that he spoke very little with Patrick, and explained very little to him, since he assumed his son was still too young to understand. However, he was more and more surprised at how much Patrick noticed and how precise his powers of observation were. Patrick's father had never known a father who would explain something to him or done things with his son-his own father had expected instant obedience or else 
meted out punishment. Patrick's mother had had a very loving father, who had allowed her to build things with her or help him in his chores. This grandfather was also now an important and helpful close relative. He was usually the one who brought Patrick to his analytic sessions.

\section{Notes}

1. Under National Socialism (Nazism) it became evident how the impulse to shame, abuse, and humiliate surfaced in ordinary human beings from underneath their civilised veneer. The desire to derive pleasure from the helplessness and fear of weaker persons, to inflict what a child suffers during toilet training, can be seen in the cruelties suffered by Jews. The close correlation between such cruelties and experiences in the anal phase, with the child's shame over nudity and soiling as well as his newly established condition of dependency with regard to his bowel movements, is confirmed by descriptions by Bettelheim (1943), Garfinkel (1956), and Loewenberg (1986).

2. It is thus naïve to take a child's tales of deprivation or parental cruelty as a realistic depiction of childhood, as for example Alice Miller $(1979,1981)$ does. This would mean that parents alone are at fault for all problems. 

CHAPTER FOUR

The third year of life
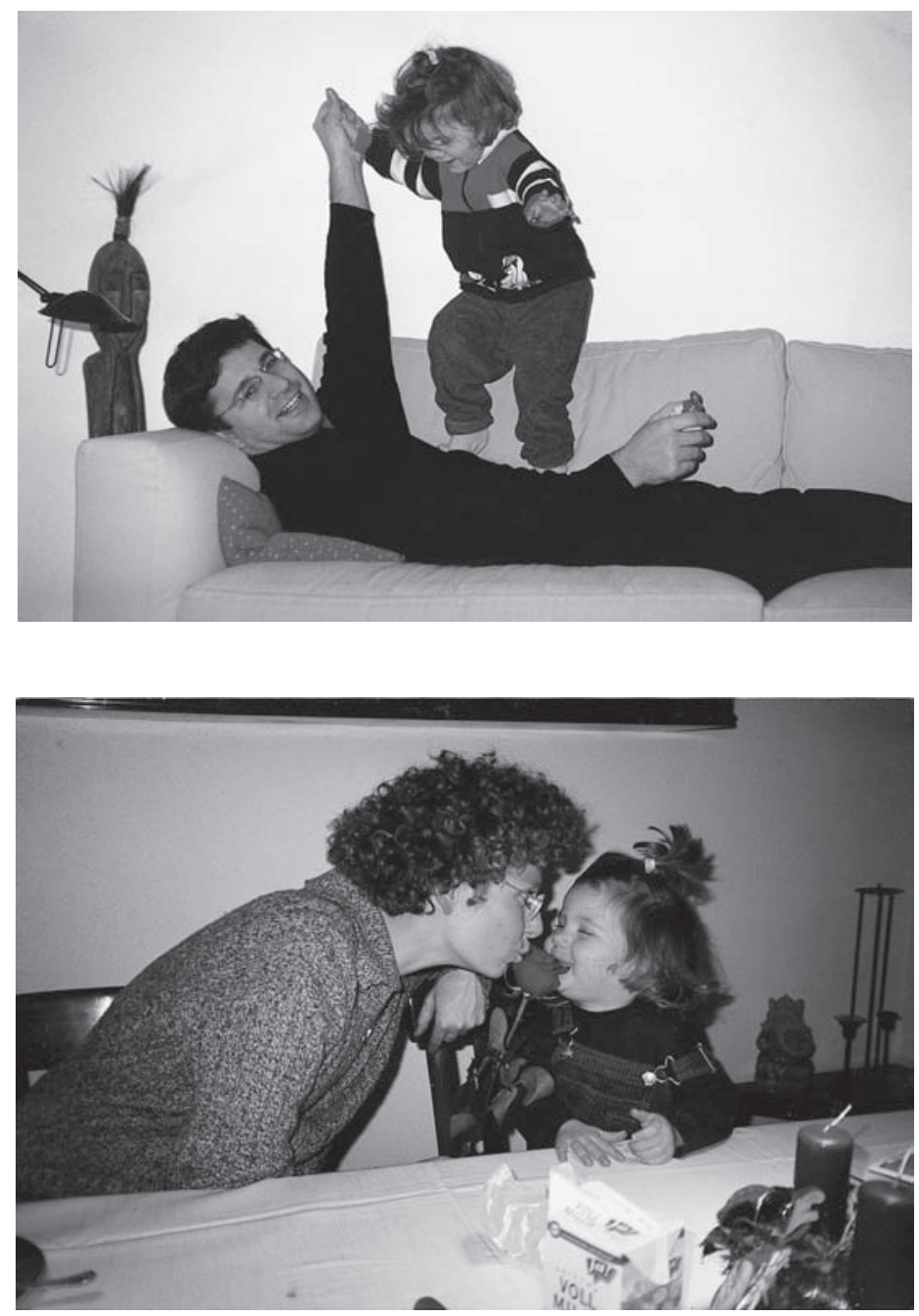

7 he third year of life is the last of three decisive years where the foundations of the personality, deep structure of the psyche, and model for perceiving the world are all formed. Recognition of the great significance of the first three years of life did not begin with Freud: Charles Darwin already was a proponent of this view. In his biography of Darwin, Bowlby described a conversation between portraitist William Richmond and Darwin, where Darwin was asked in which years a child receives his most indelible impressions. His answer was, "Without doubt the first three," and he explained that "It is a virgin brain adapted to receive impressions although unable to formulate or memorize these. They nonetheless remain and can affect the whole future life of the child recipient" (Bowlby, 1990, p. 430). Although there was even less known then than now about the links between cognitive and psychic development, Darwin comprehended the crucial importance of these years.

For those parents who had difficulties understanding their child during the first two years, however, this also means they now have a second chance. Some parents find it easier to deal with and understand a young child who can already express himself in words. The feelings of a two year old are better integrated, so that some parents are less cautious 
than with the raw, intense feelings of a baby. Yet the child's third year of life demands both clarity and tolerance on the parents' part. The child who already seems independent and who can more clearly express his wishes through gestures and words-who has better motor skills, climbing and jumping alone-can from one instant to the next, when tired or fearful, revert to the small baby requiring physical contact and safety from his mother or father. He is often overwhelmed by turbulent emotions that are frightening even to himself. Fits of rage, hurt, antagonism, and sadness segue into phases of joy, adventure, and curiosity. Particularly when they have had another baby in the meantime, parents tend to place too high demands on their two year old. He can already walk so well by himself that the parents believe he no longer needs to be carried about, reacting unwillingly when their toddler wants a rest from walking and wishes to be picked up: should they later observe this scene on video, they might experience a pang of shame, seeing how small and needy the toddler actually looks.

I should like to provide insight into several dimensions of development in the third year of life:

- Acquirement of language: symbolic thinking

- Toilet training: shame and induced shame

- Sexual identity and oedipal fantasies

- Sibling rivalry and theories on birth

- Development of a conscience

- Childhood anxieties.

\section{Development of children in their third year of life}

\section{Acquirement of language: symbolic thinking}

During the third year of life, children develop the ability to express themselves verbally in a more differentiated fashion. Only at the end of the second year does the child begin to learn language in a systematic way. He now succeeds in better distinguishing between reality and fantasy: in play, he might pretend to be sleeping, or put his teddy bear to sleep, pretending it is now night. Through imitation, he begins to form complex sentences. The two year old's thirst for knowledge is propelled by the question of "why". He wants to investigate what lies behind every observation and phenomenon, to delve into every background. Above all, the child wants an answer to the major questions 
of humanity, revolving around life and death. Where do babies come from? Where do I myself come from? Previously, it was thought that the answers to these questions should be kept from children, or that tales of the stork were appropriate. Today we understand how important it is to answer such questions accurately and yet in a form comprehensible to the child.

Words are always bound to some sort of emotion and experienced scenically. The same sentence-for instance, "What's the matter with the little girl?"- has one sound when spoken by a loving father tenderly holding his daughter, and another from an irritated older sister. In role-playing, whether with stuffed animals and dolls or toy cars and aircraft, these various emotional attributions come into play. Observers occasionally notice a child imitating a certain tone of voice or phrasing so exactly they actually believe his mother or father are speaking. At times-for instance, when the child speaks with great anger or exaggerated sweetness-a child's language becomes an expression of his distorted perceptions. Parents are often shocked at how precisely their child assimilates words, sentences, and behaviours: a two-and-a-halfyear-old girl, seeing two huge brown leaves on her grandmother's green plant, ran forward towards the plant and exclaimed: "For God's sake, for God's sake!" She was imitating her mother, who while changing her five-month-old brother's nappy, would put him on the changing table and sometimes rush over to him crying "For God's sake!" Of course, children are particularly fond of imitating what their parents say in moments of affect. Many parents do not realise that, when driving or talking on the phone, they say "Shit". Sometimes one can overhear children comparing notes on whether "My mama says shit" when she is very angry. Typically, when the child itself then says "Shit" during play, the parents indignantly forbid this. It is not easy for young children to orient themselves in the complex world of rules, etiquette, and upstanding behaviour, which things they are permitted to say and which they are not. For parents, it is a challenge to teach their children the meaning of politeness, hospitality, dealing with conflict, and mediating between differing wishes.

In learning language, the child is fundamentally helped simply by his parents' attentive listening, showing he is understood. Often, children want to say so many things at the same time that they begin to verbally stumble and stutter in expressing their thoughts. Parents need not be concerned at this. It is sufficient when they take the time to fully 
focus on their child-perhaps face-to-face-thus demonstrating that he has their undivided attention and can afford to speak slowly. Often, the child resorts to gestures in order to convey something. Since he is not yet familiar with many words, he must search for them and occasionally invent one. One little boy called every large object or animal "Daddy," in a deep voice: the size difference between him and his father was the inspiration for this, with the deep voice presumably meant to imitate his father's. There were accordingly a "Daddy" or "Baby" toy train, a "Daddy" or "Baby" apple, etc. At some point he then began to adopt the linguistic usage of his family members.

Young children can be astonishingly creative when they do not know the correct word, yet know what they want to ask for. Here is an example from an observation:

The two-and-a-half-year-old Karl brought his grandmother a picture book for her to read to him, saying with great emphasis a certain word that she, however, did not understand. She tried to guess what he meant, asking him if he would rather hold the book himself or sit on her lap, with her holding it for him. No, that wasn't it. When she had become quite bewildered, he began joyfully to sing quite clearly an English song, "Jingle bells". Since the picture book was in English and Karl's older sister, who was already learning English in kindergarten, sometimes requested that the book be read to her in English, the grandmother now asked Karl if she should read it in English. "Ja, Englisch", replied Karl, now pleased, and listened with delight, repeating aloud such words as "big".

Karl could not remember the word "Englisch", but he could certainly remember that his sister had asked the grandmother to read the book in an unknown language with words that sounded different. He seems also to have known that "Jingle bells" was an English song, and thus sang it to clue his grandmother in.

The time when children begin to speak fluently varies greatly. Some already babble at the age of two, sing complete songs, and murmur counting rhymes, whereas others are still speaking in one-word sentences and expressing themselves with gestures. As long as a child can indeed express itself, albeit with gestures and calls, this is a good indication that his verbal understanding is fine-even if he does not speak yet. 
A child's pleasure in language depends largely on the manner in which his parents respond. Are for the most part punishment, correction, prohibition, and criticism being conveyed to the child? It can be helpful for the parent to observe how often she or he is saying "No", "Get away!", "Leave that alone!", to the child-prohibitions and corrections, often in an annoyed or upset voice. Are these balanced by a comparable amount of encouragement, praise, and recognition? We can praise the child, telling him he has "done well" or is a "good girl"; a simple "Yes" or "Just try it" have an encouraging effect. During my infant observation in London, I was surprised how often the mother picked up her little boy with obvious joy and said "What a clever boy!" or "Well done!", "Jolly good!", “Fine!". The little boy's radiant glow and his considerable stamina demonstrated how his self-confidence was growing from day to day. For young children, it is good when praise and criticism are in balance. A child who is only criticised and corrected has less motivation towards learning to speak. Reading and singing with the child serve to further his vocabulary. It is unnecessary to correct the child's grammatical mistakes-when parents repeat the inaccurately pronounced word or use it in another sentence, the child will hear this and correct itself. With older siblings, it is important to see that they not mimic or mock the child when it makes language mistakes.

A crucial aspect for self-confidence is whether the child is resilient against setbacks or gives up right away. When parents accept their child's personality and harbour positive expectations for him, this in turn helps the child persevere. Often parents put pressure on their child to learn a new skill faster than his personal rhythm allows. This tends to backfire: the child then receives the impression he cannot fulfil his parents' expectations.

An important developmental step consists in recognising the difference between a symbol and the thing it symbolises. Implicitly, symbols bear similarities with what they symbolise, and thus can be constructed by the child himself. Signs, for instance words, are assigned by convention and are thus a product of social life: accordingly, the same object will receive a different "sign" in each language. Until his fourth year of life, the child exhibits a tendency towards magical thinking; only afterwards do words become firmly associated with their corresponding objects. When a crocodile or witch is depicted in a picture book, and equated by a child with his distorted image of an evil mother, the child can develop the impression that a crocodile or witch is actually 
under his bed. The word, as verbal symbol, then renders its object truly present. Hanna Segal (1978) coined the term "symbolic equivalence" for this phenomenon. When a child equates three beautiful pebbles it has found with himself and his parents, this can seem so real for the child that he carefully puts them to rest every night next to his bed. The piece of wood he rides in play is then truly a horse, which can fly over the meadow; the Lego gun is a truly dangerous weapon, which the child refuses to surrender. ${ }^{1}$ This symbolic equation is a normal rite of passage. It is believed that formation of symbols originates when the child is distracted from his preoccupation with his mother's body towards the environment, which is less charged with anxiety. The child seeks new, conflict-free relationships with objects (substitute objects). This also means a certain amount of fear is necessary to motivate the child in his development. As long as the symbol is equated with what it symbolises, the child believes he has both under control-implying a unity between the symbolist, the symbol, and that which it symbolises, whereas we can only speak of true symbolisation when the child is capable of recognising a distinction, and hence a difference, between himself, the symbolised object, and the symbol. We understand symbolisation as an important ability the ego exercises in attempting to deal with its fears. If the child can see the symbol and what it symbolises as separate from himself, he can then accept reality and the limits of his own influence. Accordingly, fairy-tale figures such as the witch and queen, the king and man-eater, Punch and the crocodile stand for aspects of childhood feelings and wishes. Struggling with each other in the fairy tale as representatives of the child's inner conflict, they provide the child with relief and release. Through the fantastic exaggerations in stories (the hundred-year sleep of Sleeping Beauty), reactions that would seem incommensurate for everyday situations (for instance, a mother's absence) become comprehensible and acceptable. The young child experiences his mother's absence as an "eternity", even when she is only gone for a half an hour. In a fairy tale, good is just as present as evil, which is fascinatingly and frighteningly powerful. Bruno Bettelheim pointed to the significance of fairy tales in his book The Uses of Enchantment (1975): "They help children to explain unconscious inner processes through images, and thus the image, expressed through words, is used to comprehend unconscious feelings ... The child experiences rage not as rage, but rather merely as the impulse to hit, to destroy, to silence." In the fairy tale, the threat of inner rage is expressed by a demon or robber 
whose aim is to destroy everything. At the end, the dangerous robber is vanquished or tamed, just as the child wishes to learn control over his aggressive impulses.

The thinking of a two- to three-year-old child encompasses aspects of various thought processes. In many areas, the child can make realistic assessments, while being under the grip of magical thinking in still other areas. By the term "magical thinking" we understand the conviction that fantasies, wishes, and images actually occur, that is, differentiation between fantasy and reality is not yet distinct. Just as the magician would use it, a magic word suffices to make everything correspond to the child's wishes. Accordingly, the learning of words and their meaning often gives rise to major difficulties. Selma Fraiberg (1980) supplies one example:

\begin{abstract}
David, a two and a half year old boy, was going to fly to Europe with his parents. He understood the idea of an airplane, which he had often seen in the sky. Everyone was looking forward to the trip. But after a while, David's parents noticed that he stopped asking about "Jurop", and even seemed anxious when his parents discussed it. They tried to find out the source of his anxiety. However, he obviously didn't want to talk about it. Finally, David came out with a heartbreaking confession: "I can't fly to Jurop!" And tears ran down his cheeks. "I don't know how to fly yet!"
\end{abstract}

David understood well the idea of an aircraft, but could not know that people embark in one. "I don't know how to fly" shows that he presumed his omnipotent parents could fly, but that he would still have to learn how. David had understood the word "airplane", but not yet the concept of an airplane as a vehicle, meaning child and adult were speaking a different language.

Through language, the child begins to develop an objective selfimage. He can recognise himself and his possessions, he can say "Mine" and "That belongs to me". He uses language to tell himself a story or sing to himself when falling asleep. Some children tell themselves or their stuffed animals lengthy stories. The child's connection to other people acquires a new quality. Language also enables the child to narrate a story about himself. However, in the third year of life, symbolic and concrete thinking, that is, when the child melds himself with the 
symbolised object, exist alongside one another. Here is an episode that could be entitled "I am the train":

A two-year-old girl put plastic train tracks together so that they resembled a puzzle. With her mother's help, it became a circle. The girl now put a Lego train on the tracks and asked the mother to drive the train. The girl ran alongside the train next to the tracks: she seemed herself to be a train too. She was proud that she could run faster than the train. Only after she had run ten times around the track did she herself try to drive the Lego train. When the train derailed, she said "Uh-oh, broken!" and tried to put it back on the tracks. She then switched back to running, observing simultaneously how her mother played with the train: the mother made the wagon come to a standstill, opened the doors, and asked the figure inside if it wanted to get out, then taking it out and driving the train further. When the girl sat down again in order to play with the train, she asked another figure: "Out?" Shaking her head vehemently, she answered for the figure: "No!", closed the doors, and the train travelled on.

In this short sequence, we see how in play, the girl shifts back and forth between two experiential forms. At times, she is the train, fascinated by the movement, running around the circle of train tracks with great seriousness; then, she becomes the person who wants to play with the train and the figures inside. With her, the figure does not wish to get out, but stays inside the wagon. Since the girl's mother is just now pregnant, the figure's remaining inside the train could point to her wish to remain in the baby relationship with her mother.

The developmental phase in which the child learns to distinguish between concrete and symbolic thinking occurs in the third year of life. In the following scene, we can see how a five-year-old girl is able to clearly differentiate between a symbol and what it symbolises, whereas her two-year-old brother falls into a panic:

The grandmother had not fulfilled a request the five-year-old girl had made. In protest, the girl took the chair the grandmother had been sitting on, and with great indignation carried it in the next room, because she was angry at the grandmother. Her little brother watched her with growing agitation. Then he ran crying into the 
other room and unsuccessfully tried to impede her from moving the chair. The sister had come back to the table and sat down. In tears, the brother tried to bring the chair back into the dining room. His grandmother went over to him, thanked him, and helped him to bring the chair back. He immediately ceased his crying, sat down and began to eat.

The sister is furious at her grandmother and expresses her anger indirectly: she would prefer to push the grandmother away, but instead takes her chair. She can distinguish between the grandmother and her chair and knows that the real grandmother will remain in the room, even when she takes her chair out of it. For the little brother, however, the grandmother is one and the same thing as her chair. For him, his sister's action is as threatening as if the grandmother herself might then be gone and he would be completely alone. He cries and falls into a panic. Only when the grandmother helps him bring back the chair is he consoled.

\section{Toilet training: shame and induced shame}

According to unanimous expert opinion, toilet training should not begin before the end of a child's second year. That sounds reasonable enough, but this new idea constitutes a revolutionary change, comparable to notions concerning a father's presence during birth or whether (and how long) a baby should be breastfed. It is important to be aware that the postponement of toilet training constitutes not only a rational decision, but also demands that the parents recollect their own experiences. Since the whole area of body excretions is fraught with shame and taboos in our Western civilisation, it is seldom discussed openly. But the question of when a child or grandchild should be put on the potty will surely remind every mother, father, and grandparent of their own experiences. Were these traumatic, as for Max's mother, who was compelled to complete her toilet training under enormous pressure within the course of a few weeks, just when a new baby had come into their family? Was the now-father laughed at when he defecated in his pants or wet the bed as a child, delivered up to his siblings' scorn, his sheets exhibited at breakfast to the whole family? Or was he called "ShitPatrick" and humiliated? Was he tied to his crib until he performed in his potty? Was the now-mother struck after she knocked over her potty 
while standing up from it? Many people attempt to not think about their own experiences since these were so painful and humiliating. An important contribution of psychoanalysis, however, consists in exactly that: encouraging parents, grandparents, and teachers to remember their own experiences and get in touch with their painful, joyful, or pleasurable feelings in order to gain sensitivity to the feelings of young children. Even more taboo than painful feelings are the secret pleasurable feelings that are linked to bodily excretions. It is difficult to recall the pleasure that stimulation of the intestinal mucous membranes afforded (and still affords) during bowel movements. With adults as well, the rituals therewith associated are usually secret. Even in amorous relationships, it is not easy to relax sufficiently for "delivering up" one's stool in an unfamiliar apartment. When under stress or in transit, excretion of the stool is difficult for many people. Some celebrate going to the toilet, bringing books or newspapers which they then read with pleasure. Something normally no longer accessible to our consciousness is the pleasure we once had in playing with our excrement, our desire to touch it. In symbolic form-kneading clay or plasticene, playing with sand at the beach or with similar substances-it is easier to abandon ourselves to the pleasures of touching, kneading, and forming.

Can parents, grandparents, and teachers enable young children to acquire a better attitude towards their own bodies, or does envy here play an unconscious role? Is it difficult to grant the child something that the parent was not allowed? Might the child be allowed to feel pride and joy in his body excretions instead of shame? Is he allowed to urinate while bathing, observing and exhibiting himself? Is he allowed to keep his full nappies on as they warmly envelop his backside, even if smelly? One could also say that a relaxed approach to their child's body excretions constitutes a chance for parents to revise their attitude towards their own bodies. One mother, for whom toilet training had been a long phase of desperate struggle with a nanny, told of how at first she had been disgusted by faeces when she was changing her daughter. With her husband's help, who had acquired an uncomplicated attitude towards his bodily excretions, she was able to exert less pressure on her children. Granting one's own child the freedom to determine the point when he is ready to sit on the potty or toilet can become a greatly enriching experience. When parents manage to adopt an attitude of observation and tolerance, this can also lead to a newly tolerant attitude towards their own bodies. Parents can help their children 
in an important direction-a positive attitude towards bodily control and self-control-and derive pride in this. When they take a supportive approach, not interfering but instead offering their child suggestions, this lays the foundation for the child's stable feeling of autonomy and self-control.

The most important motor for child development is the child's overriding wish to grow up, to be able to do everything as his beloved parents and other adults do. The parents' confidence that their child can accomplish the steps necessary for toilet training lends additional support. Interestingly, children develop their own feeling of modesty bit by bit, protecting the borders of their bodily privacy. Although many children at first want a parent at their side when they sit on the potty or toilet, they may later wish the mother or father to turn their back and look away, and in the next phase only call their parents once the act is completed.

Can concrete guidelines be made for structuring this sensitive phase of development, when questions of retention and release, possession and relaxation, power and order are central? The American paediatrician Brazelton provides helpful suggestions for parents helping their child toilet train, suggestions I would like to here briefly outline:

As a basic principle, it is first emphasised that the parents must understand that toilet training is an achievement of the child and not of the parents.

1. Acquaint the child with his potty, showing it and making clear that it is the child's potty.

2. After a week or so, have the child sit on the potty completely dressed, while you sit next to him and read something to him. In this way, he accustoms himself to sitting on the potty for a certain time daily.

3. The next week, ask the child whether he minds your taking his nappies off so that he can sit with his naked backside on the potty. Explain now and again: "You see, I do that every day. And Papa and Grandma too."

4. In the third week, take the child with his soiled nappy to his potty, undo the nappy, and drop it into the potty, explaining that he can later do his business directly into the potty. Don't flush the child's stool while he is still watching, since the child has the feeling that his excrement constitutes a part of himself. 
5. When this fifth step comes to pass should be completely dependent on the child. In general, it is better to make a pause in toilet training whenever the child is unwilling to cooperate with one of the steps. You can suggest to him you take his clothes off and let him run around with his naked backside, best of all outdoors. Tell the child he can sit on the potty when he wants. If he is ready, he will perform in the potty. Leave the product in the potty so that the child can admire it. Congratulate the child, without undue exaggeration.

6. When the child is truly ready, you can let him run about without his pants for longer periods. If he urinates or defecates on the floor, then put a nappy on him right away. Simply say: "We'll try later again. There's no rush." Base your actions on the fact that the child wishes to imitate the people he loves.

7. In learning to urinate at the toilet, a boy should start by sitting down. Only later should his father show him how he can urinate standing.

8. Toilet training in the night should only begin when the child remains dry during his midday nap and he gives some indication he wants to remain dry at night. Wait until he is truly ready-his nappies should be dry for a period of at least four to six hours during the day (see Brazelton, 1992, pp. 190-193).

Children with older siblings usually toilet train more easily since they wish to emulate their siblings. With toilet training as in other matters, it is important that parents know their child. The child is often torn between contradictory wishes; one father related how his son wanted to sleep without nappies at all costs-when the father nevertheless insisted on giving him a nappy, he went into a corner to defecate happily into the nappy, so that he had to be changed again. The father then decided to put a nappy on his son shortly before he turned the lights out at night, and that nappy, conversely, remained dry.

Most girls successfully toilet train earlier than boys. It requires considerable maturity to get up during the night and go to the toilet. In our society, it is not easy to develop a relaxed attitude towards toilet training, since older generations have been put under pressure.

When children are given freedom to determine their own timing for toilet training they often comprehend the process quickly, within one or two weeks. They link bodily excretions to the satisfaction of being 
able to control their bodies, in consequence not attributing too much significance to the whole subject. Some children go to the toilet without any great complications, singing and taking pleasure in their products. Children whose toilet training devolved into a power struggle between them and their parents remain peculiarly enthralled to anality, as can be read in the writings of the Marquis de Sade.

\section{Sexual identity and oedipal fantasies}

The love a baby receives from his mother and father in the first three years of life constitutes the foundation of his adult capacity to love. We know that the love between mother and baby precedes any other, with the love between man and woman based upon it. This love, tenderness, and security is not something abstract, but is expressed corporally and psychologically. The baby has corporal sensations of pleasure when his skin is touched, when he maintains eye contact with his mother, or has her nipple in his mouth. After weaning, he loses this especially intense oral experience of pleasure, to regain it later at the first romantic kiss. The father often feels rejected during this early phase, excluded from the intimate baby-mother relationship, although his position is of great importance for the baby from birth on. In the beginnings of psychoanalysis, the significance of the father was at first underestimated. Today, paramount importance is attributed to the psychological triangle babymother-father (Green, 1993; Grunberger, 1976; Klein, 1928; Stork, 1974). Ross Lazar (1987) points to the "antecedents of triangulation". Based on detailed observations, Ermann and Lazar show how both the father and the mother can assume maternal-nurturing and paternal-structuring functions in infant and child (Ermann \& Lazar, 2003). We know today that both the quality of the parental relationship and the emotional support from the father decisively mark a baby's development.

A special quality can be detected in the way mothers behave with sons and fathers with daughters. Freud pointed out that "sexual selection" has already manifested itself with the parents. "A natural predilection usually sees to it that a man tends to spoil his little daughters, while his wife takes her sons' part; though both of them, where their judgment is not disturbed by the magic of sex, keep a strict eye upon their children's education. The child is very well aware of this partiality and turns against that one of his parents who is opposed to showing it" (1900a, p. 257). The small girl may flirt with her father, candidly and 
without embarrassment expressing her wish to marry him. The little boy wishes to be his mother's protector and lover, sit at her side, or lie in her bed and be admired by her for his strength. They express their preferences for which parent should dress them today, wipe their backsides, or carry them. Often, children put on their parents' shoes, literally and figuratively wishing to walk in their footsteps. Here an example from an observation:

Three months before his third birthday, on a Sunday morning, Daniel came into his parents' bedroom, still quite sleepy. At first he seemed surprised to find them both together. With an expression of great irritation, he went to the side of the bed where his father lay, and hit him on the chest with the full force of a two year old. Then, proud and satisfied, he went to his mother on the other side of the bed, kissed her, and climbed into bed with her. The entire scene was so intense that the father could barely conceal his amusement. (Reid, 1993, p. 60)

Through his blow to his father's chest, Daniel shows that he wants him out of the picture, then climbing into his mother's bed like a lover and kissing her. Daniel is perfectly serious about wanting to be his mother's lover; for him, striking his father's chest may prove he has actually driven him off briefly and can now possess his mother completely, albeit for a short interval. This wish embodies an important developmental step exhibiting the ongoing solidification of his masculine identity. Here, laughing at him or mocking him would demonstrate the actual physical and emotional superiority of the father, suffocating the son's emerging feeling of self-worth. It is important that fathers are able to be generous towards their young son, taking his wishes seriously even during a situation where it must be made clear that the mother is the father's wife. When a father himself is still captive to a powerful rivalry between him and his father or an older brother, he can find rivalry with his little son threatening. In order not to be once more ousted, he competes with his young son in all seriousness, never able to let him win at a game, demonstrating his own superior skill, quickness, and knowledge in every area. For the little boy, his strong father's superior power becomes so convincing that he cannot discover the confidence needed to challenge him, preferring instead to remain a fearful underling. The repressed rivalry then emerges in provocative behaviour towards the father, as with Patrick, or the boy later attempts to dominate smaller 
or weaker peers. Malcolm, often subject to fits of rage, nevertheless drew pictures of himself as a small, fearful rabbit. Only gradually can sons and daughters come to accept that the relationship between their mother and father has quality distinct from their love towards their children. The same holds true for a girl desiring to usurp her mother's position vis-à-vis the father.

Freud termed a son's wish to be his mother's husband, replacing his father, the "oedipal phase" in reference to the classical Greek saga of Oedipus. ${ }^{2}$ For Freud, not only the tragedy itself was important but especially the process of recognising its central deed, and the wish to simultaneously know and not know-in analysis, the same basic position that reveals unconscious feelings and wishes (Steiner, 1999). Freud's interpretation of a child's wish to replace his parent of the same sex has been both celebrated and attacked as a model for understanding unconscious motivations. The oedipal triangle is of major significance for understanding the web of relationships between father, mother, and child. It helps explain the difficult situation of the child, who wishes as a "small" man to have his mother for a wife or a "small" woman to have her father for a husband. The child is at the mercy of a host of turbulent feelings. The girl loves her mother, who now appears to be her rival. The boy loves and admires his father, whom he would simultaneously like to drive away from his mother's side. Only gradually does the child start to recognise that he is still young and excluded from his parents' sexual relationship. The insult of being too young and inadequate and not being an equal substitute for a parent-whom the child has driven away in his fantasy-poses a substantial emotional challenge. Only when the child accepts that parents can make babies through a creative sexual act and that he will also be able to do this when he is big and grown up can he distance himself from his oedipal fantasies. This acceptance of the parents as a couple, with the child's inevitable exclusion from it, also constitutes an important step in the child's thinking. The child can then view itself vis-à-vis a couple that is thinking of it, and witness a relationship where he is not a participant but nevertheless included in the parents' thoughts. Ron Britton has called this the "triangular space" (1989, p. 86). The child experiences his parents speaking of him, loving him, and thinking of him. This model is then internalised by the child as a prototype for self-reflection, enabling him to develop a "psychic space" and exercise self-reflection, just as the parents have reflected on him: the child acquires the capacity for 
seeing himself in interaction with others and for entertaining another point of view, while retaining his own perspective for self-reflection. The acceptance of the parental, creative pair represents an internal concept of the dyad, which can give birth to something new. This involves not the process of two people coming together in a relationship, but also thinking as a process, where two thoughts can come together and give rise to a new thought. If positive aspects and the child's trust in his parents' love have the upper hand, he can then accept being excluded. But if the unconscious feelings of rivalry, jealousy, and wish to destroy the parent of the same sex prevail, the child can then feel threatened by his parents. Often the child's unconscious guilt feelings for his jealous fantasies are manifested through provoking his parent of the same sex until punishment is meted out. The child's aggressive fantasies and wishes are then directed outwards and manifested as fear of witches, ghosts, or monsters in dreams who threaten the child and make him afraid. In Patrick's nightmares, fantasies regarding his parents' sexual union and his destructive wishes must have contributed to his fear of ghosts.

After a phase of oedipal desires and rivalry, the child's ability to accept distance and the reality of the parental couple becomes anchored in his experience of having an existence separate from his mother. The child then has given up his desire for omnipotence and control over his mother. This entails an integration of the good and bad aspects of the mother, in that the child comes to see the mother and father as whole persons-sometimes present, sometimes absent and unattainable. If a two-year-old child cannot accept the reality of separation and reunion, he takes refuge in his fantasy world where he believes he has total control-now willing to cripple his thinking and experiencing of the world rather than accept the painful reality of separation, and preferring to live in his unreal, distorted psychotic world rather than surrendering omnipotent control. This is, however, a poor position for mastering the difficult oedipal phase that follows. Perception of the parents' sexual relationship then also becomes a mortal threat. As Klein (1946) and Bion (1959) have shown, the psychotic would rather distort his thinking than accept reality. The parental couple's hated unification is not seen as the bond between two separate persons, but as a dangerous, exclusive unity of one monster. Consequently, the lack of ability to accept the separation and unification of the parents also limits thinking. The subject has no clear thoughts about himself and a world to which 
he could forge a link, but instead bizarre, destructive thoughts of being situated in a destructive and dangerous world. Feldman compares the positive development of thinking during the oedipal phase to a distorted alternative:

One important consequence of this view of the Oedipal configurations that exist in the patient's inner world is that it enables us to study their influence on his basic mental functions. If the patient negotiates the Oedipus complex in a relatively healthy way, he has an internal model of an intercourse that is, on balance, a creative activity. This seems to be directly connected with the development of the patient's capacity to allow thoughts and ideas to interact in a kind of healthy intercourse. On the other hand, the phantasy that any connection forms a bizarre or predominantly destructive couple seems to result in damaged, perverse or severely inhibited forms of thinking. (1989, p. 106)

For the parents, this phase of oedipal wishes demands great tolerance for the child's attempted insertion of himself between the mother and father. It is easy for children to activate feelings of jealousy or neglect in their parents. An appropriate response would be to show the child the true difference between adult and child, also supplying him with the confidence that he will later be just as big and attractive as his mother or father. The better the father or mother succeeds in tolerating rivalry with the son or daughter, simultaneously conveying to the child that he is loved, the easier the child can later identify with his parent of the same sex. It is difficult for the child's development when the parent of the opposite sex encourages the child's wishes, treating him as a substitute for the spouse.

Relinquishing the oedipal desire leads to increased closeness with the parent of the same sex and thus to solidification of sexual identity. The girl would like to become a woman like her mother, the boy wishes to emulate his father.

I can give here only an abbreviated and schematic description of this important developmental phase. It should also be pointed out that the child's desire to be an amorous partner is to some extent directed at his parent of the same sex. Since human beings have a fundamental bisexual tendency, both the girl and the boy can choose their parent of the same sex as a love object. This is usually a peripheral phenomenon that once again gains significance in puberty. 
In children's play, these emotional conflicts can be expressed and have a healing potential. For instance, the game of running between father and mother, being caught by both of them, serves to show the child that there are moments when he is at the centre of both parents' attention: both are waiting for the child, and he can run to either of them, determining by whom he wishes to be caught. The child's cries of elation and joy show how tonic this game can be.

\section{Sibling rivalry and theories on birth}

In the third year of life, the question of where babies come from is of central interest for a child. The child is poised at the threshold between young childhood and childhood: he must soon take leave of his babyhood. The age difference between siblings is often two to three years. Many parents want to have children close in age to one another so that they can later play well together. Having a sibling certainly enriches the child's life: he must learn to share, he no longer stands alone vis-à-vis the parental couple, but has natural allies against the parents. Children together can learn a great deal from each other and play together, a possibility not afforded the only child. But sibling love is not necessarily a given. With luck, it is the result of a long learning process. The birth of a new baby requires careful preparation of the older child in order to help him through this transition.

At first, a new baby is an intruder. Why do the parents need a new baby?, asks the firstborn child. Am I not enough for them? Do they want another baby because I am too naughty, impudent, difficult? Even when a child is glad to have a new sibling, he will often want to send the same sibling back when seeing how much attention he requires. In his The Interpretation of Dreams (1900a), Freud reported on the dream of a four-year-old girl: "A whole crowd of children-all her brothers, sisters, and cousins of both sexes-were romping in a field. Suddenly they all grew wings, flew away and disappeared" (p. 253).

After the death of another child who was a close relation, the girl had asked what became of children when they die. The answer must have been that they grow wings and turn into little angels. In the dream, this explanation is now extended to having all her siblings grow wings and — the main point-fly away. The girl—the baby-killer-was the only survivor of the whole crowd. The hostile intention of moving all other siblings out of the way is expressed in this dream through their 
butterfly-like embodiments, which then fly away. The motive for the siblings' death is rooted in the egoism of the child, who would like to win out over his siblings, competitors for parental love and attention.

We can assume that two- or three-year-old children observe their mother's new pregnancy closely. Children are precise observers and register every change, especially in their mother's body. One mother who thought she ought to at first keep her pregnancy a secret was studying her daughter's reaction. Susi had noticed that her mother and father took different positions when urinating; she wanted to observe this closely and asked questions about the anatomy of the female and male body.

"Already before the parents told her about the new baby in the mother's belly, Susi-somewhat older than two years-had noticed differences, was particularly attentive, and irritated. Since, after eating, her own belly was especially full and round, she was convinced that she had a baby in her own belly. Every time the parents talked about the baby, she patted her own belly and said 'Baby'. As the mother's belly, after the fifth month, became bigger and bigger, this irritated her, and she stopped pointing to her own belly. Especially when the mother drew her husband's attention to the embryo's movements and had him feel them, Susi pushed herself between them. With a sad, determined 'No', Susi pulled her mother's sweater down, taking the father's hand away with a pleading look. She seemed to know that there was a difference between her full belly and the belly of her mother, which was constantly growing bigger and in which something was moving. Only at times did Susi flare up in hatred against her mother, when the mother took something away from her. Usually she cuddled particularly close to her mother, as if she herself wanted to be a baby and go back into her mother's belly. The parents reacted with great understanding, not laughing at 'their baby', instead telling her that she could later, when she was grown up, have a baby with her husband. The father gave Susi a baby doll, whom she could feed and change herself, which she did for long stretches of time and with great care. Sometimes, however, she threw the doll across the room or dragged her by one leg."

Susi has to struggle with contradictory feelings. She is in a phase where she competes with her father and mother. At the same time, she wishes not to renounce her position as her mother's baby. At first she comforts herself with the illusion that she is the one who is having a baby. But as her mother's pregnancy progresses, she must concede 
that her belly cannot keep pace with her mother's. She seems to feel painfully inferior when her mother is demonstrating the embryo's movements. She can accept her father's present and play mother with the doll, until her feeling of rivalry gains the upper hand. Her parents' understanding helps her manage these contradictory feelings.

When the parents and Susi were visiting an aunt, where there was a little baby, Susi was very interested. Later she went over to the crib, looked at the baby, and returned the baby's smile. When other people then also wanted to come over to the carriage, she pushed them carefully but firmly away and said "Susi!" —as if she wanted to express that this was her baby and nobody else should play with it. When the baby later cried, a mixture of grief and pain could be seen in Susi's face, as if she and the baby were one and the same person. At the same time, she expressed concern, as if she had to take responsibility for the baby. When the baby's mother picked him up and put him to her breast, Susi seemed satisfied. She took the baby's rattle, played with it, then ran to her own little bed, threw the rattle in and said "Susi".

Susi vacillates between identifying with the baby and her wish to be his mother. Finally, the wish to take the baby's rattle away prevails. How do parents and friends react to such feelings when they arise? The reaction depends on how well they have integrated their own feelings and fears. The less aware they are of their own feelings, the greater the danger they will respond with mockery and humiliation, forgetting how vulnerable the young child is. It is easy to laugh when a small girl or boy thinks she or he has a baby in her or his belly. Sometimes the small child is asked by a family acquaintance where "your baby" is. If the adults then laugh, the child will feel injured and withdraw. Only when we look small children in the eye do we see how seriously they take this matter and how urgent their desire is to have the same capacity as their mother. Can we understand how painful it is to be informed that only the parental couple can in fact make a baby?

The anger and jealousy directed at a mother who is making a new baby is considerable. Sometimes the child simply hits his mother, seemingly without motivation. Such tumultuous feelings also feel threatening to the child himself. Parents often have difficulty perceiving the intensity and explosiveness of their child's jealousy and desperation, thus failing to give these feelings space for exploration. If the parents show understanding, the child's guilt feelings will be ameliorated and 
he no longer feels he is bad; both parents and child understand he has both hostile and loving feelings. In the period after the new baby's birth, the child often forges a closer connection to the father, forming a kind of couple with him. Other relatives, such as grandparents, aunts, or uncles can help the older child to feel less neglected. Here is an illustration:

The grandmother came to visit. When the six-month-old baby began crying, the grandmother-with his mother's permissiontook him up. The three-year-old sister sat on her mother's lap and stirred her cup of tea. The mother said the baby was hungry and prepared to breastfeed it. The sister ran to her grandmother and said, "Grandma, I'm coming over to you," as if she wanted to console her since the mother had taken the baby away. She sat next to the grandmother, putting wooden blocks in a box, and turning her back on the mother and baby. Afterwards, she stood up, got a big book about birds, sat back down on her grandmother's lap, cuddled up to her, and asked her to read to her.

The little girl seems not to sense her own jealousy at being displaced from her mother's lap, instead projecting these feelings onto the grandmother and then consoling her. The baby can now lie in his mother's arms undisturbed, drinking peacefully and vigorously, with one hand stroking the mother's breast. The mother alternately watches the drinking baby and her daughter on the grandmother's lap. We see that in a hundred little sequences, daily and hourly, new social groupings arise, demanding from all participants great emotional flexibility and simultaneously making possible a rich variety of roles and combinations.

It can also help to explain to the child the sequence of generationsthat mama was once in grandmother's belly and papa in his mother's belly. It is difficult for children to imagine that their powerful mother was at one time a little baby in the belly of their grandmother. But this serves as an introduction to recognising the cycle of life: birth, growing to adulthood, aging, and facing death.

A three-year-old boy had very often asked his mother in whose belly his mother, his grandmother, his great-grandmother, his father, his uncle, and his aunts had been. When he was at his grandmother's the next day, he wanted to tell her of his new knowledge. He said: "Grandma, you aren't a woman, you are a girl, because you were also in my mother's belly." Although he had heard the correct explanation, 
he could not imagine that his mother and his grandmother had also once been babies.

In preparing their child for the new baby, it is important that the parents state the real reason they are having it - that they want a second or third baby. One reason often supplied - that they are having a new baby so that the older child will have someone to play with—will be hard to comprehend, making for disappointment when the little baby only lies in his crib, cries, drinks, and sleeps.

Answers to sexual questions should be given when the child asks. Whereas earlier generations attempted to divert the child's curiosity regarding the question of where babies come from with tales of the stork, today the opinion prevails that a child should be answered truthfully in basic human questions. Through Freud and psychoanalysis it became clear how damaging the consequences are when children's legitimate questions are not answered at all or with false explanations. Freud, in his "The Sexual Enlightenment of Children" (1907c), writes: "A child's intellectual interest in the riddle of sex, his desire for sexual knowledge, shows itself accordingly at an unexpectedly early age" (p. 133). In truth, it is more surprising how blind parents often are to children's questions regarding the origin of babies, and how often they overlook their child's interest in the physical differences between the sexes. Even today, it is difficult for many parents to speak freely and naturally about the differences between the sexes, birth, and how a baby is conceived. In parentchild therapy, one mother spoke about her new pregnancy while her son, not yet three, played with toy animals and cars. He listened attentively and then came over to his mother. He held out the bull to her, on which the genitals were depicted, and asked what it was. The mother looked at it briefly and said, "That's a cow." When the child looked at her in surprise, I expressed his doubts by saying that Christoph is asking himself whether that is really a cow. The mother looked at me in surprise, reddened, and then turned to her son, then explaining to him that it was actually a bull, the masculine animal of the cattle family. We then discussed how difficult it was for her to explain to Christoph that a bull is necessary for the cow to have a calf, just as his parents had made a baby with each other.

The question of when and how children should be enlightened as to the facts of sexual life cannot be answered in generalities, but is based on the child's interest. It makes sense to answer only the questions the child himself asks. Children are first interested in the anatomical 
differences between man and woman, explanation of which should include the uterus and egg cells already present in a girl's body and later in the woman's. The question of how babies emerge from the mother's body is usually posed only later, but this of course also depends on whether the child has seen a pregnant woman. Only afterwards comes the question of how the baby came into the mother's belly. Even children whose questions are answered truthfully often put more faith in their own fantasised theories of birth, related to their experience: one theory is that a baby comes from kissing, or from the mother's eating certain foods. Later, in analogy to the elimination of faeces, may come the theory that the babies emerge from the mother's anus or through urination. This theory offers little boys the advantage of humouring their own wish to have a baby. Traces of blood the children see, or sounds of parental coitus, can also lead to a sadistic interpretation of sexual intercourse. Menstruating girls sometimes have the fantasy that procreation occurs through the mixture of blood (see Freud, 1908c, $216 \mathrm{f}$.). These childhood theories of birth can sound more plausible to a three year old than the explanation given by parents: one mother told of how important she considered it to provide her daughters with an adequate explanation of sex, waiting patiently until the daughters asked the relevant questions. They willingly took up her explanation of where babies came from, and acted out birth in play, by putting the teddy bear or doll first under their sweater and then letting it be pulled out by the other child. When the daughters then asked how the baby got into the mother's belly, the mother tried to explain in simple words that the father put his penis into the mother's vagina in order to fertilise her eggs in her womb with his semen. Both girls looked at her sceptically, and the four year old then said: "Come on, mommy, I don't believe that." When the mother asked her what she did believe, she said with great conviction: "Babies come from kissing." But even then, when for example this child still believes in a theory of oral procreation, it makes sense to provide her with an accurate answer she can later come back to.

A major problem is posed by sibling rivalry, particularly when the age difference is less than two years and the children are of the same sex. When one child is especially plagued by jealousy, hitting the baby and wounding it with bites, it must be asked whether the mother or father is projecting an unresolved rivalry of their own onto the older child. 
Much depends on the parents' ability to help their children get along and learn how to negotiate. One mother showed her daughter how to hold out a new toy to her crawling brother, instead of taking away the other toy he was holding in his hand. He then in fact did let go of the other toy, without crying, and the older one could pick it up. Rivalry and fighting are a natural part of the picture, and the question is how children learn to defend their own space and simultaneously allow the other child to retain his space. I would like to describe a birthday party held for an older sister, where the father succeeded in a creative fashion to put the two-year-old brother's frustration to constructive use:

The older sister, Susi, was celebrating her fifth birthday; she got a cake with five candles to blow out. Susi sat on her aunt's lap, with her brother Karl on his highchair. They all sang, "Happy birthday, dear Susi," Karl also sang at the top of his voice, since he already knew the song from his play group. With shining eyes, he looked at his sister as she counted the candles and blew them out. Then, Karl swung his legs, became restless and said "Me too." His father, who had seen him becoming restless, said: "You want to also have a birthday?" The mother added that Karl was going to have his third birthday in two months. Karl listened attentively, smiled, and stretched out three fingers, but nevertheless still had an unhappy expression on his face. Then his father got an idea: he put a small candle on Karl's piece of birthday cake and lit it. Karl had watched him closely doing this, his face lit up, and he looked shyly from one person to the next, as everyone now began singing, "Happy birthday, dear Karl." He sang with them loudly and happily and pointed to himself when he sang "Karl". Then he blew the candle out, but wanted everything to be repeated again. The father lit the candle once again, and Karl sang the song alone, giving special emphasis to his name. Then he clapped enthusiastically. The whole group had listened to him and clapped with him at the end. When the sister finally unpacked her presents, he watched with interest.

When the father observed his little son becoming restless, he could empathise with him. He found a solution that on the one hand respected Karl's wish to also be at the centre of attention and celebrated, but on the other hand conveyed to him that today was his sister's birthday. 
His mother had tried to help by reminding him of his soon impending birthday, but that was still far off. Karl needed immediate attention. One can easily imagine how Karl, through unintentionally knocking over a glass, clumsily climbing down from his highchair, or causing himself a minor injury, could have otherwise drawn attention to himself and thus disrupted the party.

When Karl two months later had his birthday, his sister helped him unwrap his presents, interrupting this to run back to the table and stuff two huge pieces of cake into her mouth-probably a form of oral compensation for her jealousy.

As soon as the toddler leaves his crib or walker, parents are often faced with the difficult task of giving both children attention and space to play in. How can the older child be protected from the relative chaos of a crawling child? Is there a place to play that is safe from the toddler? Some older children retreat to a bunk bed, building something there or playing in peace. Or parents might provide a high table the smaller child cannot reach.

Siblings' life with one another is made easier through the great interest and admiration younger children have for their older siblings-as can be heard in a baby's gleeful, joyful squeal when his sister enters the room. Ordinarily, a baby follows every motion of his older sibling. The way the older child plays is important. When the new baby begins to crawl and to walk, he will try to run after his older sisters or brothers, which can be both flattering and bothersome. Siblings learn from one another with great ease, with younger ones precisely observing and attempt to imitate the older. Younger children often face the problem of being excluded by older siblings. It is better to intervene as little as possible, since children are able to develop their own forms of interaction. Here are two examples of a small child solving a situation without his parents' help:

The five-year-old sister played with a friend with Duplo stones. She put the stones onto her fingers, and they became people who now talked with each other, went out, and had things happen to them. Both girls were lying in the sister's bed and covered themselves with blankets. The two year old wanted to play too and tried to climb under the covers, which the bigger girls prevented him from doing. Karl went back a short distance, nevertheless remaining in the vicinity, and observed them both. When the girls were 
completely absorbed in their game-one figure attacked the other, wounding it so that it had to be brought to the hospital-Karl slipped under the foot end of the blanket unnoticed. At first he observed the two of them, then he took a stuffed dog and met the two girls' figures as a dog, which they accepted. They then included him in the game.

Karl has learned not to withdraw immediately or sulk when he is rejected. He has developed perseverance and social sensitivity, and can introduce himself into the older girls' game. It is important that he achieves this alone, finding an entry to the older two girls and being accepted by them. Younger children learn how to precisely observe social behaviour through interacting with their siblings.

Now another scene where the parents intervene:

The three children, both the bigger girls and Karl, were playing together. Karl was hungry, came into the kitchen to his parents, and showed he was hungry. The father gave him a bag with wholewheat biscuits and asked him to also give this to the two other children. When the father later passed by the children's room, he saw that the bigger sister had the bag and was giving out the cookies. The father insisted that she give it back to the brother and that he should be able to give out the cookies. The sister gave her brother the bag unwillingly, turned back to her friend, and both of them went back into the corner to play. When the brother wanted to play with him, they wouldn't let him, so that he went back crying to the kitchen.

In this scene it becomes evident that the older sister followed her father's instructions only reluctantly, afterwards taking revenge on her brother for this. For parents, maintaining justice between siblings is a difficult task. On the one hand, the younger child has need of his parents' protection; on the other hand, he is often cruelly punished by his siblings for the parents' intervention and then excluded. One mother recalled that, as the fourth child, she was constantly being taken under the mother's protection against her older brothers and her older sister. For this, she was then cruelly punished by her siblings, mocked, and teased while her mother was gone during the day. The older siblings convinced the younger girl that her mother was so nice to her only in 
order that she would not realise she was not her real daughter. As proof, they pointed out the younger sister's eye colour, which was different from theirs and their mother's.

Naturally, older siblings cannot be allowed to strike the younger child. Yet often it is the younger child who incites a struggle by taking something away from the older ones or destroying something they have built. It is dangerous to always assume the older child began the fight. Since the adult can never really know for sure who began an argument, it is advisable to establish a rule with the children that they either agree about the use of a toy or it will be taken away. It is astonishing how children are then capable of finding a mode of exchange or some other solution in order to receive back a confiscated toy.

Nevertheless, competition and envy can be expected, often in the form of food envy. One example of this occurred at a dinner table, where the mother had cooked the favourite dish of both children, spaghetti. When she had put the spaghetti on both children's plates and gone back into the kitchen to get the spaghetti sauce, the four-year-old sister had taken spaghetti from her two-year-old brother's plate and contentedly put it in her mouth. The brother protested loudly and cried. The mother, who had seen this, took some spaghetti from the daughter's plate and gave it to the son, who immediately stopped crying and ate it with a satisfied look. The mother's calm reaction served to recalibrate the situation. A lengthy scolding or harangue would presumably have led to the daughter crying or further escalation.

The slowly emerging love between siblings is often attributed too little importance. A positive relationship between siblings constitutes an enrichment, since this sibling relationship has a special quality and can last a lifetime.

One mother told how her two-and-a-half-year-old son greeted his sister when she came home from kindergarten just as eagerly as his mother, by running to her and then making three circles around her before he embraced her.

The extent to which an older child comprehends her special position vis-à-vis her younger sibling is shown by the following scene:

The grandmother had picked up the older child from kindergarten. When she rang the bell and came into the house, the happy "Hello" of the little brother was heard from the second floor. When the grandmother looked up to see him, the sister said: "Grandma, 
he doesn't mean you, he means me!" She had already placed herself in a position where the brother could see her.

If the parents succeed in curbing sibling rivalry by avoiding undue comparison between their children, instead accepting each child in his individuality, then sibling love can develop.

\section{Development of a conscience}

The formation of a conscience occurs over the course of the third year of life. If the parents treat their child with respect and set clear limits for him, he gradually begins to internalise rules and commands. He will have guilt feelings when he does something wrong, and try to call his parents' or other adults' attention to this. Already during the second year of life, he often knows quite precisely what is allowed and forbidden. When the child has the idea of doing or touching something forbidden, his glance at the parents clearly indicates awareness of his transgression. He is also capable of sticking to rules, but usually requires parental reminders. In order to develop an autonomous conscience (superego), it is necessary that the child compare rules to his spontaneous wishes and impulses, slowly learning to postpone the direct satisfaction of his wishes when they contradict the norms of good conduct and social demands. The parents' praise, and their recognition for the child's postponement of this direct satisfaction, compensates the child for this sacrifice. The conscience of a three year old is not yet autonomous, but dependent on the praise of adults. In this area, too, the child strives to emulate adults and learn self-control, an important characteristic of adulthood. A four-year-old child said to his mother: "You can give it to my brother first, I'm already big and can wait." The example parents set, and the experiences the child makes when he behaves in a disciplined manner, are important factors in the formation of a conscience. Here we must again consider that the internalised images of the parents do not correspond to their actual behaviour, but are modified by the child's fantasy into an image of gigantic, almost omnipotent parents. The smaller the child is, the bigger and stricter his parents appear to him, the more threatening and forceful a loud voice or chastisement. The early forms of the conscience are thus rigid, strict, and despotic. During his second year of life, the child already has quite clear ideas of what he may and may not do-yet he believes he will 
be held accountable not only for his acts but also for his thoughts and fantasies. A child who is furious that his father or mother is going away even though he wants them to stay can then in his fantasy cause them harm. Accordingly, the child often then actually breaks some rule-in order to be punished.

A child's wishes in his third year, however, are usually so urgent and immediate that compromise becomes necessary. The child has his wish fulfilled-simultaneously reciting to himself the parent's prohibition.

\begin{abstract}
A three-year-old girl, who often was allowed to help her mother cook, wanted to break the eggs that were on the table. She knew, however, that she was not allowed to do that on the kitchen floor and without her mother. She hesitated for a minute, then climbed up on the chair, took one egg after another, and broke them, saying in a strict voice: “No, no, no!" (Fraiberg, 1959)
\end{abstract}

She repeats her mother's words, thus demonstrating that she knows full well she should not break the eggs. Nevertheless, her wish to break them and feel their soft yolks is so strong that satisfying it gains the upper hand. The next observation shows a similar situation:

\begin{abstract}
Three-year-old Benjamin, who was playing with the window, opening and closing its reinforcement mechanisms, knew full well he should not do so. The danger was that he would damage the glass with the metal rods; at the same time, moving them around made an interesting noise. Benjamin glowed with pleasure as the noise became louder and louder. Presumably at the point when his mother would intervene, he said "Enough now!" while continuing the forbidden motion, even more energetically, and accompanied this with ever more energetic and emphatic "Enough now!"s in a resolute tone similar to his mother's.
\end{abstract}

When Benjamin feels like playing with the window and metal rods, he usually attempts to find moments when he is alone in the room. When his mother is cooking, he often steals over to the window, turns around while eating something, and begins very carefully to play with the rods. At first his mother tolerates this, but when Benjamin becomes too wild, she tells him "No," He usually ignores this, acting as if he has not heard her, and continues fooling with the rods without looking at his mother. 
Sometimes he is lucky and the mother is distracted, especially when he is sufficiently discreet. Only when the mother tries to end his forbidden game, saying "No. Stop!" and angrily taking the rods away from him with the words "Enough now!", does he desist and burst into loud tears. In the scene described above, Benjamin finds a compromise: he fulfils his desire to play with the metal rods, but preserves his mother's prohibition by repeating her exact words.

Parents must patiently repeat the rules, demonstrating them for months until the child will follow them by himself. If, however, he has internalised the rules he will strictly monitor them on his own. When friends or grandparents are visiting, the three-year-old child will then demonstrate to them how they must do things, and can become quite unhappy when the visitor behaves otherwise: Susi reacted with tears when her grandmother cut tomatoes in thin slices. "Not that way, grandma!" she said. Only after patient questioning did the grandmother learn that Susi's mother cut the tomatoes differently. "Should I cut them that way too?" asked the grandmother. Relieved, Susi said yes and then commented with satisfaction: "Yes, that's how to do it!"

When brought into contact with other families and children in play group or kindergarten, three year olds become acquainted with other families' rules. They observe closely what another child is allowed to do or not to do, and compare that with their own experiences. The three year old slips quickly into the role of the educator, whose duty it is to monitor the upholding of rules. One example of this:

\begin{abstract}
Stephan (two and a half years old) went shopping with his grandmother, before she picked up his older sister from kindergarten. The grandmother asked him to take a "twist-anddrink-bottle". He first took a yellow one for himself, saying "For me," then-without being asked-a red one, saying his sister's name. When the grandmother wanted to take two more bottles, Stephan said in a friendly but determined tone of voice: "No, only one!" With a smile, the grandmother put the two bottles back. Stephan looked at her sharply, nodded in agreement and turned to his own bottle.
\end{abstract}

Stephan is protecting his sister's interests. He is convinced that a bottle must be purchased not only for him but also for her. He also knows what colour she would choose. When the grandmother wants to buy 
still more bottles, he reacts as his parents would, allowing only one for her.

Here, his father's tone can be detected in Stephan's voice-clear and consequential. Stephan is used to his father patiently and repeatedly giving him the chance to put a bottle back on the shelf himself. He now treats his grandmother as he has been treated by his father. Therefore, it can be considered a good investment in the future for parents to be consequential, determined, and nevertheless friendly when establishing rules. The less clear rules are-for instance, if sometimes something normally forbidden is tolerated, with the child being yelled at or hit the next time-the more confusing it is for the child, who will then conduct himself similarly in conflicts with other children, yelling and striking out.

Parents can quickly become desperate when they say "No" to their child and he does not react. This is not a sign of stupidity or stubbornness on the child's part. His wishes are eminently intense-and he cannot yet say "No" to his parents. Parents then may employ more drastic methods, and the situation escalates into a conflict. An annoying, obstreperous child then does what has been forbidden him, out of revenge; a battle front has been established, and there is imminent danger of being drawn into a power struggle where there is no more room for learning and negotiation. Parents will protest that it is not possible to allow children access to everything. This is true, and the learning of limits is most important. How can parents help their child to accept rules? It is recommended to distract the child, offering him a substitute for what is forbidden. A child who is not yet able to control his impulses can perhaps at least steer them in another direction: the child who has the impulse to take his father's CDs out can be given some old CDs to play with, which he can put in and out of their boxes as often as he wants. Or the parent can place sturdy old books or newspapers on a shelf, which can be left to the child to play with. It is helpful when parents allow and enable their child to express his wishes and feelings.

With the development of language ability, it becomes easier to ask the child questions or help him by saying what we believe he might be thinking. "You can tell me what you want" can help a child to desist from crying, yelling, or striking out in lieu of actually expressing his wishes. In any case, however, patience is imperative in guiding the child on the path from impulsive behaviour to reasoned thought, towards selfcontrol and capacity for compromise. This pedagogical process requires 
months and years, and even though we might expect better self-control at the end of the child's third year, we should not be surprised at frequent derailments.

Often a child feels offended or hurt by his parents' commands, criticism, or prohibitions. Some children then retreat to their room or a corner of the apartment where nobody can see them. Other children hide under their crib or in their mother's bed. It is best to grant the child this possibility for retreat. It is important that parents understand the child's expression of hurt feelings and not make fun of him. Whether they tend to go to the child, or give him the time he needs to sulk and then come back on his own from his retreat, depends on their character and that of their child. A child experiences an insult or injury at least as intensively as an adult. Often the child also honestly believes he has been unjustly treated. If it is possible to discuss this later, then children and adults learn to communicate and thus lay the basis for empathy and sensitivity.

These suggestions, however, should not lead to parents thinking they must never lose their self-control with their children. Particularly for parents, it is an important learning process to observe how often they reach their own limits, lose their temper, or become impatient. Children forgive their parents many mistakes and inconsistencies when they feel loved. Some parents report becoming so angry when their child hit them or bit them that they hit or bit back. In such cases the adult ego has collapsed, and the parents act out of their childlike component on the same level as the child. In this case, is it is also futile for parents to be ashamed, reproach or be angry at themselves. Those are feelings about feelings that do not alter what has happened. It would be better for parents to recognise their limits and to recognise how massively a child's intense impulses can undermine our adulthood. It helps (perhaps also with the partner's aid) to reflect on what caused such a loss of temper. Perhaps the child evoked a parent's own memory of unjust treatment, mockery, or exclusion. When we are overwhelmed with an intense memory, it helps if we attempt to understand it.

\section{Childhood anxieties}

The third year of life is a turbulent year of intellectual and emotional development. Important developments are also occurring in the child's fantasy world - a whole range of dramas, the relinquishing of 
unfulfillable fantasies concerning the parents before the child finds an identity as man or woman. Toilet training is linked to the question of body control, outer and inner order, taking and surrendering. It is thus not surprising when children who have previously exhibited little fear now suddenly are afraid of any number of things-particularly objects from everyday life. The child may suddenly be afraid of the vacuum cleaner, of the dark; he may be convinced that a monster or crocodile is under his bed. He can also fly into a panic when his faeces are flushed down the toilet or the bath water is let out. Separation from his parents in the morning, when the child goes to kindergarten, can suddenly become an ordeal. Children whose eating habits were previously unproblematic might now refuse certain foods. Often, the child's problems are manifested at night when he goes to bed. It is helpful for parents to know that these fears are connected to this sensitive stage of development. Often it takes some time before parents discover the source of their child's fears. The sexual differences between girls and boys can be a source of fear, since many children assume that girls' and boys' bodies originally looked the same, that is, both had a penis that then vanished or was dismembered. It is often difficult to comprehend the background of a child's inexplicable fears. Here an example:

\begin{abstract}
Stefan exhibited great fear of going to the toilet, and asked his mother to check whether the window was closed before he could be convinced to use the facilities. His mother went along with this, and wisely refrained from teasing him or calling him silly, although she had no idea why he wanted the window closed. One day, he supplied an additional bit of information: "Close the window, so that a bird can't fly in." Still mystified, his mother asked: "What would a bird do?" "Peck off my pecker," answered Stefan. He had recently learned that girls are built differently, and assumed they had lost their "peckers". Now he wanted to be certain that the same wouldn't happen to him. (Reid, 1993, p. 99)
\end{abstract}

It could also be that Stefan has seen a woodpecker pecking on a tree to get at worms, or a robin digging for worms. He then linked this to his fantasies of losing his "pecker". Perhaps he also believes he has been bad and therefore will be punished. An important contribution of psychoanalysis is the emphasis on inner reality. For Stefan, his fear is real: it is not assuaged when his parents react "rationally" and try to persuade 
him out of it. Far more important is to help the child address his fear. Only in this way can the child-but also his parents-get the chance to recognise the reasons behind the fear. It is no use telling the child he need not be afraid. When a fearful child is mocked, this results only in his believing he must keep that fear secret, thus withdrawing into himself. He will then avoid things connected to his object of fear, and we as adults have even less chance of learning the reason behind the fear.

It was previously thought that showing fear-particular for boys-is a sign of weakness. Some fathers thought they must exorcise this "weakness" and delinquency through especial strictness. One father told of being tied to a tree in a forest by his own father at dusk in order to conquer his fear of the dark. The result was that the son's trust in his father was damaged; he withdrew from him and now also had acquired a fear of his father. Thomas Mann described the consequences of a "hard" or "strict" upbringing on a sensitive, fearful child in his novel Buddenbrooks (1901). The son, who wished to be strong and robust and was considered the successor to his father's business, broke down under this pressure. He was not recognised for his own personality, but instead "cropped" to his father's ideas of a son. When fears are not permitted to be shown, the child has no other path than expressing them somatically, through corporal problems or illness. Lack of understanding for childhood fear seems to be one of the major causes for child breakdowns. To react to fear with strictness, scorn, or humiliation produces a deep feeling in the child that he is not understood, and strengthens his fears of inadequacy and not measuring up to his parents' expectations.

Per Olav Enquist, in his The Doctor's Visit (1999, p. 38 ff.), also describes how King Christian VII of Denmark, after his mother's early death (he was two years old at the time), received only militaristic drills and strict discipline, blows, and humiliations, intended to make him strong and resilient, but ending instead in his psychic confusion-instead of love, which would have furthered his personality. For his teacher, Count Reventlow, education should be a "spiritual subjugation", meant to break the student's independence. The most important didactic instrument was the whip.

The opposite approach to children's fears-reacting overprotectively-is also unhelpful. When parents wish to spare their child contact with the object of his fear, they never grant him the chance to cope with that fear. Some parents may react with even more fear than their child, with the child then adopting his parents' exaggerated fear: 
if his powerful parents are afraid of a dog or spider, the small child will believe those animals are truly threatening. If the parents are quick to worry that their child could fall down and thus never allow him to climb, the child will then believe he is truly clumsy or that the world is a dangerous place. Parents' cheerful confidence that their child can manage what he has to will give him enough confidence in his own powers to begin experimenting and collecting experiences.

Hans Zulliger emphasises how important it is to understand childhood fears. In his book Our Children's Fears, he describes several examples of children who became "stupid" or sick through fear (1971). A child who was afraid of a dog because she unconsciously feared her body would be maimed by it was helped when her father played dog with her-first the father assumed the dog's role, then the child did (ibid., p. 65 ff.). Being in contact with one's own fear guarantees compassion and tolerance towards others.

I shall now turn to the development of Kelly and Max, who were studied within the framework of the infant observation and follow-up research studies. Since the student's infant observation only took place until the end of their second year, data here is less complete and thorough. Experiences from their children's third year came up in the interview with the parents, however. Subsequently, the development of a child who entered therapy during his third year of life is described.

\section{Developmental history of the children Kelly and Max}

Kelly in her third year of life

The observer's perspective

In her third year, Kelly's parents—by now divorced—had developed a routine for her care. Kelly spent the night every other weekend at her father's, who had set up a room for her. I observed Kelly both with her mother and with her father. The observation took place on the evening before the mother left on a trip. The mother was planning to be gone for three days; Kelly would be taken care of by an au pair girl and her grandmother.

Kelly had an animated discussion with her mother concerning the preliminaries to taking a bath. Her mother let her choose the bath salts and playthings she wanted to take with her into the bathtub. 
Kelly wanted something that would make "a lot of bubbles". The mother watched with pleasure as Kelly described the bubble-foam with her gestures. Later, the mother requested Kelly in a friendly tone of voice to take her clothes off. It sounded rather like a new sort of game. Kelly took off her clothes in the children's room. When her mother came back, Kelly collected the clothes strewn about the room and gave them to her. The mother put a chair in the bathroom so that I could observe Kelly. They negotiated on the right water temperature and how many playthings Kelly could take into the bathtub. When Kelly stuck her big toe into the water, full of bubbles, she realised she had to go to the toilet. The mother laughed and said: "It's the same thing every day, she always forgets to go to the toilet." Kelly ran to the toilet and came back. (Diem-Wille, 1992)

Kelly shows that she is able to undress by herself. Forgetting to go to the toilet before her bath could constitute a game for her, involving on the one hand her childlike wish to urinate in the bathtub and the other her wish to be "grown up" and go to the toilet. Since the mother related that Kelly never liked to take baths, her back and forth out of the water could also be an indication of her fear of water.

She then went into the bathtub, with a helpful push from her mother, sat down and played. Her mother left the room to let Kelly play by herself. Kelly prepared tea for me, filled up various containers with water. She showed me how she could fill the plastic figure of a fat man with water so that the water could come out between his legs like urine. She laughed high-spiritedly, was happy, and offered me the watering can to fill. She enjoyed pouring water from one container into the next, always explaining to me what she was doing at that moment; she laughed and smiled at me. (ibid.)

In this scene, Kelly shows how she enjoys directing the action. In the bathtub, she seems to be in a universe of omnipotence where she has everything under her control-making tea, pouring it out, making the man urinate, etc.

While washing Kelly's hair, the mother explained to her that everyone has to wash their hair. Kelly laid her head back and the mother washed her hair. When she was done, Kelly was rather cold and her 
mother remarked that water made things cold. She took Kelly, who was cold and shivering, out of the bathtub. The mother said that she had already reacted this way at three months, she had always cried in the bathtub. The mother wrapped Kelly in a bath towel and rubbed her dry. Kelly screamed in a mixture of laughter and pain. When her mother dried off her arm, she cried out in pain because she had a small cut in her thumb, which she showed the mother. Both of them went into Kelly's room, where Kelly refused to put on her pyjamas. She would only accept her bath towel. As soon as her mother left the room to get the hair dryer, Kelly dropped the bath towel, looked insulted, and crossed her arms over her chest. Then she thought for a minute and hid herself in her bed. When the mother came back, she looked at me with alarm, then understood, and began to look for Kelly. Kelly laughed pleasurably each time her mother did not find her, until she finally did. (ibid.)

In this sequence, one can recognise certain repressed feelings. For starters, it is remarkable that Kelly's mother does not find herself able to refill the bathtub with warm water in order to keep Kelly warm. Can we understand that as an indication that the mother is incapable of providing a warm climate in the house? Can Kelly's crying while being dried off also be founded on a pretext, linked to her mother's departure early the next morning? Can her crying also mean: "You are hurting me by going away!"? Perhaps it is also a communication aimed at the observer, in the sense of: "Look what my mother does to me."

Kelly's crying seems out of proportion, and does not correlate with the relaxed atmosphere of her bathtub play. This hypothesis is supported by Kelly's hiding herself. Now Kelly has vanished, and her mother has to look for her. Her mother's shock could also be linked to other fears she harbours-she is concerned about how Kelly will manage during their first three-day separation.

At their goodnight kiss, the mother explained to Kelly once again the arrangement for the time they would spend apart. Kelly did not complain. It sounded more like the careful plan of a sports coach, and less like a mother's empathetic explanation.

From an observation of Kelly with her father, with whom she regularly spent every other weekend:

She was painting with watercolours. Her father stayed close by her, and asked each time what she was painting. She said she was 
painting two houses, and then painted windows in various colours. She asked him what colour she should use. Kelly's father named a colour; Kelly repeated the word and recognised which colour it was. Kelly asked him how paper was made. He explained to her the entire process in simple terms, beginning with the chopping down of trees, the ways they were cut. Kelly repeated every word new to her and listened to him attentively. It seemed to be a familiar process that Kelly asked him something and he answered her in quite simple, but interesting and illustrative words. He spoke with her in a warm, unpatronising way ... She drew many windows in both houses. Kelly said she could draw six or eight windows. Then she wanted to paint her father's nose red, but he leaned back and suggested she paint her finger. (ibid.)

We can see how Kelly's father supplies her with knowledge in a manner Kelly can easily absorb. He is able to adjust to Kelly's young age and to her mode of absorbing explanations. He seems to enjoy teaching her, providing her with a model of how enjoyable it is to know so much. Her drawing shows that she has developed an inner space for two houses, one where she lives with her mother, and one where she lives with her father. He can tolerate her drawing two houses. He links earlier experiences to the present and thus enables her to establish continuity between the time when she was smaller and the present. The fact that she wishes to paint her father's nose could mean she wants to show him he is curious - sticking his nose into things. Or she could desire to make him look ridiculous through the red nose. He is nevertheless able to say no, he can set limits, and she seems relieved at this.

As the observation progresses, we read that Kelly and her father sang the observer a song. Kelly knew the melody and the words. Her father explained that he had a cassette of this song that Kelly would enjoy listening to. Later, Kelly wanted to sing with her father and dance. Here a sequence from the observation:

When he asked her what they should do now, she wanted to listen to the entire cassette. He reminded her that at 3:00 he wanted to record a soccer game, and put a cassette in. He switched on the video recorder and both of them danced. Kelly was a bit manic. Her father asked her what usually happened when she became too wild. She answered: "We both fall down!" and seemed to understand 
what he meant. He held out both hands to her and they danced together, then he picked her up and swung around with her in a circle, something she seemed to love. She wanted him to continue. He sat her on the floor and said she was already too heavy and not a baby any more. When she asked him again, he picked her up one more time. (ibid.)

Both of them seem to have fun singing and dancing. But there is also a seductive quality to Kelly: her father seems to recognise her potential for becoming too heady, too wild. Already at the outset, he sets her a limit by mentioning the soccer game he wants to record. While dancing with her father, Kelly seems to find a third person especially important as observer.

Although Kelly's parents' divorce occurred unusually early, she seems to be able to preserve an intense relationship to both parents.

\section{Perspective of the parents}

Kelly's mother is aware that the long period of breastfeeding with Kelly is related to her marital problems. She referred to the fact that she was breastfeeding Kelly up until the age of two and a half. When the problems with her husband began, Kelly was eighteen months old. Breastfeeding was then "like a bond" between Kelly and her, the mother said - a process of paramount emotional importance to her. She described the weaning in precise detail:

So, we sat down one day and I said to her: "Look, Kelly, you're too big to be breastfed." Kelly usually came over and said "Nimmel," since she couldn't say "nipple". I said to her: "I think we should really stop this." We negotiated. I said: "We'll stop on Monday." That was it, and we never looked back.

This was before the au pair girl arrived; Kelly was already able to drink out of a saucer. The scene does not sound like a mother-child interaction, but more like a conversation between adults. Kelly adjusted and did not request the breast any more. Kelly's mother compared weaning to giving up smoking, something the smoker must also renounce with great seriousness. The au pair girl's impending arrival seems also to have contributed to Kelly's mother tackling the weaning process. 
A tendency we have already seen in Kelly's second year of life is here continued: Kelly's mother finds Kelly overly feminine, but also feels commanded by her, just as she is by her own mother. "Kelly is very conservative. She always tells me what to do. 'You work too much, Mummy, that's why you're cross.' She definitely heard that from my mother."

Kelly seems to have a different idea of being a woman than her mother. For this reason, Kelly's mother sometimes feels herself attacked from two sides. She is quick to perceive differences between her and Kelly as a form of virtual criticism, saying: "In spite of all my efforts, she loves playing with dolls and loves wearing beautiful dresses and having a beautiful hairdo. Kelly says then: 'When I'm big, I want to have a lot of babies.'"

Her attitude as mother, however, now seems to have become realistic. At the outset, she wanted to be a perfect mother who would do everything right. "Now I feel that I do things as well as I can. And that's it. And when I make mistakes, well, that's life. I don't do anything intentionally in order to hurt Kelly, but I can't be perfect. I can only be good enough."

It seems that Kelly's mother has discovered a form for integrating her life as a mother and a demanding profession, with the grandmother supplying significant help. Kelly's grandmother has moved to London in order to help her daughter take care of Kelly. Kelly's mother seems slightly jealous of Kelly, but also seems to regard her mother's help as a major relief.

For Kelly's father, his daughter seems to truly be the centre of his life. He still finds it painful not to be able to provide the kind of ordered family for Kelly that he had with his own parents. Kelly's father described all the things he finds fascinating in Kelly:

The fact that she's already so womanly, at this early age. She is ... sometimes really coquettish, and she knows it-I find that surprising. She seems to be quite conscious of her sexuality. I hadn't expected that, to be honest ... She's a funny child, pleased and uninhibited, I think ... She is really creative, makes up games, makes up songs. Sometimes when I'm playing around, I sing instead of talking. For instance: "It's time to go to bed. Let's go sleep." And Kelly answers then by singing: "OK Dad, if you want." 
Kelly's father depicts his and Kelly's musical dialogue with obvious pleasure. He observes her often as she draws or plays, singing to herself or to her doll. "She can sing real intervals," he asserts proudly, this being something she herself discovered without his teaching her. To her father, Kelly is apparently a fascinating person, one he observes with joy and wishes to get to know. It is as if Kelly has opened access to a new aspect of life. He describes this as a miracle in which he is able to participate. He also seems to be a good observer: "She is funny and I like the idea that Kelly is creative ... I saw the children in kindergarten. She takes the initiative and tells them, let's do something, and the others agree and do it ... she is really positive."

Questioned on discipline, Kelly's father says he doesn't believe at all in hitting her. Kelly shouldn't have too many rules, but the rules she has should truly be held to. "I say to her then: "Look, Kelly. You know the rules!" As an example, he told of how Kelly sat on the floor to eat and he then reminded her of the rule that she had to eat at the table - and she should accept that, he said. Sometimes Kelly was a little wild, but she was a child. His role models for bringing her up were two friends, a pair of teachers who explained to children the reasons for a rule and motivated them to think about it themselves-or the children themselves should find a solution to a problem. "I try to remember this interaction. It's not easy, but you should at least try. The more often you try, the easier it is," said Kelly's father.

He described in detail his vision for Kelly's education.

Kelly is a sensitive, extremely empathetic child. When something's not right with somebody else, she is very sympathetic ... that's why I think she will have a social kind of profession, maybe doctor or teacher. One of the things she really likes to do since she's been in kindergarten is to play teacher. She takes a book then, holds it up it front of her and says: "Can everybody see this?" I'm happy with everything as long as it's good for her. It's her health and happiness that's important to me.

Kelly's father seems to think a great deal about Kelly, with the focus on his wish to develop her personality, to further her talents and capabilities, in order to help her become a happy human being. Often his unhappiness is evident at not being able to see her regularly every morning, 
since she now attends kindergarten: one week seems dreadfully long to him. Every week, he is surprised at how much she has changed.

Kelly is supported and furthered by both her parents and sees how important she is to both of them. One possible burden on her could be the feeling she must cheer her parents up, therefore assuming a position that extends beyond her role as a child.

\section{Max in his third year of life}

\section{Observer's perspective}

The observer maintained contact to Max's family for two more years, but made only a cursory summary of her impressions. She noted that Max already spoke English and German at two years and two months, without mixing the two languages or becoming unsure.

At three, however, Max spoke a mixture of English and German, with English predominating.

Max seemed intensely occupied with things that were "kaputt" or needed repair. He built a house from Lego and when all the figures were inside, he had it rain into the house. The roof had to be repaired, but the motorcycle that was going to bring help was also broken. When his mother suggested he call somebody by phone, the play telephone didn't work either. It seemed to be a hopeless, desperate situation, with nevertheless an element of fun. His mother also told me Max was very possessive and jealous—at present, he was incapable of sharing. He woke up every night three times.

From these few remarks, we cannot form a clear picture of Max's inner state. He seems to use his game towards retaining the power to break things and determine whether they can be repaired. Apparently, he is in a difficult phase causing him to wake up three times a night. He seems to worry that he might have broken something. His waking up in the night indicates unresolved inner conflicts.

During a visit by the observer when Max was four years old, she learned the family had spent the previous year in Germany. Max told the observer that here in England, he had had many more friends and had greatly missed them. Max's mother told the observer there had been a crisis in Germany when Max had twisted a vertebra, which was extremely painful. For six weeks, he refused to go to kindergarten and was depressed. His parents were greatly concerned, since he 
was almost unable to walk. One doctor believed this could be Max's expression of how unhappy he felt in Germany. There, too, Max had friends in the same house and a big yard. His mother was surprised how much he had missed his friends; a half hour after his return to London he played together with them as if he had never been gone.

During the observer's visit, Max at first hid behind his mother and did not recognise the observer.

This description conveys a picture of Max finding it difficult to express his feelings-perhaps he is exhibiting them in psychosomatic form. He is shy and hides behind his mother, like a little child with strangers.

\section{Parents' perspective}

Max's mother emphasises how important it was for her to grant Max more space than she had had as a child. She would prefer to intervene less than she does, for instance in toilet training and eating: Max himself should decide when he is full or wants to go to the potty, and this has worked out well-Max began to go by himself to the potty before he was two.

Max's mother has had difficulty saying no. Like her husband, she also had the impression she was allowing Max too many liberties. "It is fascinating", she said, "to watch his development. Everything he can suddenly do, these changes." Sometimes she found it difficult to tolerate Max's refusals to do things when he was recalcitrant. Questioned as to what three wishes she would have for Max, she said:

One clear wish is that he becomes able to be independent, to make decisions and not to be afraid of what other people expect from him. The second wish is something I myself could not do, since I was very formal-to be sensitive both to himself and to others. And third, I want him to be content with himself.

All three wishes tend to reflect that Max should have things better than his mother did. Particularly in emotional terms-being able to recognise his emotions and attaining harmony within himself-his mother would like him to be self-confident and tranquil, rather than merely orienting himself to others' wishes. Presumably, Max's mother learned to appreciate these dimensions of her own personality development in therapy. Max should have things better than she did. For the mother, 
Max's learning and education tends to be an "anti-topic", which could also have to do with the fact that Max, at the age of four and five, was already highly ambitious and far above average in his scholastic achievements.

Max's father considered himself as attentive to Max as his own father had been to him. It worried him that he sometimes became terribly irritated at Max. There had been two or three incidents where he had completely lost his temper and "seen red". He was afraid he could have harmed Max. He related:

It happened when Max was three, then when he was three and a half, and the last time when he was four. He was getting on my nerves, because he was damaging things by drawing on the floor and so forth. Or Max hit me-which he sometimes did. When I told him he should do something, he came over and hit me in the face. Then I picked him up, brought him upstairs and threw him in his bed. Afterwards, I was thinking I had been totally out of control. Max must have been very scared. I felt like I could kill him ... I could have broken his neck. That only happened three times. I made a resolution not to let it get that far again. I tried to make space between me and my feelings ... When I brought him upstairs, I said to myself: "Calm down. Stay cool!"

These outbreaks of rage were very troubling for Max's father, not so much because he really had threatened Max, but because of the intensity of his own feelings. He was afraid of his own murderous impulses. It is almost as if the repressed rage towards his own brother he had earlier mentioned might have only now surfaced. In the marriage, too, both he and his wife avoided controversy, so that Max's father had no practice in dealing with his anger. Only gradually did he learn to understand his rage and irritation. He became able to stand outside himself and calm himself down. His mother had often had inexplicable fits of rage that he as a child could not understand. Thus, he emphasised that his own fits of rage always were linked to provocative actions from Max.

Questioned as to what he found fascinating about children, Max's father spoke of discipline and conflict, because they related to his own sense of self and need for security. His goal was to make Max into a friendly and generous person. In self-criticism, he added that he and his wife had not yet helped Max, since they had in a certain sense spoiled 
him: they were not firm or consequential enough as parents. Max was a very competitive child. He wished to be the strongest and best at everything, and was afraid of the consequences of not winning.

The descriptions Max's father provided show that he actively reflected on his activities and role as father, as well as discussing them extensively with his wife. For him, his mission as a father is closely linked to the development of his own personality-a challenge and almost a test of self-perception.

Questioned as to what three wishes he would have for Max, the father answered:

My first wish is that he stays healthy and has a long life. The second wish is that he develops into a great person, and the third wish is related to the second: he should get brothers and sisters. That would help him.

Although his father is concerned at Max's inability to share, Max's teacher describes him differently-as getting along well with the other children, and as agreeable. Max's behaviour in and away from his family seems to vary.

After describing the development of Kelly and Max during their first three years of life, I should like to describe one parent-child therapy and then the psychoanalysis of a child whose parents sought help for him in his third year.

\section{Development of children in therapy}

\section{Marietta and her close relationship to her mother}

A woman contacted the Semmelweis Women's Clinic, seeking to take advantage of the "Help for Parents and Small Children". ${ }^{3}$ Her four year old Marietta suffered from constipation. She had been to every available doctor, and at times the problem became so acute that she had to have her colon evacuated at the hospital.

The mother came to the first counselling alone, since she did not wish to discuss this embarrassing matter in front of Marietta. Her husband, a prominent politician, could not attend, since he had little time available and left care of the children to her. The mother confided to me how desperate she already felt: all her attempts had failed. The problem 
had begun approximately a year and a half ago. Marietta often did not go to the toilet for ten days, until her belly swelled up and caused her pain. She would then receive an enema, wept uncontrollably and did not want to surrender her faeces. At the dentist's, too, her behaviour seemed impossible. She would not allow the dentists or nurses to look in her mouth. She screamed and bit-it had already been twice necessary to give her an anaesthetic in order to treat her teeth. Only at the end of the session did the mother mention in passing that she also had a son who was nine months old-but she vigorously rejected any suggestion that Marietta's constipation might have something to do with the pregnancy. Marietta was completely uninterested in the baby or the pregnancy; the baby was no problem at all. However, the mother wished to come back once more with both children.

At the second session, the mother turned up with Marietta and the nine-month-old baby Alex.

Marietta was a pretty child. She was so shy that she hid behind her mother and only looked at me when she believed I was not looking at her. She did not touch any of the toys, but remained the entire hour lying behind her mother on the couch, playing with a frilly pink horse she had brought with her. The baby lay in his car seat and slept.

I asked the mother to tell me about Marietta's birth. The mother had worked as a photographic model through the sixth month of the pregnancy. Marietta was very interested in listening to this story. At one point, she asked her mother what the picture on the wall-the crosssection of a man's body - was. The mother explained, and I wondered aloud whether Marietta might also be interested in what she had been like as a baby in her mother's body. The mother asked Marietta whether she should draw her a picture of this, whereupon Marietta nodded her head. The mother, who was an academic painter, sketched herself as pregnant, with Marietta as the embryo. Alex had by this time woken up and made contact with me; the mother took him out of his car seat and he examined the room. Marietta emerged from her hiding place behind her mother for a moment and admired the drawing, which her mother explained to her. When I asked Marietta about her horse, the mother answered for her that Marietta loved horses and was already a good rider-one horse had just had a foal.

When the mother said this, Marietta suddenly wanted to leave, and began to sob. I remarked that the questions about babies and new foals had been very disturbing. The mother was taken aback; in her family, 
sexuality was taboo. Marietta very much wanted to bring the drawing with her and put it in her mother's bag.

The mother cancelled the next session since both children were sick. The alternative date she also cancelled because she herself was sick. In the following week, the mother called up and requested a new appointment, which was only possible two weeks later. A week after this, however, the mother appeared, and was apprised of her mistake by the secretary. She became very agitated and wanted the name of another therapist who lived closer to her. I told her we could discuss this in the next meeting. The mother had read a discussion of my book Career Women and Career $\mathrm{Men}^{4}$ and asked me for the exact title, since she wanted to buy it.

At the third session, the mother arrived alone and revealed to me that she wished not to come any more. She said she had already previously been in group therapy. Before every session, she thought she would not live through it. With all her strength, she then forced herself to attend. It was traumatic and terribly painful to narrate the various stories from her childhood. It helped her a great deal, but was also very painful, she said. She told of her infinite loneliness as a child, when nobody had cared about her. I felt completely outdone when she poured forth all these stories and nevertheless wanted to end therapy. I said to her that her ending this relationship that had just begun was like ending a pregnancy. The mother looked at me in surprise and said she had found out today that she was not pregnant. "I was thinking, now it's happened, and I would have to have another abortion," she said laughing. Marietta's mother had already had seven abortions: she told me about them for the first time and remarked how painful these losses had been for her. She had always made light of the abortions: they were just like enemas, she said. Then she asked me if it would make sense to keep coming to me.

I interpreted for her that she was without hope and that I should assume hope for her and Marietta. After this, the mother said she thought I had come too close to Marietta in the previous session. Marietta had put the drawing in her music book she took to motherchild singing. We tried to reflect together on whether Marietta might have the wish to become pregnant like her mother, and whether that was the reason she was retaining her faeces. Marietta's behaviour had completely changed: she wanted a nappy again and could now move her bowels without any problem. Often, she wanted to play baby; 
that made her mother inexplicably angry-suddenly, Marietta was so intensely occupied with the subject of babies. "Our maid was pregnant, her baby was stillborn. Our cat was sterilised and Marietta asked a lot of questions about that," said the mother with surprise.

The mother was uncertain whether she had answered all my questions truthfully, since nobody had ever talked with her about "that". Her husband found it a very good idea that she come to me.

In the fourth and last session, two weeks after this, the mother mentioned as if incidentally that Marietta's problem was solved. "Marietta overcame her block and doesn't need nappies any more either," she said, then talking at length about her new exhibit. For the last several weeks, she could paint with colours; previously she had only used shades of grey and black. She showed me the invitation for the new exhibition of her paintings she was currently preparing, and added that she felt there was so much happening inside her right now; her life was once again colourful.

\section{Discussion}

The mother was able to turn to a therapist to receive help for her daughter. In this short therapy, I saw the little girl only once. The focus of the therapeutic work lay in the mother's relationship to her daughter. The bond between them was so close that the daughter seemed to unconsciously express the mother's problems. By being able to speak with me about her suppressed traumatic experiences, the mother came into contact with her feelings and lost her urgent need to project them onto her daughter. For her, all sexual questions and dramatic events had been taboo. Only when the mother addressed her own problems in therapy was Marietta freed. She was able to express her wish to once more be a baby and not to surrender her faeces (by asking to wear a nappy). Already after two weeks, she could overcome this transitional phase and then go to the toilet. An additional improvement was that Marietta's father now apparently found it easier to speak with her about sexual matters, which was also a relief for the mother.

\section{Nikolaus_lost in the world}

I first saw Nikolaus with his parents within the frame of parent-child therapy in the Family Centre at the Semmelweis Clinic. The two-yearold Nikolaus seemed quite deranged; his parents looked completely 
exhausted. The father began by saying: "We're up against the wall, we don't know what else we can do!" Nikolaus had attacks of rage, wouldn't hold his parents' hands, ran into the street. In one close call, his mother had rescued him from under a tram. He was jealous, bit other children, slept poorly, and rendered his parents helpless with his overpowering fits of rage. They no longer had the confidence to leave the house with him. Over the course of twenty minutes, a flood of complaints about Nikolaus burst over me. Meanwhile, Nikolaus had put a puzzle together, after having asked me how it worked, then managing it himself. He played with cars, built a garage where he placed all of them carefully, climbed up alone onto the table and back down. It was if there were three needy children in the room, with the parents seemingly more desperate and lost than Nikolaus. When the flood of complaints had ebbed, I told the parents they had just conveyed to me how burdensome they found the situation and how desperate they were. Then I described all the things Nikolaus had played at during the half hour. Both parents seemed to be surprised I could see so many positive things in their son's playing. At first the father and then the mother named things that Nikolaus could do well. He loved looking at books alone or being read to, he could play with concentration and paint beautifully. The first session ended on a conciliatory note, as if the parents now could see the positive sides of Nikolaus. Since the mother implied that she believed her marriage had failed, I offered to see each of them alone: helping the parents seemed to be the most urgent task. Both of them needed someone who listened; they needed a place where they could tell the painful stories of their childhood and its deprivations.

In the second and third session, the parents came to me as a couple and used the sessions to tell of their childhood in a thorough and very moving manner. Both of them had felt very alone, lost, and misunderstood as children. Both had longed to have someone who would give them attention and understanding. After both had spoken of their situation as children, they spontaneously made a connection between themselves and their son, who felt just as lonely and rejected as they had. Both parents were very emotional, the father wept. When the mother once again began to speak of her hopeless marriage, I asked her how they had met each other. Because of their fear of disappointment, both parents had at first had problems committing to a relationship. The mother began to speak warmly of how back then, she liked everything about her husband: he was masculine, compassionate and 
creative, tender, interested in culture. Now it had all changed: they fought over every trifle. When they had first met, they had fallen in love and quickly married. They had only four to five months to get to know one another before Nikolaus was born. The father was now trying to win his wife over, hopeful that they would reconcile. When I asked when they had last taken time together for themselves, they were both surprised. Since Nikolaus had been born, the three of them were always together. They now planned a weekend for the two of them, although apprehensive that they would argue the entire time. At the end of the session, the mother said that Nikolaus, who never showed his feelings, had cried when he found out that he could not come to therapy with them today.

In the fourth session, all three of them came. The mother looked very young - as if transformed through some kind of enchantment. "There has been a new approach of tenderness," she commented. She and the father had physical contact throughout the whole session. The weekend had been surprisingly nice. Since it had rained most of the time, they spent most of the day in bed, in the sauna, or meditating. They could finally be with each other again without disturbances; they could talk, read, and make plans for renovating their apartment. Well prepared for the weekend, Nikolaus had borne the four days without problem. He now walked with them hand in hand, was trusting and tender; he even came up to them to cuddle, which he had never done before. Since, however, it was clear to the parents that the problems with Nikolaus lay deeper and since they wanted to help him solve them before he entered school, they asked if I could take him in therapy in the autumn (see Klitzing, 2003).

\section{Therapy of Nikolaus}

Nikolaus very quickly made a strong, positive transference to me. He wanted to come back and play again. At the beginning of therapy, when he was almost three years old, his vocabulary was very limited: he spoke in one-word sentences, but could express himself very well nonverbally. Some of his problems became evident only in the sessions with me, since his parents had not mentioned them: he put various objects in his ears and in his nose and ran around with them. He stuck an eraser, a small pencil sharpener, or a piece of paper as a "pacifier" in his mouth, and chewed on them. 
His parents informed me only during the course of therapy of some important facts about how the problems with Nikolaus had begun. A few weeks after his birth, his mother fell ill with a serious intestinal illness, which constituted a crisis for the entire family. Since she wished not to take any medication or go to the hospital, her husband cared for her at home. She resorted to homeopathic remedies and had to stay in bed for several weeks. In spite of her physical weakness, she continued to breastfeed Nikolaus, who spent many hours with her in bed. Only after six months did she show a slight improvement. Since the mother had never been breastfed as a child, it was very important to her to breastfeed Nikolaus as long as possible-in fact, this lasted eleven months. Nikolaus then weaned himself, according to her: he bit her breast until, after three days, she had to accept his rejection. The father had had to move to another city to work after half a year, and greatly feared losing his wife.

In the first phase of therapy, Nikolaus's behaviour oscillated between self-destructive actions-wishing to cut his own finger, sticking small objects in his ear or two pencils up his nose and running about with them-and his wish to take me and the room into his complete possession. In this domain, he wanted to be in control. At home during this phase, Nikolaus wanted to be a baby again: he lay down in bed next to his mother as he had done during her six-month illness. His aggression had begun only after her health had improved and she already could get up, the mother remembered. It became clear that the mother had a problem with gradation: everything was either good or bad. She was afraid that the therapy could be bad for Nikolaus, if he was allowed to show his aggression with me. Almost reluctantly, she remarked on how much he could now talk and how well he observed everything. Now the mother could also finish her master's thesis on which she had worked for two years-something that both relieved and pleased her.

After two months, Nikolaus's behaviour had improved noticeably, his parents said. At day care, he played fantasy games with a child one and a half years older than him, he constructed a cave or a bear family, and was very creative. At home, too, there were promising signs. He was beginning to want to dress himself. In the foreground were his fears when he had to go to sleep, and his eating habits. His mother was disturbed by his aggression when he built a rifle and wanted to shoot down his father and robbers. The father, who had already been 
unemployed for a year, now found an interesting job corresponding to his interests and education.

For Nikolaus, the therapy sessions were important; he could hardly wait until the holidays were over, and it was difficult for him to leave when the session ended. An important theme in his play was the warrior dinosaurs he built out of plasticene, as well as the crocodiles that wanted to bite off his feet and made dangerous noises at night. He seemed to experience me as a person who did not fear his aggressive fantasies, to whom he could show his disappointment and rage at separations, someone who helped him to understand his feelings. He sometimes reacted fearfully to my interpretations, as if what I had just said could now in fact occur. Gradually, he began to see the difference between a fantasy or a word and a concrete, threatening object, such as when he believed the crocodile could bite him.

Nikolaus had enormous difficulties allowing persons he loved (his objects) leave, because he wanted to exert total control over them. One time, his mother arrived with a screaming Nikolaus, who could not calm down because his mother had let his hand go briefly to ring my bell. When Nikolaus was angry at me, he defecated in his nappy; he also showed through other means how angry and miserable he felt. Nikolaus distinguished between a good father figure, with whom he telephoned in play, and a bad father figure, whom he represented as a "hunter" and had come to punish Nikolaus. As soon as he was able to talk in the transference with me about his great curiosity and excitement regarding all the sounds and actions in the night between his mother and father, his sleep disorders vanished. He wanted then to adopt the role of my husband; he was a fisherman who gave me many little fish (babies). He insisted on wrestling with me on the couch, wanted to take off my shoes, sweater, and other articles of clothing and accepted my setting of limits only reluctantly. Sometimes, when Nikolaus thought he had filled the room with repulsive figures, they became so concrete in his fantasy that I had to go with him into the waiting room, since he thought the figures truly existed and would kill us. He also attempted to draw me into his sexually exciting games and fantasies of what his parents did during the night, wishing to make me just as excited as he was. In his play with the dinosaurs, Nikolaus showed that he was afraid that one of them could hurt the other. When I interpreted to him this fear, his fear of going to sleep was lessened. In role playing, he now assumed the role of hunter with his big rifle. At the session's conclusion, when 
Nikolaus refused to leave and ran back into the therapy room, he was constructing a situation where he and I were a couple, where his father should feel excluded, which in fact was painful for the father.

When he wished not to leave at the end of the session, Nikolaus managed to provoke his father every time. He bit his father in the back when the father wanted to put his shoes on him. In the sessions, Nikolaus also managed to make me angry at him, eliciting in me the wish to grab him.

In this phase, the parents also began to set clearer limits, to have Nikolaus go to sleep without his pacifier and to not play naked in bed with him any more, which had stimulated his sexual fantasies. Release was expressed through many variations in his games. He was aware of his violent fantasies and, in play, wanted me to cut him open with the scissors or dismantle his caterpillar tractor. In the midst of this heated game, he had to go to the toilet. He expressed his fear of being caught and swallowed by having me catch and consume him, as crab or stingray. When Nikolaus felt himself understood through my interpretations, the quality of his games would change abruptly, he became gentle, came over to me or laid his head briefly in my lap, then shifting quietly to another game, as if we had taken care of one subject for that session. When he asked me once to change his full nappy, I helped him and he wanted to remain without a nappy, which I allowed. Within a short period, he went to the toilet alone.

Ending the analysis after a year and a half constituted yet another difficult time for Nikolaus, since without my help, he was afraid of once more becoming as confused and fearful as he had previously been. On the day after he had heard that the analysis would soon end, he hit me abruptly in the face when I was quite close to him. After this, he was afraid of the devil, held tightly onto his penis, and was convinced that I didn't want to see him any more.

The parents, however, were able to provide him enough time to make a gradual ending. He was able to express his thoughts and feelings through creative play and in words. He had not only increased his vocabulary inordinately, but had also become freer and more skilful in his physical movements. From an awkward, rather bearlike child, who threw things about and tended to fall down, he had become a lively child who could use his great intelligence. Nikolaus could now also show his grief when his mother departed. Nikolaus's mother had also learned to demonstrate to him he could do things alone: for instance, 
she had first doubly wound his scarf around his neck so that he almost strangled himself while taking it off, until she demonstrated to him how he should unwrap it; she also showed him how he could hold the two ends of his zipper so they would fit together. Since it was his father who brought Nikolaus to the sessions, he had more connection to what was happening in them, whereas it was often hard for the mother to accept that Nikolaus so enjoyed the sessions and was making such progress. However, his new independence brought such relief to her life that she was able to provide Nikolaus with emotional support for the therapy. When the family went together to a coffeehouse and Nikolaus ate his snack alone, then read his book, with spectators envying the parents for their sweet-natured son, a new perspective opened for them. They could also better respond to Nikolaus's wishes, as he was now able to express them in words.

\section{Discussion}

Unlike in infant observations, we have no report from a neutral observer in therapy and are therefore dependent on information from parents and material from the child's play in therapy. The mother's account of her long illness, which forced her to stay in bed for a month, prompts the question of whether this could have actually been a phase of post-natal depression. The burdensome relationship to her own mother, whom she described as cold and distant, could have been stirred up once again in the mother through Nikolaus's birth. Both parents seem to either have received or requested hardly any help from their families. Was Nikolaus overly challenged in his first months of life, and was he attempting to console his fragile mother? Presumably, as an infant he registered his mother's neediness and then became a "good" baby, tending to provide her with support in his first six months. In any event, his growth and maturing was of paramount importance for his mother-something to which she subjugated her own health. The healthier and more robust the mother then became, the more difficult and obstreperous Nikolaus became. Presumably, the early dissolution and demarcation of borders between him and his mother was not stable or well grounded. His compulsion to control everything and to completely subsume people into his possession constituted a central theme in his play for quite some time. Although he was not yet three when he began child analysis, he 
could express himself astonishingly well in symbols and readily took up my interpretations.

The father was a warm-hearted man, deeply interested in his son's well-being, and considered it very important to be a better father to Nikolaus than his own father had been to him. However, turbulent feelings of rivalry might have become reactivated in him, causing him at times to react like a child, as when he bit Nikolaus back.

Nikolaus was able to express his confusion through play and step by step build a clearer delineation between himself and the other person, which afforded him the possibility of separation together with loving reunification. Drawing on positive, loving aspects of his mother's and father's relationship, he was able to identify with his father and distinguish his aggressive fantasies concerning his parents' nightly activities from the level of reality.

\section{Notes}

1. A characteristic of schizophrenics who remain fixed at this stage of development is that they cannot distinguish between embodiment through things and words: they defend themselves against a threatening word by turning their head away, as if it were a shot from a gun.

2. In the tragedy of Oedipus, Laios, the king of Thebes is told by an oracle of Apollo that his son will kill him. King Laios and Jocasta pierce the feet of the newborn baby and give him to a shepherd, who is meant to leave him to die. The shepherd spares Oedipus' life and brings him to Corinth to the childless King Polypus and Queen Merope. When Oedipus, now a young man, hears that he is not their true son, he goes to Delphi to consult the oracle. There he is also told he will kill his father and marry his mother. In order to protect Polypus, Oedipus removes to Thebes. He comes to a place where three roads meet and there happens to get into a fight where he kills the passenger of a carriage and three of his four servants-only one of them escapes. Arrived in Thebes, he finds the city tyrannised by the Sphinx, but he manages to solve the Sphinx's riddle. The Sphinx thereupon commits suicide and the city offers Oedipus the crown of Thebes along with the hand of the widowed Queen Jocasta in marriage. Oedipus rules Thebes for seventeen years, until the city becomes once more afflicted by the plague. When the oracle is consulted, it says that the city is polluted with the murderer of the king. Oedipus swears to find this murderer. In a long sequence ensuing from the prophet Teresias' revelation that Oedipus is the murderer of 
Laios and not the son of Polypus, Oedipus recognises his guilt. Jocasta takes her life and Oedipus blinds himself with Jocasta's broach.

3. Parent-young child therapy is offered to parents of children under five. Prompt, unbureaucratic individual counselling is offered for problems such as eating and sleeping disorders, problems with contact, separation anxiety, and jealousy at the birth of a sibling. Up to five consultations can be provided.

4. Gertraud Diem-Wille (1996), Karrierefrauen und Karrieremänner. Eine psychoanalytisch orientierte Untersuchung ihrer Lebensgeschichte und Familiendynamik. 
CHAPTER FIVE

Outlook and perspectives: mastering early childhood

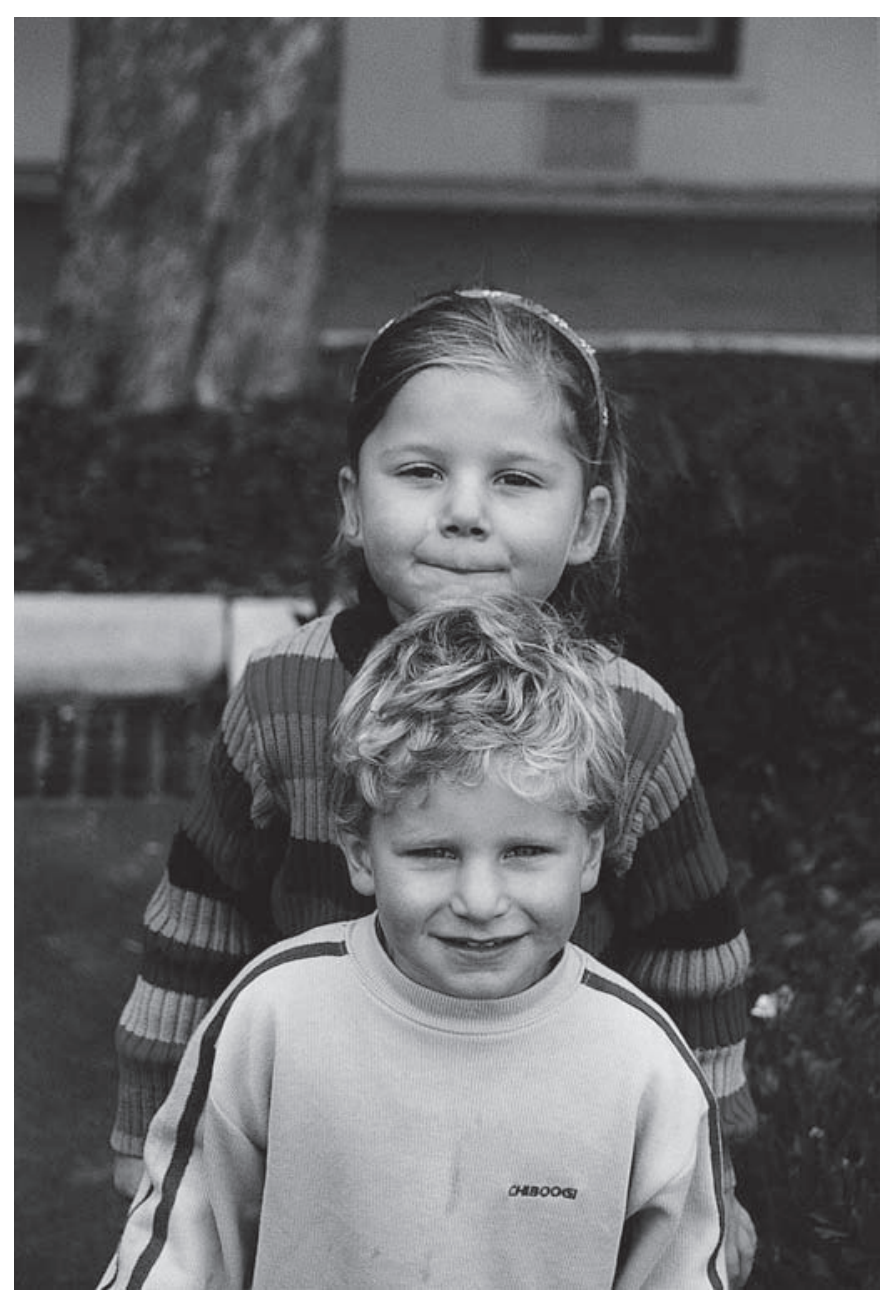





\begin{abstract}
ccompanying a child through his dramatic first three years is a major challenge and responsibility for the parents, since this is the time during which the underlying pattern of the personality is formed. This collaboration in shaping the personality of a new person is something uniquely enriching and satisfying, but also strenuous. Dostoyevski's maxim-“Being with children heals the soul"unfortunately expresses only half the truth. Contact with children can also activate the most unfortunate side of a person, eliciting cruelty and hate, when the requisite psychic and practical support is lacking. As Nietzsche remarked, what child would not have cause to weep over his parents? In this case, he was alluding to the flip side of the coin, parental shortcomings and inadequacies. Only both sides together comprise a whole picture. A child alters the lives of his mother and father radically, whether they actually live together with the child or are separated from him, whether they maintain contact or avoid all contact. In their inner experience, they are a father or mother, fulfilling their obligations as best they can, or bearing the responsibility for leaving their child in the lurch, giving him up or offering him for adoption. For a child who has been separated from his parents, too, this fact influences the basic tenor of his life.
\end{abstract}


I have posed high demands on the reader in attempting to establish a connection between everyday experiences with young children and psychoanalytic theories on child development in the first three years of life, supplemented with experiences from therapy. At the core of this undertaking, so to speak, are three different perspectives: first, the approach of empirical research, assembling data through observation and questioning; secondly, a reconstruction of insights gained in therapy sessions; and thirdly, generalisations based on clinical data, used towards forming various theories. A friend of mine who read the manuscript found my descriptions of children under observation more affectionate than those of children in therapy. This shows how important it is to give consideration to "normal" parents and "normal" children, since for families in therapy, their troubles and fear of abnormal development often relegate positive, loving aspects of the relationship between child and parent to the background. On the other hand, the fact they accept therapeutic help indicates how important these parents find it to encourage their child's development. This deep-lying love for a child is a paramount factor in the healing process, making possible the collaboration between therapist and parents. It was of crucial importance for me to depict both sides, the unique enrichment of life through children and also the difficulties parents face in their task. It should also be pointed out that despite the many efforts being made to more precisely investigate the early years of life and the genesis of the emotional relationship between parents and child, there is still not any one unified or closed theory: knowledge concerning these early years is still open, a work in progress.

How can scientific and clinical insights be made fruitful for parents and pedagogues? Can recommendations be formulated, along the lines of "the best for any child"? Can a thread be discerned for pedagogues and parents seeking to proceed correctly? By now, this book should have communicated to the reader that the search for simple recipes and "threads" is futile, and presumably only sets parents under more pressure. Accordingly, I have never spoken of a "best" way for the baby or small child, but have instead attempted to understand how a relationship between parents and baby/child could be improved. Every mother and every father develops a unique relationship with their child. The parents' personalities, their life situations, and their basic emotional make-up influence the child's development. Knowledge of the conflictladen inner tensions during the child's development in his first three 
years should help parents to relinquish unrealistic notions of an ideal upbringing. It is a difficult but also felicitous task to help the child master these first years, investigate the world, and come to know his own body and emotions.

In a fashion unlike any other scientific discipline, psychoanalysis has demonstrated-through numerous case studies-the significance of early emotional experiences and the shelter parental love provides, and accordingly the serious consequences of neglect, coldness, and early separation. In the first phase of psychoanalytic pedagogy around 1920, it was hoped to prevent neurosis by avoiding the "mistakes of upbringing": if the child was treated with love, not told lies about the facts of life, and had parents open to his wishes and questions, then he must perforce become happy. It was soon evident, however, that there exists no upbringing free from conflicts, frustrations, and suffering. The focus was shifted to parents helping their child master the unavoidable frustrations and difficulties of life through love and empathy.

With parents longing to devise a better upbringing for their children, all pronouncements from psychoanalysts were taken as inflexible rules and laws. The emphasis on the mother's emotional significance, her physical and psychic warmth, was interpreted to mean it was imperative she stay at home with her children. In fact, John Bowlby and others contended that mother and baby should not be separated in the first three years of life. Instead of taking this as a socio-political impetus to provide conditions necessary for a mother's two-year baby leave, it was misunderstood to mean that any working mother was a bad mother, who was damaging her baby.

I believe that although ambiguously formulated psychoanalytic insights by analysts such as Anna Freud, Bowlby, Lebovici, or D. W. Winnicott contributed to this misinterpretation, it was also fed by the strict superegos of mothers and fathers believing they must "be there" for their baby non-stop. The list of presumed duties and offences is comprehensive and also contradictory. Women have made the justified criticism that such rigid demands only increase pressure on working mothers. In fact, it is impossible to establish generalised principles without considering the particular situation of a given family. The relief provided a mother by a babysitter, grandparents, or a play group can help parents to better meet the demands of parenting. Similarly, a baby's development will be better nurtured by a loving nanny 
than by a mother who is burdened by unresolved conflicts with her own mother, or who forces herself to stay at home, overburdened and unhappy.

Thus, the goal of this book is not to provide fixed norms and wholesale advice to be implemented in the concrete situations of particular families. On the contrary: the point is to make parents and pedagogues sensitive to babies' needs, including not only the baby under their care but also the baby they themselves were. Only when adults become attuned to their own emotions, longings, fears, and injured feelings can they also be open for the archaic feelings of the baby and small child. For every adult, interaction with small children revives their own happy and painful experiences. Emphasising the significance of the first three years of life is meant to counter the misconception that a small child does not yet feel psychic or spiritual pain, does not yet notice his mother's absence, changes in his living situation, sources of humiliation, or security. Only when we fail to look closely, only when we wish not to see the happy or desperate expression in a baby's eyes, can we conclude that he does not yet have emotions or emotional perceptions. Observing a baby, perceiving his state of being emotionally, are the prerequisites for understanding how the relationship between baby and adult develops. An essential component of the psychoanalytic attitude in childrearing consists in helping the baby empathetically to deal with frustrations, disappointments, and failures in small increments. When the authority figure respects the baby's personality and independence, the foundation for a solid self-confidence will be laid. It is therefore necessary to learn and accept the baby's personality, trusting him to manage the demands of life step by step. Love for the baby and faith in his ability to calm himself, go to sleep on his own, play by himself, and investigate the world around him constitute a solid foundation. Here, the term "alone" does not mean the child is simply left to himself, but rather that he is granted his own initiative to move and discover his body, with the adult as participant but not initiating the initiative.

It sounds so simple for adults to accept a child's personality. Naturally, it is important to point out that we adults always entertain ideas of what is good for the baby, wishes as to how he should behave, at times including ambitious goals-sometimes, the same goals we have for ourselves-and we consequently can become impatient. The task of understanding a child confronts us in a very special way with 
our own personalities, with our own wishes, ideas, and limits. A baby's inconsolable, uncontrollable cries can make us furious in a way we would previously have considered inconceivable, eliciting the impulse to simply strike out, scream, or do anything to make the baby stop. A baby or small child, however, can also inspire amazing quantities of generosity, love, patience, dedication, and understanding, more than we knew we had. It would be a mistake for parents or caregivers to be shocked or ashamed at their impulses. Acknowledging loving and angry impulses, patient and uncontrollable reactions is an important basis for recognising good and evil and maintaining a tolerant attitude towards oneself and the child. It helps to remember that a baby's crying is not a criticism that we are not good enough; more likely, the baby simply is going through difficult processes of digestion or learning. If parents can register and contain the child's painful feelings, then the child can internalise his parents' understanding and begin to find solace within himself. Internalising a secure good object is the basis for being alone without loneliness: for the child, the mother or the father is not only alive when physically present, but is also internally accessible as a parental image. At the same time, the baby and small child will have to learn how to deal with disappointment alongside positive, loving experiences. Nobody can always do everything right, and even some judicious behaviour on the parents' part, for instance setting limits, saying no, or establishing periods of separation, will necessarily cause frustration. If his experiences with the parents are mainly positive, the child can then learn to integrate good and bad experiences.

Psychoanalysis's emphasis on the significance of the early years has helped usher in many changes concerning pregnancy, birth, and child care in Western Europe. Not necessarily separating the mother from the newborn directly after birth provides a better basis for early bonding between baby and mother, with the mother feeling less radically alone and the baby experiencing a gentler transition between the womb and his new environment, due to epidermal contact with its mother. But even that does not constitute a maxim. Some women are so exhausted from giving birth that they subsequently need time for themselves and are grateful when the father holds the baby. With fathers' increased participation in preparations for birth and the birth itself, a new dimension has opened in the relationship between father and baby and between the parents themselves, since fathers feel less excluded than before. Film documentation of children separated from their mothers during 
hospital stays has led to a reversal in procedure: for the last ten years, the mother stays with her child in the hospital. ${ }^{1}$

The baby is born into one specific family whose nationality, language, social status, and milieu it assumes. The world is imparted to the infant via his parents, their particular way of speaking, moving, smell, their psychic closeness or distance to the child. Although the baby is born as an individual, with abilities, talents, and a particular constitution, his psychic and physical experiences in the early years influence his fundamental consciousness and the structure of his personality-comparable to a pattern in a loom, woven out of threads from the baby's inborn personality and his parents' personalities. In pedagogy, the image of a gardener often arises, influencing a tree's growth through the manner of care, watering, pruning, and training. I believe this image is too superficial. It is important to understand just how deeply the influence of parents and caregivers impacts on the pattern of a child's personality. How, for example, does the child accept the offer of his mother's breast, and how does the mother in turn react to a joyous, matter-of-fact or unwilling baby when he does so? This involves basic forms of give and take, of accepting help-and the fundamental fact that the mother has something the baby needs. Bott Spillius (2001) describes one baby's relatively neutral acceptance of his mother's breast, writing: "For example, it was characteristic for (this) baby who was still quite young that it took the breast only with great hesitation; its father, who was watching, said: 'He only takes it when he thinks it's just a coincidence. I think he will never have the feeling he truly needs it.' The father presumedactually, he was convinced, and no doubt reading his own feelings into the baby - that his child didn't want to have too much to do with this 'other', this 'not-I' thing, from which it received its nourishment." We know nothing of what this baby actually is imagining-whether, for instance, his image of the breast might be overwhelming and distorted. From psychoanalysis, we know that a child's early image of his parents corresponds not to how they actually are, but rather to an image the child makes of them as he registers and comprehends actions and motions, that is, the inner object is always distorted and never completely corresponds to outer reality. For the observer, it is fascinating to see how many ways children resemble their parents, how they adopt gestures, words, and reactions, and how the behaviours of child and parents play on each other, both in the positive and negative sense. The mother and father constitute the baby's first social environment. 
A mother can be described as a social uterus, and her recognition of the baby's growth and development constitutes the first building block in the baby's own body image: the baby links his bodily sensations to recognition from his mother-her proud encouragement as she tells him: "You can already crawl!" or "You can already stand up!"

The intensity of this mutual intertwining becomes clear when we observe a relationship where minimum requirements are not fulfilled: when the baby suffers such massive deprivation that he develops grave disorders and becomes "autistic". Under the rubric "autism" we understand a severe personality disorder massively impeding children in their mental and emotional development. Autistic children do not form normal emotional relationships to adults. "They do not play normally, and frequently carry out strange repetitive rituals and behaviors. These features are often accompanied by severe developmental delay in all areas of the child's functioning" (Alvarez \& Reid, 1999). They seem to possess no concept of a world where other thinking persons could interest them or find interest in them. The lack of the normal ability to imagine, interpret, or recognise other people's feelings or understand their unspoken intentions indicates the absence of a rich inner world where memories and fantasies can be stored. Autism is considered an inborn deficiency by some scientists (Frith, 1989; Leslie, 1987), by others as a defect of intersubjectivity, as a lack of sense for other human beings (Alvarez \& Reid, 1999; Hobson, 1993; Trevarthen, Aitken, Papoudi \& Robarts, 1996). An autistic child, unreachable for his parents and siblings, elicits in them permanent pain, shock, and grief.

When we observe grave developmental disorders such as autism, we can better understand how in these few years a "healthy" baby grows into a human being who can communicate with other people in a differentiated manner and has already formed the foundations of his personality. Every day of interaction between parents and baby or young child consists of a hundred mini-sequences and scenes that are repeated daily, thus forming deep structures. These scenes from daily life seem trivial, but are laden with the richness of human relationships, resolution of conflicts, and modalities of psychological process shaping the child's further behaviour. In order to make tangible these many-layered interactions, I will now discuss two "dramas from daily life": the first scene from the perspective of an infant observation, the second scene from the autobiography of the psychoanalyst Wilfred Bion. 


\section{Scenes of escalation: "I am a worm ..."}

A two-and-a-half-year-old girl took a can of Coca-Cola out of the refrigerator, one she had been given by her mother when they were out shopping. She was at first only allowed to put the can on the table, until she had finished her vegetable soup. After she had eaten the soup by herself with a spoon, she wanted to open the can. Her father helped her do this. When she wanted to drink out of the can, however, her father intervened forcefully, saying in a sharp tone: "No, you will not drink out of the can. You can pour it into the glass." The girl at first looked at him in amazement, then burst into tears, crying louder and louder, inconsolable. The father's cousin, who was sitting opposite them, suggested getting a straw, but there weren't any. The angry father held the can in his hand and then put it demonstratively in front of the child, who briefly became hopeful she might be allowed to drink out of it after all, and stopped crying for a moment. The father said emphatically: "You can't drink from this can. I don't want you to drink Coca-Cola at all, it's not healthy!" When he pointed to the can, the girl burst into tears again, as if he had deeply hurt her, and tossed and turned desperately in her chair. The volume of her crying increased further. The cousin commented that the girl seemed simply contrary.

The mother and the grandmother had been looking on silently without intervening. Then the grandmother stood up and suggested the girl come help her in the kitchen; when the girl nodded, the grandmother took her up in her arms. The girl slowly calmed down as the grandmother let her look into the cooking pots and explained what she was cooking in them. When the girl was once again calm and helping to put the food on the plates, the grandmother asked her: "What kind of animal are you?" The girl answered meekly: "A worm." Surprised, the grandmother repeated: "A worm?" In a somewhat more cheerful voice, the girl said: "Maybe a chick." "A chick with yellow fluff, who hatched out of an egg?" said the grandmother in reference to a picture book they often read together called My Goose, Betsy, which described how a goose lays eggs and sits on them until the chicks hatch.

Meanwhile, the mother had come in and brought the can. She had negotiated with the father until they agreed that the girl could drink from the glass and, between meals, out of the can, as she had done with the mother in the afternoons at the swimming pool. The little girl sat down on her little stool and drank the rest of the liquid out 
of the can. At the table, she drank out of the glass, as she had been instructed.

\section{Discussion}

The girl had received a little brother a few months before. On the afternoon preceding this scene, the mother had taken a can of soda to the swimming pool, out of which she and the girl drank alternately. For the little girl, drinking out of the can represented something from the adult world where she had been allowed to participate. It was incomprehensible to her that her father would forbid this, and she presumably experienced his reaction as a cruel form of exclusion from the adult world - the birth of the new baby was already a shock. Her wish to not express her considerable jealousy and unconscious envy of her mother was then manifested somatically. In the first two weeks after the birth of her brother, she was sick with a herpes infection in her mouth that impaired her eating. She could only ingest liquids and lost almost three kilos. Afterwards, she fell ill again twice. Only after three months did she slowly begin to show her jealousy. Her way of dealing with this seemed to consist in becoming like her mother-close to her but nevertheless independent. She could already dress herself, tie her shoes, and had learned in two weeks to go to the potty and then to the toilet. Now all this pseudo-adult behaviour seemed to collapse. Reacting to the brusque decisiveness of her father's stricture, she seems to have felt herself helpless as a worm. After she had expressed this sense of powerlessness in the image of a worm, she found a more positive comparison, that of a chick. On the one hand, the image of the "chick" entails the knowledge that she is no longer a baby-already hatched out of the egg - and on the other hand, it embodies the hope of learning, growing up, and then becoming a goose that can lay eggs itself.

The father wanted to make sure the rule of drinking only out of a glass at the table was followed. His sharp tone of voice presumably had more to do with the discussion between him and his wife and his view that Coca-Cola should not be bought for his children. The fact that guests were present could also have played a role. Subsequently, the mother was able to negotiate a compromise with the father where he could preserve his authority and the mother could support him in enforcing the rules, with the daughter's wish nevertheless partially satisfied. This example also demonstrates how in every scene from 
daily life, a multitude of coalitions and figurations influence the social dynamics of a family.

\section{Second example}

Now to the second example, which is told from the adult's perspective. In the second volume of his autobiography, All My Sins Remembered. The Other Side of Genius (1985), Bion describes the following scene in which he is a single father, whose wife died giving birth to their daughter:

Yet now I felt as never before; numbed and insensitive. That something was wrong, must be wrong, was brought home to me one weekend when I was sitting on the lawn near the house and the baby was crawling near a flower bed on the opposite side of the lawn. She began to call out to me; she wanted me to come to her.

I remained sitting. She now made to crawl towards me. But she called to me as if expecting me to come to fetch her.

I remained sitting.

She continued to crawl and now her calls became distressful.

I remained sitting.

I watched her continue on the painful journey across the vast expanse, as it must have appeared to her, that separated her from her Daddy.

I remained sitting but felt bitter, angry, resentful. Why did she do this to me? Not quite audible was the question, "Why do you do this to her?"

The nurse could not stand it and got up to fetch her. "No," I said, "let her crawl. It won't do her any harm." We watched the child crawl painfully. She was weeping bitterly now but sticking stoutly to her attempt to cover the distance.

I felt as if I were gripped in a vice. No. I would not go. At last the nurse, having glanced at me with astonishment, got up ignoring my prohibition, and fetched her. The spell snapped. I was released. The baby had stopped weeping and was being comforted by maternal arms. But I, I had lost my child.

I hope there is no future life.

I had begged Betty to agree to have a baby: her agreement to do so had cost her her life. 
I had vowed to look after the child. It was not a promise to Betty; it was an unexpected vow to myself. It was a shock, a searing shock, to find such depth of cruelty in myself. I have since often recalled Shakespeare's words: "Nymph, in thy orisons be all my sins remembered."

\section{Discussion}

Bion introduces this scene by indicating his depressed mood and his guilt feelings over the premature death of his young wife. A twentyyear-old serving in France during the First World War, he could not obtain leave for the birth of his daughter, and consequently felt responsible for his wife's death. It is not his inactivity in this scene that horrifies him, but the cruelty of not considering his little daughter's wish to be picked up. He simply remains sitting, rejecting her and denying her more and more urgently expressed wish. Ever more desperate, she is finally picked up by the nanny. Did Bion unconsciously wish his daughter to feel just as desperate and lonely as he himself may have felt in this moment? Her birth cost his wife her life, for which he also blamed himself. His failure lay in denying help, in not answering the child's cries-and, under attack by his own cruel superego, he became convinced that he had lost his daughter. Perhaps the crawling baby expressed his longing for Betty, who was unreachable in the realm of the dead and could not come back to him. This description also demonstrates the emotional narrowing that is typical of depression: nothing has ground beneath it, and Bion feels forsaken, his pessimistic, black view of the world mirrored in his self-reproach. The absent mother is experienced by the young child as bad, since with her demise she has withdrawn her protection, and the child accordingly feels herself delivered up to the world unprotected, left to hunger and pain. Bion himself must have felt lost and forsaken, full of bitterness and grievance, so that he had no access to his motherly qualities in this moment. In remaining seated, he expressed his passive aggression and cruelty, while simultaneously experiencing empathy with his daughter, who in spite of the wide distance between them wished to crawl to him.

The present, caring mother-in Bion's example represented by the nanny-provides warmth, consolation, and love. In her arms, the small girl quickly calms down. Only in Bion's fantasy does he lose his daughter-in fact, children quickly forgive their parents the suffering 
and frustrations they cause, since the manifold loving and tender experiences have a neutralising effect. The baby's experience in its mother's body before birth has already imparted the knowledge of maternal goodness, nourishing it and keeping it warm.

The joy and joyful enchantment of existence, as embodied in the image of a good mother, is expressed by Eichendorff (1815) in the following lines of a poem:

The fall wind the branch doth rustle,

How swift the world doth bustle,

Keep the little child warm.

\section{Note}

1. The film Grief: A Peril in Infancy was made in 1947 by René Spitz. It shows the small African-American girl Jane in a Mexican orphanage, whose mother was forced to leave her there. At the beginning of the three-month separation, she is a happy, smiling girl who plays cheerfully. One week later, she has become depressed, avoiding eye contact and reacting to any situation with bitter tears. When the mothers are allowed back to their children in less than three months, children can recover quickly, as shown in this film when Jane's mother does in fact return to her. Another influential documentary film was made in 1952: A Two-Year-Old Goes to Hospital (director: James and Joyce Robertson). It shows the dramatic change in a girl undergoing an operation, through the forced separation from her mother in the hospital. 


\section{REFERENCES}

Ainsworth, M., Blehar, M., Waters, E. \& Wall, S. (1978). Patterns of Attachment: A Psychological Study of the Strange Situation. Hillsdale, NY: Lawrence Erlbaum.

Alvarez, A. (1992). Live Company. Psychoanalytic Psychotherapy with Autistic, Borderline, Deprived and Abused Children. London: Tavistock/Routledge. Alvarez, A., \& Reid, S. (Eds.) (1999). Autism and Personality. Findings from the Tavistock Autism Workshop. London: Routledge.

Audard, C., \& Grosz, A. (2000). Recognition. News and Events, the Institute of Psychoanalysis (UK), Spring and Summer: 1-4.

Badinter, E. (1980). Die Mutterliebe. Geschichte eines Gefühls vom 17. Jahrhundert bis Heute. Munich, Germany: Piper.

Baldwin, M. W. (1992). Relational schemas and processing of social information. Psychological Bulletin, 112: 461-484.

Baumgart, M. (1991). Psychoanalyse und Säuglingsforschung: Versuche einer Integration unter Berücksichtigung methodischer Unterschiede. Psyche, 49(9): 780-809.

Beck, K. (2002). Vater warden-ein Abenteuer. (Degree thesis, University of Vienna.)

Belsky, J. (1999). Interactional and contextual determinants of attachment security. In: J. Cassidy \& P. R. Shaver (Eds.), Handbook of Attachment: Theory, Research and Clinical Applications (pp. 249-264). New York: Guilford. 
Bernstein, A., \& Warner, G. M. (Eds.) (1984). Women Treating Women. (Case material from women treated by female psychoanalysts.) Madison, CT: International Universities Press, 1986.

Bettelheim, B. (1943). Individual and mass behavior in extreme situations. In: Surviving and Other Essays. New York: Vintage 1980.

Bettelheim, B. (1975). The Uses of Enchantment. New York: Knopf.

Bick, E. (1964). Notes on infant observation in psychoanalytic training. Interntional Journal of Psychoanalysis, 45: 558.

Bick, E. (1986). The experience of the skin in early object relations. International Journal of Psychoanalysis, 49: 484-486. Republished in The Collected Papers of Martha Harris and Esther Bick (pp. 114-118). Strath Tay, UK: Clunie, 1987.

Bion, W. R. (1959). Attacks on linking. International Journal of Psychoanalysis, 40(5-6). Reprinted in: Bion, W. R. (1967). Second Thoughts (pp. 93-109). London: Karnac, 1990.

Bion, W. R. (1962). Learning from Experience. London: Heinemann Medical.

Bion, W. R. (1985). All My Sins Remembered. The Other Side of Genius. London: Karnac.

Black, D. M. (2006). Psychoanalysis and Religion in the 21st Century: Competitors or Collaborators? London: Routledge.

Bourne, S., \& Lewis, E. (1984). Pregnancy after still birth or neonatal death. Lancet, July: 31-39.

Bowlby, J. (1951). Maternal Care and Mental Health. WHO Monograph Series, No. 2. Geneva: World Health Organization.

Bowlby, J. (1957). An ethological approach to research in child development. British Journal of Medical Psychology, 30(4): 230-240.

Bowlby, J. (1969). Attachment, Volume 1. New York: Basic Books.

Bowlby, J. (1979). The Making and Breaking of Affectional Bonds. London: Tavistock.

Bowlby, J. (1980). Mit der Ethologie heraus aus der Psychoanalyse: Ein Kreuzungsexperiment. In: K. Grossmann \& K. Grossmann (Eds.), Bindung und menschliche Entwicklung. John Bowlby, Mary Ainsworth und die Grundlagen der Bindungstheorie (pp. 38-54). Stuttgart, Germany: KlettCotta, 2003.

Bowlby, J. (1987). Bindung. In: K. Grossmann \& K. Grossmann (Eds.), Bindung und menschliche Entwicklung. John Bowlby, Mary Ainsworth und die Grundlagen der Bindungstheorie (pp. 22-26). Stuttgart, Germany: KlettCotta, 2003.

Bowlby, J. (1990). Charles Darwin. A Biography. London: Hutchinson.

Brazelton, T. B. (1992). Touchpoints: Your Child's Emotional and Behavioral Development (second edition). Reading, MA: Addison-Wesley, 2006.

Briggs, S. (1997). Growth and Risk in Infancy. London: Jessica Kingsley. 
Britton, R. (1989). The missing link. Parental sexuality in the Oedipus complex. In: R. Britton, M. Feldman, \& E. O'Shaughnessy (Eds.), The Oedipus Complex Today. London: Karnac.

Chasseguet-Smirgel, J. (1964). La sexualité femin. Paris: Payot.

Chertok, L., Bonnaud, M., Borelli, M., Donnet, J. \& Revault D'Allones, C. (1969). Motherhood and Personality. Philadelphia, PA: Lippincott.

Datler, W., Trunkenpolz, K. \& Funder, A. (2002). Alleine unter Fremden. Zur Bedeutung des Trennungserlebens von Kleinkindern in Kinderkrippen. In: Jahrbuch für psychoanalytische Pädagogik. Giessen, Germany: Psychosozial.

Daws, D. (1989). Through the Night. Helping Parents and Sleepless Infants. London: Free Association.

Daws, D. (1999). Beratung bei Schlafproblemen mit Kindern. In: W. Datler \& H. Figdor (Eds.), Die Wiederentdeckung der Freude am Kind. Psychoanalytisch-pädagogische Erziehungsberatung heute (pp. 143-153). Giessen, Germany: Psychosozial.

De Masi, F. (2003). Das Unbewußte und die Psychosen. Psyche, 57: 1-34.

deMause, L. (Ed.) (1974). Hört ihr die Kinder weinen. Eine psychogenetische Geschichte der Kindheit. Frankfurt, Germany: Suhrkamp.

Deutsch, H. (1944). Psychology of Women, Vol. 1. New York: Gruen \& Stratton.

Diem-Wille, G. (1996). Karrierefrauen und Karrieremänner. Opladen, Germany: Westdeutscher .

Diem-Wille, G. (1997). Observed families revisited-two years on: a follow-up study. In: S. Reid (Ed.), Developments in Infant Observation. The Tavistock Model. London: Routledge.

Diem-Wille, G. (1999). Über den Zusammenhang zwischen Trennungsproblemen einer Mutter und Schlafproblemen eines Kindes. Robineine Falldarstellung einer Eltern-Kleinkind-Beratung. In: W. Datler \& H. Figdor (Eds.), Die Wiederentdeckung der Freude am Kind. Psychoanalytischpädagogische Erziehungsberatung heute. Giessen, Germany: Psychosozial.

Diem-Wille, G. (2000). Niemand hat mir jemals etwas gesagt ... Eine Falldarstellung einer Eltern-Kleinkind-Therapie aus der Tavistock Clinic. Jahrbuch für Psychoanalytische Pädagogik, 10. Giessen, Germany: Psychosozial.

Diem-Wille, G. (2007). The Early Years of Life (Die frühen Lebensjahre). Psychoanalytic Developmental Theory According to Freud, Klein and Bion. London: Karnac, 2011.

Diem-Wille, G., Finger, K. \& Heintel, G. (1998). Psychoanalytische Pädagogik in der Allgemeinen Pädagogischen Ausbildung für das Lehramtsstudium. In: G. Diem-Wille \& J. Thonhauser (Eds.), Innovationen in der universitären Lehrerausbildung. Innsbruck, Austria: Studien-Verlag. 
Dolto, F. (1984). Zwiesprache von Mutter und Kind. Munich, Germany: Kösel. Dornes, M. (1993). Der kompetente Säugling. Die präverbale Entwicklung des Menschen. Frankfurt, Germany: S. Fischer (Geist und Psyche).

Dornes, M. (1997). Die frühe Kindheit. Entwicklungspsychologie der ersten Lebensjahre. Frankfurt, Germany: S. Fischer.

Eichendorff, J. (1815). Zum Abschied meiner Tochter. In: W. D. Rasch (Ed.), Werke. Munich, Germany: Hanser, 2007.

Elias, N. (1969). The Civilizing Process, Vol. I, The History of Manners. Oxford: Blackwell.

Enquist, P. O. (1999). Der Besuch des Leibarztes. Munich, Germany: Hanser.

Erdheim, M. (1984). Die gesellschaftliche Produktion von Unbewußtheit. Frankfurt, Germany: Suhrkamp.

Erikson, E. H. (1959). Identity and the Life Cycle. New York: International Universities Press.

Ermann, G. (1996). Erfahrungen mit der Methode der Babybeobachtung. Die Schulung psychoanalytischer Kompetenzen. In: Forum der Psychoanalyse, 12: 279-290.

Ermann, G., \& Lazar, R. (2003). From dyad to triad. Observations on the similarities and differences in the roles and functions of mother and father in infantile development. In: Infant Observation, 5(3): 83-100.

Fairbairn, W. R. D. (1952). Psychoanalytic Studies of the Personality. London: Tavistock.

Fallaci, O. (1979). Brief an ein nie geborenes Kind. Frankfurt, Germany: S. Fischer. (In Italian: Lettera a un bambino mai nato. Milan: Rizzoli, 1975; in English: Letter to a Child Never Born. New York: Simon and Schuster, 1976.)

Feldman, M. (1989). The Oedipus complex: manifestations in the inner world and the therapeutic situation. In: R. Britton, M. Feldman \& E. O'Schaughnessy (Eds.), The Oedipus Complex Today. London: Karnac.

Ferenczi, S. (1924). Versuch einer Genitaltheorie. In: Schriften zur Psychoanalyse, Vol. II (pp. 317-400). Frankfurt, Germany: S. Fischer.

Fleck, L. (1977). Weiblicher Orgasmus. Munich, Germany: Kindler.

Fonagy, P. (1966). Das Junktim in der Kinderanalyse. Eine Fallstudie zur Beziehung von Forschung und Praxis. Forum der Psychoanalyse, 12: 93-109.

Fonagy, P. (1996). Die Bedeutung der Entwicklung metakognitiver Kontrolle der mentalen Repräsentanzen für die Betreuung und das Wachstum des Kindes. Psyche, 52, 1998: 349-368.

Fonagy, P. (1999). Psychoanalytic theory from the viewpoint of attachment theory and research. In: J. Cassidy \& P. Shaver (Eds.), Handbook of Attachment. New York: Guilford.

Fonagy, P. (2001). Attachment Theory and Psychoanalysis. New York: Other. 
Fonagy, P., Gergely, G., Jurist, E. L. \& Target, M. (2002). Affect, Regulation, Mentalization and the Development of the Self. London: Karnac, 2004.

Fonagy, P., Steele, M., Steele, H., Moran, G. \& Higgins, A. (1991). The capacity for understanding mental states: the reflective self in parent and child and its significance for security of attachment. Infant Mental Health Journal, 12: 201-218.

Fraiberg, S. H. (1959). The Magic Years. New York: Charles Scribner's Sons.

Fraiberg, S. H. (1980). Clinical Studies in Infant Mental Health, The First Year of Life. London: Tavistock.

Frank, C. (1999). Melanie Kleins erste Kinderanalysen-die Entdeckung des Kindes als Objekt sui generis von Heilen und Forschen. Stuttgart, Germany: Frommann-Holzboog.

Freud, A. (1927). Einführung in die Technik der Kinderanalyse. In: Die Schriften der Anna Freud, Vol. I (pp. 11-27). Munich, Germany: Kindler, 1980.

Freud, A. (1942). Kriegskinder. 12. Bericht. Januar 1941. In: Die Schriften der Anna Freud, Vol. II (pp. 496-654). Munich, Germany: Kindler, 1980.

Freud, A. (1944). Anstaltskinder. In: Die Schriften der Anna Freud, Vol. III (pp. 879-1003). Munich, Germany: Kindler, 1980.

Freud, A. (1946). Das psychoanalytische Stadium der frühkindlichen Eßstörung. In: Die Schriften der Anna Freud, Vol. IV, 1945-1956. Munich, Germany: Kindler, 1980.

Freud, A. (1963). Concept of developmental lines. Psychoanalytic Study of the Child, 18S: 245-265.

Freud, A. (1965). Normality and Pathology in Childhood: Assessments of Development. London: Karnac, 1989.

Freud, S. (1895). The Origins of Psycho-Analysis. Letters to Wilhelm Fliess, Drafts \& Notes, 1887-1902. M. Bonaparte, A. Freud \& E. Kris (Eds.). London: Imago, 1950.

Freud, S. (1900a). The Interpretation of Dreams. S. E., 4-5. London: Hogarth.

Freud, S. (1905d). Three Essays on the Theory of Sexuality. S. E., 7. London: Hogarth.

Freud, S. (1907c). The sexual enlightenment of children. S. E., 9: 129-140. London: Hogarth.

Freud, S. (1908c). On the sexual theories of children. S. E., 9: 209-226. London: Hogarth.

Freud, S. (1914c). On narcissism: an introduction. S. E., 14: 67-102. London: Hogarth.

Freud, S. (1915c). Instincts and their vicissitudes. S. E., 14. London: Hogarth.

Freud, S. (1920g). Beyond the Pleasure Principle. S. E., 18: 1-64. London: Hogarth. 
Freud, S. (1923b). The Ego and the Id. S. E., 19: 3-66. London: Hogarth.

Freud, S. (1925j). Some psychical consequences of the anatomical distinction between the sexes. S. E., 19: 248-260. London: Hogarth.

Freud, S. (1931b). Female sexuality. S. E., 21. London: Hogarth.

Freud, S. \& Breuer, J. (1895d). Studies on Hysteria. S. E., 2. London: Hogarth.

Frith, U. (1989). Autism: Explaining the Enigma. Oxford: Blackwell.

Gaddini, E. (1992). A Psychoanalytic Theory of Infantile Experience. Conceptual and Clinical Reflections. London: Routledge.

Gaddini, E. (1998). "Das Ich ist vor allem ein Körperliches". Beiträge zur Psychoanalyse der ersten Strukturen, G. Jappe \& B. Strehlow (Eds.). Tübingen, Germany: Edition Diskord.

Garfinkel, H. (1956). Conditions of successful degradation ceremonies. American Journal of Sociology, 61: 420-424.

Gelberg, H. -J. (Ed.) (2000). Großer Ozean, Gedichte für Alle. Weinheim, Germany: Beltz.

Gelis, J. (1989). Die Geburt: Volksglaube, Rituale und Praktiken von 1500-1900. Munich, Germany: Diederichs.

Goethe, J. W. (1783). Das Göttliche. In: Goethes Werke in zwei Bänden (7th edition). Salzburg, Austria: Das Berglandbuch, 1965.

Gopnik, A., Meltzoff, A. \& Kuhl, P. (2001). How Babies Think: The Science of Childhood. London: Weidenfeld \& Nicolson.

Gottschalch, W. (1977). Schülerkrisen. Autoritäre Erziehung, Flucht und Widerstand. Reinbek, Germany: Rowohlt.

Green, A. (1993). The dead mother. In: On Private Madness. Madison, CT: International Universities Press.

Green, A. (2000). Science and science fiction in infant research. In: J. Donald, A. Sandler \& R. Davies (Eds.), Clinical and Observational Psychoanalytic Research: Roots of a Controversy. London: Karnac.

Grinberg, L., Sor, D. \& Tabak de Bianchedi, E. (Ed.) (1993). New Introduction to The Work of Bion. Revised Edition. Northvale, NJ: Jason Aronson.

Grossmann, K. \& Grossmann, K. (Eds.) (2003). Vorwort. In: Bindung und menschliche Entwicklung. John Bowlby, Mary Ainsworth und die Grundlagen der Bindungstheorie (pp. 8-10). Stuttgart, Germany: Klett-Cotta.

Grunberger, B. (1976). Vom Narzißmus zum Objekt. Frankfurt, Germany: Suhrkamp.

Harlow, H. (1958). The nature of love. American Psychologist, 13: 673-685.

Herz, E., Thoma, M., Umek, W., Gruber, K., Linzmayer, L., Walcher, W. \& Philipp, T. (1997). Nicht-psychotische postpartale Depression. Pilotstudie zur Epidemiologie und Risikofaktoren. In: Geburtshilfe und Frauenheilkunde, 57 (pp. 282-283). Stuttgart, Germany: Thieme.

Highsmith, P. (2010). Notebook, March, 12. www.paulingendaay.com. 
Hinde, R. (1982). Ethology. London: Fontana.

Hobson, P. (1993). Autism and the Development of Mind. Hove, UK: Lawrence Erlbaum.

Hoffer, W. (1952). The mutual influences in the development of the ego and its earliest stages. Psychoanalytic Study of the Child, 7: 31-41.

Holmes, J. (1993). John Bowlby and Attachment Theory. London: Routledge.

Holmes, J. (1996). Attachment, Intimacy, Autonomy: Using Attachment Theory in Adult Psychotherapy. Northville, NJ: Jason Aronson.

Holmes, J. (2001). The Search for the Secure Base. Attachment Theory and Psychotherapy. London: Brunner-Routledge.

Horney, K. (1923). Zur Genese des weiblichen Kastrationskomplexes. Internationale Zeitschrift für Psychoanalyse, 9(2): 12-26.

Horney, K. (1930). Das Mißtrauen zwischen den Geschlechtern. Die psychoanalytische Bewegung, II. Jg. H. 6: 521-537. Reprinted in: Horney, K. (1967). Die Psychologie der Frau. Munich, Germany: Kindler.

Isaacs, S. (1948). The nature and function of phantasy. International Journal of Psychoanalysis, 29: 73-97.

Isaacs, S. (1952). The nature and function of phantasy. In: M. Klein, P. Heimann, S. Isaacs \& Riviere, J. (Eds.), Developments in Psycho-Analysis (pp. 67-121). London: Hogarth.

Jacoby, E., \& Berner, R. S. (Eds.) (2001). Dunkel war's, der Mond schien helle. Verse, Reime und Gedichte. Hildesheim, Germany: Deutscher Taschenbuch.

Jessner, L., Weigert, E. \& Fay, J. (1970). The development of parental attitudes during pregnancy. In: E. Anthony \& T. Benedek (Eds.), Parenthood (pp. 209-244). Boston, MA: Little Brown.

Joseph, B. (2001). Transference. In: C. Bronstein (Ed.), Kleinian Theory. A Contemporary Perspective (pp. 181-192). London: Whurr.

Karen, R. (1994). Becoming Attached. New York: Warner.

Kestenberg, J. (1956). Vicissitudes of female sexuality. Journal of the American Psychoanalytic Association, 4: 453-576.

King, P., \& Steiner, R. (Eds.) (2001). Die Freud/Klein-Kontroversen 1941-1945. Vols. 1 and 2. Stuttgart, Germany: Klett-Cotta.

Kitzinger, S. (2000). Rediscovering Birth. Boston, MA: Little Brown.

Klein, M. (1928). Frühstadien des Ödipuskonflikes. In: Melanie Klein. Gesammelte Schriften, Vol. I, Part 1, Schriften 1920-1945 (pp. 287-306). Stuttgart, Germany: Frommann-Holzboog, 1999.

Klein, M. (1933). Die frühe Entwicklung des kindlichen Gewissens. In: Melanie Klein. Gesammelte Schriften, Vol. I, Part 2, Schriften 1920-1945 (pp. 1-20). Stuttgart, Germany: Frommann-Holzboog, 1999.

Klein, M. (1940). Mourning and its relation to manic-depressive states. International Journal of Psychoanalysis, 21: 125-153. 
Klein, M. (1946). Bemerkungen über einige schizoide Mechanismen. In: Melanie Klein. Gesammelte Schriften, Vol. III, 1946-1963 (pp. 1-41). Stuttgart, Germany: Frommann-Holzboog, 2000.

Klein, M. (1948). On the theory of anxiety and guilt. In: Writings, Vol. 3 (pp. 25-56). London: Hogarth, 1975.

Klein, M. (1952). Die Ursprünge der Übertragung. In: Melanie Klein. Gesammelte Schriften, Vol. III, 1946-1963 (pp. 81-95). Stuttgart, Germany: Frommann-Holzboog, 2000.

Klein, M. (1957). Envy and Gratitude. London: Tavistock.

Klitzing, K. v. (2003). Wann braucht ein Säugling einen Psychoanalytiker? Von der Erforschung zur Therapie früher Beziehungen. In: Kinderanalyse. Zeitschrift für die Anwendung der Psychoanalyse in Psychotherapie und Psychiatrie des Kindes- und Jugendalters, 11: 3-19. Jg. H. 1. Stuttgart, Germany: Klett-Cotta.

Kohlheimer, R. (2002). Zur Psychologie der Kinderreime und Kinderlieder. In: S. Zwettler-Otte (Ed.), Von Robinson bis Harry Potter. Munich, Germany: Ernst Reinhardt.

Krejci, E. (1999). Psychogenese im ersten Lebensjahr. Perspektiven kleinianischer Psychoanalyse, Vol. 6. Tübingen, Germany: Edition Diskord.

Lazar, R. (1987). Die Trennung und ihre Bedeutung im frühesten Lebensalter. Kind und Umwelt, 5.

Lazar, R., Lehmann, N. \& Häußinger, G. (1986). Die psychoanalytische Beobachtung von Babys innerhalb der Familie. In: J. Stork (Ed.), Zur Psychologie und Psychopathologie des Säuglings—neue Ergebnisse in der psychoanalytischen Reflexion. Stuttgart, Germany: Frommann-Holzboog.

Lebovici, S. S. C. (1983). Le Nourrisson, la mère et le psychanalyste. Paris: Le Centurion.

Leslie, A. M. (1987). Pretense and representation: the origins of theory of mind. Psychological Review, 94: 412-426.

Lidz, T. (1974). The Person. His Development throughout the Life Cycle. New York: International Universities Press.

Loewenberg, P. (1986). Die „Reichskristallnacht" als öffentliches Erniedrigungsritual. Sigmund Freud House Bulletin, 10/Special Issue Also in: Bohleber, W., \& Kafka, J. S. (1992). Antisemitismus (pp. 39-61). Bielefeld, Germany: Aistesis.

MacFarlane, J. (1975). Olfaction in the development of social preferences in the human neonate. In: M. Hofer (Ed.), Parent-infant Interaction. Amsterdam, The Netherlands: Elsevier.

Mahler, M. S. (1979). Symbiose und Individuation. Vol. I: Psychose im Frühen Kindesalter. Stuttgart, Germany: Klett-Cotta.

Mahler, M. S., \& Gosliner, B. J. (1955). On symbiotic child psychosis. Psychoanalytic Study of the Child, 10: 195-212. 
Main, M. (1991). Metacognitive knowledge, metacognitive monitoring, and singular (coherent) vs. multiple (incoherent) model of attachment: Findings and directions for future research. In: C. M. Parkes, J. StevensonHide, \& P. Marris (Eds.), Attachment across the Life Cycle (pp. 127-159). London: Tavistock/Routledge.

Main, M., Kaplan, K. \& Cassidy, J. (1985). Security in infancy, childhood and adulthood. A move to the level of representation. In: I. Bretherton \& E. Waters (Eds.), Growing points of attachment theory and research, Monographs of the Society for Research in Child Development, 50: 66-104.

Mann, T. (1901). Buddenbrooks. Verfall einer Familie. Berlin: S. Fischer, 1930.

Metzger, H. G. (1999). Der abhängige und der kompetente Säugling-Eine kritische Relativierung der Säuglingsforschung. Zeitschrift für Psychoanalytische Theorie und Praxis, 14(4): 381-400.

Miller, A. (1979). Das Drama des begabten Kindes. Frankfurt, Germany: Suhrkamp.

Miller, A. (1981). Du sollst nicht merken. Variationen über das Paradies-Thema. Frankfurt, Germany: Suhrkamp.

Miller, L., Rustin, M. E., Rustin, M. J. \& Shuttleworth, J. (Eds.) (1989). Closely Observed Infants. London: Duckworth.

Milne, A. A. (1989). Winnie-the-Pooh. London: Mammith.

Montagu, A. (1971). Körperkontakt. Die Bedeutung der Haut für die Entwicklung des Menschen. Stuttgart, Germany: Klett-Cotta.

Moore, T., \& Ucko, L. E. (1957). Night waking in early infancy. Archives of Disease in Early Childhood, 32: 333-342.

Mussen, P., Conger, J., Kagan, J. \& Huston, A. (1990). Lehrbuch der Kinderpsychologie, Vol. 1. Stuttgart, Germany: Klett-Cotta.

Person, E. S. (1988). Dreams of Love and Fateful Encounters. The Power of Romantic Passion. New York: W. W. Norton.

Piaget, J., \& Inhelder, B. (1951). Die Psychologie der frühen Kindheit. In: D. Katz (Ed.), Handbuch der Psychologie. Basel, Switzerland: Schwabe.

Pikler, E. (1982). Friedliche Babys—zufriedene Mütter. Pädagogische Ratschläge einer Kinderärztin. Freiburg, Germany: Herder.

Pikler, E. (2001). Laßt mir Zeit. Die selbständige Bewegungsentwicklung des Kindes bis zum freien Gehen. Munich, Germany: Pflaum.

Pine, F. (1990). Infant research. The symbiotic phase and clinical work. A case study of a concept. In: F. Pine (Ed.), Drive, Ego, Object and Self (pp. 232-246). New York: Basic Books.

Pine, F. (1994). The era of separation-individuation. Psychoanalytic Inquiry, 14: 4-24.

Pines, D. (1993). A Woman's Unconscious Use of Her Body. A Psychoanalytical Perspective. London: Virago. 
Piontelli, A. (1992). From Fetus to Child. An Observational and Psychoanalytic Study. London: Routledge.

Pound, A., \& Mills, M. (1985). A pilot evaluation on newborn. Association of Child Psychology and Psychiatry Newsletter, 7: 13-19.

Rank, O. (1924). The Trauma of Birth. Baltimore, MD: Johns Hopkins University Press, 1991. (In German: Das Trauma der Geburt. Giessen, Germany: Psychosozial, 1998.)

Raphael-Leff, J., \& Perelberg, R. J. (Eds.) (1997). Female Experience. Three Generations of British Women Psychoanalysts on Work with Women. London: Routledge.

Reid, S. (1993). Understand Your Three Year Old. London: Risendale.

Reid, S. (Ed.) (1997). Development in Infant Observation. The Tavistock Model. London: Routledge.

Rhees, R. (Ed.) (1984). Recollections of Wittgenstein: Hermine Wittgenstein, Fania Pascal, F. R. Leavis, John King, M. O'C. Drury. Oxford: Oxford University Press.

Rhode, M., \& Klauber, T. (2004). The Many Faces of Asperger Syndrome. Tavistock Clinic Series. London: Karnac.

Richter, D., \& Stauber, M. (1990). Gynäkologie und Geburtshilfe. In: T. v. Uexküll, R. H. v. Adler, J. M. Herrmann, K. Köhle, O. W. Schonecke \& W. Wesiack: Psychosomatische Medizin. 4. Edition. Munich, Germany: Urban \& Fischer.

Riesenberg-Malcolm, R. (2001). Bion's theory of containment. In: C. Bronstein (Ed.), Kleinian Theory. A Contemporary Perspective (pp. 165-180). London: Whurr.

Robertson, J. (1952). A Two-Year-Old Goes to Hospital (film).

Rollin, L. (1992). Cradle and All. Jackson, MS: University Press of Mississippi.

Roper, L. (1997). Oedipus and the Devil. Witchcraft, Sexuality and Religion in Early Modern Europe. London: Routledge.

Rosenfeld, H. (1975). The negative therapeutic reaction. In: P. Giovaccini (Ed.), Tactics and Techniques in Psycho-Analytic, Volume 2 (pp. 217-228). New York: Jason Aronson.

Rühmkorf, P. (2000). Gedichte-Werk 1. B. Rauschenbach (Ed.), B. Mcquade (Trans.). Reinbek, Germany: Rowohlt.

Rustin, M. E. (1989). Encountering primitive anxieties. In: L. Miller, M. E. Rustin, M. J. Rustin \& J. Shuttleworth (Eds.), Closely Observed Infants. London: Duckworth.

Salzberger-Wittenberg, I. (1970). Psychoanalytisches Verstehen von Beziehungen. Ein Kleinianischer Ansatz. Vienna: Fakultas, 2002. (Psycho-Analytic Insight and Relationships. A Kleinian Approach. London: Routledge \& Kegan Paul.) 
Salzberger-Wittenberg, I. (1983). Die Pädagogik der Gefühle. Emotionale Erfahrungen beim Lernen und Lehren. Vienna: WUV. (The Emotional Experience of Learning and Teaching. London: Routledge.)

Salzberger-Wittenberg, I. (2013). Experiencing Endings and Beginnings, London: Karnac.

Sandler, J. (Ed.) (1991). Freud's On Narcissim: An Introduction. London: Yale University Press.

Sandler, J., Holder, A., Dare, C. \& Dreher, A. (1997). Introduction. In: Freud's Model of the Mind. An Introduction. London: Karnac.

Sandler, J., Sandler, A. -M. \& Davies, R. (Eds.) (2000). Clinical and Observational Psychoanalytic Research: Roots of a Controversy-André Green $\mathcal{E}$ Daniel Stern. London: Karnac.

Segal, H. (1978). On symbolism. International Journal of Psychoanalysis, 59: 315-320.

Segal, H. (1989). Interview, January, 13. In: Karen, R. (1994). Becoming Attached. First Relationships and How They Shape Capacity to Love. NewYork: Oxford University Press.

Segal, H., \& Bell, D. (1999). Die Theorie des Narzißmus im Werk von Freud und Klein. In: Freud's On Narcissism: An Introduction. London: International Psychoanalytical Association.

Spillius, E. B. (1994). Developments in Kleinian thoughts. Psychoanalytic Inquiry, 14:3: 324-364.

Spillius, E. B. (2001). Unterschiedliche Formen des Neiderlebens. In: C. Frank \& H. Weiß (Eds.), Kleinianische Theorie in klinischer Praxis. Stuttgart, Germany: Klett-Cotta.

Spitz, R. (1945). Hospitalism-an inquiry into the genesis of psychiatric conditions in early childhood. Psychoanalytic Study of the Child, 1: 53-74.

Spock, B., \& Parker, S. (1998). Baby and Child Care. A Handbook for Parents of Developing Children from Birth through Adolescence (revised edition). New York: Pocket, 2001.

Steiner, D. (1992). Your One Year Old. Tavistock Clinic. London: Rosendale.

Steiner, J. (1999). Turning a blind eye: the cover up for Oedipus. In: D. Bell (Ed.), Psychoanalysis and Culture. A Kleinian Perspective (pp. 86-104). London: Duckworth.

Steiner, R. (2000). Introduction. In: J. Sandler, A. Sandler \& R. Davis, Clinical and Observational Psychoanalytic Research: Roots of a Controversy. London: Karnac.

Stern, D. N. (1971). A micro-analysis of mother-infant interaction: Behaviour regulating social contact between a mother and her 3-month-old twins. Journal of the American Academy of Child Psychiatry, 10: 501-517. 
Stern, D. N. (1977). The First Relationship, Infant and Mother. Cambridge, MA: Harvard University Press, 2002.

Stern, D. N. (1985). The Interpersonal World of the Infant. New York: Basic Books.

Stern, D. N. (1991). Diary of a Baby. What Your Child Sees, Feels and Experiences. London: Fortuna.

Stern, D. N. (1995). The Motherhood Constellation. New York: Basic Books.

Stern, D. N. (2001). Handeln und Erinnern in der Übertragungsliebe. In: Über Freuds „Bemerkungen über die Übertragungsliebe". Freud heute: Wendepunkte und Streitfragen (Volume 3) (pp. 213-230). Stuttgart, Germany.

Stern, D. N., \& Bruschweiler-Stern, N. (1998). The Birth of a Mother. New York: Basic Books.

Sternberg, J. (2005). Infant Observation at the Heart of the Training. London: Karnac.

Stork, J. (1974). Fragen nach dem Vater. Freiburg, Germany: Alber.

Szejer, M. (2000). Platz für Anne. Die Arbeit einer Psychoanalytikerin mit Neugeborenen. Frankfurt, Germany: S. Fischer.

Taylor, D. (Ed.) (1999). Talking Cure. Mind and Method of the Tavistock Clinic. London: Duckworth.

Teising, M. (2000). Die Angst vor dem Pflegefall. Psychodynamische Betrachtungen. Vienna: Fakultas.

Thomas, A., \& Chess, S. (1977). Temperament and Development. New York: Brunner Mazel.

Trevarthen, C., Aitken, K., Papoudi, D. \& Robarts, J. (1996). Children with Autism. London: Jessica Kingsley.

Tyson, P., \& Tyson, R. (2001). Psychoanalytic Theories of Development: An Integration. New Haven, CT: Yale University Press.

Uexküll, T. v. (Ed.) (1994). Subjektive Autonomie. Stuttgart, Germany: Schattauer.

Waddell, M. (2002). Inside Lives. Psychoanalysis and the Growth of the Personality. The Tavistock Clinic Series. London: Karnac.

Watillon-Naveau, A. (1999). The contribution of baby-observation to the technique of parent-infant psychotherapy. In: Infant Observation and Its Application, Vol. 3 (pp. 24-32). London: Routledge.

Watillon-Naveau, A. (2001). Psychoanalytic Therapies of the Early ParentInfant Relationship: How Does It Work? (Anna Freud Memorial Lecture, Vienna.)

Williams, G. (2003). Innenwelten und Fremdkörper. Stuttgart, Germany: KlettCotta.

Winnicott, D. W. (1949). Hate in the countertransference. International Journal of Psychoanalysis, 30: 77-90. 
Winnicott, D. W. (1965). The Maturational Processes and the Facilitating Environment: Studies in the Theory of Emotional Development. London: Hogarth.

Winnicott, D. W. (1971). The use of the object. In: Playing and Reality. London: Penguin.

Winnicott, D. W. (1983). Von der Kinderheilkunde zur Psychoanalyse. Munich, Germany: S. Fischer.

Wolff, P. H. (1966). The causes, controls and organizations of behavior in the neonate. Psychological Issues, 5: 17.

Zulliger, H. (1970). Heilende Kräfte im kindlichen Spiel. Stuttgart, Germany: S. Fischer.

Zulliger, H. (1971). Die Angst unserer Kinder. Stuttgart, Germany: Fischer. 



\section{INDEX}

\section{Indexer: Dr Laurence Errington}

Note: "Freud" in subentries etc. refers to Sigmund Freud.

abdominal prone position, moving in 119

abuse see physical abuse; sexual abuse acceptance and acknowledgement of child's personality 107-109, 310

shaping (to fit parent's notions) vs. 13-14, 36

acceptance and encouragement of child's feelings (containment) by parents $171-172$

rejection $v$ s. 15,37

acknowledgement

of baby's personality see acceptance and acknowledgement

child receiving encouragement and praise and, vs. inhibition of abilities 16, 38-39 aggression (and violence) 109, 114

fantasised, breastfeeding and 82 latent, Max's 27

Malcolm's 140, 142-144

Nikolaus's 299

Patrick's 242

see also anger and rage Ainsworth, Mary 126, 181, 183-185 Alex (Marietta's 9-month-old baby brother) 294

Alexander (Max's friend) 27-28

alpha elements 171-172

Alvarez, Anna 18, 313

anal phase (psychosexual development) 154, 217

anal-sadistic stage 157

anger and rage 110, 121, 206, 254-255, 268

Malcolm's 143-144

Max's 231-233, 292

Nikolaus's 297, 300 
Patrick's 234-238, 242-243

poem about 203

see also aggression

answering questions see questions

anxieties see fears and anxieties

asexual being 111-113

asymmetric neck reflex 57

attachment theory 148, 180-188

criticism 186-188

autism 80, 313

"normal" (autistic phase/period)

$156,158,161$

auto-eroticism 151-152

autonomy 159, 196, 202, 276

Kelly 128

Max 133

toilet training 217, 259

Babinski reflex 56

babysitting 104, 125, 127, 132-133, 135

back position, moving in 119

bad feelings (child's) 13, 37, 68, 109, 113

Badinter, Elisabeth 147

battered baby 140-146

Baumgart, M. 160

behaviour

inborn 180-183

mother with son and father with daughter 261-262

Neonatal Behavioural Assessment Scale 55-58

observation of mother-child behavioural interaction 179

Bell, D. 161

belly position, moving in 119

Benjamin's conscience 277-278

beta elements 171-172

Bettelheim, Bruno 254

Bick, Esther 9, 69, 147, 172, 180, 190
Bion, Wilfred 42, 70, 76-77, 80, 103, $107,109,122,169-173,264$, 313

as single father 316-318

birth 39-49

at home 51-53, 95

family changes relating to $66-70$

Kelly's 44-49

Max's 51-54

Patrick's 54-55

separation at 60-61, 311-312

support systems at time of 59-60

see also newborn child

Bob (toddler becoming independent) 198

body

care $115-120$

interest in mother's 218

interest in one's own 73-74, 218

bottle $v s$. breastfeeding $81-88$

Bowlby, John 118, 148, 180-188

boys

mother's behaviour with son 261-262

showing fear as weakness 282

Brazelton, T. Berry 78, 84, 88, 90, 97, $124,148,216,259-260$

Neonatal Behavioural

Assessment Scale 55-58

breast 164, 166, 170, 312

Max and 229-230

newborn placed on 61

breastfeeding (nursing) 81-88,

122-124

bottle vs. $81-88$

Kelly 94, 125, 129, 222-223

Max 96-97, 133

mother's own mother having had

problems with 123

weaning from see weaning

see also milk

breast-seeking reflex 56-57 
Britton, Ron 43, 168, 219, 263

Buddenbrooks, Thomas (character in Thomas Mann's book) 80-81, 282

castration complex/anxiety 163, 218 child abuse see physical abuse; sexual abuse

childbirth position, changing practice 47

Christoph's sexual questions 270

Clemens (newborn baby) 84-85

colostrum 59, 81

commands see order; rules

communication (mother-baby/ young infant) 74-75

non-verbal 103

verbal 103

see also language; voice

concrete thinking 255-256

conscience 276-280

containment see acceptance and encouragement of child's feelings

crawling reflex 57

cruelty 113-114

curiosity 113-114

Darwin, Charles 249

daughter, father's behaviour with 261-262

Daws, Dilys 90, 102, 124

De Masi, F. 172

de Mause, Lloyd 147

death, foetal 139

twin, by killing (foeticide) 100-101

defence, mature $v s$. primitive types 14-15

case examples 36-37

depressive position 163, 167-169, 189 development (psychological) 1-62, 10-11, 125-146

1st year (4-12 months) 125-127, 131-135

2nd year of life see second year 3rd year of life 250-283

histories see histories parents' perspectives 129-131, 135-138

psychic see psychic development psychosexual see psychosexual development psychotherapy and 138-146, 234-245, 293-303

theoretical basis of a psychoanalytical interpretation 3-6

diaper see nappy

Diem-Wille, Gertraud 85, 140, 284

discipline 210-212

Kelly 289

see also limits; order; rules

disintegration 76, 120, 162

fear of 69-71, 163, 165

disorganised/resistant attachment 181

divorce see marriage breakup

Dornes, Martin 140, 148, 161, 173

eating 122, 126, 199-200, 216, 230

problem (Victoria's) 103-104

ego 151-153

rudimentary/ primitive 161-164, 173-176

egocentricity 15, 156, 179, 212, 216

Elias, Norbert 155

emotion(s) (children's)

newborn baby 43-44, 58-59

siblings 67-68

emotion(s) (parents' and other adults) 42-43 
birth (grandparents and friends) 66-67

birth (mother's emotions) 58 pregnancy (mother's emotions) 50

emotional relationship, baby-parents $10,13,68-70,107-125$

autism and 313

emotional significance of words and voices 103

empirical research 148, 161, 173, 176-177, 185-186, 189-190

criticism of concept 179-180

encouragement

child receiving acknowledgement and, vs. inhibition of abilities $16,38-39$

of child's feelings see acceptance and encouragement

Enquist, Per Olav 282

envy 66, 113, 164, 258, 275

original 164, 173

Erdheim, Mario 155

Ermann, G. 9, 261

erogenous zones 151, 153-154

external world 37, 151-152

eyes (newborns)

contact 74

movements 57

face, newborn seeing a 57

Fairbairn, Ronald 162

Fallaci, Oriana 49-50

family, birth and the 66-70

father (husband)

baby recognising special

relationship between mother and 121-122, 168

behaviour with daughter 261-262 caring (incl. feeding) and role of 122,137

in three-way/triangular relationship 4, 19, 261
Kelly's 17-23, 44-48, 94-95, 125-126, 129-130, 132, 226-227, 283, 285-289

Max's 23, 27-28, 31, 51, 53, 97-99, 137-138, 223-224, 292-293

Nikolaus's 296-299

Patrick's 33-34, 38, 237-240, 242-245

single, Bion's experience as 316-318

suggesting placing newborn baby on breast 61

toilet training and 257-258

see also oedipal phase

fears (babies/infants) and anxieties 280-283

containing/calming 72-75

depressive 167

of disintegration $69-71,163,165$

fears (mothers) 94

breastfeeding 82

feeding 122

Max 133-134

see also bottle; breastfeeding; eating; hunger; weaning

feelings (child's)

acceptance see acceptance and encouragement

bad $13,37,68,109,113$

good 13, 37, 109

play and expression of 206

projected onto parents 15,171

feelings (parents'), pregnancy and 60

Feldman, Michael 265

female child (daughter), father's behaviour with 261-262

femininity complex (boys) 218

femininity phase (girls and boys) 218

feminism and childbirth position 47

fetus see foetus

first year of life see infants 
foetus 39-41, 49-50, 60

killing 100-101

see also imaginary baby

Fonagy, Peter 77-78, 157, 176, $179-180,183,186,188$

food envy 275

see also bottle; breastfeeding;

eating; feeding; hunger;

weaning

foreplay (in sex) 154

four-year old, development from

infant to 10-11, 125-127,

131-135

Fraiberg, Selma 111, 148, 178, 216, 255

Freud, Anna 124, 155-157, 175, 188,

$190,213,309$

developmental lines concept

155-157

Freud, Sigmund 5-7, 11, 77, 148, 150-155, 158, 162, 189-190

criticisms of 160-161, 182

Klein and 161-163, 168, 190

on anal phase 154, 217

on birth 40,42

on sexual questions of child and

their answering 270

on sexuality/sexual identity 112,

150-151, 153-154, 218-219,

261,263

on sibling rivalry 266

Gaddini, Eugenio 7, 41-43, 58

Galant response 57

genitals, interest in/awareness of $112,218-219$

girl (daughter), father's behaviour with 261-262

good feelings (child's) 13, 37, 109

grandparents $65-67,269$

Kelly's 127, 223-224

and older child (with a new

baby) 269

toilet training and 217, 257-258 grasping reflex 56

Green, André 4, 180, 261

Grossmann and Grossmann 183

hallucinatory wish fulfilment 77,152 , 170

hand (own), baby's familiarising with 119

happiness (baby's) 44

in womb 40

oscillation between desperation and 71-72

happiness (parents')

breastfeeding 81

Max's parents 95

Harlow, Harry 183

hatching 159

hiding one's face (game) 207-208

Hinde, R. 183

histories (developmental) 11-12

case examples 125-146, 221-245, 283-293

children in therapy 138-146

Holmes, J. 185, 187

home birth 51-53, 95

hospital

birth in $47,52-54$

child in 136, 240-241

hospitalism 70, 148

hunger 42, 76, 164-165, 177, 199, 274

husband see father

id 150,153

images

inner see inner images

of self $4,13,41,44,121,255$

imaginary baby $4,43,78$

inborn behaviour 180-183

independence 195-197

in mobility $115-120$

individuation 157-161

infants (up to 12 months) 63-190

1st to 3rd month 70-107 
4th to 12th month 107-190

to 4 years old, development 10-11, 125-127, 131-135

psychoanalytical observation 6-10

see also newborn child

inhibition of abilities, child receiving acknowledgement and encouragement and praise vs. $16,38-39$

inner images (representations) 4, 80, 159-160, 173, 176-177, 183

of attachment 183

inner objects 178, 234, 243, 312

good/positive/secure 69, 77, 125,145

inner order $68,210,224,281$

inner reality / world 4, 11-12, 18, 59, $161,168,182,187,281$

autism and 313

chaotic 58, 235

Kelly's 18, 19

personality development and 12 innocence 109-111, 113, 169

insecure attachment 182

insecure-ambivalent/resistant attachment 181, 185

insecure-avoidant attachment 181, 184-185, 188

internal objects, good/idealised vs. bad/persecuting 12-13

case examples 35-36

internal see internal objects

internal working models 182-183, 185, 197

interpersonal world 175

Isaacs, S. 164, 173

Joseph (child), birth of 103-107

Joseph, Betty 79

Julian (case) 138-140
Kächele, Horst 148

Karl (Susi's brother) 272-274

Karl (toddler becoming independent) 199-202

Kelly (case) 17-23, 125-131, 221-227

0-3 months 91-95

4-12 months 125-131

2nd year of life 283-290

3rd year of life 221-227

birth 44-49

seven dimensions of personality 35-38

Klein, Melanie 147, 156, 161-170, 172-173, 178-179, 182, $187-189,218,264$

Krejci, E. 40, 121, 165

language acquisition

2nd year of life 213-216

3rd year of life 250-256, 290

conscience and 279

see also verbal communication

Lazar, Ross 9, 261

Lea (case) 100-102

learning, physiological 41

Lebovici, S. S. C. 148

libido 150-152, 157, 161

Lichtenberg, Joseph D. 148

limits

absence 16

explaining/learning/setting 15, 38, 90, 201, 211-212, 214, 276, $279,301,311$

see also discipline; order; rituals; rules

Lorenz, Konrad 181

love 115-116, 308

object 151-153

romantic 73,115

sibling 275-276

lovers

exploring each other's bodies 73 
foreplay (in sex) 154

language of 74-76

MacFarlane, J. 92

magical thinking 178, 215-216, 253, 255

Mahler, Margaret 148, 156-161, 175

Malcolm (case) 140-146

males see boys

Marietta (case) 293-296

marriage breakup/divorce 8

Kelly 17, 19, 49, 225-227, 283, 287

massage 97-98

Mathias (playing) 209

Max (case) 7, 23-32, 131-139, 227-234

0-3 months 95-99

4-12 months 131-135

2nd year of life 227-234

3rd year of life 290-293

birth 51-54

seven dimensions of personality 35-38

toilet training 257

megalomania 113, 152

mental representations see inner images

mentalization 183

Michael (baby), breastfeeding 85

Michi (toddler becoming independent) 196-197

milk, mother's 81

see also colostrum

mobility, independent 115-120

Montagu, Ashley 60-61, 81

mother (of baby)

at birth 60-61

baby influencing relationship between father and 126

baby recognising special relationship between father and 121-122, 168

behaviour with sons 261-262 body, child's interest 218

communication with see communication

Kelly's 17-23, 35, 37, 44-48, 91-95, 125-130, 221-227, 283-288

in three-way/triangular relationship (motherfather-child) 4, 19, 261

Max's 23-27, 30-32, 35, 51-54, 95-99, 133-138, 227-233, 257, 290-293

Nikolaus's 293-296

observation of behavioural interaction between child and 179

Patrick's 33-35, 38, 235-236, 239, $243,244-245$

symbiosis with 148, 150, 156-161

toilet training and 258

see also oedipal phase; pregnancy

mother (of mother), problems with nursing and weaning 123

nappy (diaper)

changing, case examples 92-93, 95, 301

toilet-training and 259-260

narcissism 72, 148, 150-153, 156-158, 160-162

Nazism 245

neck reflex, asymmetric 57

Neonatal Behavioural Assessment Scale 55-58

neonate see newborn child newborn child (neonate/first three months) 39-49, 70-107

older child's view of new baby 266-270

physical capabilities and their assessment 55-59 
night

support systems 59-60

toilet-training 260

waking up during 124-125, 137, 211,290

Nikolaus (case) 296-303

non-verbal communication 103

nursing see breastfeeding

object(s)

inner see inner objects

love 151-153

part 156, 164, 166-167, 189

permanence and constancy 120 ,

157,160

relationship 152, 156-157, 159, $161-163,167,175,179,183$

observation of child, psychoanalytical 6-10

Kelly 91-95, 125-129, 221-224, 283-287

Max 95-99, 131-135, 227-232,

290-291

observation of mother-child behavioural interaction 179

oedipal phase/conflict 151, 157, 168, 263-265

Oedipus, legend of 303-304

oral phase (psychosexual development) 154

order $68-69,210-212$

created in play $209-210$

inner 68, 210, 224, 281

see also discipline; limits; rituals; rules

original envy 164, 173

oxytocin 81

paranoia 152, 161

paranoid-schizoid position 163-167, 169,189

parent-small infant therapy 100-102,
$B$ and her child 123

development of infants in 138-146, 234-245, 293-303

see also father; grandparents; mother and specific topics relating to parents

part objects 156, 164, 166-167, 189

Patrick (case) 17, 32-35, 234-245

2nd year of life, in therapy 234-245

birth 54-55

seven dimensions of personality 35-39

pedagogy and pedagogues 279-280, 308-310, 312

Perelberg and Raphael-Leff 51 personality 4, 77-81

acceptance/encouragement see acceptance and acknowledgement seven dimensions 12-17, 35-39 phallic phase (psychosexual development) 154

physical abuse

child 140-146

mother 225

physiological learning 41

Piaget, Jean 120, 160, 215-216

Pikler, Emmi 115-116, 117-119

Pine, Fred 160

Piontelli, Alessandra 41

play 204-210

Kelly's 221-222

language and 215, 217-218

with water $135,217,227-229$

see also role-play

practising 159

praise, child receiving acknowledgement and encouragement and, vs. inhibition of abilities 16 , 38-39

preconception (Bion's) 76, 170, 173 
pregnancy 49-51

child's view of new pregnancy

266-267

Kelly's mother 47-48

parents' feelings during 60

therapeutic help during 100-102, 178

preoedipal phase 151, 162, 189

protective reflexes 56

psyche 11

positive core 69

psychic development 146-150, 155, 179

0-3 months 71, 76-77, 79

4-12 months $68,115,120-122$

psychoanalysis

observation in see observation

pregnancy during period of 50-51, 103-107

see also parent-small infant therapy

psychological development see development

psychosexual development 150-151

stages/phases 154

psychosis (psychotic illness) 80, 152, 168-169

psychotic world 69, 264

puberty 77,113

questions (from child) and answering them 132, 204, 250-251

sexual 266, 270-271

questions (from mother to child) 279

rage see anger and rage

Raphael-Leff, Joan 51

rapprochement 159-160

reality /world (psychological) 4, 7, 12

external 37, 151-152

inner see inner reality

interpersonal 175 reflexes, newborns 56-57

rejection

child's feelings vs. acceptance see acceptance and encouragement

sex and husband's feelings of $48,225-226$

relationships

emotional see emotional relationship

object 152, 156-157, 159, 161-163, $167,175,179,183$

parent-child, difficulties 138-139

three-way/triangular (motherfather-child) 4, 19, 261

see also father; mother

representations see inner images; self-representation

Riesenberg-Malcolm, Ruth 80, 171

rituals 130, 203

autism 313

child creating 210

going to sleep 124-125, 211

separation 214

toilet 258

rivalry $66,83,127,221,262,264$

sibling 67, 266-276

Robin (case) 140

role-play 218-219, 238, 251, 300

romantic love 73,115

rooting reflex 56-57

Roper, Lyndal 54

Rühmkorf, Peter 108, 120

rules and commands, parent's 277-290

explained and open to negotiation vs. fixed 15-16, 20,38

Kelly and 289

see also discipline; limits; order

Salzberger-Wittenberg, Isca 12, 70

Sandler, Joseph 150-151, 160-161 
schemas-of-being-with 176-179

schizophrenia 303

second year of life (toddlers) 192-245

developmental histories of three children 221-245

paths of development 194-221

secure attachment 181-182, 184

Segal, Hanna 161, 186, 254

self-awareness 160-161, 175

self-image 4, 13, 41, 44, 121, 255

self-reflection 185, 209, 219, 263-264

self-representation 158-159

separation (from mother/parents)

126-127, 157-161, 166,

195-197

at birth 60-61, 311-312

Kelly 126

language and 214

play and 210

second year of life 195-197, 207, 210

sex during or after pregnancy 48

husband's feelings of rejection 48 , 225-226

sexual abuse 113, 207

sexual intercourse 109

parents' 166, 241, 271

sexuality 111-113, 218-221, 261-266

Freud 112, 150-151, 153-154

see also erogenous zones; libido;

psychosexual development

shame and toilet training 257-261

siblings

emotions with newborns $67-68$

rivalry $67,266-276$

single parent, Bion's experience as

$$
\text { 316-318 }
$$

skin and skin-skin contact 44, 58, 81, 101,153

sleep 88-91, 124-125

going to 73, 88-91, 111, 211

problems 125-126, 210-211, 219 waking from see waking up social contact and skills with peers and adults (good vs. poor) 16-17

case examples 39, 127-129

son, mother's behaviour with 261-262

Sophie (Lea's deformed sister in womb) 100

Spillius, Elisabeth Bott 163, 170, 173, $189,312,318$

Spitz, René 70, 148, 175, 318

splitting 166

Stefan's fears and anxieties 281-282

Stephen's conscience 278-279

stepping (walking) reflex 56

Stern, Daniel 59, 74-75, 148, 150, 161, 173-180, 188-189, 215

Strange Situation 126-127, 183-185

Kelly and 126

structure, creation in play 209-210

subject permanence 120

superego 150, 153, 155, 187, 276, 317

Susi (case) 219-221, 267-268, 272, 278

symbiosis $148,150,156-161$

symbolic thinking 250-257

Szejer, Myriam 100-102, 148

teething 120-121

temperament 78

attachment and 188

breastfeeding and 83

sleep and 88

thinking and thoughts 250-257

magical 178, 215-216, 253, 255

third year of life 247-304

development 250-283

thoughts see thinking and thoughts

toilet training 216-218, 257-261

topographical theory of Freud 150, 153

transference 182, 187 
negative 156

Tyson P. and Tyson R. 157, 179

urination 217, 229

uterus (womb) 39-43, 49, 88, 100, $170,271,311$

verbal communication 103 see also language

Victoria (case) 103-107

violence see aggression

visual function, assessment in newborns 57

voice (vocal ...) 103

pitch/rhythm/dynamics 174,178

waking up (from sleep)

during night 124-125, 137, 211, 290 observing newborn baby 55-56

walking, learning 194-195

walking reflex 56

water

fear of 284

playing with $135,217,227-229$

Watillon-Naveau, Annette 138, 140

weaning 122-124

Max 133, 229-230

Winnicott, Donald 14, 44, 108-109, 111, 121, 147-148, 179, 208, 215,309

wish fulfilment 277

hallucinatory $77,152,170$

womb (uterus) 39-43, 49, 88, 100, $170,271,311$

Zulliger, Hans 206, 283 
